

\section{The power of vulnerability}

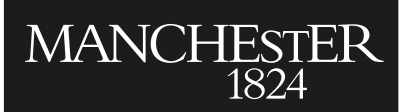

Manchester University Press 



\section{THE POWER OF \\ VULNERABILITY}

Mobilising affect in feminist, queer and anti-racist media cultures

\section{EDITED BY ANU KOIVUNEN, KATARIINA KYRÖLÄ AND INGRID RYBERG}




\section{Copyright @ ( Manchester University Press 2018}

While copyright in the volume as a whole is vested in Manchester University Press, copyright in individual chapters belongs to their respective authors.

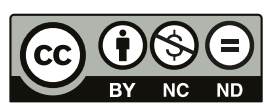

This electronic version has been made freely available under a Creative Commons (CC-BY-NC-ND) licence, thanks to the support of The Swedish

Research Council, which permits non-commercial use, distribution and reproduction provided the author(s) and Manchester University Press are fully cited and no modifications or adaptations are made. Details of the licence can be viewed at https://creativecommons.org/licenses/by-nc-nd/3.0/

Published by Manchester University Press

Altrincham Street, Manchester M1 7JA

www.manchesteruniversitypress.co.uk

British Library Cataloguing-in-Publication Data

A catalogue record for this book is available from the British Library

ISBN 978152613309 o hardback

ISBN 9781526133113 open access

First published 2018

The publisher has no responsibility for the persistence or accuracy of URLs for any external or third-party internet websites referred to in this book, and does not guarantee that any content on such websites is, or will remain, accurate or appropriate.

Typeset by Out of House Publishing 


\section{CONTENTS}

List of figures vii

List of contributors $\quad$ ix

1 Vulnerability as a POlitical language 1

Anu Koivunen, Katariina Kyrölä and Ingrid Ryberg

PART I VULNERABILITY AS A BATTLEGROUND

2 Negotiating VUlNerability in the trigger

WARNING DEBATES

29

Katariina Kyrölä

3 TRIgGeR HAPPY From content warning to censorship 51 Jack Halberstam

4 FEMINIST HURT/FEMINISM HURTS

Sara Ahmed

\section{PART II VULNERABILITY AND VISIBILITY}

5 LITTLE PINK White fragility and black social death 71 Ylva Habel

6 Visibility AND VULNERABILITy Translatina world-making in The Salt Mines and Wildness Laura Horak

7 WHITE VULNERABILITY AND THE POLITICS OF REPRODUCTION IN TOP OF THE LAKE: CHINA GIRL

Johanna Gondouin, Suruchi Thapar-Björkert and Ingrid Ryberg 
8 Spectacularly wounded White male vulnerability as heterosexual fantasy

Susanna Paasonen

\section{PART III VULNERABILITY AND CULTURAL POLICY}

9 The invulnerable body of Colour The failure and success of a Swedish film diversity initiative Mara Lee Gerdén

10 NAming, SHAMING, FRAMING? The ambivalence of queer visibility in audio-visual archives

Dagmar Brunow

11 Abortion prevention Lesbian citizenship and filmmaking in Sweden in the 1970 s Ingrid Ryberg

12 The Caring Nation Don't Ever Wipe Tears Without Gloves as a reparative fantasy Anu Koivunen

Index 


\section{FIGURES}

5.1 Motley/Brokiga merchandise in the window of the children's bookshop Bokslukaren/Book Eater in Stockholm (2018, photo: Ylva Habel)

5.2 Motley/Brokiga merchandise in the window of the art gallery Konst och Folk/Art and People in Stockholm (2018, photo: Ylva Habel)

6.1 Giovanna in The Salt Mines (screen grab, 1990: directors Susana Aikin and Carlos Aparicio)

6.2 Wu and Erika in Wildness (screen grab, 2012: producers Wu Tsang and Kathy Rivkin: director Wu Tsang)

7.1 Robin and Miranda in Top of the Lake (screen grab, See-Saw Films, 2017: directors Jane Campion and Ariel Kleiman)

9.1 Launching the Fusion Programme in January 2016 with participants Aida Chehrehgosha, Saadia Hussain, Mara Lee Gerdén, Farnaz Arbabi, Farah Yusuf, MyNa Do, Nikeisha Andersson, and Saleen Gomani together with jury members Klara Grunning, Baker Karim, and Sara Waldestam (photo: Christopher Mair)

11.1 Lesbian Front meeting in The Woman in Your Life Is You (screen grab, 1977: produced and directed by Lesbisk front Stockholm)

11.2 Eva and Maria go to the archipelago (screen grab from Eva and Maria, Tjejfilm, 1983: directors Marie Falksten, Mary Eisikovits, Annalena Öhrström)

12.1 Swedish Crown Princess Victoria awarded the prize of 'Homo of the Year' to Jonas Gardell at the annual QX gay gala, 4. February 2013 (screen grab, TV4, 2013) 
12.2 Remembering friends and lovers (screen grab from Don't Ever Wipe Tears Without Gloves, episode 3, Sveriges Television, 2012: director Simon Kaijser)

12.3 The spectacle of AIDS (screen grab from Don't Ever Wipe Tears Without Gloves, episode 3, Sveriges Television, 2012: director Simon Kaijser)

12.4 Jehovah's Witnesses' image of an afterlife (screen grab from Don't Ever Wipe Tears Without Gloves, episode 3, Sveriges Television, 2012: director Simon Kaijser)

12.5 Paul's funeral (screen grab from Don't Ever Wipe Tears Without Gloves, episode 3, Sveriges Television, 2012: director Simon Kaijser) 


\section{CONTRIBUTORS}

Sara Ahmed is an independent scholar and feminist writer. She has held academic posts at Lancaster University and Goldsmiths, University of London. Her books include Living a Feminist Life (2017), Willful Subjects (2014), On Being Included (2012), The Promise of Happiness (2010), Queer Phenomenology (2006), The Cultural Politics of Emotion (2004, 2014), Strange Encounters (2000) and Differences that Matter (1998). She is working on a new project on complaint and has just completed a book provisionally entitled What's the Use: On the Uses of Use. She blogs at feministkilljoys.com.

Dagmar Brunow is Senior Lecturer in Film Studies at Linnaeus University, Sweden. She is the author of Remediating Transcultural Memory: Documentary Filmmaking as Archival Intervention (de Gruyter, 2015). Dagmar is the editor of Stuart Hall: Aktivismus, Pop und Politik (Ventil, 2015) and co-editor of Queer Cinema (Ventil, 2018). Her research project, 'The Cultural Heritage of Moving Images' (2016-18), has been financed by the Swedish Research Council. Dagmar is also a programmer at the International Queer Film Festival Hamburg.

Johanna Gondouin is Senior Lecturer and Researcher in Gender Studies, Stockholm University. Gondouin holds a PhD in Comparative Literature and is a former postdoctoral researcher in Cinema Studies before joining Gender Studies. Her research as well as her teaching is focused on postcolonial feminist theory, critical race and whiteness studies, feminist media studies and critical adoption studies. Gondouin has recently finished the research project 'Mediating Global Motherhood: Gender, Race and Sexuality in Swedish Media Representations of Transnational Surrogacy and Transnational Adoption', funded by the Swedish Research Council (VR). She is currently leading the international research project 'From Waste to Profit: Gender, Biopolitics and Neoliberalism in Indian Commercial Surrogacy', also funded by VR. 
Ylva Habel is Assistant Professor in Media and Communication Studies, and Researcher in the field of anti-black racism at CEMFOR (Centre for Interdisciplinary Research on Racism), Department of Theology, University of Uppsala. Her research draws on black studies, postcolonial, critical race and whiteness studies, and specifically revolves around the affective economy of Swedish exceptionalist, colourblind discourses. With an interdisciplinary background in cinema studies, her analytical approach entails an interest for combining these perspectives with the optics of media history, visual and material culture. In her upcoming research, she will focus upon kindred discursive logics in recent Swedish and Dutch media debates, and examine the ways in which blackness figures in relation to perennial welfare state values.

Jack Halberstam is Professor of Gender Studies and English at Columbia University. Halberstam is the author of six books, including Skin Shows: Gothic Horror and the Technology of Monsters (Duke University Press, 1995), Female Masculinity (Duke University Press, 1998), In A Queer Time and Place (New York University Press, 2005), The Queer Art of Failure (Duke University Press, 2011), Gaga Feminism: Sex, Gender, and the End of Normal (Beacon Press, 2012), and Trans": A Quick and Quirky Account of Gender Variability (University of California Press, 2017) and has written articles that have appeared in numerous journals, magazines and collections. Halberstam has co-edited a number of anthologies including Posthuman Bodies with Ira Livingston (Indiana University Press, 1995) and a special issue of Social Text with Jose Muñoz and David Eng titled 'What's Queer About Queer Studies Now?'

Laura Horak is Associate Professor of Film Studies at Carleton University. She is author of Girls Will Be Boys: Cross-Dressed Women, Lesbians, and American Cinema, 1908-1934 (Rutgers University Press, 2016), which the Huffington Post declared one of the Best Film Books of 2016. She also coedited Silent Cinema and the Politics of Space (Indiana University Press, 2014), winner of the Society of Cinema and Media Studies award for best edited collection. She recently co-edited a special issue of Somatechnics on 'Cinematic Bodies' and the anthology Unwatchable (Rutgers University Press, 2019). She is currently researching the history of trans-made films in the United States and Canada.

Anu Koivunen is Professor of Cinema Studies in the Department of Media Studies at Stockholm University, currently working as Professor of Gender Studies at Tampere University, Finland. She has written on feminist and queer film theory, the affective turn in feminist and queer 
theory, Finnish cinema and television history, new narratives about Sweden Finns as well as mediated cultures of emotion. She has published in journals such as the International Journal of Communication, Journal of Scandinavian Cinema, Discourse and Lambda Nordica, and Cinema Journal. Her current research focuses on Jörn Donner's film-making and the intimisation of media culture in the 1960 s as well as the roles of Swedish and Finnish public service broadcasting companies in staging, mediating and managing political antagonisms. She is also co-editor of The Nordic Economic, Social and Political Model: Challenges in the 21st Century (Routledge, forthcoming 2019).

Katariina Kyrölä is Lecturer in Gender Studies at Åbo Akademi University, Finland. She has worked previously as Lecturer in Media Studies at the University of Turku, Academy of Finland Postdoctoral Fellow, and Lecturer in Cinema Studies, Stockholm University. She is the author of The Weight of Images: Affect, Body Image and Fat in the Media (Routledge, 2014) and articles in, for example, Feminist Theory, Feminist Encounters, International Journal of Cultural Studies, lambda nordica, Sexualities and Subjectivity. Her research interests include non-normative bodies in the media, queer theory, feminist fat studies, affect theory and the politics of 'bad feeling', and postcolonial and indigenous feminisms.

Mara Lee Gerdén is a Swedish poet, writer and scholar in the field of literary composition, poetry and prose. Her main research areas are twentieth- and twenty-first-century feminist post- and decolonial theory with a special focus on decolonial poetics, women's writing and theories of embodiment and agency. Her other fields of interest are queer temporality and desire/gender/sexuality. She has published several novels, collections of poetry, essays and articles. In her $\mathrm{PhD}$ dissertation, 'När andra skriver. Skrivande som motstånd, ansvar och tid' (Glänta, 2014), Lee argues for a redefinition of Otherness in relation to temporality and creativity.

Susanna Paasonen is Professor of Media Studies at University of Turku, Finland. With an interest in studies of popular culture, affect and media theory, she serves on the editorial boards of the journals Sexualities, New media E society, International Journal of Cultural Studies, Porn Studies and Social media + society. Susanna is most recently the author of Carnal Resonance: Affect and Online Pornography (MIT Press, 2011), Many Splendored Things: Thinking Sex and Play (Goldsmiths, 2018) as well as coeditor of Working with Affect in Feminist Readings: Disturbing Differences (Routledge, 2010) and Networked Affect (MIT Press, 2015) and co-author of 
Not Safe for Work: Sex, Risk, and Humor in Social Media (with Kylie Jarrett and Ben Light, MIT Press, forthcoming).

Ingrid Ryberg is a filmmaker and Senior Lecturer at Department of Cultural Sciences, University of Gothenburg. Her current research, supported by the Swedish Research Council, explores feminist and queer film cultures in Sweden in the 1970s and 1980s, resulting in academic publications as well as in a documentary feature, An Army of Lovers (2018). She has published in journals such as the Journal of Scandinavian Cinema, Studies in European Cinema and Porn Studies Journal, and is the director of the dragking documentary Dragkingdom of Sweden (2002), the feminist porn short Phone Fuck (2009) and the interactive performance installations The Setting of Desire: Cinemaoke in the Celluloid Closet (2016) and Invites: Cinemaoke in Bergman's Closet (2018).

Suruchi Thapar-Björkert is Docent and Senior Lecturer at the Department of Government, University of Uppsala. She has previously held academic positions at the London School of Economics and Political Science, Warwick, Wolverhampton and Bristol universities in the UK. Her research falls in four specific areas: Gendered Discourses of Colonialism and Nationalism, Gendered Violence in India and Europe, Ethnicity, Social Capital and Social Exclusion, and Qualitative Feminist Research Methodologies. She has published widely in these research areas in journals such as Ethnic and Racial Studies, Feminist Review, Feminist Theory, Sociological Review and Interventions. She is the recipient of many research awards including the university research award (Kraftpaket för Jämställdhet) at the University of Uppsala in 2012. 


\title{
VULNERABILITY AS A POLITICAL LANGUAGE
}

\author{
ANU KOIVUNEN, KATARIINA KYRÖL ̈̈ \\ AND INGRID RYBERG
}

Tn present-day public discussions, questions of power, agency, and the media are debated more intensely than ever as issues of injury or empowerment. Vulnerability has emerged as a key concept circulating in these discussions and their academic analyses. The \#MeToo campaign, as well as its extensions like \#TimesUp and versions in various languages across the globe, has been taken up as a key example of these tendencies, showing how the public articulation of experiences of injury, trauma, and hurt is now turning into a powerful worldwide movement. A collective of voices testifying to a persistent, repetitive vulnerability and injury caused by sexual harassment, assault, and abuse has, perhaps paradoxically, become praised as a feminist movement for empowerment, justice, and change, and a societal force to be reckoned with.

At the same time, the campaign has raised several questions: what are the limits of feminist politics that draws first and foremost on a shared public victimhood, or survivorship? How much of this vulnerability is shared, and by whom? Why is \#MeToo having an impact only now, with wealthy and often white cis-women in Hollywood at the forefront of the movement, when the issue of sexual abuse and assault has been a key struggle in feminist, women of colour, and trans activisms for such a long time? What part does social media play in the successes and failures of activist efforts such as \#MeToo, and how does it relate to broader media histories of addressing and representing painful issues and marginalised people?

One of the keys to the success of the \#MeToo movement might be that potentially anyone might be the 'me' who has experienced sexual abuse although, in practice, the people who have become the faces of the campaign primarily identify as cis-women. At the same time, the universalising 
understanding of 'woman' and its equation to being a victim or vulnerable are some of the movement's most critiqued features. In that sense, the movement can be seen to differ from another recent highly publicised and ongoing social media and activist movement, \#BlackLivesMatter, which centres black lives and steers clear of the confessional mode. ${ }^{1}$ As George Yancy states in an interview with Judith Butler (Yancy and Butler, 2015), in \#BlackLivesMatter there is a specific racial vulnerability at stake which must centralise blackness instead of any subject. While it is true that 'all' lives matter, black lives do not seem to be included in the category of lives that matter, since black men and women are killed without consequence by police officers in the United States. Black lives are concretely under threat and treated as disposable, and therefore it is urgent to call for them to matter.

What \#MeToo and \#BlackLivesMatter have in common is drawing public attention to serious, pervasive, life-destroying issues that have long been ignored by white patriarchal institutional and state power. What they both have also been accused of is that by claiming injury to a specific group, they dismiss the possibility of anyone's or everyone's vulnerability to that injury: that white people can also be killed by the police, that men can also be sexually abused. Here, vulnerability is paradoxically equated with power: a voice, an experience, or a life that matters, that is worthy of attention and compassion. But what happens to structures of privilege and marginalisation if vulnerability is understood as a universal condition of all (human) life? Such an ontological understanding of vulnerability, while true in the sense that all life is perishable, is often mobilised to discredit and undermine the validity of movements focusing on the culturally and politically produced vulnerability of specific groups.

Within feminist, queer, and anti-racist discussions, a key critique of the \#MeToo campaign has addressed its whitewashing, exclusion of transidentified and gender non-conforming people, and focus on wealthy ciswomen in Hollywood, like Alyssa Milano, Salma Hayek, Uma Thurman, and Oprah Winfrey. The black American social activist Tarana Burke first launched the slogan 'Me too' in 2006 in her efforts to offer consolation, empathy, and relief from a sense of isolation to women of colour who experienced sexual abuse in underprivileged communities. These origins of the slogan and the movement were first left out entirely, as the campaign started spreading on social media through white actress Alyssa Milano's post on Twitter. The focus on white cis-women's experiences of sexual abuse could also be seen to overshadow the magnitude and severity of sexual assault on Native women, trans people and trans women of colour (Adetiba and Burke, 2017). These debates over whose injury and vulnerability matter more, or the most, raise important issues about structural inequalities between women and what can count as 'shared experience', but 
also about how to measure levels of vulnerability, or if such measurement or 'competition' is desirable or possible at all. If a more severe injury or vulnerability should lead to more visibility and being more in the centre of campaigning, what is to be done about the vulnerability that visibility can bring, for example, to trans women of colour who may survive by passing as cis?

Many have doubted whether the \#MeToo campaign can actually produce the kinds of changes that would be needed on societal and institutional levels, or if it will remain too focused on confession and personal experience. While the campaign has, by breaking the silence around sexual and gender-based harassment, aimed to relieve victims from shame and stigma, it has also been critiqued for imposing a duty to confess, remember, and draw attention to experiences that some may be unable or unwilling to share for the sake of their own safety and wellbeing. The flood of accounts and confessions of abuse on social media channels has prompted many to turn away from the campaign and its main platforms, as continuously encountering accounts of abuse can also feel re-traumatising for victims of similar abuse (Lamotte, 2017). Thus, paradoxically, representations and accounts of injury do not necessarily succeed in producing empowerment but can also injure themselves and help produce an emphasised sense of vulnerability. In comparison, \#BlackLivesMatter has not been focused on confession at all, even if it has also demanded acknowledgement of injury and consequences for perpetrators, yet a similar re-traumatisation critique can be applied to its imagery as well.

In the midst of the debates about the \#MeToo campaign's effectiveness, there is however no question about the campaign's affectivity: how it has mobilised enormous and powerful waves of feeling, from compassion to guilt, from shame to rage. A similar affective mobilisation applies to \#BlackLivesMatter, and this affective charge not only applies to those accounting for their experiences of sexual abuse or demanding an end to state-sanctioned violence against black bodies. It also applies to white, straight, male subjects, those in privileged positions who feel that these demands for change are a threat or take something away from them. Twenty years ago, Lauren Berlant (1997) analysed the emergence of the privileged as 'injured', calling these subject 'citizen-victims' - ordinary people 'who now feel anxious about their value to themselves, their families, their publics, and their nation. They sense that they now have identities, when it used to be just other people who had them' (1997: 2). The double edge of vulnerability concretises in these moments when the feeling of injury gathers affective charge around and for the privileged: vulnerability is no longer (if it ever was) only about weakness or immobilisation, but very concretely about agency. Claims of vulnerability can translate to claims to agency and voice, 
but these claims can have completely oppositional political consequences, depending on who is making them.

In this book we interrogate the tensions, complexities, and paradoxes of vulnerability in and through the media, particularly in feminist, queer, and anti-racist media cultures and debates about the production, use, and meanings of media. Our aim is, in particular, to make sense of the new language of vulnerability that has emerged through such tensions and paradoxes, investigating its historical legacies and contemporary effects. How do various understandings and claims to vulnerability mobilise affect? What are we expected to feel when seeing, reading, or telling narratives of injury - or empowerment? When can visibility and representations of difficult or hurtful experiences produce change, and when only more vulnerability? These questions are currently asked not only in the discussions around the \#MeToo and \#BlackLivesMatter campaigns but also, for example, in debates about 'trigger warnings' which are meant to alert viewers to potentially hurtful media content, and more broadly in discussions about reparative practices and the healing potential of activist media. These are also among the questions the writers of this book address. Through a broad range of original case studies addressing popular and activist media as well as public cultural and archival policies, they, and we, examine how asymmetries of power are addressed, contested, and felt as issues of being or becoming vulnerable. Furthermore, we map out and explore the consequences of different understandings of the concept of vulnerability for feminist, queer, and anti-racist efforts.

\section{VULNERABILITY IN FEMINIST, QUEER, AND ANTI-RACIST THEORISING}

While the power, proliferation, and complexity of the language of vulnerability in feminist and anti-racist media cultures have grown all the more evident, in academic discussions the concept of vulnerability has simultaneously become increasingly popular across various disciplines. Drawing from diverse philosophical and methodological traditions and investigating a wealth of issues, both theoretical and policy-related, the rich scholarship on vulnerability is nevertheless far from constituting a sense of a shared field of 'vulnerability studies' or otherwise. ${ }^{2}$

Deriving from the Latin word vulnus [wound], vulnerability expresses the capacity to be wounded and suffer. As bodily, social, and affective beings, we all have the capacity to be vulnerable to one another and to conditions of inequality, discrimination, exploitation, or violence, as well to the natural environment. Mobilising the concept therefore entails challenging 
liberal notions of the individual subject as autonomous, independent, and self-sufficient, and somehow not touched by the capacity to be vulnerable. Mobilising vulnerability also means critiquing the ways in which this notion of the individual subject has implicitly been male, white, Eurocentric, cisgendered, and able-bodied, allowing for 'vulnerable groups' to almost automatically signify those diverging from it. Such an understanding of vulnerability as 'different from the norm' easily allows the norm to remain invisible and uncontested. But if vulnerability is seen to characterise us all equally, again the uneven distribution of violence and injury between bodies can be left without adequate attention. What does it mean, to quote Judith Butler (2016: 25), if vulnerability is figured as 'an existential condition', a universal and shared human-animal ontology of us all, or 'a socially induced condition' that characterises some bodies more than others?

Within feminist and queer theory, as well as more broadly in the humanities and social sciences, the interest in vulnerability draws on 'turns' to embodiment, ethics, affect, and ontology (Ahmed and Stacey, 2001; Clough and Halley, 2007; Garber et al., 2000; Koivunen, 2001; 2010). Furthermore, it coincides with what Robyn Wiegman (2014) has termed the reparative 'turn' in queer feminist criticism. However, the history and routes of the concept's travels are much longer and more complex. Invoked in the 1980 os in the fields of moral and political philosophy (Goodin, 1985; 1988; Nussbaum, 1986), the concept subsequently travelled across disciplines: from sociology and social policy studies (McLaughlin, 2012; Misztal, 2011; Turner, 2006; Wilkinson, 2009) to legal theory (Fineman, 2008; 2010; Fineman and Fineman, 2017); from bioethics and other forms of ethics (Straehle, 2016; ten Have, 2016) to environmental and disaster studies (Bankoff, 2001; Clark, 2010); from studies of sexual violence (Bergoffen, 2011; Gilson, 2014; 2016) and feminist philosophy (Anderson, 2003; Butler, 1997a; 2004; 2009; Gilson, 2014; Mackenzie et al., 2013) to political theory (Butler et al., 2016), international relations (Beattie and Schick, 2013), and development studies, as well as media studies (Chouliaraki, 2013; Knudsen and Stage, 2015).

For feminist theory, vulnerability is a troubling concept since its connotations with femininity and dependence as well as weakness and victimisation invoke a problematic imaginary (Gilson, 2014; 2016). As Judith Butler, Zeynep Gambetti, and Leticia Sabsay (2016: 2) argue, 'there is always something both risky and true in claiming that women or other socially disadvantaged groups are especially vulnerable. Making injustices visible may result in reinforcing gendered assumptions about vulnerability as non-agency. The discourse of vulnerability can support various political agendas, including paternalistic, racist, misogynist, homophobic, and anti-feminist ones. 
As a response, feminist scholars theorising care and dependency (Dodds, 2013; Mackenzie, 2014; Mackenzie et al., 2013; Vaittinen, 2015) or sexual violence (Bergoffen, 2011; Gilson, 2014; 2016; Honkatukia, 2011) have sought to redefine vulnerability in order to dissociate it from victimhood, passivity, and lack of agency. At the same time, feminists have theorised modes of the relational, embodied subject and redefined autonomy as a critique of liberal individualism and modes of rationality (Anderson, 2003; Hutchings, 2013; Mackenzie, 2014; Nussbaum, 1986; Shildrick, 2002). Furthermore, links with paternalism and discourses of victimisation have been problematised by focusing on vulnerability and resistance as interlinked (Butler et al., 2016: 6), and by rethinking vulnerability as 'productive', as the Swedish research programme 'Engaging Vulnerability,' ${ }^{3}$ funded by the Swedish Research Council for a full decade, suggests. Similarly, vulnerability has been seen to generate feminist research ethics, when 'receptivity' is practised as a way of remaining open for change as a scholar (Page, 2017). Erinn Gilson (2016) argues that vulnerability as a concept is 'of special value because of how it captures and expresses the complexities, tensions, and ambiguities of experiences of gender, sexuality, and power in contemporary life'.

While redefining vulnerability has been one key feminist strategy, some scholars such as Judith Butler (2016) have expressed doubt over whether the concept can be productive or should be used at all in some contexts. In Butler's (2016: 25) words, undoing the binary between vulnerability and resistance is a feminist task, but 'vulnerability cannot be the basis of group identification without strengthening paternalistic power'. She further critiques human rights discourse and legal regimes for ignoring 'modes of political agency and resistance within so-called vulnerable populations', seeing them instead as in need of institutional or state protection and advocacy (Butler, 2016: 24-5). On the other hand, feminist scholars such as Alyson Cole (2016) have critiqued the move to redefine vulnerability in contradistinction to victimisation, since if victims are not seen as victims this may inadvertently feed into politics which does not prioritise changing injustices. Cole suggests, furthermore, that there needs to be a clear distinction between those that are injurable and those who are already injured.

Expectedly, many feminist, queer, and critical race studies scholars have turned to other or nearby concepts instead of vulnerability to address the tensions between injury and power. Butler herself has, for example, preferred the concept of precariousness in other contexts (2004). Precariousness, for her, refers to the way in which all lives 'can be expunged at will or by accident; their persistence is in no sense guaranteed' (2004: 12). In this sense, precariousness, just like vulnerability, refers to the ontological fragility of life. But the contexts in which Butler discusses preciousness are more intimately linked to the possibility of death, disappearance, diminishing, or perishing 
of life: America's post-9/11 war on terror; Palestinian deaths; the treatment of prisoners in Guantanamo Bay. Vulnerability seems to thus refer more to the possibility or risk of injury - people and non-human actors can still persist indefinitely as vulnerable - whereas precariousness refers to a more imminent threat of perishing, even if the two concepts can at times be used interchangeably.

Moreover, vulnerability can sometimes resemble a synonym of marginalisation or subordination, especially when it is invoked in connection to those who suffer or experience discrimination due to how they are categorised: vulnerable groups are then usually also marginalised groups. But, despite their close allegiance, marginalisation and subordination invoke first and foremost structures and societal conditions that produce injustice and political action. Their existence does not depend as much on lived experiences - feeling discriminated against is not the same as being discriminated against - and is not necessarily as keenly connected to embodiment and corporeal fragility as is vulnerability. Perhaps most importantly for this book, however, vulnerability directly invokes and mobilises affect in that it actualises in feelings of fear, shame, compassion, anger, and many others, whereas marginalisation and subordination, while often involving a deeply affective dimension, can at least seemingly exist and thrive passionlessly, invisibly, and normalised.

Another, and perhaps less obvious, concept we see as intimately tied to vulnerability is abjection. This connection only becomes feasible when vulnerability is understood, not as an intrinsic quality of any group or a 'weakness', but as a tension between subjugation and resistance, embedded both in societal and psychic structures. Imogen Tyler (2013), drawing on French psychoanalytical feminist theorist Julia Kristeva's (1982) work, discusses what she calls social abjection in reference to groups such as Roma and asylum seekers, often deemed disposable or 'scum' from the perspective of dominant or state power, but who still resist, revolt, and fight against their subjugation. Tyler points out, however, that the demands for justice, equality, and recognition by such revolting subjects ('revolting' as in both deemed abject and involved in acts of revolt) can lead and have led to further cycles of punishment (2013: 12). A similar fear surrounds the \#BlackLivesMatter and \#MeToo campaigns discussed earlier, where the demands to recognise and end killing and harassment may also lead to even keener silencing and even more violence. Darieck Scott, in his work on blackness, abjection, and power, argues that there is counterintuitive power in abjection, particularly when it comes to black bodies which are often used as 'one of the go-to-figures for referencing abject' (2010: 12). Scott suggests that instead of trying to change past traumatic and painful narratives, images, and experiences of black abjection into ones of black heroism or 
success, such abjection, trauma, and psychic disintegration could be used as a resource for the political present (2010: 6). While abjection and vulnerability do in some ways approach each other - both are keenly connected to affect and embodiment - abjection nevertheless implies disgust, shame, and fear to a wholly different degree than vulnerability, which does not necessarily have anything to do with disgust but comes up perhaps most often in relation to compassion (as discussed later).

It is indeed worth asking how productive the approach to vulnerability or abjection - as simultaneously involving resistance can be when addressing issues like global racism and massive inequalities in basic resources and the ability to live on. What resistance could there possibly be in the utmost realisation of vulnerability - death? Ruth Wilson Gilmore's well-known definition of racism raises this question, as she describes racism as 'the state-sanctioned and/or extra-legal production and exploitation of groupdifferentiated vulnerability to premature death' (2006: 28). For Gilmore, the very group identity of racialised subjects - those subject to racism is defined through vulnerability to too-early death. The word vulnerability carries particular political weight here: the existence of state-sanctioned and societal racism cannot be negated through pointing out that not all who suffer from racist discrimination die early, but implicating death in the very definition of racism stresses the gravity of its past and present. What is at stake is not only a politics of offence or 'hurt feelings' but questions of life and death.

Black and critical race theorists such as Achille Mbembe have, in a similar vein, conceptualised death as the very heart of contemporary racism, but also as central to societal and political power more broadly, and thus also, unavoidably, resistance. In his writing on the notion of necropolitics, Mbembe suggests that instead of biopower - power managing bodies and life - today we should rather talk about necropower, technologies of managing and 'subjugating life to the power of death' (2003: 39). Mbembe connects this to the increased instrumentalisation of death in the current world politics of terror, where some bodies are allowed to live, some are regarded as disposable, and some are reduced to a twilight between life and death, existing in so-called death-worlds. However, according to Mbembe we become human subjects through the very confrontation with death, and in necropolitics resistance can also take the form of death in acts and practices like sacrifice, suicide, and martyrdom. Following Mbembe's lead in the edited collection Queer Necropolitics (2014), Jin Haritaworn, Adi Kuntsman, and Silvia Posocco set out to explore 'queer subjects invited into life and queerly abjected populations marked for death' (2014: 2), not only in war zones or 'death-worlds' but also in mundane, everyday homonationalist (Puar, 2007) practices where queer can just as well be about 
deadly exclusion as about deadly inclusion in relation to the nation state. Again, practices of resistance cannot, under such conditions, exist as the opposite to or negation of vulnerability, pain, or even death, but they build on it and draw affective force from it, just like in the previously discussed \#BlackLivesMatter campaigning. These are themes discussed in this book, especially by Ylva Habel, who interrogates Swedish debates on anti-black racist representations through the lens of afro-pessimist theory.

The double edge of vulnerability - its connections to regulation, subjugation, and death on one hand, and its power to bring together and mobilise political agency on the other - has indeed been keenly examined in queer theorising. While scholars interrogating racism and global necropolitics have tended to focus more on vulnerability as connected to structural oppression and state-sanctioned violence, in much queer theorising the need to reclaim and redefine vulnerability as a resource has been at the fore, for example in relation to vulnerable 'femmebodiment' (Dahl, 2017) and queer vulnerability in films such as Boys Don't Cry (1999) (Hagelin, 2013: 103-18). Ann Cvetkovich, in her exploration of the role of trauma and vulnerability in lesbian and queer public cultures, argues for the healing power of vulnerability in working through sexual stigma and violence. For her, sexuality and sex are areas which necessarily make the body vulnerable, but where that vulnerability also offers profoundly transformative vistas for political and personal agency. Examining practices, memories, and documentation of butch-femme sexualities and AIDS activism, among others, Cvetkovich suggests that the power of queer vulnerability lies in openness to pleasure and care as well as injury (2003: 66-7, 202-4).

In queer disability studies, or crip theory, the double edge and potential of embracing vulnerability have long been key to the project of resignifying and redefining disability, alongside able-bodiedness. Feminist and queer disability scholars and activists have thoroughly questioned the normalised association of disability to corporeal weakness and external regulation, critiquing the ideology of 'compulsory able-bodiedness' (McRuer, 2006). They have also suggested that the vulnerabilities of the disabled body are central and potentially destabilising to the very ideas of bodily and sexual normalcy (Kafer, 2013; McRuer, 2006; Shildrick, 2002). Crip theorists such as Alison Kafer (2013) have nevertheless argued that feminist disability studies' emphasis on the social constructedness of disability and the revolutionary potential of vulnerability may disregard some important material aspects of disability. For Kafer, the very real experiences of pain, exhaustion, and weakness risk becoming taboos, and some disabled people's need for care and medical intervention risks becoming depoliticised if vulnerability is only perceived as a resource for revolt and destabilising norms. 
Feminist, queer, and critical race studies scholarship on and related to vulnerability spans not only a plethora of identities, issues, and locations, but is also characterised by multiplicity and complex interlacing in terms of theoretical backgrounds and investments. Keeping in mind that in the work of many (if not most) scholars various legacies flow into each other, we can identify at least four different critical legacies contributing to theorising vulnerability across feminist scholarship as well as queer and critical race studies:

1 A phenomenological understanding of vulnerability as an ontological condition of the embodied subject (Ahmed, 2004; 2006; Butler, 2004; 2009; Cavarero, 2009; Grosz, 1994; 2008; Shildrick, 2002).

2 A psychoanalytically informed understanding of vulnerability as an effect of psychic or social trauma (Butler, 1997b; 2004; 2005; Cvetkovich, 2003; Kristeva, 2010; Oliver, 2007; Scott, 2010).

3 A new materialist notion of vulnerability as an effect of bio-technologies and material transformability (Alaimo and Hekman, 2008; Braidotti, 2006; Colebrook, 2010; Fraser et al., 2005; Kafer, 2013; Mbembe, 2003, Puar, 2007; Shildrick, 2002; Smelik and Lykke, 2008).

4. A critical theory notion of vulnerability as a particular politically produced condition and a historically specific political language (Ahmed, 2004; 2017; Berlant, 1997; 2008; Brown, 1995; 2008; Butler, 1997a; Skeggs, 2005).

These legacies of theorising also appear in studies of media, particularly of how media culture shapes subjectivities, bodies, identities, and politics. Vulnerability in this disciplinary context emerges in different theories of thinking about media 'effects', or how we function in a highly mediatised culture through various dependencies and forms of agency. In the forefront of media theoretical uses of vulnerability are phenomenological theories investigating the interlacing of embodiment and consciousness with media technologies, 'vision in the flesh', and the interconnectedness of senses (Sobchack, 2004), as well as 'haptic viewing', corporeal openness to and of film, and touch as a mode of engaging with media (Marks, 200o).

The psychoanalytical understanding of vulnerability, on the other hand, has informed feminist film theorists ever since the 1970s, as they have investigated how our gendered subjectivities are formed through affective engagements with screen images on a deep psychosocial level (de Lauretis, 1984; 1994; Silverman, 1996; Stacey, 2010; White, 1999). What is particularly interesting about psychoanalytical feminist film theories is that they have understood our susceptibility to and longing for pleasure as being our greatest vulnerability in the face of patriarchal structures of 
domination: pleasure makes us unwittingly submit to power. In comparison to today, as Kyrölä discusses in her chapter on trigger warning debates, it seems that, rather than pleasure, feelings of discomfort or anxiety are considered much more suspicious and signalling subordination.

Third, new materialist notions of engagements with media as 'wiring, 'effect,' or corporeal 'becoming' through images and technologies have become more and more influential in feminist, queer, and critical race studies' theorising of and around media (Coleman, 2008; Keeling, 2007; MacCormack, 2008; Parisi and Terranova, 2001). Finally, the critical theory notion of vulnerability concretises in investigations of media engagement as a form of political agency and a site of citizenship, or becoming intelligible as a subject (Berlant, 1997; Ouellette and Hay, 2008; Rancière, 2009; Skeggs, 2005). In the book at hand, this last strand of theorising is perhaps most prominent, although, as always, a strict distinction is impossible, and convergence inevitable.

Several of the four legacies or traditions of theorising we sketched above also merge in Judith Butler's work on vulnerability, which thoroughly informs our approach. Butler's long engagement with the concept has ranged from the discussion of hate speech and linguistic vulnerability in Excitable Speech (1997a), which links most clearly to the psychoanalytical and critical theory understandings, to theorising vulnerability as a form of activism in Notes Toward a Performative Theory of Assembly (2005) and as resistance in Vulnerability in Resistance (2016), which lean more towards a collation of phenomenological and critical theory understandings. Writing about violence and mourning in Precarious Life (2004), Butler defines vulnerability as an existential condition of us all in the phenomenological sense: 'a vulnerability to the other that is part of bodily life, a vulnerability to a sudden address from elsewhere that we cannot preempt' (2004: 29). She argues for 'a common human vulnerability', 'a condition of primary vulnerability', and 'fundamental modes of dependency' (2004:31, 49), going against an understanding of vulnerability as deprivation or absence of agency. However, 'there are radically different ways in which human physical vulnerability is distributed across the globe' (2004: 32). In Butler's analysis, vulnerability is to be discussed in relation to power, norms, and recognition, even if there is an existential dimension to it as well. Recognition is key for Butler in shifting vulnerability from universal co-dependency towards political mobilisation: 'vulnerability takes on another meaning at the moment it is recognised, and recognition wields the power to reconstitute vulnerability' (2004: 43).

Later, in Frames of War: When Is Life Grievable, Butler stresses the agency of the vulnerable body, stating that 'there are no invulnerable bodies' (2009: 25-6). While 'injury is one thing that can and does happen', the 
body's vulnerability is not reducible to its injurability. The responsiveness of the body 'may include a wide range of affects: pleasure, rage, suffering, hope, to name a few' (Butler, 2004: 34). Most recently, in the edited collection Vulnerability in Resistance, Butler further develops her characteristic idea of vulnerability as both a restraint and a potentiality, thoroughly interlacing the phenomenological, psychoanalytical, and political/critical theory understandings. Vulnerability, importantly, is not a subjective disposition for Butler, but 'a relation to a field of objects, forces, and passions that impinge on or affect us in some way' (Butler, 2016: 25).

For the purposes of this book, the notion of vulnerability (and invulnerability) as 'politically produced, unequally distributed through and by different operations of power' (Butler et al., 2016: 5) offers a productive starting point. Recognising the importance of how vulnerability can enable the norm to remain intact, this approach simultaneously resists equating the power of vulnerability with identity politics or reducing it to a 'politics of pain'. The pull of the neoliberal, individualistic narrative of 'from vulnerability to resilience' is forceful both in feminist academic discussions and contemporary public discussions and media cultures. However, in this book we want to follow up on Butler's call for understanding vulnerability as restraint as well as responsiveness, a concept rife with paradoxes, but also potential.

Furthermore, we want to stress vulnerability's contextuality and explore how exactly injury and agency, pain and power, work together when vulnerability is mobilised in the public imagination, in mediated debates, and cultural policies. Our purpose is not to argue for vulnerability as the best or extraordinarily useful concept or tool for critical research, nor against vulnerability as a concept or a starting point for activist efforts. Rather, we approach vulnerability both as a concept and a political language, offering analyses of its histories, legacies, power, and potential as well as problems in the wider social and political contexts where it has today been mobilised. What does this language do? How does the same language have many different functions in various contexts? What are the implications of conceptualising vulnerability as a basis for or a restraint to political agency, identity politics, and claims-making?

\section{VULNERABILITY AS A POLITICAL LANGUAGE}

In practical and policy work that aims to advance equality, social protection, and human rights, the concept of vulnerability is well-established today. In particular, it is used in reference to 'vulnerable populations' or 'groups' - those that embody difference from the normative subject. In 
the human rights discourse, the notion of 'vulnerable populations' has been used in order to advocate for special protection or awareness of marginalised, disadvantaged, and discriminated groups, such as ethnic minorities and LGBTQ people, vulnerable to violations of their fundamental rights. 'Vulnerable populations' have been established in human rights discourse by the Council of Europe, the European Union, the European Court of Justice, and the European Court of Human Rights (Ippolito and Sanchez, 2015; Masferrer and Garcia-Sánchez, 2016; Peroni and Timmer, 2013), and notions of vulnerable persons or groups abound in policy documents (in the UK since the 1990s - see McLaughlin, 2012). Moreover, the notion has been institutionalised in policy documents concerning research ethics since 1979 (National Commission, 1979). 'Vulnerable groups' and 'populations' are also used by the World Health Organization, in refugee and asylum policies, and in handbooks for disaster preparedness and prevention.

In queer, feminist, and critical race studies discussions, the politics of claiming rights has been broadly problematised since rights imply a certain allegiance to the nation state or other global governing bodies which can themselves be seen as agents of colonialist, patriarchal, and heteronormative power and violence (e.g. Brown, 1995; Haritaworn et al., 2014; Puar, 2007). In particular, indigenous feminist theorists have been at the forefront of pointing out how the notion of the nation state itself builds on heteronormative, capitalist, and settler-colonialist ideas about modernity and civilisation, as well as land and nature as something that can be owned, bought, sold, and separated from human and non-human beings that live in it (Arvin et al., 2013; Simpson, 2014). Even if the language of human rights and its emphasis on the inviolability of human dignity is meant to protect and preserve all on an equal basis, this aim is often far from becoming realised. The political language of rights, just like the political language of vulnerability, can be and has been decontextualised, recontextualised, mobilised, circulated, appropriated, and misappropriated.

The chapters in this book address four aspects of how the political language of vulnerability operates: (1) as a human rights discourse (Horak, Gondouin et al.); (2) as a language easily appropriated by dominant groups (Paasonen, Habel, Gondouin et al.); (3) as a contested language invoking long-running debates in queer, feminist, and anti-racist media cultures (Halberstam, Ahmed, Kyrölä); and (4) as a language translated into cultural policymaking and imaginary in a specific national context (Brunow, Ryberg, Lee Gerdén, Koivunen). Chapters by Laura Horak and Johanna Gondouin et al. provide original perspectives on the mobilisation of vulnerability in the contexts of trans activism and in the debate about transnational commercial surrogacy - contexts where the rights to safety, life, and selfdetermination are highly acute. Horak discusses two documentaries about 
translatina world-making - The Salt Mines (US, Susana Aikin and Carlos Aparicio, 1990) and Wildness (US, Wu Tsang, 2012) - arguing that both offer respectful reflections on the possibilities and dangers of representing vulnerable trans lives. Gondouin et al.s chapter on the TV series Top of the Lake: China Girl (Australia, Jane Campion, 2017) sheds light on the conflicting discourses of reproductive rights and reproductive justice, and how white and non-white vulnerabilities carry different affective weights in popular narratives about transnational commercial surrogacy.

In addition to the human rights discourse on vulnerability as an issue of structural differences between groups and exposure to risks, the proliferation of the language of vulnerability is also evident in the broad contemporary Western concerns about the fate of humankind in the midst of economic polarisation and insecurity, global terrorism, the rise of rightwing nationalism, fast technological development, artificial intelligence, the mass extinction of species, climate change, and the Anthropocene (Haraway, 2016). This general sense of being/becoming vulnerable is amplified by social media, for instance by the Facebook safety check on occasion of various attacks, emergencies, and disasters, which is critiqued for its Western bias (McHugh, 2015).

Such broad concerns make up a narrative of hovering threats and human defencelessness. In the 2010s, the evident currency of the concept of vulnerability has been attributed to the way it epitomises 'a new sense of risk' (Misztal, 2011) or even a Zeitgeist in the twenty-first century. What seems to matter in such Western narratives is a feeling of vulnerability and its anticipation, rather than experiences of violence, hurt, trauma, illness, or oppression. Vulnerability becomes, then, temporally organised through expectation and prevention, as an orientation towards a threatening and dangerous future, invoking what Cole (2016) has called blurred boundaries between those who are injurable and those already injured. In a similar vein, Sara Ahmed (2004) asks who is contained through terror and whose vulnerability is at stake, while analysing fear and anxiety around terrorism in Western countries after 9/11. Ahmed demonstrates how narratives of crisis and being under threat by imagined others justify the racial profiling, border policing, surveillance, and detention of any bodies suspected of being terrorists.

In the contemporary American and European social and cultural imaginary, the positions of being 'under attack' or 'threatened' are advocated by dominant groups, such as white men involved in men's rights activism, or anti-immigration and nationalist movements. In these contexts, vulnerability appears as 'a tactical field' of making claims (Butler et al., 2016: 45). The power of vulnerability in this imaginary became acutely apparent when the Trump administration made an alleged attempt to ban a list of 
words, including 'transgender', 'diversity', and 'vulnerable', from being used in health policies in December 2017. In a comment, Jack Halberstam (2017) proposes that the alleged ban on words addressing marginalised groups suggests to Trump's white male voter base that 'certain people are getting special entitlements' and that 'social justice measures are ... going to be detrimental to your welfare, your economic well-being, your health and so on'. Similarly, Arlie Russell Hochschild (2016: 135ff.) describes the deeply felt anger of white people in the Tea Party movement who feel that others are 'cutting the line' with governmental support. The case of Trump's word ban also makes apparent that the language of vulnerability does not only regard a competition for attention or a politics of recognition, but also a redistribution of resources and access to healthcare (Butler, 1997c; Fraser, 1997; Fraser and Honneth, 2003).

In the wake of Brexit (the UK's decision to leave the European Union), the 2016 US presidential election resulting in Donald Trump's election, and the rise of European populism, narratives of wounded nations, genders, and classes permeate news and other journalism. As a political language articulating a felt experience of our time, vulnerability is then also oriented towards the past and a sense of disappointment, betrayal (Hochschild, 2016), and distrust, and of having invested in a narrative that did not keep its promise (Ahmed, 2010; Berlant, 2011). In contemporary popular culture, such emotions are often channelled through recycled and updated versions of the figure of the sad white man or white men in crisis (Faludi, 1999), prompting calls for empathy and compassion, and recognition of white men's vulnerability (Hagelin, 2013). Susanna Paasonen's chapter in this book discusses the figure of the vulnerable white man in its recent incarnation in the hugely popular novels and films about the wealthy yet emotionally broken white straight man Christian Grey in the Fifty Shades of Grey franchise. White heterosexual male vulnerability constituted in childhood trauma not only humanises the cold and sadistic Christian, but also functions as a social and sexual fantasy, Paasonen shows. The chapter examines the notion of vulnerability as it smooths over outrageous structural privilege.

Fifty Shade of Grey, however, is only one of many examples in contemporary popular culture that lift up, offer attention to, and dry the tears of white straight men represented as wounded. In a blog post on the widely celebrated melodrama Manchester by the Sea (US, Kenneth Lonergan, 2016), Jack Halberstam (2017) reads the film as symptomatic of the Trumpian Zeitgeist and critiques the affective politics of the film. The viewers' compassion is first and foremost channelled towards the male protagonist played by Casey Affleck, who won an Oscar for his performance of a griefstricken janitor - not his wife who also mourns, or his kids who were killed in the film because of his negligence. Halberstam argues: 'Whiteness, the 
film tells us, is part of the frayed beauty of America and its power hangs in the balance in a world where bad things can and do happen to white men ... even when they themselves cause those bad things to happen!' Summarising the film's politics, Halberstam concludes: 'It is time, apparently to make America great again, to cater to the sad white man, to feel his pain, to lift him up and dry his tears' (Halberstam, 2017; see also Serisier, 2008).

In neoliberal media culture, traumatic first-person or group narratives have popular currency, suggesting a possibility to mobilise experiences of trauma to gain both cultural visibility and political advantage. The politics of representation translates into a question about whose vulnerability counts as socially and culturally legible, acknowledged, and deserving of compassion. In the age of commodified trauma narratives, a rhetoric of vulnerability may look like a competition between disadvantaged groups. Vulnerability becomes a kind of capital, a resource, or an asset, making its way into public discourse. In this book, Habel analyses how vulnerability becomes a resource and tool for white privilege in the context of public debates on racist representation in Sweden. Drawing on the work of afropessimist scholars and discussing the controversy around the children's film Liten skär och alla små brokiga [Little Pink and the Motley Crew] (Stina Wirsén, Sweden, 2012), Habel elucidates how blackness in Swedish mainstream media debates became an unfathomable 'object' as white media commentators and gatekeepers forcefully played out a sense of white fragility in response to the critique of the film's racial stereotypes. Gondouin et al. demonstrate in their chapter how the series Top of the Lake: China Girl invokes a notion of reproductive vulnerability that justifies the practice of transnational commercial surrogacy, obscures intersectional asymmetries of power, and overrides concerns for the precarious situation of surrogates in the Global South - all through an overemphasis on the emotional fragility of white couples who long for babies.

As a language so easily whitewashed and adopted both by normative legal structures and dominant groups in the public debate, the political usefulness of vulnerability as a key term in queer, feminist, and anti-racist activism has been questioned. In this book, Kyrölä's, Ahmed's, and Halberstam's chapters all engage vulnerability as a contested tool associated with identity politics as well as with its critique. Their chapters address the heavily debated issue of trigger warnings as a question in academic classrooms, activism, the blogosphere, and online forums from the United States to the United Kingdom and the Nordic countries. Kyrölä's chapter offers an analysis of how varying understandings of vulnerability are mobilised in three different contexts where the figure of the trigger warning currently circulates: in feminist online discussion forums; in the feminist, queer, and anti-racist academic opposition of trigger warnings; 
and in anti-feminist public discourses. Halberstam's chapter - reprinted from the feminist journal Signs winter 2017 issue, accompanied by a digital archive on trigger warnings - discusses requests for trigger warnings on US college campuses as conforming to paternalistic and normative structures of protection and surveillance. Ahmed's chapter - also a reprint from a post on her blog 'Feminst Killjoys' - discusses how the trigger warning debate circulates a figure of 'the too-easily-hurt student' that reactivates old notions of women's studies as encouraging hyper-sensitivity and narcissistic quests for individual self-realisation.

As seen in the debate on trigger warnings, the language of vulnerability evokes the problem of 'wounded attachments' as the by-product of emancipatory identity politics grounded in 'logics of pain' (Brown, 1995), but the same language also raises questions about the uses and meanings of representations of violence, abuse, suffering, and pain. Celebrated films and TV series such as Precious (US, Lee Daniels, 2009), Beasts of the Southern Wild (US, Benh Zeitlin, 2012), and Orange Is the New Black (US, Jenji Kohan, 2013-) have been much criticised for the ways in which aestheticised and extensive depictions of black suffering turn into a fetishising spectacle and 'Black misery porn' (Griffin, 2014). At the same time, the ethical responsibilities of news and other media coverage of human despair and death in the contexts of natural disasters and war, such as the devastating hurricane in Haiti in 2016 and the Syrian war and refugee crisis, are being intensely debated (Chouliaraki, 2013; Durham, 2018; Knudsen and Stage, 2015). In this book, chapters by Lee Gerdén, Habel, and Gondouin et al. address aspects of how black and brown bodies come to be represented as less sensitive to humiliation and pain than white bodies, less vulnerable or grievable, or less worthy of ethical tactfulness. Horak's chapter draws attention to the complex problem of how increased media visibility and attention to discrimination and hate crimes against trans people have, instead of decreasing risks, resulted in increased violence, particularly against poor and immigrant trans women of colour and sex-workers as easily accessible targets.

As Berlant argues, scenes of vulnerability that are expected to invite connection, sympathy, and engagement often produce 'a desire to withhold compassionate attachment' instead:

the aesthetic and political spectacle of suffering vulnerability seems to bring out something terrible, a drive not to feel compassion or sympathy, an aversion to a moral claim on the spectator to engage, when all the spectator wants to do is to turn away quickly and harshly. (Berlant, 2004: 9-10)

In Berlant's analysis, hence, 'we must be compelled to feel right, to overcome our aversions to others' suffering by training ourselves in compassionate 
practice' (Berlant, 2004: 11). In other words, the ethical claim to do what is right is increasingly replaced with the urge to feel right - and feeling right can easily become an empty, passing gesture designed to only barely mask one's urge to look away. In 'the humanitarian imaginary', the mediation of vulnerability and modes of soliciting compassion have thus changed. Whereas raising awareness for the suffering of others has been regarded 'a catalyst for the cosmopolitanization of solidarity', as Lilien Chouliaraki (2013) has argued, the proliferation of mediatised stories about vulnerable others has been criticised for leading to 'general suspicion or even apathy among media publics'. In the age of 'post-humanitarianism', furthermore, the spectators are less oriented towards the suffering of others than they are towards themselves.

On the other hand, the language of vulnerability has the capacity to invoke social formations that Berlant has termed 'intimate publics': 'affective scene[s] of identification among strangers' that promise 'a complex of consolation, confirmation, discipline, and discussion about how to live as an $x^{\prime}(2008)$. As collectives of individuals who have survived and are 'marked by the historical burden of being harshly treated in a generic way', intimate publics are 'juxtapolitical', according to Berlant. They attach people to each other, not by engaging dominant political institutions but through a shared sense of a 'common emotional world', 'an aesthetic and spiritual scene that generates relief from the political' (Berlant, 2008: 10). The \#MeToo campaign and most notably Oprah Winfrey's speech about surviving sexual abuse at the Golden Globe Awards ceremony in January 2018 - with the ensuing rumours and urges for her to run for president in 2020 - call into question the distinction between intimate publics and the political sphere. The figure of the survivor, prominent in Winfrey's speech as well as the \#MeToo campaign, has for some decades been gaining visibility in queer, feminist, and anti-racist activism and media cultures (e.g. Cvetkovich, 2003). While the language of survival underlines the severity of the physical and psychological pain that sexual abuse, rape, and homophobic and racist aggression bring about, and how everyone does not survive that violence, it can also raise issues about when and how the figure of the survivor is taken up. When does 'survivorship' connote a struggle to survive in the face of oppressive violence, and when does it invoke yet another narrative of heroism in the face of almost insurmountable adversity? In this book, the issue of surviving sexual and/or racialised abuse is addressed particularly in Ahmed's, Habel's, and Horak's chapters which discuss the hurt, the anger, and the things that survival can require for marginalised subjects.

Overall, the book is divided into three parts, each with a distinctive approach to the power of vulnerability. The opening part focuses on the notion of vulnerability as a battleground in queer, feminist, and anti-racist 
discussions. Part II examines the potential and limits of the language of vulnerability, illuminating how affect and vulnerability have turned into a politicised currency for not only addressing but also obscuring asymmetries of power. Part III focuses on complex intersections between media activism and state policies addressing so-called vulnerable groups. This part specifically explores Sweden as a context where feminist, queer, and antiracist activism meets progressive public policies of gender, sexual equality, and cultural diversity.

As a political language, vulnerability is not only institutionalised in human rights, social protection, and healthcare discourses but also in cultural policymaking, having a concrete impact on how resources for cultural production are distributed. This is abundantly evident in Sweden, where an increased interplay between feminist, queer, and anti-racist activism, and presumably progressive public policies of gender, sexual equality, and cultural diversity, has taken place in recent years. This has in part resulted in acclaim, in part in failure to achieve the desired effects, and in part in furious attacks from those who see particular measures to lift up underrepresented groups as a threat to the artistic freedom of others. To the latter group, such measures function as proof of how identity politics have overrun concerns about quality, a theme Mara Lee Gerdén interrogates in her chapter. In several of these debates, the Swedish Film Institute takes centre stage, also attracting much international attention. The current CEO Anna Serner has, since launching a programme for gender equality in Swedish cinema in 2013, held seminars at several top-tier film festivals and inspired policymaking within the British Film Institute and Eurimages. ${ }^{4}$ In the midst of the \#MeToo campaign, Serner announced that the institute would launch an education programme about sexual harassment, mandatory for all production companies seeking its support (Keslassy, 2017).

Against the extraordinary institutionalisation of feminist, LGBTQ, and 'diversity' perspectives in the Swedish context, this book offers a selection of original, detailed analyses of how vulnerability is set in motion in Swedish cultural policymaking, focusing particularly on the Swedish Film Institute. Chapters by Lee Gerdén, Brunow, and Ryberg investigate the political potential and constraints of the language of vulnerability for feminist, queer, and anti-racist thought and media activism, as they become institutionalised in public policies. Lee Gerdén's chapter looks at a recent Swedish Film Institute research programme on developing anti-racist and feminist film projects, asking how the programme allowed for hurtful histories to be articulated, and racial identity and 'racialised emotions' to be embraced as creative and empowering tools - but how, at the same time, the programme completely failed in listening to the voices of women of colour artists. Brunow's chapter investigates the management of queer-related 
content by the national audio-visual archives in Sweden and the UK as well as in activist archives, asking how practices of curating, cataloguing, and adding metadata have significance for whose lives, stories, and images can be remembered. Ryberg discusses the interplay between lesbian feminist filmmaking and Swedish policies on sexuality in the 1970s, making visible how lesbian self-presentation and citizenship emerged through discourses of vulnerability, such as abortion and contraception policies. In the same part, Anu Koivunen's chapter focuses on how the popular Swedish TV series and a trilogy of novels Torka aldrig tårar utan handskar [Don't Ever Wipe Tears Without Gloves] (2012), as well as the publicity around them, turned the previously unspoken trauma of AIDS and the deaths of gay men into a reparative fantasy and a resource for renewing the national self-image.

All in all, this edited collection brings together sets of media material from a variety of cultural contexts, shedding light on some of the burning issues at stake in contemporary media and cultural debates. The focus is particularly on analysing representations - from television series (Koivunen) to films (Paasonen, Ryberg, Gondouin et al., Horak), and from newspapers to online debates (Halberstam, Kyrölä, Habel) - but also on practices of archiving, remembering, and developing media content (Brunow, Lee Gerdén). Through these contexts, the chapters interrogate vulnerability as complex power relations forged through the circulation of mediatised affect, and thus they also offer a novel perspective on the recent scholarly debates on affect theories and affective methodologies. Every chapter, in its own way, questions and complicates the common narrative of our time as being too valorising about, occupied with, or fearful of vulnerability, by examining how the processes of naming and framing people or groups as vulnerable is always already highly politicised. There can be no set thing that vulnerability does or is, but the efficacy of vulnerability as a political language is fundamentally dependent on the contexts in which it is used.

As we have argued, nor is there a field of 'vulnerability studies', but the current popularity of the concept draws its power rather from its rich and varied legacies. However, there is no telling what vulnerability will do or where it will go in the future, since the language of vulnerability is clearly in motion, given the developments we have outlined above. Will vulnerability become increasingly domesticated, appropriated by dominant groups, and institutionalised as lip service that covers over continued marginalisation, like many argue has happened to the once-revolutionary concept of intersectionality (Bilge, 2013)? It remains to be seen where the language of vulnerability will go, but the urgent questions of power and powerlessness that it currently attempts to address are not likely to vanish anytime soon. 


\section{NOTES}

1 The social media campaign and hashtag \#BlackLivesMatter should be seen as partially separate from the movement Black Lives Matter, although they overlap in multiple ways (Freelon et al., 2016: 9).

2 Vulnerability studies has, however, on occasion been named as a field, both in terms of establishing such a field (Fineman et al., 2012) and critiquing it (Cole, 2016).

3 See www.engagingvulnerability.se (accessed 4 March 2018).

4. The cultural support fund of the Council of Europe, which provides funding for European cooperation at various levels of film culture.

\section{REFERENCES}

Adetiba, E. and T. Burke (2017). 'Tarana Burke says \#MeToo should center marginalized communities', The Nation (17 November), www.thenation.com/article/taranaburke-says-metoo-isnt-just-for-white-people (accessed 18 February 2017).

Ahmed, S. (2004). The Cultural Politics of Emotion. Edinburgh: Edinburgh University Press.

Ahmed, S. (2006). Queer Phenomenology: Orientations, Objects, Others. Durham, NC: Duke University Press.

Ahmed, S. (2010). The Promise of Happiness. Durham, NC: Duke University Press.

Ahmed, S. (2017). Living a Feminist Life. Durham, NC: Duke University Press.

Ahmed, S. and J. Stacey (2001). 'Introduction: Dermographies', in S. Ahmed and J. Stacey (eds), Thinking Through the Skin. London: Routledge, pp. 1-18.

Alaimo, S. and S. Hekman (eds) (2008). Material Feminisms. Bloomington: Indiana University Press.

Anderson, P. S. (2003). 'Autonomy, vulnerability and gender', Feminist Theory, 4:2, pp. $149-64$.

Arvin, M., E. Tuck and A. Morrill (2013). 'Decolonizing feminism: Challenging connections between settler colonialism and heteropatriarchy', Feminist Formations, 25:1, pp. 8-34.

Bankoff, G. (2001). 'Rendering the world unsafe: "Vulnerability" as Western discourse', Disasters, 25:1, pp. 19-35.

Beattie, A. R. and K. Schick (eds) (2013). The Vulnerable Subject: Beyond Rationalism in International Relations. New York and Basingstoke: Palgrave Macmillan.

Bergoffen, D. (2011). Contesting the Politics of Genocidal Rape: Affirming the Dignity of the Vulnerable Body. New York: Routledge.

Berlant, L. (1997). The Queen of America Goes to Washington City: Essays on Sex and Citizenship. Durham, NC: Duke University Press.

Berlant, L. (2004). 'Compassion (and withholding)', in L. Berlant (ed.) Compassion: The Culture and Politics of an Emotion. New York and London: Routledge, pp. 1-14.

Berlant, L. (2008). The Female Complaint. Durham, NC: Duke University Press.

Berlant, L. (2011). Cruel Optimism. Durham, NC: Duke University Press.

Bilge, S. (2013). 'Intersectionality undone: Saving intersectionality from feminist intersectionality studies', Du Bois Review, 10:2, pp. 405-24. 
Braidotti, R. (2006). Transpositions: On Nomadic Ethics. Cambridge: Polity.

Brown, W. (1995). States of Injury: Power and Freedom in Late Modernity. Princeton: Princeton University Press.

Brown, W. (2008). Regulating Aversion: Tolerance in the Age of Identity and Empire. Princeton: Princeton University Press.

Butler, J. (1997a). Excitable Speech: A Politics of the Performative. New York and London: Routledge.

Butler, J. (1997b). The Psychic Life of Power: Theories in Subjection. Stanford: Stanford University Press.

Butler, J. (1997c). 'Merely cultural', Social Text, 52-53:3-4, pp. 265-77.

Butler, J. (2004). Precarious Life: The Powers of Mourning and Violence. London: Verso.

Butler, J. (2005). Giving an Account of Oneself. New York: Fordham University Press.

Butler, J. (2009). Frames of War: When is Life Grievable? London: Verso.

Butler, J. (2015). Notes Toward a Performative Theory of Assembly. Cambridge, MA: Harvard University Press.

Butler, J. (2016). 'Rethinking vulnerability and resistance', in J. Butler, Z. Gambetti, and L. Sabsay (eds), Vulnerability in Resistance. Durham, NC: Duke University Press, pp. 12-27.

Butler, J., Z. Gambetti, and L. Sabsay (2016). 'Introduction', in J. Butler, Z. Gambetti, and L. Sabsay (eds), Vulnerability in Resistance. Durham, NC: Duke University Press, pp. 1-11.

Cavarero, A. (2009). Horrorism: Naming Contemporary Violence. New York: Columbia University Press.

Chouliaraki, L. (2013). 'Mediating vulnerability: Cosmopolitanism and the public sphere', Media, Culture E Society, 35:1, pp. 105-12.

Clark, N. (2010). 'Volatile worlds, vulnerable bodies: Confronting abrupt climate change', Theory, Culture E Society, 27:2, pp. 31-53.

Clough, P. T. and J. Halley (eds) (2007). The Affective Turn: Theorizing the Social. Durham, NC: Duke University Press.

Cole, A. (2016). 'All of us are vulnerable, but some are more vulnerable than others: The political ambiguity of vulnerability studies, an ambivalent critique', Critical Horizons: A Journal of Philosophy and Social Theory, 17:2, pp. 26o-77.

Colebrook, C. (2010). Deleuze and the Meaning of Life. London: Continuum.

Coleman, R. (2008). 'The becoming of bodies: Girls, media effects, and body image', Feminist Media Studies, 8:2, pp. 163-79.

Cvetkovich, A. (2003). An Archive of Feelings: Trauma, Sexuality, and Lesbian Public Cultures. Durham, NC: Duke University Press.

Dahl, U. (2017). 'Femmebodiment: Notes on queer feminine shapes of vulnerability', Feminist Theory, 18:1, pp. 35-53.

De Lauretis, T. (1984). Alice Doesn't: Feminism, Semiotics, and Cinema. Houndmills: Macmillan.

De Lauretis, T. (1994). The Practice of Love: Lesbian Sexuality and Perverse Desire. Bloomington: Indiana University Press.

Dodds, S. (2013). 'Dependence, care and vulnerability', in C. Mackenzie, W. Rogers, and S. Dodds (eds), Vulnerability: New Essays in Ethics and Feminist Philosophy. New York: Oxford University Press, pp. 181-203.

Durham, M. G. (2018). 'Resignifying Alan Kurdi: News photographs, memes, and the ethics of embodied vulnerability', Critical Studies in Media Communication 
(15 February), https://doi.org/10.1080/15295036.2017.1408958 (accessed 4 March 2018).

Faludi, S. (1999). Stiffed: The Betrayal of the American Man. London: Chatto \& Windus.

Fineman, M. A. (2008). 'The vulnerable subject: Anchoring equality in the human condition', Yale Journal of Law and Feminism, 20:1, pp. 1-23.

Fineman, M. A. (2010). 'The vulnerable subject and the responsive state', Emory Law Journal, 60:2, pp. 251-75.

Fineman, M. A. and J. Fineman (eds) (2017). Vulnerability and the Legal Organization of Work. New York and London: Routledge.

Fineman, M. A., E. P. Ziarek, C. Dayan, I. Vanni, and E. Castelli (2012). 'Theorizing vulnerability studies', Vulnerability: The Human and the Humanities Conference (3 March), http://bcrw.barnard.edu/videos/theorizing-vulnerability-studies (accessed 4 March 2018).

Fraser, N. (1997). 'Heterosexism, misrecognition, and capitalism: A response to Judith Butler', Social Text, 52-53:3-4, pp. 279-89.

Fraser, N. and A. Honneth (2003). Redistribution or Recognition? London: Verso.

Fraser, M., S. Kember, and C. Lury (2005). 'Inventing life: Approaches to new vitalism, Theory, Culture, and Society, 22:1, pp. 1-14.

Freelon, D., C. D. McIlwain, and M. D. Clark (2016). Beyond the Hashtags: \#Ferguson, \#Blacklivesmatter and the Online Struggle for Offline Justice. Washington, DC: American University, Center for Media and Social Impact, http://archive. cmsimpact.org/sites/default/files/beyond_the_hashtags_2016.pdf (accessed 26 February 2018).

Garber, M., B. Hanssen, and R. L. Walkowitz (eds) (200o). The Turn to Ethics. New York: Routledge.

Gilmore, R. W. (2006). Golden Gulag: Prisons, Surplus, Crisis, and Opposition in Globalizing California. Berkeley: University of California Press.

Gilson, E. C. (2014). The Ethics of Vulnerability: A Feminist Analysis of Social Life and Practice. New York: Routledge.

Gilson, E. C. (2016). 'Vulnerability and victimization: Rethinking key concepts in feminist discourses on sexual violence', Signs: Journal of Women in Culture and Society, 42:1, pp. 71-98.

Goodin, R. E. (1985). Protecting the Vulnerable: A Reanalysis of Our Social Responsibilities. Chicago: University of Chicago Press.

Goodin, R. E. (1988). Reasons for Welfare: The Political Theory of the Welfare State. Princeton: Princeton University Press.

Griffin, R. A. (2014). 'Pushing into precious: Black women, media representation, and the glare of the white supremacist capitalist patriarchal gaze', Critical Studies in Media Communication, 31:3, pp. 182-97.

Grosz, E. (1994). Volatile Bodies: Toward a Corporeal Feminism. Bloomington: Indiana University Press.

Grosz, E. (2008). Chaos, Territory, Art: Deleuze and the Framing of the Earth. New York: Columbia University Press.

Hagelin, S. (2013). Reel Vulnerability: Power, Pain, and Gender in Contemporary American Film and Television. New Brunswick: Rutgers University Press.

Halberstam, J. (2017). 'White men behaving sadly', Bullybloggers.com (28 February), https://bullybloggers.wordpress.com/2017/02/22/white-men-behaving-sadlyby-jack-halberstam/ (accessed 4 March 2018). 
Haraway, D. (2016). Staying with the Trouble: Making Kin in the Chthulucene. Durham, NC: Duke University Press.

Haritaworn, J., A. Kuntsman, and S. Posocco (2014). 'Introduction', in J. Haritaworn, A. Kuntsman, and S. Posocco (eds), Queer Necropolitics. New York: Routledge, pp. 1-27. Hochschild, A. R. (2016). Strangers in Their Own Land: Anger and Mourning on the American Right. New York: The New Press.

Honkatukia, P. (2011). Uhrit rikosprosessissa: haavoittuvuus, palvelu ja kohtelu [Victims in the Criminal Process: Vulnerability, Services, and Treatment], Oikeuspoliitisen tutkimuslaitoksen julkaisuja 252. Helsinki: Oikeuspoliittinen tutkimuslaitos.

Hutchings, K. (2013). 'A place of greater safety? Securing judgment in international ethics', in A. R. Beattie, and K. Schick (eds), The Vulnerable Subject: Beyond Rationalism in International Relations. New York and Basingstoke: Palgrave Macmillan, pp. 25-42.

Ippolito, F. and S. I. Sanchez (eds) (2015). Protecting Vulnerable Groups: The European Human Rights Framework. Oxford and Portland: Hart Publishing.

Kafer, A. (2013). Feminist, Queer, Crip. Bloomington: Indiana University Press.

Keeling, K. (2007). The Witch's Flight: The Cinematic, the Black Femme and the Image of Common Sense. Durham, NC: Duke University Press.

Keslassy, E. (2017). 'Swedish Film Institute launches sexual conduct education program, Variety (15 November), http://variety.com/2017/film/global/swedishfilm-institute-launches-sexual-conduct-education-program-1202615474/ (accessed 6 March 2018).

Knudsen, B. T. and C. Stage (2015). Global Media, Biopolitics, and Affect: Politicizing Bodily Vulnerability. New York: Routledge.

Koivunen, A. (2001). 'The affective turn?', in A. Koivunen and S. Paasonen (eds), Conference Proceedings for Affective Encounters: Rethinking Embodiment in Feminist Media Studies. University of Turku, School of Art, Literature and Music, Series A, No. 49.

Koivunen, A. (2010). 'An affective turn? Reimagining the subject of feminist theory', in M. Liljeström and S. Paasonen (eds), Disturbing Differences: Working with Affect in Feminist Readings. London: Routledge, pp. 8-28.

Kristeva, J. (1982). Powers of Horror: An Essay on Abjection, translated by L. S. Roudiez. New York: Columbia University Press.

Kristeva, J. (2010). Hatred and Forgiveness, translated by Janine Herman. New York: Columbia University Press.

Lamotte, S. (2017). 'For some, \#MeToo sexual assault stories trigger trauma not empowerment', CNN (19 October), http://edition.cnn.com/2017/10/19/ health/me-too-sexual-assault-stories-trigger-trauma/index.html (accessed 17 February 2018).

MacCormack, P. (2008). Cinesexuality. Aldershot: Ashgate.

Mackenzie, C. (2014). 'The importance of relational autonomy and capabilities for an ethics of vulnerability', in C. Mackenzie, W. Rogers, and S. Dodds (eds), Vulnerability: New Essays in Ethics and Feminist Philosophy. New York: Oxford University Press, pp. 33-59.

Mackenzie, C., W. Rogers, and S. Dodds (eds) (2013). Vulnerability: New Essays in Ethics and Feminist Philosophy. New York: Oxford University Press. 
Marks, L. (200o). The Skin of the Film: Intercultural Cinema, Embodiment, and the Senses. Durham, NC: Duke University Press.

Masferrer, A. and E. Garcia-Sánchez (eds) (2016). Human Dignity of the Vulnerable in the Age of Rights: Interdisciplinary Perspectives. Suiza: Springer.

Mbembe, A. (2003). 'Necropolitics', Public Culture, 15:1, pp. 11-40. Translated by L. Meintjes.

McHugh, M. (2015). 'Facebook's tragedy features and the outrage they inspired', Wired (16 November), www.wired.com/2015/11/facebook-safety-check-french-flag-filtertragedy-features-and-the-outrage-they-inspired (accessed 5 March 2018).

McLaughlin, K. (2012). Surviving Identity: Vulnerability and the Psychology of Recognition. Concepts for Critical Psychology. New York: Routledge.

McRuer, R. (2006). Crip Theory: Cultural Signs of Queerness and Disability. New York and London: New York University Press.

Misztal, B. A. (2011). The Challenges of Vulnerability: In Search of Strategies for a Less Vulnerable Social Life. Basingstoke: Palgrave Macmillan.

National Commission for the Protection of Human Subjects of Biomedical and Behavioral Research (1979). The Belmont Report: Ethical Principles and Guidelines for the Protection of Human Subjects of Research. Washington, DC: Department of Health, Education, and Welfare.

Nussbaum, M. C. (1986). The Fragility of Goodness: Luck and Ethics in Greek Tragedy and Philosophy. Cambridge: Cambridge University Press.

Oliver, K. (2007). Women as Weapons of War: Iraq, Sex, and the Media. New York: Columbia University Press.

Ouellette, L. and J. Hay (2008). Better Living Through Reality TV. Oxford: Blackwell.

Page, T. (2017). 'Vulnerable writing as a feminist methodological practice', Feminist Review, 115, pp. 13-29.

Parisi, L. and T. Terranova (2001). 'A matter of affect: Digital images and the cybernetic re-wiring of vision', Parallax, 7:4, pp. 122-7.

Peroni, L. and A. Timmer (2013). 'Vulnerable groups: The promise of an emerging concept in European Human Rights Convention law', International Journal of Constitutional Law, 11:1, pp. 1056-85.

Puar, J. (2007). Terrorist Assemblages: Homonationalism in Queer Times. Durham, NC: Duke University Press.

Rancière, J. (2009). The Emancipated Spectator. London: Verso.

Scott, D. (2010). Extravagant Abjection: Blackness, Power, and Sexuality in the African American Literary Imagination. New York and London: New York University Press.

Serisier, T. (2008). 'Laura Bush and Dan Brown: Whiteness, feminism and the politics of vulnerability', in A. Moreton-Robinson, M. Casey, and F. Nicoll (eds), Transnational Whiteness Matters. Lanham: Lexington Books, pp. 147-64.

Shildrick, M. (2002). Embodying the Monster: Encounters with the Vulnerable Self. London: Sage.

Silverman, K. (1996). The Threshold of the Visible World. New York: Routledge.

Simpson, A. (2014). Mohawk Interruptus: Political Life Across the Borders of Settler States. Durham, NC: Duke University Press.

Skeggs, B. (2005). 'The making of class and gender through visualizing moral subject formation', Sociology, 39:5, pp. 965-82. 
Smelik, A. and N. Lykke (eds) (2008). Bits of Life: Feminism at the Intersections of Media, Bioscience, and Technology. Seattle and London: University of Washington Press.

Sobchack, V. (2004). Carnal Thoughts: Embodiment and Moving Image Culture. Berkeley: University of California Press.

Stacey, J. (2010). The Cinematic Life of the Gene. Durham, NC: Duke University Press.

Straehle, C. (ed.) (2016). Vulnerability, Autonomy, and Applied Ethics. London: Routledge.

Ten Have, H. (2016). Vulnerability: Challenging Bioethics. London: Routledge.

Turner, B. S. (2006). Vulnerability and Human Rights. University Park: Pennsylvania State University Press.

Tyler, I. (2013). Revolting Subjects: Social Abjection and Resistance in Neoliberal Britain. London and New York: Zed Books.

Vaittinen, T. (2015). 'The power of the vulnerable body', International Journal of Politics, 17:1, pp. 100-18.

White, P. (1999). Uninvited: Classical Hollywood Cinema and Lesbian Representability. Bloomington, IN: Indiana University Press.

Wiegman, R. (2014). 'The times we're in: Queer feminist criticism and the reparative "turn", Feminist Theory, 15:1, pp. 4-25.

Wilkinson, I. (2009). Risk, Vulnerability, and Everyday Life. New York and London: Routledge.

Yancy, G. and J. Butler (2015). 'What's wrong with all lives matter?', New York Times (12 January), http://shifter-magazine.com/wp-content/uploads/2015/o1/WhatsWrong-With-All-Lives-Matter.pdf (accessed 18 February 2018). 


\section{Part I}

\section{VULNERABILITY AS A BATTLEGROUND}





\title{
NEGOTIATING VULNERABILITY IN THE TRIGGER WARNING DEBATES
}

\author{
KATARIINA KYRÖL $\ddot{A}$
}

Cince around 2012, the use of trigger warnings or content warnings has $\checkmark$ spread all over the Internet and, to some extent, academic classrooms. Warnings about content that may be upsetting, offensive or that could trigger post-traumatic stress responses abound online, particularly in contexts where the addressed include people or groups deemed marginalised, disadvantaged or traumatised. Trigger or content warnings have most commonly been linked to online images and texts explicitly depicting sexual violence, mental illness, or sexist, racist, ableist, cis-sexist or heterosexist subordination.

These warnings have unsurprisingly elicited heated debate in academic circles: debate pieces appear on a regular basis in scholarly journals and blogs, such as Inside Higher Ed; the feminist journal Signs has assembled a digital archive of resources ${ }^{1}$ on trigger warnings; and the first book-length collection of essays about them, Trigger Warnings: History, Theory, Context, appeared in 2017 (Knox, 2017). The online magazine Slate declared year 2013 as the 'year of the trigger warning' (Marcotte, 2013). To a large degree, views have become polarised into 'against' and 'for' camps. At the same time, in many feminist, queer and anti-racist social media groups and discussion forums, the use of trigger warnings or content warnings has become standard practice and is taken as a necessary part of online discussion in spaces that are dedicated to fighting marginalisation and abuse based on gender, sexuality, ability, race or ethnicity. Trigger warnings have become expected and normalised in what are called safe - or safer - spaces online.

The point of departure for this chapter is my own initial doubt, even confusion, about trigger warnings. As a feminist media scholar long involved in interrogating 'bad feelings', and convinced they serve a purpose in 
challenging unjust power structures (Kyrölä, 2015; 2017), I felt such warnings ring disconcertingly of avoidance - and it seems that this point of departure is shared by most feminist, queer and critical race studies scholars who have participated in the public debate so far. However, something about the strong dismissal of trigger warnings bothered me as well, since they obviously serve an important purpose to those who request them, which led me to investigate the debate more thoroughly and to question my own initial reservations. This chapter thus examines first and foremost the online debates about trigger warnings or content warnings during the last few years, providing a mapping of the discourses around them, while another important aspect of the debate, namely the educational or classroom aspect, is not at the centre of focus. My aim here is not to argue against or for trigger warnings per se, but to invite readers to re-evaluate their own stances, as I have done, and understand what exactly we oppose or side with, when we oppose or side with trigger warnings. I do argue that it is essential to carefully analyse how trigger warnings are being used in various contexts and how they mobilise varying understandings of vulnerability, since they can be and are being used for completely oppositional political purposes - both to create alternative worlds where the marginalised set the pace, and to ridicule feminist, queer and anti-racist efforts.

The figure of the trigger warning currently seems to circulate most intensely in three key contexts: (1) feminist discussion forums and peer support communities where the use of trigger warnings or content warnings is a desired, required and normalised practice; (2) feminist, queer and antiracist academic critique of trigger warnings which emphasises the pedagogical value of negative affect and discomfort; and (3) anti-feminist online spaces where trigger warnings are seen as a condensation of how 'feminism has gone too far' in 'policing' what can and cannot be said. For feminist discussion forums, I use the rules for a Finnish closed Facebook group called the 'Laid-back Feminist Group' (in Finnish, 'Rento feministiryhmä') as an example, alongside some public online and academic debate pieces, including Sara Ahmed's. For the feminist, queer and anti-racist opposition of trigger warnings, I examine a selection of key texts by, for example, Jack Halberstam and Roxane Gay. For the anti-feminist ridicule of trigger warnings, I exemplify broader tendencies in the discourse through selected online articles. In each of these contexts, I aim to show that vulnerability is understood in somewhat different but overlapping ways: as a standpoint that both prohibits and enables; as a necessity to life that must be embraced; and as a paradoxical position where claims to power are made through claims of disempowerment.

In feminist and peer support discussion forums, trigger warnings have been seen as protection for vulnerable groups, an attempt to create safer 
spaces for those living with trauma or societal stigma. The intention of giving a trigger warning is usually to make apparent that the giver of the warning cares for the wellbeing of their audience members and wants to protect them from encountering potentially distressing content without warning or preparation. It is less important whether that content is actually experienced as distressing or traumatising by anyone, and more important to signal what the content may entail as well as perform the gesture of care. From this perspective, trigger warnings enable people to make informed choices about when, how or whether to engage, instead of being bombarded without warning with content that can produce emotional distress and therefore prohibit engagement (Carter, 2015; Cecire, 2014).

For the feminist anti-trigger warning public debaters, the same warnings have been seen as extensions of a culture of overprotection and paradoxical celebration of victimhood, focusing on individual psychology rather than oppressive structures. From the opposing perspective, the proponents of trigger warnings infantilise themselves and unwittingly pathologise the reading and watching practices of already marginalised groups, as if they were unable to take a critical distance from what they see, hear and read. Those opposing argue that trigger warnings can repress discussion and the representation of difficult or hurtful matters, when a feminist, queer and anti-racist stance to the world almost always means dealing with very hurtful matters - and hurt, pain and anger can have great value as feminist tools. Furthermore, the things that can trigger actual post-traumatic stress are usually unpredictable, such as a sound, a colour, or an arbitrary word or image, and even if triggers were known and obvious, avoidance is not effective treatment (Freeman et al., 2014; Friedersdorf, 2015; Gay, 2012; Halberstam, 2014a; 2017).

Even more recently, trigger warnings have become the latest favourite target of mockery for anti-feminists and some white liberal feminists alike, as well as for those opposing 'excessive political correctness' in the era of Donald Trump and the rise of right-wing nationalism in many European countries. In this context, trigger warnings have dismissively been called another symptom of 'generation snowflake' - the generation that came into adulthood in the 2010s, presumably more fragile and easily offended than the previous ones (GQ, 2016; Hartocollis, 2016). I bring this context into focus not to present it as a perspective among others but to examine how some of the language used in feminist contexts has been disconcertingly adopted into anti-feminist discourse. Scholars, activists and public debaters should be aware of the potential allegiances they may build, even if inadvertently, with anti-feminist voices, or white supremacist, trans-exclusionary feminist discourses. 
While the debate and the division between pro and anti camps have most forcefully taken place in the North American context, the same debates are also happening in other parts of the world like the Nordic countries, the location from which I am writing. Academic culture in the Nordic countries is different from the United States and Canada, for example in terms of the cost of education, but online cultures and practices of communication spread quickly across the world, like trigger warnings have. As many students and staff members participate in online communities, the online debates at the focus of this chapter cannot be held fully separate from educational contexts. Regardless of one's location and stance on trigger warnings, the question of how to deal with potential trauma and the varying backgrounds and identifications on university courses and online communities alike is a pertinent one.

Trigger warnings have been connected to an 'ethos of vulnerability' (Brunila and Rossi, 2017) in contemporary Western culture, where a shared vulnerability, in terms of shared experiences of trauma, oppression and victimhood, is underlined by the 'vulnerable' themselves as a key basis for claims to rights, recognition and voice. At the same time, and as pointed out in the introduction to this volume, vulnerability has a long history of being used as an authoritative concept, justifying the management and control of groups and populations from the 'outside' because they are deemed vulnerable. Both ways of employing vulnerability have further been linked to the rise of therapy culture where, it has been claimed, individual and psychoemotional approaches to trauma and oppression are easily prioritised over structural, political and policy efforts (Brown, 1995; Brunila and Rossi, 2017: 2-3).

In many ways, the debate about trigger warnings concretises key questions about vulnerability. This chapter asks how the varying uses of trigger or content warnings in online debates negotiate vulnerability and agency in relation to media content. Whose and what feelings matter in debates on trigger warnings? What bodies become vulnerable in various contexts, how is vulnerability understood in them, and how does it relate to agency - how subjects seem to gain and lose agency through vulnerability?

\section{RESPECTING VULNERABILITY: TRIGGER WARNING POLICIES IN FEMINIST ONLINE COMMUNITIES}

The background of trigger warnings has been identified as lying, on one hand, in online peer support and therapeutic forums and message boards for people with eating disorders, experiences of rape or sexual assault, or mental illness ever since the 1990 - members of these communities often 
(although not exclusively) being women or members of various marginalised groups (Washick, 2017). In the late 199os, trigger warnings also began to appear on feminist website message boards and blogs such as on xoJane and the Ms. Magazine forum, signalling care and safe spaces (Vigliano, 2014). In this sense, the history of trigger warnings can be connected to the simultaneous rise of cyber-feminist utopias about the Internet: how it could enable a different kind of world that would function based on the needs of the marginalised, and free us from identity-based hierarchies and oppression (for an overview see Bromseth and Sundén, 2011).

On the other hand, the background has been located in fan fiction (Lothian, 2016), where content warnings were also used in the 1990s. In fan fiction, however, the purpose of trigger warnings was not only to turn away those who did not want to encounter, for example, homosexual content or suicidal ideation, but also to lure in those who took pleasure in engaging with precisely that. The use of content warnings was community created and community driven, or, as Lothian (2016) phrases it, about queer worldmaking practices outside the world of the mainstream and more broadly acceptable pleasures. Into the 2010s, the terms 'content warning' or 'content note' have become more popular in fan fiction communities (Washick, 2017: 90), while the term 'trigger warning' has been saved more for explicitly shocking or violent content. As all these terms have become popularised, they are regularly used interchangeably.

In feminist, queer, anti-racist or disability activist groups and forums online, the rules and guidelines often direct participants in using trigger or content warnings. More often than not, these online spaces are moderated by a group of peers. The place of warnings is in the beginning of a post or a share, sometimes with empty space in between the warning and actual content, so that the content is hidden from appearing simultaneously with the warning. The aim is to create a non-discriminatory, safe or safer space for the participants - in other words, warnings can be seen as a part of such forums' feminist world-making practices, with the acknowledgement that the world at large is not and will not be as accommodating.

World-making, according to José Esteban Muñoz (1999: 195-6), is not only about alternative views of how the world could or should be, but about reordering, reshaping and decomposing, creating a space where different things are possible as compared to the 'real world' while using the real world as raw material. World-making practices are about potentiality, imagining what could be outside of the hegemonic order, building alternate realities. Trigger or content warnings, as they appear in feminist, queer and/ or anti-racist online forums and groups, participate in such world-making in the sense that they transform a world which functions on the terms of the privileged, where the hurt of the marginalised is constantly normalised 
and swept aside, into a world where the marginalised and the hurtfulness of structures and practices that subordinate them are highlighted and prioritised. Trigger or content warnings can be seen as one of the starting points for such world-making that ultimately aims to build an alternative reality, whether that is called a 'safe space' or something else.

For the purposes of this chapter, I received permission from the moderators of the Finnish Laid-back Feminist Group, a closed group on Facebook, to use their collectively created rules (a document within the group last edited 13 November 2017) as research material. ${ }^{2}$ I have been a member of the group for some time but have not participated beyond an infrequent 'like', only quietly observing. By applying to the group, members agree to follow the rules, which include not sharing content from the group to other websites or people outside the group. Feminist groups and publicly vocal feminists overall tend to be targets of intense anti-feminist trolling and harassment, thus this rule is meant to not only protect the privacy of the participants, but also protect them from online and offline attacks. Such policies are typical of closed feminist, queer, anti-ableist or anti-racist forums and groups, which poses challenges for studying online community formation in them (Association of Internet Research, 2012). The rules document, however, can be seen as an anonymous, collectively formed and continuously developing text which can exemplify some of the principles by which such feminist online groups can function, without specifically jeopardising the privacy or safety of any of its members. Nevertheless, the rules also acknowledge and warn members about sharing anything too personal, since the moderators cannot guarantee that no one in the group of thousands will share content elsewhere.

The group's name includes the adjective 'laid-back' because, as the rules document states, it is a group inclusive of people interested in learning about feminism who are not necessarily well-versed in feminist thought and discourse yet. The rules explain that inadvertent mistakes with language use or such are fine as long as members are willing to learn and correct themselves. That said, the rules also state that the group does not tolerate anti-feminist behaviour, which includes racism, ableism, cis-sexism, homophobia, and sexism, and if a member does not correct themselves after a warning, or does not follow the rules otherwise, the moderators will expel them from the group. Typical posts to the group include sharing links to and thoughts about media examples, political decisions, articles, or current events, as well as requests for advice in various situations.

The rules also require trigger or content warnings (with the abbreviation TW, CW or SV, the last one for the Finnish word 'sisältövaroitus', that is, 'content warning') before disturbing content. What counts as disturbing content is left open, but examples given include 'TW animal torture' and 
'TW violence against children'. Warnings can be requested by moderators or participants if the person posting did not include them, and the rules instruct that requests should be followed. In practice it is relatively common to see warnings before posts in the group, but many posts come without warnings, which means, after a while, that they were not requested either.

Notably, the 'Laid-back Feminist Group' functions through what the rules call 'the principles of safe space, where we prioritise listening to the oppressed. Before you comment, find out about your privileges'. The rules document also explains that moderators can close a comments section to people other than those oppressed by the matter at hand. I interpret this to mean, for example, disallowing white people from commenting on a racist incident, or prioritising trans voices when discussing cis-sexism. While the principle can raise questions about identity, such as definitions of a nonwhite identity and the fluidity of gender identification, it clearly recalls a standpoint feminist epistemological stance. Importantly, feminist standpoint theories (Collins, 2009; Harding, 1993) have demanded accountability for the specificity of knowledge producers' viewpoints, with a broader goal of challenging how the white, male perspective often cloaks itself as a 'universal' or 'neutral' perspective, dominating discussion and knowledge about marginalised groups from the 'outside'. Instead, standpoint feminisms place particular value on the experiences, voices and knowledge of subjugated groups and people broadly, and specifically about issues that concern them.

Similarly, in the Laid-back Feminist Group, what counts as vulnerability to various forms of oppression, a lack of a voice or a disadvantage in the world outside is turned into a prioritised voice, a demand for explicit recognition, respect and space. What is at stake, then, is not so much the individual possibility of being triggered into post-traumatic stress or anxiety, but the gesture by the community that it will function on the terms of those that are most fragile within the group and ask for care, that it will make space for the marginalised, the traumatised; that it will not allow the dominant to dominate, even if the dominant are the majority. Vulnerability becomes the basis of this standpoint feminist stance, which can be seen as a powerful world-making process. The risk is that it will inevitably estrange and exclude some people, groups and feminists, but that is the price for a collective space where the privileged do not speak for others but concretely step aside (Alcoff, 1991).

On the other hand, by setting the possibility of trauma as the norm and bottom line, this stance does place everyone within the group as vulnerable unless-otherwise-proved, implementing a kind of an equality of vulnerability. As Valeria Souza has argued in the blog post 'Triggernometry' (2014), trigger warnings can be seen as progressive from a disability perspective since they assume mental disability as the default state rather 
than able-mindedness or able-bodiedness. Angela Carter (2015) takes a similar perspective, framing trigger warnings as a question of access and making spaces accessible, not a question of safety or coddling all-toofragile egos. The issue of prioritising access for those potentially disabled by trauma connects back to the history of trigger and content warnings in the peer support and therapy-focused online groups. However, the Laidback Feminist Group does not assume or require any shared experiences or identity (such as 'survivor' or 'woman') from its participants in order to allow access, only a shared politics of intersectional feminism before anything else, as defined in the rules. These shared politics then lead to shared practices, including warnings.

At the same time, there can be 'dark' sides to this world-making and standpoint-based, default disability-assuming community building. For example, acceptable participation demands learning the rather specific language and discourse - including the correct use of trigger warnings - of feminist activism. Those who have not yet spent much time in feminist, queer and/or anti-racist contexts, and who have not taken gender studies classes or read feminist books, might not master the rules of the activist community quickly enough, and in those instances they risk being seen as unwilling to learn and are expelled. Learning the culturally and linguistically specific intersectional feminist discourse, and adopting the 'good feminist discussant' position and voice, may be more challenging and timeconsuming than the rule of expulsion-from-the-second-warning allows.

Furthermore, online discussions overall tend to quickly escalate into debates and even full-blown conflicts where affect runs intense (Paasonen, 2015). In order to keep the community functional and de-escalate a conflict, it might sometimes be necessary to shut down discussions either by removing a participant or closing a chain of comments, and the moderators of the Laid-back Feminist Group reserve the right to do this in the rules - a right which they have also exercised in the group. However, again, the wiggle room for marginalised subjects to express emotion is broader, according to the rules, than for the privileged: the rules forbid tone policing, which refers to intervening or policing the tone in which the oppressed talk about their own experiences of oppression. As an example, the rules mention a situation where an oppressed person is instructed to stay calm when they are being oppressed.

The discourse in an activist-oriented feminist community is not entirely similar to academic feminist discourse, at least not in the form familiar to me: despite my study and work history of two decades in feminist thought and theorising, the regular inclusion of content warnings and the typical ways of phrasing posts and comments took me some time to get used to and learn. What has to be noted here is that groups that function according 
to the principles of safe space similar to the Laid-back Feminist Group are already most likely to stay around for a while, which also means that the language of trigger and content warnings is already here to stay. Regardless of the reservations or the outright rejection of warnings by many academic feminists, which I will discuss in the next section, many feminist, queer and anti-racist scholars and students participate in, learn and want to follow the principles of similar activist groups and communities, and by doing so are passionately involved in alternative world-making. Trigger warnings in these spaces are not about the avoidance of difficult issues or creating a false sense of safety, but about showing care and recognition, and enabling access and informed engagement to potential and actual participants living with trauma.

Sara Ahmed (2014a), in an essay called 'Feminist hurt/feminism hurts' on her blog Feminist Killjoy and republished in this book, points out how the hurt expressed by those who have been traumatised by sexism or racism is often heard as imposition. This hurt, this imposition, can take the form of, for example, a trigger warning - which is then claimed to limit someone else's freedom to speak without one. But Ahmed turns the issue around: even if the requests or demands for warning may feel like an imposition or are turned into censorship, they are in fact not asking for limitations in the sense of less, but are about asking for more: more consideration for the context, the situatedness and the affective force of the material, and thus more complexity.

Yet, even if trigger warnings are understood as feminist standpoint practices, as radical alternative world-making, as an expression of the need to situate and complicate the affective force that the world can grab us through, the question remains about when and in what context to use trigger warnings. Their predecessors, like content labels on consumer products, began to be used in the United States in the 1930 s and since spread from food, alcohol and tobacco to cultural products, first in the form of film classification and age ratings (Souza, 2014). These labels and ratings, just like trigger warnings, seem to most often concern relatively easily identifiable things like (presumably) harmful substances, clear physical or emotional violence and eating disorders or suchlike, but problems arise immediately, when they are - or are not - used with finer and deeply normalised structures of oppression or marginalisation addressed, maintained or produced. For example, most contemporary media content and political decision-making functions according to the binary and heteronormative gender system, dividing all bodies into either men or women, and despite that system's violent reduction of all gender and sexual expressions and identifications into two categories, would it be necessary to add a trigger warning about cis-sexism and/or heterosexism to all examples of them when shared in a safe space or 
a classroom context? I will return to the question of when to use and not use trigger warnings in the next section, as the difficulty or impossibility of answering the 'when' question is one key motivation for those who choose not to give warnings.

Another difficulty arises from the possibility and reality that any feminist idea, principle or practice can (and often will) be taken out of its original context and used for purposes precisely opposite to what the idea or principle was created for (see Gill and Elias, 2014). Trigger warnings have also been de-rooted and appropriated to various contexts at the same time as claims of vulnerability have gained more ground as claims to rights and voice that cannot be silenced. In these cases, vulnerability becomes something that anyone experiencing hurt can 'claim' for themselves, whether that hurt derives from the momentary loss of structural privilege or from structural oppression. Therefore, it has become possible for Trump supporters to ask for safe spaces on liberal campuses (Hartocollis, 2016), or Christian conservative students in the United States to ask for (and receive) a trigger warning for (or be excused from engaging with) sexually explicit content or homosexual themes on university syllabi through claiming vulnerability to religion-based oppression, when their religious beliefs are against homosexuality (Cooper, 2014; Levinovitz, 2016).

The language of triggers has furthermore been adopted in transexclusionary feminist demands to exclude transwomen from 'women-only safe spaces' because even the potential presence of a penis can, they claim, be triggering for rape survivors - who, within this logic, can only be cisfemale (Phipps, 2016). The discussion becomes entirely something else and shockingly violent, when the very existence of a person and a gender identity becomes named as 'triggering', when a body, not a text or image, becomes a 'trigger' by its mere presence. Such practices stand in radical contrast to the principles of safe space in communities such as the Laid-back Feminist Group, which explicitly prohibits trans-exclusionary feminist practices within its discussions. This only goes to show how the language of triggers can be used for entirely different, and indeed oppositional, purposes.

\section{EMBRACING VULNERABILITY: ACADEMIC FEMINIST ANTI-TRIGGER WARNING ARGUMENTS}

The feminist anti-trigger warning arguments have mostly been made in the context of higher education, touching upon the use of such warnings online and in activist communities only in passing. The majority of such writing and engagement has simultaneously expressed compassion and concern for students struggling with racist, sexist, heterosexist and cis-sexist or ableist 
marginalisation, as well as mental health issues and sexual harassment and violence (Freeman et al., 2014; Gay, 2012; Halberstam, 2014a; 2014b; 2017). Next, I want to look more closely at some key arguments of the anti-trigger warning camp. They are, first, the unpredictability of how trauma and posttraumatic stress disorder (PTSD) work; second, the difficulty or impossibility of deciding when to warn and when not to in terms of media material; and third, the value of staying with discomforting and overwhelming - or perhaps especially discomforting and overwhelming - reactions and affect.

In her essay 'The safety of illusion/the illusion of safety' (2012), the wellknown black feminist public intellectual Roxane Gay argues that there is no trigger warning that could guarantee anyone's safety, that they are about an illusion of safety that may function contrary to its purpose. Gay's essay is spotted with sentences that begin 'when', such as 'when I smell Polo cologne' and 'when someone comes up behind me unexpectedly', signalling moments that function as triggers for her, as she has publicly relayed her own complicated struggles with PTSD from having been gang-raped as a young girl. According to Gay, there can never be trigger warnings for all that might trigger a post-traumatic stress reaction for a rape or sexual assault survivor, because such triggers are unpredictable, even to those experiencing them. Anything can be a trigger for someone - furthermore, trigger warnings can also make things more appealing, just like age restrictions for media content can make it all the more attractive for some. However, Gay also states that, regardless of how ineffective and impractical she considers trigger warnings, the illusion of safety they produce can be powerful and important, even if it is an illusion. The voice she uses is that of someone who has much experience of becoming triggered, a voice from the 'inside'; an empathetic, even if suspicious, voice that unequivocally argues that vulnerability will always be a part of life and corporeality as well as media consumption, and that pain has value, even if a cost too.

Trauma therapists, similarly, have argued that PTSD cannot be treated effectively with the avoidance of possible triggers, which trigger warnings might enable - if such triggers can even reliably be identified (Waldman, 2016). A group of prestigious gender, queer and critical race studies faculty (Freeman et al., 2014) also point out in their statement about why they see trigger warnings as flawed that university faculty are not therapists nor trained in treating PTSD. Therefore, resources should be directed to offering sufficient professional care to students who suffer from mental health issues and disabilities, since trigger warnings can never substitute treatment.

Here, a differentiation between a trigger warning and a content warning becomes important, although their meanings slide into each other after much interchangeable use. The term 'trigger' connects particularly to PTSD and the sudden, potentially violent and disabling reactions to 'triggers' like 
images, sounds, smells, words, and touch that may recall a traumatic event. Also, the argument against trigger warnings from a PTSD perspective is, like Gay's, highly convincing - after all, it does seem futile to try to fight complex trauma with the simple addition of the letters 'TW'. However, it seems that in their contemporary activist uses, trigger or content warnings are not really used with post-traumatic stress disorder sufferers in mind more so, the use of terms like 'trigger' and PTSD in these contexts appears to lend the warnings more legitimacy in the therapy cultural context. When warnings are seen first and foremost as a call for recognition of and care for the suffering that racist, sexist, heterosexist and cis-sexist hegemonic structures produce for members of subordinated groups, then the argument against trigger warnings as ineffective treatment loses much of its meaning.

The argument indeed recalls the critiques that feminist consciousnessraising and political therapy groups in the 1960s and 1970s faced in terms of the investment in the personal as political. Carol Hanisch (1969), who is usually credited with the well-known feminist slogan, actually argued that dismissing such groups as therapy or focused on personal problems is to dismiss their political dimension, since they do not aim to solve personal problems by offering personal solutions. Their focus is on seeing both problems and solutions as political, as in having to do with oppressive structures, not individual successes or failures in dealing with them. Similarly, trigger and content warnings in groups such as the Laid-back Feminist Group are not so much for those who suffer personally or are diagnosed with PTSD, but those who are structurally oppressed and carry the trauma of that oppression.

The more important question thus becomes: what counts as content that warrants a warning in a world that is so thoroughly structured by unjust norms and hierarchies - hierarchies that feminist, queer and critical race studies teachers and online communities are dedicated to revealing and unravelling? Jack Halberstam, in his several texts about trigger warnings (2014a; 2014b; 2017), has addressed precisely this difficulty of when and where to warn as a key reason why trigger warnings are, according to him, counterproductive, as they seem to set representations and practices in a flawed hierarchy of oppressiveness based on affective reaction. In the essay 'Trigger happy' (2017), republished in this book, Halberstam gives the example of how silence and invisibility - the complete lack of representation - can potentially be just as traumatising or discomforting as an explicit representation, such as the exclusion of issues of race, gender or class altogether from philosophy or political science classes. Another example that Halberstam discusses is a course he taught on the Holocaust, where he showed the film Nuit et brouillard [Night and Fog] (1955, dir. Alain Resnais), with brutal imagery of dead, naked, piled-up bodies, to the students' shock, 
while they were captivated by and wanted to see more of Triumph des Willens [The Triumph of the Will] (1935, dir. Leni Riefenstahl), a film specifically meant to make Nazism aesthetically and ideologically appealing through veiling it in visual pleasure. Indeed, it is of essential importance to question why seemingly inconspicuous and pleasurable to watch content usually does not warrant a warning, even if it is ideologically deeply disturbing, just as it must be asked why the lack of representation does not warrant a warning. However, while Halberstam considers this an example of why trigger warnings do not make sense overall, I suggest that the difficulty of deciding 'when' could just as well necessitate more questioning, careful contextualisation and collective consideration of why, when and if to warn.

Indeed there was a time when feminist, queer and critical race studies scholars were much more worried about the treacherousness of pleasure than about pain and hurt. For example, in the 1980s Mary Ann Doane (1982) interrogated the ways Hollywood cinema constructs the female body as an idealised and pleasurable spectacle. Through a recognition and pull of similarity, the female spectator has no choice but to over-identify with the image, unless she fully rejects it. The reward is pleasure and idealisation, and the price is submission to a patriarchal structure of gendered subordination where women are reduced to beautiful surfaces. According to feminist psychoanalytical film theory approaches, such as Doane's, it is pleasure that makes spectators unwittingly and unavoidably vulnerable and open to identifying with power structures that will keep them subordinated, whereas in the pro-trigger warning arguments, subordination is often taken up as something that is easily recognisable in representation and discourse through viewers' and readers' upset reactions.

On the other hand, one of the key critiques directed at feminist psychoanalytical approaches is that they have often assumed a rather stable similarity between the gendered spectator and the image of a gendered human form to be a prerequisite for the 'suction' into the image. The impossibility of predicting reactions based on such an assumed similarity is also one of the key feminist anti-trigger warning arguments: that it is impossible to say, for example, that seeing explicit racism is more triggering than silence about racism for those that live with the trauma of everyday racism, or that every black person would be equally upset or anxious about a representation of racism. Such 'competitions' of what kind of content wounds more, or who are the ones most vulnerable to potentially triggering content, come up easily when trigger warnings become standard practice, Halberstam (2017) points out. On the other hand, these 'competitions' that Halberstam critiques are also direly necessary in order to not accept or condone the claims to victimhood by members of structurally privileged groups, such as white men in right-wing and white nationalist movements habitually do, 
or to not claim a false symmetry between all levels and forms of structural subordination, for example that between transwomen of colour and white cis-women.

I tried to tackle these complications around shock and normalisation, pleasure and trauma, when to warn and when not to, in my own teaching in Finland in 2015 on a course about media and the body. One of the course themes was trigger warnings and sexually violent content (see also Kyrölä, forthcoming). The students read blog texts advocating for and against trigger warnings, as well as the main points of an empirical study by Martin Barker et al. (2007), who had been commissioned by the British Board of Film Classification (BBFC) to study audience reactions to five films that depict sexual violence. One of those films was À ma soeur! (Fat Girl, France, 2001, dir. Catherine Breillat), which we watched for class. The students were then asked to compare their own reactions and reflections to those of Barker and his group's respondents, as well as form an opinion of whether trigger warnings or censorship were necessary in relation to the film.

Fat Girl ends in a notorious rape scene that has been the film's most debated feature, and has been censored in some countries. In this scene, a twelve-year-old girl, Anaïs (Anaïs Reboux), is raped in the woods by a nameless male attacker after he has brutally killed her sister with an axe and strangled her mother at a rest stop by a highway. The students were given access to the censored version of the film, and separately to the rape scene (about five minutes long) - with my explicit warning that the scene would include rape. I did not require them to watch it, but all of them chose to do so. However, instead of the rape scene, many of the students wanted to discuss the more insidious sexual abuse elsewhere in the film, particularly a lengthy (twenty-five-minute) scene earlier in the film where a young man pressures Anaiis' fifteen-year-old sister Elena (Roxane Mesquida) to have intercourse with him with Anaïs in the room. To the students, it seemed hypocritical that the scene which directly portrayed rape was censored and accompanied by warnings, while the scene about sexual abuse was not. Many reviews of the film even discussed the lengthy scene as one of seduction, not abuse. The students broadly agreed that the film was very discomforting to watch overall, but that was precisely how it should be, given its topic of sexual abuse and gendered sexual agency.

Today, in the post-\#MeToo world, I would very likely make the choice to give a content warning about the whole film, not only the explicit rape scene, and the possibility for an alternative assignment. However, this example testifies to how the lines of what warrants a warning - or when, or if - are necessarily changing according to how gendered, racialised and sexual power structures shift in culture and society. Should we include a trigger warning or content warning about sexual abuse for all films or other 
content that include a scene of heterosexual 'seduction' or a woman reluctantly 'giving in to desire' - one of the most common tropes representing female desire according to Linda Williams (1989)? That might have seemed ridiculous only a little while ago, but no more, as sexual harassment and the blurry lines of consent and abuse around sex have finally become highprofile topics.

The feminist anti-trigger warning arguments, or perspectives suspicious of the effectiveness and purpose of trigger warnings, seem to have one thing in common: they place great value on feelings of discomfort and even hurt as necessary parts of pedagogy and learning, and they take vulnerability as an unavoidable condition of embodied life, which should be embraced rather than rejected. This view of vulnerability, that can be characterised as phenomenological and ontological (Butler, 2004; Shildrick, 2002), does still take into consideration the ways in which the basic human and non-human openness to the world, the porousness and fragility of corporeality, are distributed unevenly between groups of bodies. This allows some groups to maintain the privilege of relative safety, despite it being a fragile illusion, while others are deemed exceptionally vulnerable and thus disposable or subjected to paternalistic management measures. The feminist anti-trigger warning stance sees warnings as a measure to create such an illusion of safety, which in this logic easily translates into a paradoxical position of privilege that students who are unwilling to be uncomfortable exercise. Black feminist professor Brittney Cooper (2014), in her argument against trigger warnings, suggests that being and staying comfortable is actually at odds with the very foundation of what it means to get an education, especially in the gender and critical race studies classroom. Cooper also sees this tendency as understandable in the context of a broader results and testfocused neoliberal educational culture and the financial pressures to get a college degree, regardless of what one actually learns in the process. The more effective strategy for changing the world, for Cooper as well as other feminist trigger warning critics, is to stay with the discomfort and deal with vulnerability even when it is almost unbearable, since it will become more endurable through learning feminist tools of analysis and critique.

In my teaching and research I have also studied and argued for the ethical and political value of feeling bad, uncomfortable, guilty, disgusted and angry when engaging with problematic media materials from a feminist, queer studies and critical race studies perspective, a stance that has long roots in these critical traditions (Kyrölä, 2015; 2017). I no longer think, though, that the use of trigger or content warnings would be at odds with such an approach which embraces vulnerability and so-called bad feeling. Many proponents of trigger warnings in fact argue that such warnings can be a prerequisite for the ability to engage with discomfort and bad feeling, 
since without warning that ability might be compromised (Carter, 2015). But it matters deeply who or what instance asks for a warning and in what context, as trigger warnings can surely become a tool of condescending, paternalistic control, just as their refusal and the suggestion to just 'suck it up' and take a critical distance can seem condescending and paternalistic.

\section{MOCKING OR APPROPRIATING VULNERABILITY: ANTI-FEMINIST ANTI-TRIGGER WARNING DISCOURSE}

The most disconcerting way in which trigger warnings have been mobilised today concerns the anti-feminist stances which see them as ridiculous symptoms of a culture of victimhood, or how 'whiny', overly protectionoriented and narcissistic young people, particularly feminist and queer youth and students of colour, have become. For example, the magazine $G Q$ (2016) ridicules 'Millennials' who have become 'Generation Snowflake: a collective that quivers at the slightest breeze and dissolves at the slightest upset. The deployment of the term 'Generation Snowflake', or 'snowflake' more broadly, appears regularly in distinctly anti-feminist contexts, where complaints against using insensitive words, such as racist or sexist slurs, are seen to limit freedom of speech. The GQ article is accompanied by an image of students of colour protesting with a sign saying 'Decolonise Education: Rhodes Must Fall', in reference to the student-led campaign which started in South Africa to remove statues of white imperialist oppressors from university campuses, and to produce cultural countermemory (see e.g. Bosch, 2016). The article asks where to draw the line - if the presence of imperialist oppressors is perceived as triggering, should the faces of all oppressors, like Hitler and Mussolini, be removed from books and museums too? The image seems an odd choice, since the Rhodes Must Fall campaign never actually utilised the language of triggering or warnings, but the campaign has repeatedly been taken up as an example of the 'cult of the victim' (O'Neill, 2015). 'Snowflakes' are rarely white in this discourse that mocks trigger warnings, which points towards its investment in white supremacy and white patriarchal sense of disenfranchisement. The vulnerability of easily triggered 'snowflakes' is seen as a false claim of victimhood, which has the barely hidden purpose of gaining power and unwarranted privilege through sinister calls for compassion and care.

Those feminists who mobilise the problematic figures of the 'snowflake' and 'overly fragile students' in debating trigger warnings should seriously reconsider their use of such figures, since they can easily play into the antifeminist and white supremacist discourses that ridicule and seek to silence marginalised voices seeking change. Feminists opposing trigger warnings 
may want to be extra careful about the tone with which they discuss trigger warnings and those who request them, if they want to avoid siding with anti-feminist and white supremacist voices. Disquietingly, the feminist and anti-feminist critics of trigger warnings often share a humorous and mocking tone, perhaps accompanied with a meme or a text about being 'triggered by trigger warnings', popular in the anti-feminist blogosphere, but found in Halberstam's first blog post about trigger warnings too (2014a). This tone leaves the proponents of trigger warnings with no other role than that of feminist killjoy.

The white, masculinist anti-feminist anti-trigger warning stance intersects with the feminist anti-trigger warning stance also in the claim that this is an issue of generational differences, and that the previous generation was not as fragile (Halberstam, 2014a). Transfeminist writer and activist Julia Serano (2014) has indeed critiqued Jack Halberstam for too broad strokes and simplifications about feminist generations and for dismissing the younger activists for their oversensitivity and 'killjoy' or 'no fun' approaches. Serano argues that the activist strategies of previous generations often cease to work for the next, as the world has also changed drastically through social media. However, women and marginalised people who 'take things too personally' have also been around as figures of concern for decades, and the vocal worry about complainers turning the nation into a narcissistic well of oversensitivity is not something that characterises our time alone. For example, Imogen Tyler (2007) has pointed out that the narcissistic, self-centred feminist was in fact already a popular figure in the anti-feminist discourses in the 1970 s and 1980 o - and then, too, it was argued that such feminists are a part of a new, broader narcissistic malaise.

The feminist-mocking anti-trigger warning discourse has even adopted other arguments of the feminist anti-trigger warning camp. Another one is the approach to vulnerability and the inevitable cruelty of this world: that vulnerability is an ontological condition of existence, and in order to be able to live in the world as a mortal who will experience hurt, one must learn tools to 'suck it up'. Yet a further similar argument concerns the difficulty of drawing the line between when to warn and when not to, and what to show and what not to: both feminist and anti-feminist critics of trigger warnings agree that the line is impossible to draw.

However, the important difference is that, in the anti-feminist discourse, there is very little if any recognition of the political dimensions of vulnerability and the ways it becomes asymmetrically lived, managed, assigned and made palpable for various groups in global and local power structures. The subordinated groups that ask for trigger warnings are seen as ridiculous, their requests for recognition of their suffering unjustified and whiny, claiming that those who do not 'submit' to such requests are victims of 
harassment and falsely accused of racism or sexism. The feminists opposing trigger warnings disagree with trigger-warning proponents about the effectiveness of warnings, but agree about the existence of injustices and the goal of a world free of oppression. The anti-feminists opposing warnings see no real or deep structures of oppression, just a world that is an equally cruel and trying place for all. However, as Marilyn Frye (1983) stated in the 1980 os in response to anti-feminist claims that everyone suffers, and thus everyone is oppressed: 'This is nonsense. Human beings can be miserable without being oppressed, and it is perfectly consistent to deny that a person or group is oppressed without denying that they have feelings or that they suffer.

Paradoxically, trigger warnings themselves can also be used for antifeminist, racist and transphobic purposes that completely defy their original purpose, as mentioned in this chapter in relation to trans-exclusionary feminists. Freeman et al. (2014) argue that the complaints made about the lack of appropriate trigger warnings tend to be disproportionately directed towards faculty who teach critical race studies and feminist and queer theory. The material that educators in these critical fields ask students to engage with is most often upsetting by nature, and the ways we ask students to engage with that material is meant to unsettle normative, ordinary and perhaps comfortable ways of thinking. The irony is that trigger warnings are not asked - or expected - from people or groups that are already assumed to not care. They are asked of those who are assumed and expected to care, but the risk is that disagreement about how to show that care can result in divisiveness, even the adoption of anti-feminist discursive figures like 'snowflakes' or (other) feminists as narcissists.

\section{VULNERABLE WORLD-MAKING}

Vulnerability has, in the contexts discussed above, been understood as a structurally produced disadvantage that can be countered by a standpoint epistemological privileging of the voice of and care for the vulnerable; an ontological, necessary condition which should be explored and embraced head on in order to fight the way it is used for managerial politics; or a false claim of disempowerment and thus a false attempt to gain more power.

Two of the contexts I have discussed, the feminist trigger warnings policies and the feminist anti-trigger warning arguments, can be seen to participate in feminist world-making, following Muñoz's (1999) reflections on queer of colour performance as world-making - even if they suggest different routes and strategies. For those feminists who support trigger warnings, their absence produces a barrier or a wall that restricts or prevents their 
mobility (Ahmed, 2014b), or the mobility of those they want to show they care about. Their alternative world-making, enabled by trigger warnings, concerns a world where the marginalised could roam free without the barrier of fear, without constantly, accidentally running up against the wall of sexism, racism, cis-sexism or heterosexism. In this sense, groups like the Laid-back Feminist Group in part recall the feminist separatist groups of the 1970 in terms of alternative world-making and rules different from those of the 'outside' world. For feminist separatist groups, the best way to not only imagine but practice how to build a world free from white capitalist patriarchal oppression was to detach from it, create barriers that shield from it, break down everyday practices that define it, and exclude people who benefit from it (Valk, 2008).

The anti-feminist and white supremacist voices that oppose trigger warnings do not see or recognise walls or structural oppression in the world, but prioritise an equally shared, ontological vulnerability and suffering. For them, the world is an even playing field, and trigger warnings are yet another symptom of how 'whiny' people of colour, queers and feminists are in the face of unavoidable pain. This discourse includes a paradox though, since trigger warnings also get to represent walls that could restrict the movement and 'free speech' of the privileged, the claimed 'victims' of trigger warnings. One of the most disconcerting findings of my mapping of the discourses around trigger warnings is the extent of how much feminist anti-trigger warning language intersects with and is co-opted by anti-feminist and white supremacist contexts.

The feminists who oppose warnings, just like those who support them, see that the world, as it is now, is structured by barriers that produce marginalisation and privilege, distributing vulnerability asymmetrically. However, their suggestion is to push up against such barriers and trust that this pushing will not break those who push, instead of turning away from the barriers through practices such as warnings. But feminist support for warnings is not quite the opposite of pushing either, as evidenced by the fierce opposition that trigger warnings have encountered: it takes another kind of pushing to make space for and turn towards an alternative world. The difference is perhaps rather the difference between pushing with one's back and pushing head first - a matter of which direction you face. The advantage of a community facing inwards while pushing is that it then might be easier to glimpse an alternative, although fragile and complicated, world where the currently marginalised have the power, where their voices are privileged, and where gestures of care towards them abound. It is important, however, that both 'sides' of the debate recognise the value and effort of how the other side pushes, since the alternative worlds we long to inhabit may not be that different. 


\section{NOTES}

1 The Signs digital archive on trigger warnings is available at: http://signsjournal. org/currents-trigger-warnings/\#digitalarchive (accessed 4 June 2018).

2 I contacted the moderator who created the document in November 2017, explained the purposes of the research and the article, and requested permission to use the rules document in my research, with the understanding that the moderators would check and, if needed, correct the article before publication. The moderators gave permission for this. In early February 2018, I sent a preproofread article draft for them to check, and on 8 February they gave permission to move forward with the publishing process without corrections.

\section{REFERENCES}

Ahmed, S. (2014a). 'Feminist hurt/feminism hurts', Feminist Killjoys (21 July), https://feministkilljoys.com/2014/07/21/feminist-hurtfeminism-hurts (accessed 17 December 2017).

Ahmed, S. (2014b). 'Atmospheric walls', Feminist Killjoys (15 September), https:// feministkilljoys.com/2014/o9/15/atmospheric-walls (accessed 4 February 2018).

Alcoff, L. (1991). 'The problem of speaking for others', Cultural Critique, 20, pp. 5-32.

Association of Internet Research (2012). Ethical Decision-Making and Internet Research, http://aoir.org/reports/ethics2.pdf (accessed 4 June 2018).

Barker, M., E. Mathijs, J. Sexton, K. Egan, R. Hunter and M. Selfe (2007). Audiences and Receptions of Sexual Violence. London: British Board of Film Classification.

Bosch, T. (2016). 'Twitter activism and youth in South Africa: The case of \#RhodesMustFall', Information, Communication E Society, 20:2, pp. 221-32.

Bromseth, J. and J. Sundén (2011). 'Queering internet studies: Intersections of gender and sexuality', in M. Consalvo and C. Ess (eds), The Handbook of Internet Studies. Chichester: Wiley \& Blackwell, pp. 270-30o.

Brown, W. (1995). States of Injury: Power and Freedom in Late Modernity. Princeton: Princeton University Press.

Brunila, K. and L.-M. Rossi (2017). 'Identity politics, the ethos of vulnerability, and education', Educational Philosophy and Theory, 50:3, pp. 287-98. https://doi.org/ 10.1080/00131857.2017.1343115.

Butler, J. (2004). Precarious Life: The Powers of Mourning and Violence. London: Verso.

Carter, A. (2015). 'Teaching with trauma: Trigger warnings, feminism, and disability pedagogy', Disability Studies Quarterly, 35:2, http://dsq-sds.org/article/view/ 4652/3935 (accessed 17 December 2017).

Cecire, N. (2014). 'On the "neoliberal rhetoric of harm"' (7 July), http://nataliacecire. blogspot.fi/2014/o7/on-neoliberal-rhetoric-of-harm.html (accessed 17 December 2017).

Collins, P. H. (2009 [1990]). Black Feminist Thought: Knowledge, Consciousness and the Politics of Empowerment. New York: Routledge.

Cooper, B. (2014). 'No trigger warnings in my class: Why you won't find them on my syllabi', Salon.com (20 May), www.salon.com/2014/05/20/no_trigger_warnings_ in_my _class_why_you_won\%E2\%80\%99t_find_them_on_my_syllabi/ (accessed 17 December 2017). 
Doane, M. A. (1982). 'Film and the masquerade: Theorising the female spectator', Screen, 23:3-4, pp. 74-87.

Freeman, E., B. Herrera, N. Hurley, H. King, D. Luciano, D. Seitler and P. White (2014). 'Trigger warnings are flawed', Inside Higher Ed (29 May), www.insidehighered. com/views/2014/05/29/essay-faculty-members-about-why-they-will-not-usetrigger-warnings (accessed 14 January 2018).

Friedersdorf, C. (2015). 'The rise of victimhood culture', The Atlantic (11 September), www.theatlantic.com/politics/archive/2015/09/the-rise-of-victimhood-culture/ 404794 (accessed 17 December 2017).

Frye, M. (1983). 'Oppression', in The Politics of Reality: Essays in Feminist Theory. Trumansburg: The Crossing Press, https://feminsttheoryreadinggroup.wordpress. com/2010/11/23/marilyn-frye-the-politics-of-reality-oppression (accessed 4 February 2018).

Gay, R. (2012). 'The illusion of safety/the safety of illusion', The Rumpus.net (27 August), http://therumpus.net/2012/08/the-illusion-of-safetythe-safety-of-illusion (accessed 17 December 2017).

Gill, R. and A. S. Elias (2014). "Awaken your incredible”: Love your body discourses and postfeminist contradictions', International Journal of Media and Cultural Politics, 10:2, pp. 179-88.

$G Q$ (2016).'Millennials:Stopbeingoffendedby, like,literallyeverything', $G Q(12$ August), www.gq-magazine.co.uk/article/millennials-created-generation-snowflake (accessed 17 December 2017).

Halberstam, J. (2014a). 'You're triggering me! The neoliberal rhetoric of harm, danger and trauma', BullyBloggers (5 July), https://bullybloggers.wordpress.com/ 2014/07/05/you-are-triggering-me-the-neo-liberal-rhetoric-of-harm-dangerand-trauma (accessed 17 December 2017).

Halberstam, J. (2014b). 'Triggering you, triggering me: Making up is hard to do', BullyBloggers (15 July), https://bullybloggers.wordpress.com/2014/o7/ 15/triggering-me-triggering-you-making-up-is-hard-to-do (accessed 17 December 2017).

Halberstam, J. (2017). 'Trigger happy: From content warning to censorship', Signs: Currents, http://signsjournal.org/currents-trigger-warnings/halberstam (accessed 17 December 2017).

Hanisch, C. (1969). 'The personal is political', in Writings by Carol Hanisch, www. carolhanisch.org/CHwritings/PIP.html (accessed 3 February 2018).

Harding, S. (1993). 'Rethinking standpoint epistemology: What is "strong objectivity"?', in L. Alcoff and E. Potter (eds), Feminist Epistemologies. New York and London: Routledge, pp. 49-82.

Hartocollis, A. (2016). 'On campus, Trump fans say they need "safe spaces"', New York Times (8 December), www.nytimes.com/2016/12/o8/us/politics/political-divideon-campuses-hardens-after-trumps-victory.html (accessed 17 December 2017).

Knox, E. J. M. (2017). 'Introduction: On trigger warnings', in E. J. M. Knox (ed.), Trigger Warnings: History, Theory, Context. Lanham: Rowman \& Littlefield, pp. xiii-xxi.

Kyrölä, K. (2015). 'Toward a contextual pedagogy of pain: Trigger warnings and the value of sometimes feeling really, really bad', Lambda Nordica: Nordic journal on LGBTQ studies, 1, pp. 131-44.

Kyrölä, K. (2017). 'Feeling bad and Precious (2009): Black suffering, white guilt, and intercorporeal subjectivity', Subjectivity, 10:3, pp. 258-75. 
Kyrölä, K. (forthcoming). 'Squirming in the classroom: Fat Girl (2001) and the ethical value of extreme discomfort', in N. Baer, M. Hennefeld, L. Horak and G. Iversen (eds), Unwatchable. New Brunswick: Rutgers University Press.

Levinovitz, A. (2016). 'How trigger warnings silence religious students', The Atlantic (30 August), www.theatlantic.com/politics/archive/2016/o8/silencing-religiousstudents-on-campus/ 497951 (accessed 14 January 2018).

Lothian, A. (2016). 'Choose not to warn: Trigger warnings and content notes from fan culture to feminist pedagogy', Feminist Studies, 42:3, pp. 743-56.

Marcotte, A. (2013). 'The year of the trigger warning', Slate (30 December), www. slate.com/blogs/xx_factor/2013/12/30/trigger_warnings_from_the_feminist_ blogosphere_to_shonda_rhimes_in_2013.html (accessed 17 December 2017).

Muñoz, J. E. (1999). Disidentifications: Queers of Color and the Performance of Politics. Minneapolis: University of Minnesota Press.

O'Neill, B. (2015). 'Never mind Rhodes - it's the cult of the victim that must fall', Spiked (28 December), www.spiked-online.com/newsite/article/never-mindrhodes-its-the-cult-of-the-victim-that-must-fall/17762\#.WxZkVO6FPIU (accessed 4 June 2018).

Paasonen, S. (2015). 'A midsummer's bonfire: Affective intensities of online debate', in K. Hillis, S. Paasonen and M. Petit (eds), Networked Affect. Cambridge, MA: MIT Press, pp. 27-42.

Phipps, A. (2016). 'Whose personal is more political? Experience in contemporary feminist politics', Feminist Theory, 17(3), pp. 303-21.

Serano, J. (2014). 'Regarding "generation wars": Some reflections upon reading the recent Jack Halberstam essay', Whipping Girl blog (13 July), http://juliaserano. blogspot.fi/2014/07/regarding-generation-wars-some.html (accessed 14 January 2018).

Shildrick, M. (2002). Embodying the Monster: Encounters with the Vulnerable Self. London: Sage.

Souza, V. M. (2014). 'Triggernometry', It's Complicated blog (21 May), http:// valeriamsouza.wordpress.com/2014/05/21/triggernometry (accessed 1 June 2015).

Tyler, I. (2007). 'The selfish feminist: Public images of women's liberation', Australian Feminist Studies, 22:53, pp. 173-90.

Valk, A. M. (2008). Radical Sisters: Second Wave Feminism and Black Liberation in Washington, D.C. Chicago: University of Illinois Press.

Vigliano, A. (2014). 'How the "trigger warning" took over the internet', BuzzFeed (5 May), www.buzzfeed.com/alisonvingiano/how-the-trigger-warning-took-overthe-internet?utm_term=.bukOOAxb9\#.cbXNNly1n (accessed 17 December 2017).

Waldman, K. (2016). 'The trapdoor of trigger words: What the science of trauma can tell us about an endless campus debate', Slate (5 September), www.slate.com/articles/double_x/cover_story/2016/o9/what_science_can_tell_us_about_trigger_ warnings.html (accessed 14 January 2018).

Washick, B. (2017). 'An "app" for that: The case against the "equal access" argument for trigger warnings', in E. J. M. Knox (ed.), Trigger Warnings: History, Theory, Context. Lanham: Rowman \& Littlefield, pp. 86-120.

Williams, L. (1989). Hard Core: Power, Pleasure, and the 'Frenzy of the Visible'. Berkeley: University of California Press. 


\title{
TRIGGER HAPPY
}

\section{From content warning to censorship}

\author{
JACK HALBERSTAM
}

$\mathrm{T}$ rigger warnings have become standard fare on some college campuses over the past few years. But they have also been the occasion for intense debates about pedagogy, classroom conduct, the use of media in the classroom, and the nature of trauma. In general terms, a trigger warning is a cautionary note that may be added to syllabi or online sites to alert readers, students, or casual browsers about violent or sexually explicit images and text in the materials on a site, in a course reader, or up ahead in a blind chain of Internet clicks. The trigger warning could easily be read simply as a protocol proper to new media forms in the early twenty-first century. However, because the call for trigger warnings on college campuses coincided with new sets of regulations around sexual interactions, sexual assault, and teacher-student relationships, they have instead become a site for dynamic and often polemical debates about censorship, exposure, sensitivity, and the politics of discomfort. In this short piece I want to explore the function of the trigger warning and the import of the debates to which it gave rise.

I will begin with two examples of college campuses where students introduced requests for classroom policy changes around syllabi and trigger warnings. In the first example, in 2012 Oberlin College, a small liberal arts school in Ohio known for its eclectic students and social justice agendas, circulated an online guide intended to help professors to avoid assigning and presenting potentially 'triggering' material in their classrooms (Oberlin, 2013). As numerous articles commented, most professors in 2012 had never heard of trigger warnings, let alone Tumblr sites (where trigger warnings were popularised and proliferated), and were not opposed to them so much as ignorant of their purpose. When professors understood what they were 
being asked to do, a standoff ensued between faculty, administrators, and students, and eventually the online resource was removed.

In another instance, at the University of California at Santa Barbara, a student demand for content warnings on all syllabi sparked furious debates and a national conversation. In a 2014 article on trigger warnings in the New York Times (Medina, 2014), UC Santa Barbara was credited as the origin of the trigger warning, and the article described the trigger warning as having 'ideological roots in feminist thought'. Santa Barbara student Bailey Loverin, who identifies herself as a victim of sexual assault, had called for campuswide trigger warnings after being surprised by a film screening in one of her classes that featured a rape (Loverin, 2014). When asked whether she herself was triggered by the in-class screening, Loverin said she was not but she feared for her fellow students and approached the professor to propose that he should have issued a warning before showing the material. The fact that Loverin herself did not feel triggered by the material suggests that the trigger warning conforms to a normative structure of surveillance. It is often called for by some people, not on their own account but on behalf of others, and in this way it conforms to a structure of paternalistic normativity within which some people make assumptions about harm, and about right and wrong, on behalf of others who supposedly cannot make such decisions for themselves.

In addition to these two sets of campus debates, students at Northwestern University protested in 2014 when a professor - writer and provocateur Laura Kipnis - suggested that new campus sexual harassment policies were unnecessarily draconian and that they were creating a culture of 'sexual paranoia' (Kipnis, 2015a). In addition to specific objections to Kipnis's characterisation of the relationship between a graduate student and a professor that was under scrutiny in relation to charges of rape against the professor charges that Kipnis discounted by calling them 'melodramatic' - students felt that Kipnis was downplaying the dangers of sexual predation on campus and dismissing the negative impact of the hierarchies that organise both studentfaculty interactions and interactions between students. The students in this case marched in a protest and called for Kipnis to be dismissed (Kipnis, 2015b).

These examples illustrate the intensity of the contestations that have developed around trigger warnings in a relatively short period of time. What are we to make of these fights? Why do students believe so fervently in the trigger warning, and why do so many faculty oppose them? Could it be that the trigger warning developed and took on meaning through a series of intergenerational miscommunications and misunderstandings? However innocent the original source of these misunderstandings may have been, it is clear that we now have a full-blown conflict over pedagogy, media, and a politics of harm.

Before digging in to the problems inherent in a culture of warnings, let me first try to outline the history of content warnings. Much, if not most, 
of the material that we watch on TV and in cinemas in the United States has been prescreened and assigned a code to indicate the appropriate age of potential viewers. Thus a PG movie, to give an obvious example, warns parents that some of the material in the film might not be appropriate for young children. An R-rated film restricts the screening to audiences over the age of seventeen unless accompanied by an adult. The Motion Picture Association of America produced these ratings in the late 1960s after removing an older system of censorship known as the Hays Code. Whereas the Hays Code, which dates back to the 1930s, prescribed what could and could not be shown (you could show a married couple in single beds but not a double bed; you could not show homosexuality or alcoholism, etc.), the new ratings were supposed to be recommendations and warnings rather than limitations. Given the way that we now use these codes to prejudge the content of the films we want to watch, why do trigger warnings strike so many people as intrusive and prescriptive?

As the history of film ratings shows, in contemporary contexts, audiences do not want extensive precensorship of visual culture. Skirmishes over explicit content warnings in relation to musical lyrics in the mid-1980 (Tipper Gore pioneered parental advisories in 1985), and over what could or should be shown in museums in the late 1980s and early 1990 os (see contestations over Robert Mapplethorpe's show 'The Perfect Moment') also led to often unwanted content warnings in galleries, on CD labels, and in museums and cinemas. So, in a media landscape dotted with warnings about explicit lyrics, violent imagery, raunchy humour, and nudity, what makes a trigger warning inflammatory? Unlike the content warning, the trigger warning is not limited to cautioning a general audience about what they are about to watch. The trigger warning, on the contrary, presumes and to a certain extent produces putative viewers or listeners who want to know what is to come in class or online because they fear their reaction to such material and wish either to mentally prepare to engage with it or to avoid it altogether. The trigger warning, in other words, believes in a student or viewer who is unstable and damaged and could at any moment collapse into crisis. And the fact that these calls for content warnings come at a time when college campuses are paying much more attention to students with disabilities could be muddying the waters around what constitutes posttraumatic stress disorder, what kinds of allowances should and must be made in any given classroom for students with disabilities, but also at a time when we are beginning to question the desire to diagnose every neurotic symptom.

The trigger warning could potentially have passed muster had it simply been requested by bodies of students who, recognising that the terrain of visual and online cultures has expanded exponentially in the past two decades, wanted help navigating the potential impact of new intelligent 
classroom with its PowerPoints and video clips, its slide shows and media support. Had the request been for a simple warning about content to come, few faculty would have resisted; most would have complied. After all, in the 1970 and 1980s, when many of today's professors were undergraduates and graduate students, classrooms were very different places. Wooden desks screwed to the floor were the norm rather than light and mobile desks on wheels. Professors lectured in poorly lit and poorly ventilated great halls, and students wrote notes by hand and could only fact check later by taking laborious trips to the library. People smoked in classrooms, for God's sake! Visual imagery in the art history classroom depended upon carousels of slides, and film courses depended upon after-hours screenings of mostly canonical films. And now? Nowadays students sit at tables, they snack and look at their own screens. They take notes on smart pads or have note takers; they expect entertainment, and unless they are in the presence of an extremely charismatic lecturer, they do not want to sit for hours facing forward while the professor waxes lyrical. Times have changed. Professors rely upon media support. Large lecture courses are punctuated by keynote slide shows and PowerPoints, and examples from popular culture help to illustrate some of the claims that the professor wants to make to increasingly sceptical, fact-checking, and attention-challenged students.

The generational differences in pedagogical styles, in classroom technologies, in mediascapes, and in the relations between canons and experimental or alternative archives have all transformed the contemporary classroom into a wild zone where on any given day, in any given class, a student can expect to be bombarded with material - not at the pace that the culture generally dumps information, imagery, and news onto audiences but certainly at a pace that would have been unthinkable a few decades ago. The student, under these conditions, can surely be forgiven for feeling a little gun shy in the classroom and for asking for a sense of what kind of image might be next in line on the PowerPoint.

There is not much controversy in the account I have just given. Where the students and the professors begin to fall out, I suspect, is when the student not only asks for a content warning but also claims that he or she or they need the content warning because they are wounded, vulnerable, and could easily experience a flashback to some bad experience from the past if images are projected willy-nilly and without warning. Most of the articles and essays that support trigger warnings presume that new modes of visual representation demand new protocols for reception. Most of the articles and essays that reject trigger warning do not dispute the demand for new accountability around reception. What they take issue with is the projection of the student as a fragile organism with no intellectual immune system and a minefield of a psyche that may explode into pieces at any moment. 
This depiction of young people as spoiled, over parented, and overly invested in their own trauma, fuelled an article in The Atlantic in September 2015 by Greg Lukianoff and Jonathan Haidt on 'The coddling of the American mind'. Describing a surge of sensitivity around what they called 'microaggressions' and a cultivation of codes that they describe as 'vindictive protectiveness', Lukianoff and Haidt attributed the new campus climate to helicopter parenting, renewed investments in health and safety, overzealous crackdowns on bullying, and an education that represented the world to students as bristling with dangers that lurked in everything from peanut butter to paedophilic predators. When you add social media to the mix and the tricky physics of virality that skews the affective scales of often rather local and mundane events, turning them overnight into causes célèbres, you have a perfect storm of representational mayhem. And as for trigger warnings, Lukianoff and Haidt argue that they are part of a paternalistic practice demanded by small groups of students.

Lukianoff and Haidt hit some of the important markers of this new terrain of student vulnerability, but they also fail to see the complexity of contemporary student bodies, never mind their diversity. Race barely enters into their discussion, and sexuality and gender issues only appear as vectors for the new sensitivity. And this is in general the problem with standoffs between the trigger warning refusers and the trigger warning demanders. The refuseniks cast diverse student populations as monochromatic groups of spoiled children who have been sheltered and pampered, protected and coddled. The trigger-happy folks, on the other hand, fail to account for vast discrepancies within and among student bodies and they mark sexual violence in particular as the most damaging and the most common cause of trauma among students. Both sides ignore the differences between and among students, and all fail to account for the differences that race and class make to experiences with trauma, expectations around protection, and exposure to troubling materials. For example, we could argue that immense damage is done in the classroom through the casual avoidance of certain topics rather than in the act of calling attention to others. So while representations of sexual violence certainly could be very troubling to students who have been subject to such abuse, so could the lack of any and all attention to dynamics of race and class in, say, a philosophy classroom focused upon the Enlightenment or a political science classroom where issues of nationalism are being discussed. Trigger warnings presume that the real offence is in the marking, and yet scholars for years have paid careful attention to the vexing problem of a lack of representation, of silence or invisibility, or to the introduction of certain materials into the classroom only as negative examples. How does this work? Well, many commentaries on contemporary masculinity quickly arrive at gangsta rap when 
they want to offer a clear example of sexist lyrics and behaviour. And yet numerous soft-rock songs by John Mayer, Keith Urban, and others convey deeply sexist messages while strumming along to a benign rhythm. In Keith Urban's song 'A Little Bit of Everything' (2013), he proposes: 'I want a cool chick that'll cook for me / But'll dance on the bar in her tan bare feet'. Okay, he wants a woman to happily perform domestic labour for him and give him a lap dance ... nice! And yet, there are few classrooms where this song would be thrown out as a quick and intuitive example of sexism in popular music. Meanwhile, Jay $\mathrm{Z}$ can sing: 'If you're having girl problems I feel bad for you son / I got 99 problems but a bitch ain't one' (2003). Here Jay Z is detailing the pressures he faces and has faced from police, music executives, and radio stations while saying that women are not his problem, but the use of the B-word, despite its positive context, immediately gives it a sexist tag when we use the standard of audible and visual insult.

And this is the problem, of course - insults, damage and trauma are as likely to be triggered and inflicted by what is not said or shown as by what is loud and clear. To give one more example, in a class I taught on the Holocaust a few years ago, students were appalled and shocked on the first day of class when I showed clips from Alain Resnais's classic 1955 film Night and Fog. The now all-too-familiar imagery of bodies being shovelled into shallow graves, of mounds of rotting and emaciated flesh, was more than some students in the class wanted to see, and they left the room. However, a few weeks later when we watched a clip from Leni Riefenstahl's 1935 Triumph of the Will, Adolf Hitler's millennium speech at the end of the film, the students were spellbound and asked to see more of the clip. One could argue here that the clips from Night and Fog need to be seen without warnings ahead of time in order to allow the students to grapple with their own shocked reactions before delving into the history of the representation of genocide. And one could also argue that warnings must and should be issued before showing clips from the mesmerising, or as Susan Sontag (1975) famously put it, 'fascinating' representations of fascism that Riefenstahl created. The clips from Night and Fog must shock; the clips from The Triumph of the Will need to be stalled in their bid to seduce the viewer into an unwitting sympathy with the straight lines and orderly flow of fascist aesthetics.

And what has feminism got to do with all this? We recall that trigger warnings are often considered to be feminist in origin and connected in some way to women who have experienced sexual violence. Most of the calls for trigger warnings both online and on campuses seem to come from groups or individuals who identify as feminist. But here is the irony of it all - the classes most likely to be affected by trigger warnings are also feminist or women's and gender studies classes. Think about it - people are not asking for trigger warnings in biology or even political science classes. Very often, the classes where we might expect to find potentially triggering material being shown 
are in fact social justice classes that depend upon materials that depict, discuss, or critique various forms of violence, from sexual violence to racialised violence, from war to riots, from police brutality to the horrors of slavery or the Holocaust. Has feminism taught students to be wary of representation itself? Do trigger warnings, in some way, hearken back to the sex wars of the 1980 os and specifically the discursive battles around pornography led by writers and thinkers like Andrea Dworkin and Catharine MacKinnon? If pornography was the theory and rape was the practice, as Robin Morgan (1974) famously wrote, then in this new paradigm is explicit representation of sex or violence the trigger or the consequence, the cause or the effect, the problem or the solution? And if in fact feminist classrooms, in part, have created an understanding of oppression as victimisation and of activism as the control of representation, then what does this say about teaching, pedagogy, and the mediatised worlds in which we find ourselves?

In conclusion, the trigger warnings battles indicate a new level of sensitivity to explicit materials in classrooms and online. While some content warnings (asking for some indication about what lies ahead on a blind digital trail) are quite reasonable given how much explicit material circulates on screens nowadays, we do need to question the relations between explicit representations and trauma. 'Triggering' as a term conceals a complex response system that operates in all of us as we navigate the world, but instead of defending viewers and students from difficult material, the trigger warning boils all explicit material down to assaultive imagery while at the same time it reduces the viewer to a defenceless, passive, and inert spectator who has no barriers between herself and the flow of images that populate her world. It is for this reason that we must oppose the trigger warning not because we want the right to show any and all materials whenever we want but because it gives rise to an understanding of self that makes us vulnerable to paternalistic modes of protection. Will those who ask for trigger warnings to keep them safe today be more likely to surrender civil liberties when the government offers to keep them safe tomorrow? Does the triggered self fetishise safety and demand a prophylactic relation to reality? Can we refuse the entitled requests for comfort that student/clients now bring with them to the classroom? Can we still dare to be surprised, shocked, thrilled into new forms of knowing?

\section{NOTE}

1 This chapter is reprinted with the kind permission of Chicago University Press and Jack Halberstam. Originally published as: J. Halberstam, 'Trigger Happy: From Content Warning to Censorship', Signs: Journal of Women in Culture and Society, 42:2 (Winter 2017), pp. 535-42, https://doi.org/10.1086/688189. () 2016 by The University of Chicago. All rights reserved. 


\section{REFERENCES}

Kipnis, L. (2015a). 'Sexual paranoia strikes academe', The Chronicle of Higher Education (27 February), www.chronicle.com/article/Sexual-Paranoia-Strikes/ 190351 (accessed 10 March 2018).

Kipnis, L. (2015b). 'My Title IX inquisition', The Chronicle of Higher Education (29 May), www.chronicle.com/article/My-Title-IX-Inquisition/230489 (accessed 10 March 2018).

Loverin, B. (2014). 'Trigger warnings encourage free thought and debate', New York Times (19 May), www.nytimes.com/roomfordebate/2014/05/19/restraint-ofexpression-on-college-campuses/trigger-warnings-encourage-free-thoughtand-debate (accessed 10 March 2018).

Lukianoff, G. and J. Haidt (2015). 'The coddling of the American mind', The Atlantic (September), www.theatlantic.com/magazine/archive/2015/o9/the-coddling-ofthe-american-mind/399356/ (accessed 10 March 2018).

Medina, J. (2014). 'Warning: The literary canon could make students squirm', New York Times (17 May), www.nytimes.com/2014/05/18/us/warning-the-literary-canoncould-make-students-squirm.html?_r=o (accessed 1o March 2018).

Morgan, R. (1974). 'Theory and practice: Pornography and rape', in Going Too Far: The Personal Chronicle of a Feminist (1978), New York: Vintage Books, p. 169.

Oberlin (2013). 'Sexual offense resource guide: Support resources for faculty', https://web.archive.org/web/20131222174936/http:/new.oberlin.edu/office/ equity-concerns/sexual-offense-resource-guide/prevention-support-education/ support-resources-for-faculty.dot (accessed 10 March 2018).

Sontag, S. (1975). 'Fascinating fascism', The New York Review of Books (6 February), www.nybooks.com/articles/1975/02/o6/fascinating-fascism/ (accessed 10 March 2018). 


\section{4 \\ FEMINIST HURT/ \\ FEMINISM HURTS ${ }^{1}$}

SARA AHMED

Tn my last post, I explored the question of fragility (Ahmed, 2014e). Behind

1 my exploration was a reposing of the question of response and responsibility: how can we respond to the histories that leave some bodies, some relationships, more fragile than others? How can we face up to those histories of losing face?

We can be shattered by what we come up against.

And then we come up against it again.

We can be exhausted by what we come up against.

And then we come up against it again.

The question of survival is a political as well as life question. Perhaps survival seems too modest a political ambition. Not for some. Not at all. Survival becomes a political craft for those who, as Audre Lorde describes, 'were never meant to survive' (Lorde, 1978: 32).

And: the histories that leave us fragile are often those that bring us to a feminist room. This is what I want to reflect on here. What are the implications for feminism that our points of entry are often sore points? How many of us became feminists because of experiences of violence? I cannot separate my feminist history from my experiences of violence. What a tangle. Messy.

Feminist work is often memory work. We work to remember what sometimes we wish would or could just recede. As I have been working on Living A Feminist Life (Ahmed, 2017), I have been remembering. It is not that memory work is necessarily about recalling what has been forgotten: rather 
we gather memories like things, so they become more than half-glimpsed. We bring things into view. Feminist work is often about timing: sometimes we were too fragile to do this work; we would risk being shattered.

There is one time I remember, very acutely, still. I was out jogging, just near my home. A man whirled passed on a bike, and put his hand up the back of my skirt. He did not stop; he just carried on cycling as if nothing had happened; as if he had not done anything. I stopped; shaking. I felt so sick; invaded, confused, upset, angry. I was the only witness to this event; my body its memory.

What do we do when these kind of things happen? Who do we become? I kept on going. I began jogging again, but I was transformed. I became much more nervous. Every time someone came up behind me, I was ready, tense, waiting. Self-modification: how in anticipation of violence we inhabit our bodies, worlds, differently.

So many of us have so many experiences like this: they seem to accumulate over time; they carry more and more weight. Sexism: being weighed down as well as worn down. You seem to receive the same message again and again: the flasher at school who keeps returning; the time you walk past a group of boys and girls on the way home when one of them shouts out to you to come back because you are 'fuckable', and they all laugh; that time you come across a man masturbating under a tree in the city parklands who tells you to come and take a look and comes after you when you hurry away; the time when you are walking down a street with your sister and a man jumps out of the door exposing himself; the time you are waiting at a bus stop and a group of men in a car stop and ask you to get in, and you run as fast as you can to get away as they shout and jeer; the time when you fall asleep on a long flight under a blanket and you wake up with a man's fingers all over you. I remember each of these experiences, and others, as if they happened yesterday: the sound of the voices, of the car as it slowed down, the bike that rushed past, the door that opened, the sound of the footsteps; the kind of day it was; the quite hum of a plane as I woke up. It is like my senses were magnified, during or after the events; a memory can preserve a feeling, you can feel it again. These experiences: what effects do they have? What do they do?

It feels wrong. You feel wrong. In feeling wrong something is wrong. In my paper 'Black feminism as life-line' (Ahmed, 2013a), I asked how we acquire the words for this something. In that paper, I also recalled another experience I had when I was walking close to home. Two policemen in a car pulled up next to me: one asked 'Are you Aboriginal?' The other one quipped, 'or is it just a sun tan'. It was an extremely hostile address, and it was an unsettling experience at the time. It was an experience of being made into a stranger, the one who is recognised as 'out of place', as the one who does not belong, whose proximity is registered as crime or threat. 
The racialisation of the stranger is not immediately apparent, disguised we might say, by the strict anonymity of the stranger who after all, we are told from childhood, could be anyone. My stranger memory taught me that the 'could be anyone' points to some bodies more than others.

We learn how violence is directed; how the 'could be anyone' is someone. I think of feminist and anti-racist consciousness in terms of acquiring knowledge of directedness.

Let me share an example from Audre Lorde's autobiography, Zami:

Tensions on the street were high, as they always are in racially mixed zones of transition. As a very little girl, I remember shrinking from a particular sound, a hoarsely sharp, guttural rasp, because it often meant a nasty glob of grey spittle upon my coat or shoe an instant later. My mother wiped it off with the little pieces of newspaper she always carried in her purse. Sometimes she fussed about low-class people who had no better sense nor manners than to spit into the wind no matter where they went, impressing upon me that this humiliation was totally random. It never occurred to me to doubt her. It was not until years later once in conversation I said to her: 'Have you noticed people don't spit into the wind so much the way they used to?' And the look on my mother's face told me that I had blundered into one of those secret places of pain that must never be spoken of again. But it was so typical of my mother when I was young that if she couldn't stop white people spitting on her children because they were Black, she would insist it was something else. (Lorde, 1984: 17-18)

An event happens. And it happens again. The violence is directed from the white body to the black child, who receives that violence by shrinking, shrinking away from its sound. But the mother cannot bear to speak of racism, and creates an impression that the violence is random. Racism is a pain that is hard to bear. Consciousness of racism becomes retrospective, and the question of its timing does matter. You learn not to see racism as a way of bearing the pain. To see racism, you have to unsee the world as you learnt to see it, the world that covers unhappiness, by covering over its cause. You have to be willing to venture into secret places of pain.

Some forms of 'taking cover' from pain - from not naming the causes of pain in the hope that it will go away - are to protect those we love from being hurt, or even to protect ourselves from hurt, or are at least meant as a form of protection. But to conceal the causes of hurt can make others the cause of their hurt. Audre Lorde shows throughout her work that we should not be protected from what hurts. We have to work and struggle not so much to feel hurt, but to notice what causes hurt, which means unlearning what we have learnt not to notice. We have to do this work if we are to produce critical understandings of how violence, as a relation of force and harm, is directed toward some bodies and not others. In The Promise of Happiness (Ahmed, 
2010a), in reflecting on Lorde's example, I suggested that we could follow Raymond Williams (1977) to explore 'structures of feeling', but also consider 'feelings of structure'; feelings might be how structures get under our skin. ${ }^{2}$

Structures are thus not independent of bodies; structures are about how violence gets directed towards some bodies and not others. As my example of the institutional brick wall from previous posts (Ahmed, 2014C; 2014d) showed, what some of us come up against, others do not experience. Structures can bruise some bodies whilst not appearing to affect others.

It matters how we think about feeling. Feelings are how structures become affective; how we are 'impressed upon' in our encounters with others; how we are impressed differently, affected differently, by what we come up against. And if the violences that leave us fragile are those that bring us to feminism, no wonder a feminist bond is itself fragile: an easily broken thread of connection. Perhaps we need an account of some of these breaking points (Ahmed, 2013b) by not assuming we know what breaks at these points.

Perhaps it is in teaching rooms or seminar rooms that we can think more of this fragility as a space that can occupied. I have been reading some of critiques of trigger warnings in the past six months relating primarily to the migration of this term from the feminist blogosphere into US classrooms. And there have been many critiques: my sense is that the rush to critique almost warrants the term 'moral panic'. I think this term 'moral panic' is warranted because of some of the inflationary logics in use. These critiques tend to inflate what is intended by trigger warnings (from a specific technique for dealing with PTSD to a more generalised culture of warnings about any or all potential harms) and they also take form as narratives of crisis: trigger warnings have been identified as causing the demise of academic freedom, as being anti-intellectual, as a symptom of neoliberalism, as evidence of narcissism - almost as a sign of the 'end of education' itself.

I will not engage with these critiques directly, nor will I address the question of trigger warnings in a full and systematic manner (trigger warnings are rather remote from the pedagogic scene in which I have been taught to teach). ${ }^{3}$ What has interested me is how these critiques have created a general impression: positing a hurt, traumatised or hypersensitive student against the rigorous demands of intellectual culture.

The figure of the too-easily-hurt student is familiar to anyone coming out of Women's Studies: indeed many of the charges against Women's Studies as anti-intellectual often rested on claims that in Women's Studies all we do is talk about hurt feelings. And I suspect there is a longer history at stake here, whereby feminism itself is understood as politically impoverished (and damaging to the left) because of its concern with individual consciousness and suffering. As Imogen Tyler explores in her important paper, 'The selfish feminist', much anti-feminist rhetoric in the 1970 os and 1980 os mobilised 
a diagnosis of narcissism: 'One of the central arguments made by these accounts of cultural narcissism is that politics, mainstream and/or countercultural politics had degenerated into individual quests for self-awareness and self-realisation' (Tyler, 2007: 180). ${ }^{4}$ Whilst consciousness raising was about exploring how the personal is political, these anti-feminist critiques worked to reframe feeling as only and just personal. Feminism becomes a symptom of 'the me decade'.

This widely circulating figure of the too-easily-hurt student thus has a longer history, one that might also relate back to the figure of the feminist killjoy: the hurt of some gets in the way of the happiness of others.

Can we think about the politics of hurt differently? I have always taught courses on racism and colonialism, ever since I have taught. I thus bring difficult histories in the room, often difficulties that manifest as stuff (an image, a written document, a thing). I think asking ourselves how we do this is something we must always do. These histories are alive, they are not over. Racism and colonialism are the present we are in. So how we bring these histories into the room does matter. I remember one time, it was a rather difficult time, and I was about to show a film that was dealing very explicitly with histories of violence against black women. I was going to be talking about histories that persist. I stopped. I did not show it. Something about the occasion stopped me. Other times I have shown the film.

Stopping and starting; we hesitate; things splatter. I do not assume that I know what I am doing in what I am bringing or not bringing into the room. I hope to be willing to listen. If students find what I bring to the room makes it hard for them to be in the room, I want to find another way to bring things in, or at least to ask myself about different ways of bringing things in. This is a hope of course: I get things wrong, we all get things wrong. Things do shatter. The fragility of the pedagogic encounter is something I take for granted because the histories I bring up are or can be shattering for those in the room, for some more than others, for some in different ways than for others. And I too am in the room. I too can be shattered by what I bring with me. Can be, have been.

There were a couple of experiences I had early on that made me aware of what it means to bring histories that leave us fragile into the room. One time a student doing an undergraduate degree in English Literature and Women's Studies came to my room in tears. She said that a lecturer had shown a film that involved a graphic depiction of rape. When she had been upset by this, he had basically said to her that she was 'taking it literally' and that the rape was a metaphor. His assumption of the aestheticisation of rape allowed him to show and to keep showing a film with a structural indifference to the effects it might have for some students. Hurt was dismissed as literalism. The same year an MA student in Women's Studies came to my 
room also visibly upset. A tutor on a feminist theory course had shown some images from nineteenth-century science depicting women's genitals. Apparently she had left these images in the middle of the table throughout the session, mostly uncommented upon. When a student complained about this at the end of the session, the tutor laughed. I did not hear more about this laughter but I learnt from the fact that it was possible to laugh.

The insistence on one's right to use certain kinds of materials can become a scathing indifference to how these materials affect others. Neither of these students was asking for the removal of these materials from the classroom. But perhaps their expression of hurt is already heard as censoring. And that's what is at stake here: how hurt is heard as wrong (you are wrong to be hurt) and as an imposition (Ahmed, 2014a). An imposition here is what is treated as alien (out of place) and, in the academic context, it is something that would get in the way of our freedom, of our freedom to show what we do, to do what we show. No wonder those who ask us to change how we introduce certain materials (as potentially causing harm) have become killjoys: those who get in the way. Hurt itself becomes framed as censoring: as requiring the removal of some offending thing. ${ }^{5}$ But actually the killjoy here is asking for more, not less: asking for us to complicate the materials; to situate the materials; to consider how materials can create ripples in how they move us: matter as motion, as deviation. Of course we cannot always anticipate how things affect somebody, but that does not mean we cannot learn about how things are affective by how others are affected. I might be thrown by how you are thrown.

Of course some public expressions of hurt can close spaces down. So too, of course, can public expressions of what some might call reason. It is collective work to keep spaces open especially when we are talking about histories that hurt. No wonder feminist spaces are tense, intense. ${ }^{6}$

Feminist hurt. We might say if hurt brings us to feminism, feminism can also hurt (from feminist hurt to feminism hurts). We might let ourselves be hurt all over again. When I teach, I teach about things that still hurt. I am willing this still. When I write, I stay close to the histories of violence. Sometimes I write with tears, in tears. I read the work that reminds me of this hurt: I read about racism, sexism, injury, injustice. These words become lifelines too, allowing me to live on by going on.

Hurt: still. We are moved because it hurts still.

We are not over it; it is not over.

The desire to get over suffering is of course an understandable desire, one that might express a longing to do more than describe social relations of force and harm. Rosi Braidotti suggests in her work on affirmative ethics that 'repugnant and unbearable events do happen' but then concludes that 'ethics consists however in reworking those events into positive relations' (Braidotti, 2006: 13). She argues that 'paradoxically, it is those who have 
already cracked up a bit, those who have suffered pain and injury, who are better placed to take the lead in the process of ethical transformation' (2006: 14). Perhaps the relationship between leadership and suffering is only paradoxical if we assume that suffering is stifling. We learn from what Braidotti rightly points out: those who have been undone by suffering can be the agents of political transformation.

We might need to attend to bad feelings not in order to overcome them, but to learn by how we are affected by what comes near, which means achieving a different relationship to all our wanted and unwanted feelings as a political as well as life resource.

I think what can be underestimated even within some feminist work is the difficulty of giving our attention to - and sustaining our attention on certain forms of suffering. The desire to move beyond suffering in reconciliation, the very will to 'get over it' by asking others to 'get over it', means those who persist in being hurt become causes of general unhappiness. Their suffering becomes transformed into disappointment that we cannot simply put such histories behind us.

My exploration of the figure of the melancholic migrant in The Promise of Happiness (Ahmed, 2010a) was also about how some forms of hurt become understood as what stops us from just 'getting along. The melancholic migrant is the one who is too attached to their own injury; who won't let go. And from the mobility of this figure, we can hear an injunction: let go! Just let go!

The scripts often imply more; they attach the problem of bad feeling to how those who are the problem understand that feeling. The melancholic migrant is the one who won't let go of the pain of racism by letting go of racism as a way of understanding that pain. It is as if the insistence on being hurt by racism is what stops racism from just 'going away'.

This is why I think the refusal to let go of an injury might require a certain willfulness. We might have to become stubborn just to hold on.

And I keep wanting to say: slow down. Listen.

Bad feelings are creative responses to histories that are unfinished. They are not the only responses. And we are not finished.

\section{NOTES}

1 This essay is reprinted with the kind permission of Sara Ahmed. Originally published as: S. Ahmed, 'Feminist Hurt/Feminism Hurts", Feministkilljoys.com, 21 July 2014, http://feministkilljoys.com/2014/07/21/feminist-hurtfeminism-hurts/.

2 Some recent anti-feminist writings (think vampire's castle, think 'the politics of denunciation') have implied feminism is problematic when it/we 'call out' individuals (because we need to focus on structures rather than individuals). My 
arguments here are a refutation of these modes of analysis. Structures when imagined as 'without' individuals can be very easy places to be! You can do anything, and say: the structure did it! This is why 'institutional racism' can also be limited as a frame: if individuals tend to dis-identify from structures (especially structures of governance), then they do not see themselves as implicated in racism. The most extreme version of this argument I have read implies that women who are survivors of rape or assault should not name those who assaulted them because to name would be to individualise violence and to disrupt the possibility of working collectively. This example shows us what is at stake. The individual disappears at the moment he is called to account. Perhaps he then reappears as the one who can save the left from the moral demise caused by feminists amongst others. I will be returning to how individualism has historically been used as a charge against those who question existing social norms (such as the family) in future posts.

3 I do recognise that when a call, or even a demand, is transformed into a mandate, things change. But let's be clear: anything can become a technique to manage difference. In On Being Included (Ahmed, 2012), I explored how equality becomes part of audit culture: something that can be measured. It was tricky to make this critique. Equality becomes a political idea and ideal because of inequalities. Feminists amongst others have struggled against the institutionalisation of inequalities. And yet equality has become part of the bureaucracy, without question. It is important that we do not make equality into a symptom of bureaucracy. This would precisely negate or obscure our political work in challenging inequalities. And indeed, this negation and obscuration is evident in how some can dismiss equality as 'just another part of audit culture. My research explored the consequences of the ease of this dismissal. Equality is treated as something imposed by management that radical academics (who tend to dis-identify from institutions) can thus ignore. As I explored in an earlier post (Ahmed, 2014b) feminism itself can be identified with the management/state, as those who are imposing social norms on otherwise free radicals. You can see here how important it is that critiques of how equality can become part of audit culture do not reduce equality to audit culture. I would suggest we need the same level of nuance in response to trigger warnings: if they can become a management technique we should not reduce them to a management technique. The reduction would be a failure to respond to, and be responsible for, other histories of struggle that are at stake in the very arrival of these terms, including struggles around disability.

4. One question I hope to explore is whether neoliberalism is now functioning in a similar way to narcissism: as a diagnostics (and dismissal) of the political struggles of feminists, anti-racists and queers as being 'just about' identity (rather than structure), as being 'all about me', and as thus causing the demise of the family, community, the left, and so on. I will return to this question in future posts.

5 In The Promise of Happiness (Ahmed, 2010a), I explored the figure of the easily offended Muslim. The Muslim who is offended is the one who would restrict our freedom of expression. This is how freedom of expression then becomes the freedom to be offensive. These political figures, by being charged with bad feeling, are doing something: they are enabling some freedoms to become re-assertions of the right to occupy space.

6 See the section 'feminist tables' in Ahmed (2010b) for further discussion. 


\section{REFERENCES}

Ahmed, S. (2010a). The Promise of Happiness. Durham, NC: Duke University Press. Ahmed, S. (2010b). 'Feminist killjoys (and other willful subjects)', The Scholar and Feminist Online, 8:3 (Summer), http://sfonline.barnard.edu/polyphonic/print_ ahmed.htm (accessed 3 September 2018).

Ahmed, S. (2012). On Being Included: Racism and Diversity in Institutional Life. Durham, NC: Duke University Press.

Ahmed, S. (2013a). 'Black feminism as a life-line', Feministkilljoys.com (27 August), https://feministkilljoys.com/2013/o8/27/black-feminism-as-life-line/ (accessed 3 September 2018).

Ahmed, S. (2013b). 'Breaking points', Feministkilljoys.com (8 December), https:// feministkilljoys.com/2013/12/o8/breaking-points/ (accessed 3 September 2018).

Ahmed, S. (2014a). 'Imposition', Feministkilljoys.com (14 April), https://feministkilljoys. com/2014/04/14/imposition/ (accessed 3 September 2018).

Ahmed, S. (2014b). 'Problems with names', Feministkilljoys.com (25 April), https:/feministkilljoys.com/2014/04/25/problems-with-names/ (accessed 3 September 2018).

Ahmed, S. (2014c). 'Practical phenomenology', Feministkilljoys.com (4 June), https://feministkilljoys.com/2014/06/04/practical-phenomenology/ (accessed 3 September 2018).

Ahmed, S. (2014d). 'Hard', Feministkilljoys.com (10 June), https://feministkilljoys. com/2014/06/10/hard/ (accessed 3 September 2018).

Ahmed, S. (2014e). 'Fragility', Feministkilljoys.com (14 June), https://feministkilljoys. com/2014/06/14/fragility/ (accessed 3 September 2018).

Ahmed, S. (2017). Living a Feminist Life. Durham, NC: Duke University Press.

Braidotti, R. (2006). Transpositions: On Nomadic Ethics. Cambridge: Polity.

Lorde, A. (1978). Black Unicorn. New York: W. W. Norton.

Lorde, A. (1984). Zami: A New Spelling of My Name. London: Sheba Feminist Publishers.

Tyler, I. (2007). 'The selfish feminist', Australian Feminist Studies, 22:53, pp. 173-90. Williams, R. (1977). Marxism and Literature. Oxford: Oxford Paperbacks. 



\section{Part II}

\section{VULNERABILITY AND VISIBILITY}





\title{
5 \\ LITTLE PINK \\ White fragility and black social death
}

YLVA HABEL

\begin{abstract}
Human Life is dependent on black death for its existence and for its conceptual coherence. There is no World without blacks, yet there are no blacks who are in the World. The Black is indeed a sentient being, but the constriction of Humanist thought is a constitutive disavowal of blackness as social death; a disavowal that theorizes the Black as a degraded human entity. (Wilderson, 2016)
\end{abstract}

Drawing on the intellectual work of afro-pessimist scholars such as Frank B. Wilderson III, I want to elucidate the ways in which blackness and black life have become contested, unfathomable 'objects' in Swedish mainstream media debates. I locate my discussion at the interface between those debates, afro-pessimist legacies and my position as a black film and media scholar before, during, and after the release of the animated children's film Liten Skär och Alla Små Brokiga [Little Pink and The Motley Crew] (Stina Wirsén, Sweden, 2012). My aim is to examine the ways in which the film's pickaninny figure, Little Heart, and the hurtfulness of this stereotype were discussed and contested in the debate around the film. I argue that the debate ended up producing a sense of white fragility as a priority instead of dealing with anti-black racism, its consequences for black people, and its ongoing maintenance through representation.

Before I delve into the turbulent reception of the film, let me first begin by saying something about the partly auto-ethnographical point of departure for this text. I draw on my own participation in the debate around the signification of blackness in Little Pink, but these experiential accounts are not to be understood as purely personal or individual experiences of black positionality. Like Saidiya Hartman (2008: 5) claims, 'the autobiographical 
example ... is not a personal story that folds onto itself; it's not about navel gazing, it's really about trying to look at historical and social process and one's own formation as a window onto social and historical processes, as an example of them. In several respects, this is an auto-ethnographical text that intermingles reflections on various stages of the debates with a contextualised understanding of what black people, and specifically black women, run up against in our encounters with neoliberal white supremacy (Hage, 1998; hooks, 1989: 112). For ethical reasons, I will refrain from revealing the identities of the black women and other black online commentators involved in the struggles with me. You know who you are.

Moreover, I should state that I write from an exceptionalist national context. Despite its historical and ongoing corrosion, the national image of the Swedish welfare state still provides a solid basis for exceptionalist discourses on equality, in which race and racism are absent (Habel, 2012a). Enabling a continued hold on the public imaginary - and, by extension, orchestrating and setting the limits of the thinkable and speakable in contemporary powerevasive media debates on race - these discourses serve to reformulate, salvage, and update purportedly collective imaginings of racial inclusion, innocence (Wekker, 2016), and democratic values as watchwords for dialogue.

Swedish cultural investments in political innocence have been grounded in collectively held images of being historically exempted from colonial involvement and racialising structures. As several scholars, including myself, have claimed, Sweden has come to imagine itself as a race-less, tolerant country, which is supposedly less affected by postcolonial relations than other nations (Habel, 2012a; Keskinen et al., 2009; Neergaard and Mulinari, 2017). Our history of welfare politics and our contributions to egalitarianism, diplomacy, and foreign aid are well known. Throughout contemporary history, Sweden has marked - and marketed itself - as a moral superpower - a haven of democracy and neutrality. As Katarina Schough (2008) claims, Swedish collective identity involves imagining our country as a de-territorialised, ethereal space. To be black in Sweden is therefore complicated in many ways, and has been explored by a growing group of scholars and free intellectuals (Abdullahi, 2015; Cátia Suzana, 2015; Habel, 2008; 2012a; 2015; Habel and Kanyama, 2014; Habel and Sawyer, 2014; Keyune-Backström and Sawyer, 2015; Keyune-Backström et al., 2015; McEachrane, 2014; McEachrane and Faye, 2001; Miller, 2017; Ndow-Norrby, 2015; Polite, 2007; Sabuni, 2015; Sawyer, 2000).

Since 2011, the Swedish public sphere has roared with debates around cultural images of blackness. The release of the Swedish film Play (Ruben Östlund, 2011) gave a spark to powerful critiques regarding racist, specifically black stereotypes, on a broader scale than before. Play depicts two pre-teen white middle-class boys who become the hostage of a group of black boys 
and teenagers from the 'suburbs', who steal their phones in a shopping mall. The white boys are taken from the mall and forced to spend a long humiliating day in capture, without knowing what is going to happen next. The imagery of the film encourages intimate identification with the white boys' situation, the camera lingering on their fearful faces as they are subjected to threats and gratuitous and capricious cruelties from the black boys.

Black people and people of colour, who until then had often been held back by unacknowledged, unofficial, and hidden forms of censorship, spoke up on social media and blogs to critique Play. Earlier, examples of public media engagement in anti-racism and racist stereotypes were more far apart - and not accorded more than marginal, fleeting attention by the mainstream media coverage. The main reason for this protest - inspired in part by Jonas Hassen Khemiri's forty-seven-point elegy over the film (2011) - was that white daily press columnists from left to right on the political spectrum had openly ridiculed the anti-racist critique of Play, while at the same time denying black people the possibility to respond (Linderborg, 2011; Wiman, 2011). At this point in time, I was the first black person in Sweden with a doctorate in cinema studies, yet I was barred from publishing a response to the film.

Then a YouTube sequence of Afro-Swedish artist Makode Linde's performance work 'Painful Cake ${ }^{1_{1}}$ went viral in spring 2012. He had created a naked Saartje Bartmann-like figure in cake material, with himself as the head, made up in glaring blackface. Minister of Culture Lena Adehlson Liljeroth cut the first piece of the cake and chose to start at the vaginal area, then fed a piece of it to Linde. From there, a new wave of debates started - which, at first sight, appeared to be game-changing. Suddenly, we found ourselves invited, even called upon, to comment on the problematic of blackface and the reproduction of racist stereotypes. This time we kept raising our voices, and during most of 2012 one debate followed another. For the first time, a relatively big group of black intellectuals, activists, educators, and academics, including myself, could make themselves heard on the cultural arena.

What became interesting as well as painful to observe during this period was that debates created 'chains' entailing uncontrolled seepage or overlap between context, medium specificity, and genre. Dominant voices in press and media debates bandied about easy generalisations of culture and representation in ways that incessantly derailed attempts to keep a focus on the specificity of films, artworks, or comic books. It can be argued that the big controversy over Little Pink in the autumn of 2012 was given a threemonth build-up, constituted by the succession of escalating but repetitive debates: the artist Makode Linde's performance work 'Painful Cake' in April and his next performance work 'The Last Supper in June', both in which he performed in blackface, and the controversial premiere of Little Pink which 
took place in late September. Just a few days after the premiere of Little Pink, yet another debate ignited around the colonial and racist imagery of the Tin Tin albums after they were taken away from the children's section at the Cultural House in central Stockholm.

Yet, powerful voices within the mostly white mainstream media contributed significantly to compartmentalising each of these debates. Hence, the dramaturgy and discursive logic of each debate became excruciatingly repetitive, suggesting that earlier arguments from black critics were neither heard nor absorbed by the press, cultural institutions, or public service media covering the debates. Kitimbwa Sabuni (2012) referred to this as 'white rage.' Significantly, white cultural critics and debaters in Swedish daily newspapers, such as Jonas Thente and Björn Wiman of Dagens Nyheter, the daily with the largest circulation in Sweden, would start all over again for each controversial cultural product, thus making every particular debate almost thematically and discursively identical. A key tendency among these critics was to deny that anti-black racist stereotypes retain similar colonial meanings in Sweden as elsewhere, or that they could be harmful overall. Through each step of the way, the exceptionalist discourse in these debates followed the dramaturgy of several predecessors in Europe. One of the clearest examples is the perennial denial that Zwarte Piet in the Netherlands embodies an offensive black stereotype (Essed and Hoving, 2014; Habel, 2012a; 2012C; 2012d; Keskinen et al., 2009; Martina, 2012; Wekker, 2016). I will return to the Netherlands context and the Zwarte Piet debate since, as I will argue, it is instructive for the Swedish debates in several ways.

\section{TICKLED PINK: PLEASURABLE WHITE FANTASIES AND ROWDY RECEPTION}

What about the film Little Pink and the Motley Crew itself? How could a children's film create such a national stir? How did its reception unfold within the series of debates outlined above? In August 2012, shortly after the film's premiere in late September was announced, critique was raised against the figure of Little Heart, a crudely drawn and easily recognisable pickaninny stereotype. A group of academics, myself included, tried to approach the film's distributor Folkets Bio ('People's Cinema', a network of leftist film theatres in Sweden) on its public Facebook page and gently request a discussion about this racist stereotype. They responded on the page, claiming that we should not judge a film before having seen it, and then more-or-less withdrew from further conversation. Folkets Bio went as far as deleting several posts by us and them on their page. Fairly quickly, we were characterised in the larger debate as having acted threateningly and 
aggressively vis-à-vis Folkets Bio and the film's director Stina Wirsén, with whom we had not been in direct contact at all. As a small token of good will, they took down the film posters - featuring Little Pink, Little Heart, and the rest of the Motley Crew - for the upcoming film.

During the rest of the year, little by little, I got sucked into an increasingly disturbing dynamic created around Little Pink. Shortly after Folkets Bio's withdrawal from accountability and dialogue, the journalist Arash Mohktari (2012) contacted me, wanting to link an interview with me to a conversation with the actor Stellan Skarsgård, Little Pink's narrator voice. Standing beside Mohktari while he called Skarsgård, I could hear the latter screaming at the top of his voice, claiming that the whole discussion about racist imagery in the film was a ridiculous non-issue, and that he refused to say anything more about it. Speaking with me was out of the question.

By then, I knew that the opening of the film at Folkets Bio in the city of Lund in southern Sweden had been cancelled (Löfvendal, 2012). Having been asked to write a short piece on Little Pink for the online debate site for public service TV show SVT Debatt (Habel, 12 September 2012), I braced myself and went to the preview screening in Stockholm. The film itself turned out to deliver a series of more-or-less shocking un-surprises. The animated figures Little Pink, Little Worm, Bosse, Little Heart, and Ruta/Square are all created in Stina Wirsén's signature watercolour aesthetics, and have wordless voices, like whistles and differently pitched horn instruments. Little Heart's voice has the crude, hoarse sound of a broken trombone. She has been given the features of a classic pickaninny figure: a pitch-black face, a round white mouth, and braids adorned with red hearts (instead of the conventional red bows) standing up from her head.

Throughout the loosely constructed narrative, drawn against a white background, the group of toddler figures are exposed to various heretofore unknown things and creatures that appear before their eyes through fluent watercolour technique; by way of the cues given by the pedagogical narrator voice, the figures learn to interact with the novelties and each other. They dance and sing, tease each other, play, and eat. Little Heart's behaviour is erratic and implicitly brutal: at one point, she cannibalistically forces Bosse down into a big pot and tries to cook him. She is also the only one among the figures who does the cleaning, and who readily exposes her 'nipples' when undressing to do gymnastics. She is the only female character that is clearly sexualised, also engaging in long passionate kisses with Little Worm.

On the opening day of Little Pink in Stockholm, a small black demonstration took place outside the film theatre Zita; protesters were photographed carrying signs saying 'I'm not a pickaninny, I'm a person' and 'We are not your Motley Crew'. Staffan Carlsson, who posted the collection of images on Flickr, photographed the demonstration, and I posted them on my 
Facebook account, which was public at the time. ${ }^{2}$ The statement 'We are not your Motley Crew' was shortly after given a homepage created by the freelance intellectual and programmer Oivvio Polite: NotYourMotleyCrew.com (2012), where black people and other people of colour protesting against the pickaninny figure could upload a picture of themselves, holding up their critical message to the camera.

By this time, Little Pink had become such a sensitive topic that the online review of the film issued by SVT was quickly taken down (noted by Lundström, 2012). In it, Isabel Espinoza (2012) had stated that she refused to review such a racist film. ${ }^{4}$ During the fall, mine and other debaters' written critiques of Little Pink were instantly met by a disproportionately crude backlash, such as that by the cultural columnist Jonas Thente (2012), who wrote that 'academic hags' and 'quasi-academics' like me should stop writing debate articles to fish for research funding. He furthermore mentioned his genitals, as if that had something to do with the matter. In his view I, even though I was not named in his text, 'invented' racism in order to criticise it. At this early stage, several white debaters critiqued Thente for the baseness of his attack and questioned whether it could be fruitful to carry on a discussion at 'penis-level' (Krutmeijer, 2012). Others critiqued Thente's name-calling, while also pointing to the general dominance of white voices in the debate (Grelsson, 2012). The author and illustrator of children's books Eva Susso (2012) in turn argued that we must not be 'one-eyed and pale', but recognise that a well-known black stereotype cannot be re-signified at will. Karoline Eriksson (2012) wrote: 'Someone should have woken up and pulled the emergency brake [on this film, especially] since Makode Linde's Cake caused such severe reactions earlier this year'.

However, these voices of early support were quickly drowned out by liberal white supremacist voices and a few tokenised allies of colour. The black debater Sherlot Jonsson (2012), a former employee at the Discrimination Ombudsman, argued that Little Pink exemplified 'diversity' and equalised representation. Most of the all-white cultural columnists at Dagens Nyheter who had been former colleges of Stina Wirsén retaliated against us, while withholding opportunities for black critics and other critics of colour to respond in their debate columns. Björn Wiman, editor of Dagens Nyheter's cultural section, was an important gatekeeper who invited participation solely from his white colleagues, such as Erik Helmerson, Sverker Lenas, and Ulf Stark, a celebrated writer of children's books (Stark, 2012). Ovvio Polite (2012C) pointed out this nepotism in the evening paper Expressen and received no response. Earlier in October he started an online timeline on the NotYourMotleyCrew page, collecting as many debate entries on the film that he could find.

The white anxiety over being denied the pleasure of freely delving into this type of colonial imagery incessantly resurfaced during the year's many 
debates, specifically those revolving around Little Pink. All attempts to address the fact that black stereotypes were part of an anti-black genocidal history lingering in the present (Habel, 2012C; 2012d; Rubin-Dranger, 2012a) were fiercely rejected, partly through accounts of how these were enjoyable images for children (Lenas, 2012; Wiman, 2012). Points about how black people's children were put in harm's way by racist stereotypes (Polite, 2012a) or that blackness could be portrayed in non-offensive ways (Rubin-Dranger, 2012a) went unheard by adversaries. Stina Wirsén (2012), who had made herself scarce before the premiere for the film, dismissed critics as generally ignorant, without naming or addressing anyone in particular. Björn Wiman of Dagens Nyheter (2012) went as far as bluntly outing his desire to 'eat' the black Other (hooks, 1992) by writing that taking away all the colourful representations of black and other people of colour, that he and so many others enjoyed, would signify 'draining all the sugar out of the juice'.

As much as the discussions around Little Pink exemplified expressions of bell hooks's seminal arguments in the essay 'Eating the Other' (1992), I would like to turn to aspects of Afrodiasporic theorisation formulated both before and after bell hooks's critique, such as anticolonial critique and afro-pessimism. The free intellectual and activist Egbert Alexandro Martina combined these strands in his text 'The delicious pleasure of racism' (2012), in which he explores the argumentatory logic of Zwarte Piet defenders in a Dutch context. He writes that 'one of the main arguments used in defence of Zwarte Piet is that Sinterklaas is a "fun" and joyous occasion for children and by getting rid of the figure we are denying children a source of pleasure'. He goes on to argue that this way of reasoning demands not to be put into question, and 'repackages (the trauma of) slavery as racially innocent fun' (Martina, 2012). Similarly, in the Swedish context of the Little Pink debate, black critics' arguments went unheeded. Regarded as the under-vegetation of humanity, we could not be heard. Step by step, it dawned on me that there can be no such thing as establishing a relationship of reciprocity and accountability vis-à-vis black people. We were natural clowns.

In late October, Oivvio Polite and Joanna Rubin-Dranger revealed that important parts of the fierce resistance against our critique had been motivated by Wirsén's large-scale business interests launched in twelve countries via an Internet-based licence company (Rubin-Dranger, 2012b). 'Brokiga är business' ['Brokiga is business'], Polite stated, adding that the product line was extra popular in Japan (2012b). Others, whose identities I am not at liberty to reveal, drew attention on social media to the fact that preceding her visit to Japan that autumn, Wirsén had received considerable support from the Swedish Institute, and had prepared a multifaceted launching campaign of her new product line Brokiga [Motley], consisting of fabrics, clothes, toys, dolls, and baby outfits (Habel, 2012b). 


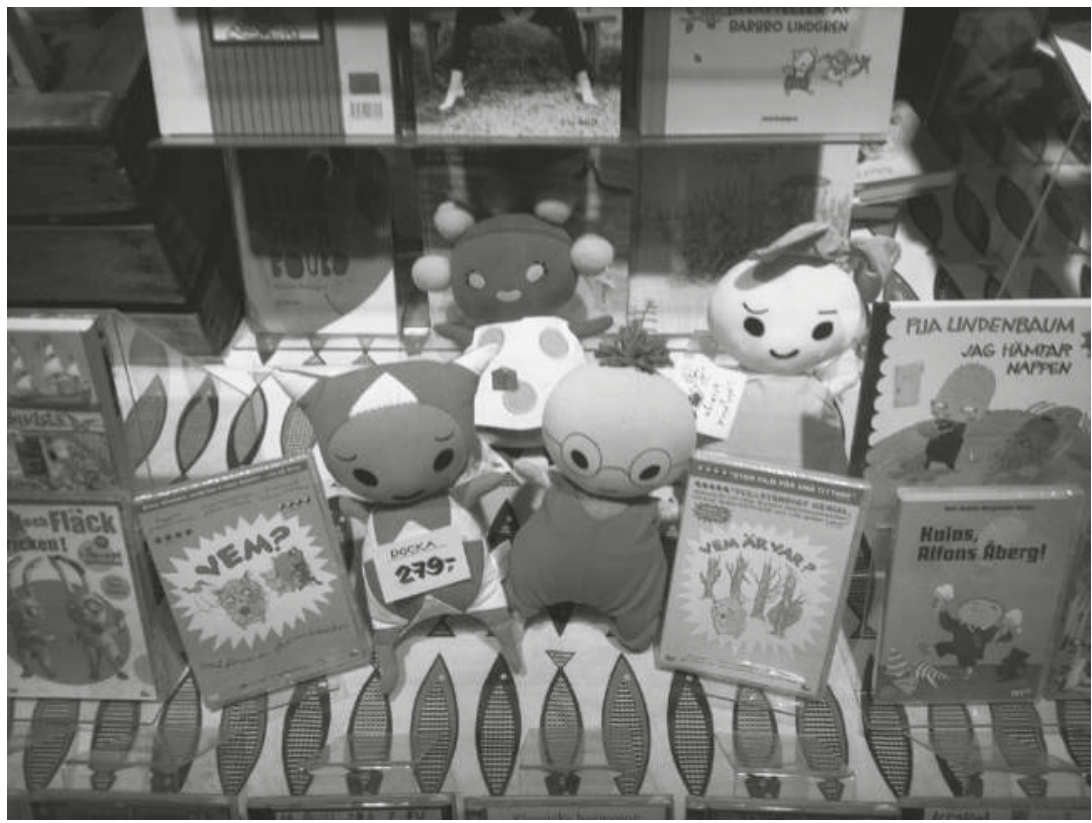

Figure 5.1 Motley/Brokiga merchandise in the window of the children's bookshop Bokslukaren/Book Eater in Stockholm.

By November, I and several other black critics, whose identities I cannot reveal, had talks about the many ways in which we were beginning to feel bruised and exhausted. For some of us, friendships and family bonds were strained or shattered. Other black people, I was told, had lost or left their jobs on account of the debate, since it had entered into organisations and cultural institutions by way of position taking. As I write this, the Motley products are still broadly available in online shops. Some of them can be seen in the children's bookshop Bokslukaren's window in Stockholm (see figure 5.1), and a selection of Wirsén's original paintings of Brokiga are in the window of the art gallery Konst och Folk, just a stone's throw away (see figure 5.2).

\section{THE NEED FOR AFRO-PESSIMIST THEORISATION IN SWEDEN}

Before going back to the discussion about the conditions of possibility for black critics during and after the debate around Little Pink, I need to address the specific predicament of the black populations in the Swedish and Scandinavian contexts, intimately tied to the broader European discourses 


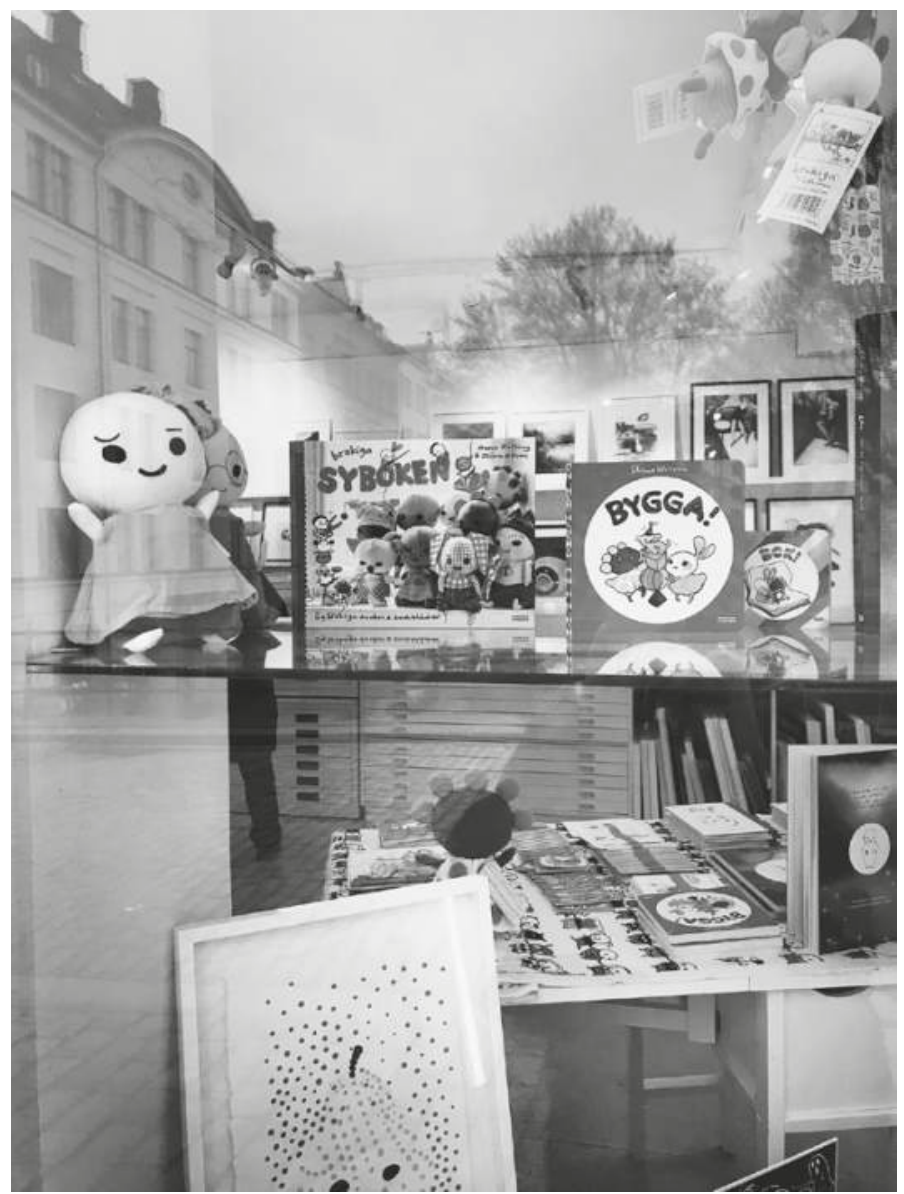

Figure 5.2 Motley/Brokiga merchandise in the window of the art gallery Konst och Folk/Art and People in Stockholm.

regarding the relationship between everyday racist oppression and our limited power to fight anti-black stereotypes. In several ways, European nations share a deep collective investment in normative colour-blindness, departing from a welfare-and-democracy-saturated, self-congratulating, liberal-minded White supremacy that refuses to acknowledge its own existence. What gives these national self-images their staying power is that they rely on an automatic, principally inclusive collectivity based on an unexamined presumption that equality stands in a metonymic relation to racial/ non-racial/white sameness (Daun, 1996).

It can be argued that our shared, global history, involving the active participation in the transatlantic slave trade and anti-black genocide, has been 
and to a large extent continues to be forcefully denied in Sweden. Studies on it certainly exist but remain unheeded in everyday culture. ${ }^{6}$ This denial goes on, even though Little Pink's depiction of Little Heart as a crude pickaninny stereotype harks back directly to the already-established relationship between the dehumanising black stereotypes created during plantation slavery and what Orlando Patterson (1982) calls black social death.

Therefore, speaking with Christina Sharpe (2016), it is of utmost importance to redact our whitewashed history-writing in order to address the ways in which the black diaspora is affected by what Sharpe calls the 'after-life of slavery' in both a US and a global context. She takes her cue from Saidiya Hartman, who writes:

If slavery persists as an issue in the political life of black America, it is not because of an antiquarian obsession with bygone days or the burden of a toolong memory, but because black lives are still imperilled and devalued by a racial calculus and a political arithmetic that were entrenched centuries ago. This is the afterlife of slavery - skewed life chances, limited access to health and education, premature death, incarceration, and impoverishment. I, too, am the afterlife of slavery. (Hartman, 2008: 6, italics mine; see also Kilomba, 2010)

Anti-black racism, understood as an economic endeavour and not as a moral failing (Ferreira da Silva, 2015) also has global signification, even if exceptionalist discourses have stubbornly denied that it has a bearing on the Swedish context. One of the many important contributions of afro-pessimist theorisation is that it straightforwardly addresses how the African diaspora is positioned as the constituting outside of the category of the human and humanist thinking (Weheliye, 2014; Wilderson, 2016). Frank B. Wilderson III (2016) writes:

Afro-pessimism offers an analytic lens that labor as a corrective to Humanist assumptive logic. It provides a theoretical apparatus which allows black people to not have to be burdened by the ruse of analogy - because analogy mystifies, rather than clarifies, black suffering. Analogy mystifies black peoples' relationship to other people of colour. Afro-pessimism labors to throw this mystification into relief - without fear of the faults and fissures that are revealed in the process.

So, what does it entail to advance afro-pessimist thought in the context of Swedish cultural debate?

The racist and particularly anti-black verbal violence which erupted around Little Pink can be placed within the larger colour-blind framework of neo-racism (Balibar and Wallerstein, 1991) or 'racism without racists' (Bonilla-Silva, 2006). Of course, as Eduardo Bonilla-Silva (2006) has shown, this discourse is not limited to Europe or the US - black Canadian scholars 
point to collectively held images of Canada as a peaceful, colour-blind, postracial nation (Chariandy, 2015; Hudson and Kamugisha, 2014). What black populations in all these contexts share is a relatively weak position and that they are constantly called upon to 'prove' that racism is damaging and dangerous. The existence of anti-black racism (if it is allowed to be named as such, that is) is regarded as an opinion among other opinions. This tendency to make black embodied existence under anti-black regimes an 'opinion' could be seen as one of the most tangible aspects of contemporary black social death. I will attempt to clarify how this tendency functions by interlinking national exceptionalist discourse with the repetitive logics of debates (Habel, 2012a).

In recent years, exceptionalist discourses in Europe have grown fangs, or in other words have turned increasingly aggressive - while claiming purity, virtue, peacefulness, and innocence. In her book White Innocence (2016: 18), Gloria Wekker argues that Dutch cultural and political discourse on white non-racialised innocence is exceedingly strong. Exemplifying the aggressive 'ignorance' with which innocence is defended, she writes: 'The behaviour and the speech acts of his [Zwarte Piet's] defenders do not speak of innocence but rather of "an ignorance, militant, aggressive - not ... confined to the illiterate and uneducated but propagated at the highest levels of the land ... presenting itself unblushingly as knowledge".

I want to make a specific point of returning to the crude cultural situation within which discussions around Little Pink and its contextual framework in 2012 had to take place. Some of the most disturbing white supremacist positioning strategies that remained widely unacknowledged in the debates entailed giving leeway to increasingly predictable arguments, put forward by white debaters in defence of embracing and accepting black racist stereotypes as harmless. The argumentative logic expressed around Little Pink can be summarised in typified statements such as: 'But this is censorship! You are impending free speech! You are making yourselves enemies of democracy through this line of argument', or 'You are being ridiculously oversensitive! This is just harmless fun for kids!' Only marginal variations were allowed in these discussions, if at all.

A whole range of contradictory impulses where produced by the debate on Little Pink. Significantly, white debaters resorted to a bandying about with agency, as if they had been reduced to helpless victimhood. In his text on white rage, Sabuni (2012) called out Erik Helmerson for falsely accusing the National Afro-Swedish Organization for being violent and loud-mouthed, when in fact they had only responded to questions posed to them by public service media. Polite, pointing out the apparent gatekeeping and nepotism involved in the position of Dagens Nyheter's cultural section, added: "[Wiman] writes that the debate climate has made "an artist withdraw 
part of her authorship in despair". A courageous artist has been silenced by the PC-mob. Criticism against racist stereotypes in children's culture is to be compared with the fatwa against Rushdie' (2012c).

Little Pink's maker Wirsén described herself as having been forced, through pitiless attacks from us critics, to stop drawing the pickaninny figure Little Heart (when in fact, she did not). In her retrospective interview, she likened us to all-powerful tyrants (Jofs, 2013), even if she, for almost a year, had made no attempts listening to us or interacting with us. In August 2012, I and a group of academics offered to arrange a meeting with her and Folkets Bio. She did not respond (Habel, 2012d). In October, the African film festival in Stockholm CinemAfrica, where I had just been made a board member, tried again, but Folkets Bio and Wirsén remained unresponsive. At every turn, white rage and tears were followed by lies, demonisation of black people, and a refusal to engage in further dialogue.

Since Sweden has lagged behind many other countries in getting to grips with its colonial past, significantly by repeatedly silencing any serious public discussion about our colonial history (Habel, 2012a), 'we' had a lot of catching up to do. Yet, in accordance with so many other Western contexts, black people in Sweden as much as elsewhere are expected to provide the emotional and educational labour of informing white people about the meaning and consequences of anti-black racism, in ways that are palatable to white people. As much as this is an impossible task, we are not let off the hook. On the one hand, we are required to speak from what can be called the non-place of black social death (Patterson, 1982; Sharpe, 2016); on the other, we are not allowed to describe the ways in which dehumanisation endangers us.

A return to a comparison with the Dutch context is instructive. In his article 'Finding a way out of the polder' (2015), Egbert Alejandro Martina points to a specifically dangerous aspect of white fragility revolving around Eurocentric, idealised images of democracy - especially when they are elucidated in relation to anti-black racism. He points to the many ways in which his own intellectual and activist work has come to be regarded as 'too political,' 'too radical. 'What does it meant to be "too political"?' he asks, pointing to unmarked expectations that anti-racist struggles should be kept within, not exceeding the limits of the politically 'reasonable', i.e. a given consensus around an imagined, race-less common good. He writes: 'My demand is, by its very nature, in a relation of excess vis-à-vis the political, and, therefore, unreasonable both in terms of meaningfulness and practicality. To fundamentally question the legitimacy of established ways is seen as not only an assault on "freedom" and "democracy", but also a subversive act against the nation itself" (2015:3). 
Thus, acting and writing in resistance to anti-black racism is framed as an impossible standpoint, at odds with legality and eligibility for personhood (Martina, 2015: 3; Weheliye, 2014: 77). Martina's politically acute observation can fruitfully be juxtaposed with the Little Pink debates to elucidate the various ways in which the arenas of anti-racist struggle in general and those of anti-racist cultural media criticism in particular become conflated. First, the massive, annihilating burden of compromise put on black anti-racists becomes instrumental in paralysing their radius of action through compulsory adherence to the alleged due process, as described above. Second, the punishments dealt out to black people for articulating protest also took on similar forms: de-legitimisation, silencing, bereavement, and expulsion.

Having had my share of both being subjected and bearing witness to the accelerating normalisation of anti-black racism, I no longer see a valid reason to presume that there is a clear distinction between battles over cultural images or battles for black survival - they are inextricably intertwined. From a strict film and media studies position, I would not have made such a claim before 2011. But since then, black people have been bruised-by-wayof-media debate in ways clearly pointing to the close connection between culturally and socially dehumanising practices, involving black people, particularly women, being treated as working mules and/or objects for the benefit of non-black people's enjoyment. As Katherine McKittrick states, black people are returned to the 'nowhere of black life' that came with the colonial invention of our shared 'non-personhood' (McKittrick, 2017: 99) in a new world in which we do not exist (Wilderson, 2016).

In the article 'The machinery of dehumanization' (2014), Egbert Alejandro Martina critiques the logic according to which state sanctioned anti-racist agencies address the problem of racism in the Netherlands through what he calls 'itemization' of racism into racist 'events', 'actions', and incidents. He writes: 'The purpose of neoliberal (state-sanctioned) "anti-racist" politics is, thus, not to bring about the end of an anti-black world, but to redirect anticolonial struggles into safe business models, such as anti-discrimination agency, which, in a larger sense, manage, redirect, and defuse black rage. These agencies give us a false sense of hope' (Martina, 2014). Martina elucidates how the stubborn refusal of reciprocity and accountability gets black people bruised, manhandled, and killed, socially and literally. Social or factual death is imminent in his writing:

As black and non-black people of colour we need to think about how we understand antiracism. By which I mean, we need to reckon with the 'biopolitics of antiracism', the ways through which some black lives are marginally fostered and supported, while other black lives are made vulnerable, difficult or impeded to the point of death. The devastating irony is, as Saidiya Hartman notes in 'Fugitive Dreams', that black people in Western societies are 
less vulnerable because we are 'safely situated within the enclosure of empire and foreign capital, which is the very same force making the lives of Africans vulnerable and disposable'. The semblance of humanity (of black folks in the West) is brought about and maintained through accumulated structural adjustments; the ongoing paternalistic colonial project of fashioning Black people into human beings deserving of rights. (Martina, 2014)

Philomena Essed's coinage of the term 'entitlement racism' reminds us yet again of how forcefully whiteness is linked to rights (Essed and Hoving, 2014). Entitlement racism, she argues, entails the growth of shamelessly articulate attacks on black people and other marginalised groups. Saying what one wants about already vulnerable, suppressed groups has increasingly come to be seen by European white majorities as a part of their freedom of speech. An understanding of entitled humanity as whiteness - the stable, possessive individual (Cherniavsky, 2006) - is contrasted to the lingering, unspoken constitution of black bodies as property. Hortense Spillers calls this relation 'being for the captor' (2003: 206). In her article 'Toward a black feminist poetics', Denise Ferreira da Silva writes: 'From without the World as we know it, where the Category of blackness exists in/as thought - always already a referent of commodity, an object, and the other, as fact beyond evidence' (2015: 81).

What became very clear to me was that as an Afropean within the academy I had, up to this point, been positioned as a human-aspiring object that Martina describes above, paternalistically cued into a being 'deserving of rights.' The case of Little Pink and its almost year-long framework firmly reinstated me as an object - and, ironically, it was enabled by the negotiated agency and voice I had been invited to express in the debate. In my encounter with white adversaries, I was constantly reminded that I was not a dialogue partner, but 'an object in the midst of other objects' (Fanon, in Ferreira da Silva, 2015: 87).

\section{FEELING GOOD ABOUT WHITE FEMININITY}

Frequently, the emotional labour of black people - particularly black women - is expected and, yes, demanded; but it can be just as quickly cast aside when it offends the white entitled sensibilities we criticise. During the Little Pink debate and those following it, I both witnessed and became subjected to the stubbornness with which white debaters would uphold their bad faith and pursue me on my Facebook account for the sake of argument - something which sooner or later transformed into open harassment and stalking. Of course, these online incidents were not unique: in recent years, black women on Twitter have similarly pointed to the many ways in 
which white people search them out with the explicit purpose to harass them through thinly veiled 'disagreement', and then stalk them for days or weeks to inflict even more harm (see the anonymous blogger and artist Trudy in the blog Gradient Lair, or on Twitter, @TheTrudz; also see Macias, 2015: 99). As Trudy argues, the very presence of black women's influential voices online is seen as a provocation by many whites. They are 'hurt' by black expertise, intellectual interaction, and creativity (Trudy, 2014a; 2014b).

In her essay 'White fragility', Robin DiAngelo elucidates how white affective registers play out when white people are confronted with the realities of racism. Being made to feel uncomfortable over racism is equalled to being endangered and/or bruised by the critique articulated by black people and people of colour. The word 'fragility' implies, as DiAngelo argues, that whites may indeed feel disempowered and weak in these contexts (2011: 56). However, even if I have not yet seen published research on the term, on more than one occasion I have witnessed black scholars and free intellectuals (whose names I cannot reveal) in online discussions beginning to question whether we can talk of these reactions of refusal, denial, and anger as 'fragility'. This is because the performative behaviour of 'fragility' crying, being silent, withdrawing, or even leaving - leads white people to feeling victimised and then retaliating with violence and/or abusive behaviour: stalking, shouting at, punishing black people. Accordingly, in these situations they wage the full power of white supremacy.

As implied, the debates surrounding the particular example of Little Pink appeared to feed off and become mobilised by each other. Most importantly, and as I will try to exemplify here, white fragility in these interactions wielded imagined vulnerability as a tool, or, if you will, a form of affective currency. As Judith Butler writes: 'Vulnerability takes on another meaning at the moment it is recognized, and recognition wields the power to reconstitute vulnerability' (2004/2006: 43).

In the context of Little Pink, white people hearing about the vulnerability of racialised others, and black people in particular, entailed that white people themselves felt vulnerable to blame, as well as shame through being faced with the unavoidable significance of global anti-black history. Even if this was certainly not the first or only time that I analysed white Swedish bafflement over critiques of anti-black stereotypes (Habel, 2008), I now drew comments of shock and surprise, simply by drawing attention to the passivity and lack of reflection (Habel in Mohktari, 2012) involved in what I called white separatist processes of decision-making (Habel, 2012d). A recurrent impression from the already mentioned debaters defending the film was that children's films, and especially those for toddlers, should go unexamined as feel-good experiences placed outside the social and political. How could I ruin their pleasure? 
In her book The Promise of Happiness (2010), Sara Ahmed elucidates how white people mobilise happiness in expansive ways to tone down or silence anti-racist protest and political controversy. She means that the normative, unmarked subject's post-political demand for happiness departs from the premise that if something 'is good', 'it feels good' (2010: 6). Hence, in a social context where happiness, connected to prosperity, becomes a 'selfevident good', the marginalisation of the oppressed is heard/interpreted as something that in itself creates unhappiness and misery (Ahmed, 2010: 13). Describing the particular image of the black feminist killjoy, she writes: 'you can be affectively alien because you affect others in the wrong way: your proximity gets in the way of other people's enjoyment of the right things, functioning as an unwanted reminder of histories that are disturbing, that disturb the atmosphere' (Ahmed, 2010: 67).

The post-political need for happiness in this debate found several outlets, specifically foregrounding white women who took a specific interest in Little Pink and Tintin in the Congo during September 2012. They would claim that if 'old' racist stereotypes were only contextualised and explained properly they would be harmless, and furthermore educating, for children. During the same period, many white women who I encountered in Facebook discussions argued that 'we' - meaning themselves, the parents of white children - should neither censor the narratives offered to children nor change history. Neither should 'we' be over-protective, but instead explain problematic images to them - because that was the honest way to go. Children, too, must meet reality. A Facebook friend of mine mockingly suggested that we should all do that - over a glass of wine, some porn and a cigarette. This satirical take on what can be regarded as harmful to the unmarked category of 'children', and what shouldn't be, became instructive. Black children's safety and wellbeing was repeatedly placed beyond the scope of discussion (Polite, 2012a).

Something that quickly became obvious in these encounters with white, mostly female, debaters was their need to feel good about themselves and their chosen position on the matter. When notions of social vulnerability got into public and semi-public circulation, they were transformed into a form of currency - something to possess - connected to already established relationships between a given or even expanded set of virtues in gendered, sexual, and racialised terms. Hereby, I witnessed white cis-hetero women with nuclear families stepping into the foreground. In various ways, Sarita Srivastava (2006), Beverley Skeggs (2006), and Raka Shome (2011) have elucidated how Victorian white womanhood as being caring, respectable, prudent, virtuous, and selfless lingers in contemporary white gender norms and cultural discourses. In particular, Shome's concept of white femininity as signifying global motherhood becomes useful for describing the 
ways in which the white women debating on Facebook carried themselves in our encounters - promoting themselves as carers and bearers of finer sensibilities and as capable of emotional depths they imagined lacking in black women.

Accordingly, they regarded their stance as inherently good and therefore politically immune. Critiquing them online and calling them out when they engaged in racist and violent behaviour against black women was risky business. In my encounters with their limited repertoire, I was frequently tone-policed and de-legitimised, and observed that what I regarded as a fairly standardised 'white tears' situation was a new experience for them. Their punishment for me, for not accepting the alleged non-ambiguity and purity of good white intentions in Little Heart at face value, was to seek me out via email to force me to continue the 'discussion'. I abstained.

One of the most clear-cut examples of white supremacist response, cloaked as injury, came from Stina Wirsén, who had remained silent for most of the autumn of 2012, but who was invited to give the last word in an interview for the magazine $V I / W E$ in an article called 'The heart that broke' in mid-2013. In it, she argues that she was hunted down by online commentary, a frenzied 'drive', stating: 'One person used their own and other people's children, who were made to stand outside the Cinema Zita with placards on the opening night [in fact, it was in the early afternoon], reading "I'm not a Pickaninny, I'm a person". Afterwards, these images rolled on a homepage' (Jofs, 2013). She then goes on to argue that critics had been cynically lying in wait for an image on which they could pounce. These were lies. Images did not roll, nor did anyone force their children to protest.

During late autumn 2012, feeling exhaustion nearing, I and other black women would take longer and longer breaks from social media in order to avoid constantly having to encounter violence from white women. In order to avoid being poisoned by the onset of never-ending 'misogynoir' - a term later coined by Moya Bailey ${ }^{7}$ - we would call each other, both for the purpose of mutual support, to give each other advice on which kinds of interviews one should avoid as black person, and which white 'anti-racist allies' to stay away from. Most of us were punished by various forms of silencing: deliberate misconstruction of our arguments, stalking, and/or demonisation.

Standing your ground as a black critic - specifically a black woman largely became understood as being divisive, toxic, and even threatening social cohesion. White adversaries could expand the concept of 'debate' at will at any given moment, resorting to the stalking I mentioned. The comments were typical of social media discussions where black women in and by themselves are often constructed as toxic and excessively 'angry' (see 'This tweet called my back,, 2014). On social media, the effects of white 
imagined fragility became multiplied in powerful ways, allowing for black people in general, and black women in particular, to be hunted and 'dragged' on social media through the use of screen-dumped statuses, posts, and mentions. Punishments were frequent, involving demonisation, lies, total disqualification, and character assassination.

The debate exemplified, all in all, in stunning accuracy a similar dynamic which Audre Lorde addresses in her essay 'The uses of anger' (1997) about how black women's anger is deemed toxic and destructive by white people who do not want to face it:

For it is not the anger of black women which is dripping down over this globe like a diseased liquid. It is not my anger that launches rockets, spends over sixty thousand dollars a second on missiles, agents of war and death, pushes opera singers off rooftops, children in cities, stockpiles nerve gas and chemical bombs, sodomizes our daughters and our earth. It is not the anger of black women which corrodes into blind, dehumanizing power, bent upon annihilation of us all unless we meet it with what we have, our power to examine and to redefine the terms upon which we will live and work. (Lorde, 1997: 285)

\section{THE AFTERMATH: THINKING AFRO-PESSIMIST FUTURES}

What took place in the aftermath of the Little Pink debates was an ambivalent and very painfully turbulent process, entailing white dominant voices shutting down the most straightforward and scathing forms of black critique, while at the same time enabling watered-down versions of 'critique' voiced by white commentators. According to this discursive logic, antiracism - institutional as well as non-institutional - quickly became an object of value, but only in the hands of mainly white cultural commentators. After the storm around Little Pink had blown over, an exponentially growing number of white columnists and media personalities felt called upon to organise anti-racist events, and participate in 'debating racism and antiracism, often muting the voices black people in the process. Recurrently, our presence was not required, or for that matter desired. Rather, it was feared as a potential disturbance to conversations on race. For example, around the same time as the Little Pink debates raged in September 2012, a panel on anti-black racist stereotypes was held at the yearly literature fair in Gothenburg - without a single black participant.

Increasingly, after this period of debate, I have observed that keeping the particularity of anti-black racism at bay at all cost has become the prerequisite for making the terms of these debates allegedly acceptable 'to all'. As Egbert Alejandro Martina argues, 'dialogue, compromise and consensusseeking strategies' employed for the alleged sake of democracy and inclusive 
dialogue must thus 'regulate the range of critiques' (Martina, 2015). And during the years following the Little Pink debates, I have noted that to an increasing degree, a whitewashed, neoliberal version of intersectionality (Hill Collins and Bilge, 2016) has become instrumental in barring black people from ever reaching the point when 'we all' can speak about the particularity of anti-black racism and the specificities of the social and real-life threats to which we are exposed. The tug-of-war is tangible, and we are losing ... Additionally, since black people are firmly placed outside the category of the human we cannot possibly act and be understood as subjects. Neither do we get support from other racially oppressed groups; they must necessarily distance themselves from connections to and solidarities with black people in order to advance their own liberation (Ray et al., 2017).

As young black intellectuals and activists became visible in the public debate post-2012 and in the long Little Pink debate, the normalisation of anti-black racism has simultaneously continued to escalate, locally as well as globally; and the direct connection between anti-black stereotypical imagery and anti-black violence has been increasingly visible. Expressions of white fragility and white preferences for how 'we all' should work against anti-black racism 'constructively' have grown proportionately, and continue to hold on in the public imaginary. So, which types of agency are expected of black people in debates (the only dialogue genre to which we are mostly offered to participate)? White normative 'anti-racist' discourse prescribes a passive optimism and 'hope for change' as one of the important 'tools' with which to deal with racism. In effect, white people are being hopeful at our expense.

I see a menacing development that pushes black people to the margins, making us obsolete. Given this state of affairs, I think it is important to return this open time-window to the early stages of the roaring Little Pink debates, when our voices were (at least in some way) heard. A young generation of voices came forward during and after this debating peak, and new constellations of cultural and political resistance were formed, such as 'The Room,' 'Black Coffee, 'The AfroSwedish Academy', and a Swedish 'Dear White People' page on Facebook. Yet, Afro-Swedish cultural workers, intellectuals, activists, and researchers are in dire need of academic and cultural strategies for redacting and re-historicising our cultural-political context in order to visualise the inseparable connectedness between past and present antiblackness, such as was exemplified in the case of the figure of Little Heart.

And what are the lessons to be learned from afro-pessimist thinking, juxtaposed with a discussion about the non-place from which black debaters are required to speak? As Christina Sharpe argues, the non-place of black people must be acknowledged as a starting point, and we need to remain grounded in the insight that the world and its way of imagining the human is anti-black per se. Therefore, history must be redacted through reinscribing 
what has been erased (Sharpe, 2016: 9, 107). And as Denise Ferreira da Silva shows, black feminists need to produce 'other ways of knowing and doing ... without the charge of irrationality, mysticism or idle fantasy' (2015: 90). I would argue that these powerful pieces of advice can lead us to refuse the interpellation to debate our humanity, which has already been denied. Given the dire conditions of possibility for black people in Sweden to engage in cultural dialogue, I have come to argue that we should say 'no', and instead turn to each other to advance our struggle through 'doing and knowing differently' (Ferreira da Silva, 2015).

\section{NOTES}

1 Available at www.youtube.com/watch? ${ }^{=1}{ }_{1}{ }_{9}$ EggiqhmY (accessed 5 March 2018).

2 Staffan Carlsson's group of images are available on Flickr: We are Not Your Motley Crew, www.flickr.com/groups/2130269@N22/ (accessed 5 March 2018).

3 Oivvio Polite, NotYourMotleyCrew.com, partly accessible through Wayback Machine: https://web.archive.org/web/20121016195603/http://notyourmotleycrew. com (accessed 4 March 2018).

4. Since then, the review has been put back online, but as a version in which the critique has been toned down slightly. See www.svt.se/kultur/musik/skulle-aldrigfalla-mig-in-att-betygsatta-den-har-filmen-1 (accessed 6 March 2018).

5 Oivvio Polite, NotYourMotleyCrew - the Debate: http://notyourmotleycrew. com/thedebate (accessed 3 March 2018).

6 For several overviews and summaries of existing research see Habel 2012a; 2012b; 2015.

7 The term 'misogynoir' was coined later, and is explained by the anonymous intellectual blogger Trudy on Gradient Lair (2014a). The larger part of Trudy's blog has been closed down as a result of widespread plagiarising, which she talks about here: www.gradientlair.com.

8 The name paraphrases the seminal and women of colour feminist book edited by Cherrie Moraga and Gloria Anzaldúa, This Bridge Called My Back (1982).

\section{REFERENCES}

Abdullahi, M. (2015). 'I sysselsättningspolitikens namn', Ord \& Bild, 1-2, pp. 42-8.

Ahmed, S. (2010). The Promise of Happiness. Durham, NC and London: Duke University Press.

Balibar, E. and I. Wallerstein (1991). Race, Nation, Class: Ambiguous Identities. London: Verso.

Bonilla-Silva, E. (2006). Racism Without Racists: Color-blind Racism and the Persistence of Racial Inequality in the United States. Boulder, New York, Toronto and Oxford: Rowman \& Littlefield.

Butler, J. (2004/2006). Precarious Lives: The Powers of Mourning and Violence. London: Verso. 
Cátia Suzana, E. (2015). 'Diagnos: Intersektionell nedtryckhet', Ord E Bild, 1-2, pp. $49-64$.

Chariandy, D. (2015). 'Black Canadian literature: Fieldwork and "post-race"', in C. Sugars (ed.), The Oxford Handbook on Canadian Literature. Toronto: Oxford University Press, pp. 539-63.

Cherniavsky, E. (2006). Incorporations: Race, Nation, and the Body Politics of Capital. Minneapolis: University of Minnesota Press.

Daun, Å. (1996). Swedish Mentality. University Park: Pennsylvania State University Press.

DiAngelo, R. (2011). 'White fragility', International Journal of Critical Pedagogy, 3:3, pp. 54-70.

Eriksson, K. (2012). 'Liten Skär och all Små Brokiga: svårt som vuxen att inte reagera', Svenska Dagbladet (21 September), www.svd.se/svart-som-vuxen-att-intereagera (accessed 6 March 2018).

Espinoza, I. (2012). 'Skulle aldrig falla mig in att betygsätta den här filmen', SVT Nyheter (22 September), www.svt.se/kultur/musik/skulle-aldrig-falla-mig-inatt-betygsatta-den-har-filmen-1 (accessed 5 March 2018).

Essed, P. and I. Hoving (eds) (2014). Dutch Racism. Amsterdam: Rodopi B.V.

Ferreira da Silva, D. (2015). 'Toward a Black feminist poetics', The Black Scholar, 44:2, pp. 91-7.

Grelsson, E. (2012).Vi vita samtalar gärna om rasism', Göteborsposten (17 September), www.gp.se/kulturnoje/1.1067046-elin-grelsson-almestad-vi-vita-samtalargarna-om-rasism (accessed 6 March 2018).

Habel, Y. (2008). 'Whiteness Swedish style', Slut/ The Intersectional Cultural Journal The End, pp. 41-51.

Habel, Y. (2012a). 'Challenging Swedish exceptionalism? Teaching while black', in K. Freeman and E. Johnson (eds), Education in the Black Diaspora: Perspectives, Challenges and Prospects. London: Routledge, pp. 99-122.

Habel, Y. (2012b). 'Rörelser och schatteringar inom kritiska vithetsstudier', in Helena Hörnfeldt, Tobias Hübinette and René Rosales Leon (eds), Om ras och vithet $i$ det samtida Sverige. Stockholm: Mångkulturellt Centrum, pp. 45-82.

Habel, Y (2012c). 'Den svenska vithetens blinda fläck', Svenska Dagbladet (20 September), www.svd.se/den-svenska-vithetens-blinda-flack (accessed 6 March 2018).

Habel, Y. (2012d). 'Vita "antirasister" måste försöka se mer än sig själva', SVT Debatt/ SVT Opinion (12 September), www.svt.se/opinion/vita-antirasister-masteforsoka-se-mer-an-sig-sjalva (accessed 6 March 2018).

Habel, Y. (ed.) (2015). Ord E Bild: Svensk symfoni i svart, 1-2, pp. 4-13.

Habel, Y. and M. Kanyama (2014). 'Att tala till oss själva', MANA, 2-3, pp. 32-5, http:// tidskriftenmana.se/wp-content/uploads/2014_2-3.pdf (accessed 1 March 2018).

Habel, Y. and L. Sawyer (eds) (2014). 'Refracting African and Black diaspora through the Nordic region', special edition of African and Black Diaspora: An International Journal, 7:1.

Hage, G. (1998). White Nation: Fantasies of White Supremacy in a Multicultural Society. New York: Routledge.

Hartman, S. (2008). Lose Your Mother: A Journey Along The Atlantic Slave Trade. New York: Farrar, Straus and Giroux. 
Hassen Khemiri, J. (2011). ' 47 anledningar till att jag grät när jag såg Ruben Östlunds film Play', Dagens Nyheter (18 November), www.dn.se/kultur-noje/film-tv /47anledningar-till-att (accessed 4 March 2018).

Hill Collins, P. and B. Bilge (2016). Intersectionality: Key Concepts. Cambridge: Polity. hooks, b. (1989). Talking Back: Thinking Feminist, Thinking Black. Boston, MA: South End Press.

hooks, b. (1992). Black Looks: Race and Representation. Boston: South End Press.

Hudson, P. and A. Kamugisha (2014). 'On Black Canadian thought', CLR James Journal, 20:1-2, pp. 3-20.

Jofs, S. (2013). Interview with Stina Wirsén, 'Hjärtat som brast', Vi, 7, www.vitidningen.se/hjartat-som-brast (accessed 6 March 2018).

Jonsson, S. (2012). 'Svart och vit på lika villkor', Svenska Dagbladet (24 September), www.svd.se/vit-och-svart-pa-lika-villkor (accessed 1 March 2018).

Keskinen, S., S. Tuori, S. Irni and D. Mulinari (2009). Complying with Colonialism: Gender, Race, and Ethnicity in the Northern Region. Aldershot: Ashgate.

Keyune-Backström, V. and L. Sawyer (2015). 'Vita skratt', Ord E Bild, 1-2, pp. 94-106.

Keyune-Backström, V., J. Kiros, C. Astorga Diaz and M. Echevarría Quezada (2015). Rummet. Stockholm: Ordfront Förlag.

Kilomba, G. (2010). Plantation Memories. Munster: UNRAST-Verlag.

Krutmeijer, M. (2012). 'Rasismdebatt om tecknad figur landar på penisnivå, Aftonbladet (13 September), www.aftonbladet.se/kultur/article15431777.ab (accessed 6 March 2018).

Lenas, S. (2012). 'Synd om det leder till mer rädsla', Dagens Nyheter (11 September), www.dn.se/dnbok/dnbok-hem/sverker-lenas-synd-om-det-leder-till-mer-radsla (accessed 6 March 2018).

Linderborg, Å. (2011). 'Provokation utan ansvar', Aftonbladet (24 November), www. aftonbladet.se/kultur/article13979089.ab (accessed 28 February 2018).

Löfvendal, B. (2012). 'Biograf stoppar visning av Stina Wirséns film', Svenska Dagbladet (19 September), www.svd.se/biograf-stoppar-visning-av-stinawirsens-film (accessed 6 March 2018).

Lorde, A. (1997). 'The uses of anger', Women's Studies Quarterly, 25:1-2, pp. $278-85$.

Lundström, J. (2012). 'SVT drar tillbaka recensionen av Wirséns film. Dagens mest omstridda biopremiär är en barn- och kortfilm. När hände det senast?', FLM (21 September), http://flm.nu/2012/o9/svt-drar-tillbaka-recension-av-wirsens-film (accessed 2 September 2018).

Macias, K. (2015). 'Tweeting away our blues: An interpretative phenomenological approach to exploring black women's use of social media to combat misogynoir'. Diss., Nova Southeastern University, http://nsuworks.nova.edu/cgi/viewcontent. cgi? article $=1024 \&$ context=shss_dcar_etd $($ accessed 6 March 2018).

Martina, E. A. (2012). 'The delicious pleasures of racism', Processed Life, https:// processedlives.wordpress.com/2013/10/15/the-delicious-pleasures-of-racism (accessed 6 March 2018).

Martina, E. A. (2014). 'The machinery of dehumanization', Processed Life, https:// processedlives.wordpress.com/2014/06/14/the-machinery-of-dehumanization (accessed 6 March 2018). 
Martina, E. A. (2015). 'Finding a way out of the polder', Processed Life, https:// processedlives.wordpress.com/2015/09/02/on-facts-proof-and-the-receptionof-black-critique-in-white-dutch-media (accessed 6 March 2018).

McEachrane, M. (2014). Afro-Nordic Landscape: Equality and Race in Northern Europe. New York: Routledge.

McEachrane, M. and L. Faye (2001). Sverige och de Andra: Postkoloniala perspektiv. Stockholm: Natur och Kultur.

McKittrick, K. (2017). 'Commentary: Worn out'. Southeastern Geographer, 57:1, pp. 96-10o.

Miller, M. (2017). 'Figuring blackness in a place without race: Sweden, recently', ELH, 84:2, pp. 377-97.

Mohktari, A. (2012). 'Barnfilm väcker rasismdebatt', Sveriges Radio, $P_{3}$ (7 September), http://sverigesradio.se/sida/artikel.aspx? programid=1646\&artikel=5262162 (accessed 6 March 2018).

Moraga, C. and G. E. Anzaldúa (1982) This Bridge Called My Back: Writings by Radical Women of Color. New York: Kitchen Table.

Ndow-Norrby, F. (2015). Svart Kvinna. Stockholm: Natur och Kultur.

Neergard, A. and D. Mulinari (2017). 'Theorising racism: Exploring the Swedish racial regime', Nordic Journal of Migration Research, 7:2, pp. 88-96.

Patterson, O. (1982). Slavery and Social Death: A Comparative Study. Cambridge, MA: Harvard University Press.

Polite, O. (2007). White like Me: Utvalda texter om rasism 1992-2007. Stockholm: Danger Bay Press.

Polite, O. (2012a). 'Se till mig som liten är', Expressen (26 September), www.expressen. se/kultur/se-till-mig-som-liten-ar (accessed 3 March 2018).

Polite, O. (2012b). 'Brokiga är business', Expressen (26 October), www.expressen.se/ kultur/brokiga-ar-business (accessed 6 March 2018).

Polite, O. (2012c). 'Nepotism i hjärtefrågan', Expressen (27 November), www. expressen.se/kultur/nepotism-i-hjartefragan (accessed 6 March 2018).

Ray, V. E., A. Randolph, M. Underhill and D. Luke (2017). 'Critical race theory, Afropessimism, and racial progress narratives', Sociology of Race and Ethnicity, 3:1, pp. $1-12$.

Rubin-Dranger, J. (2012a). 'Vem är rädd?', Svenska Dagbladet (23 September), www. svd.se/en-bild-kan-vara-rasistisk-utan-avsikt (accessed 2 September 2018).

Rubin-Dranger, J. (2012b). 'Den rasistiska ikonens logik', Expressen (3o October), www.expressen.se/kultur/den-rasistiska-ikonens-logik (accessed 6 March 2018).

Sabuni, K. (2012). 'Vit vrede tystar diskussionen om Tintin-albumens rasism', SVT Nyheter (25 September), www.svt.se/opinion/vit-vrede-tystar-diskussionen-omtintinalbumens-rasism (accessed 6 March 2018).

Sabuni, K. (2015). 'Vit mission', Ord E Bild, 1-2, pp. 107-9.

Sawyer, L. (2000). 'Black and Swedish: The cultural politics of belonging. Diss., Michigan, UMI Dissertation.

Schough, K. (2008). Hyperboré: Föreställningar om Sveriges plats $i$ världen. Stockholm: Carlsson förlag.

Sharpe, C. (2016). In The Wake: On Blackness and Being. Durham, NC and London: Duke University Press. 
Shome, R. (2011). 'Global motherhood: The transnational intimacies of white femininity', Critical Studies in Media Communication, 28:5, pp. 388-406.

Skeggs, B. (2006). Formations of Class and Gender: Becoming Respectable. London: Sage.

Spillers, H. (2003). Black, White, and in Color: Essays on American Literature and Culture. Chicago: Chicago University Press.

Srivastava, S. (2006). 'Tears, fears and careers: Anti-racism and emotion in social movement organizations', The Canadian Journal of Sociology, 31:8, pp. 55-90.

Stark, U. (2012). 'Med Lilla Hjärtat på rätta stället', Dagens Nyheter (13 September), www.dn.se/kultur-noje/debatt-essa/med-lilla-hjartat-pa-ratta-stallet (accessed 6 March 2018).

Susso, E. (2012). 'Enögda och bleka', Expressen (17 September), www.expressen.se/ kultur/enogda-och-bleka (accessed 6 March 2018).

Thente, J. (2012). 'Måste vi forska fram rasismen för att hålla den aktuell?', Dagens Nyheter (10 September), www.dn.se/blogg/bokbloggen/2012/o9/10/maste-viforska-fram-rasismen-for-att-halla-den-aktuell (accessed 5 March 2018).

'This tweet called my back' (2014). Model View Culture (13 December), https:// modelviewculture.com/pieces/thistweetcalledmyback (accessed 3 March 2018).

Trudy (2014a). 'Explanation of misogynoir', Gradient Lair, www.gradientlair.com/ post/84107309247/define-misogynoir-anti-black-misogyny-moya-bailey-coined (accessed 1 March 2018).

Trudy (2014b). 'Misogynoir and the concerted effort to deny black women joy', Gradient Lair, www.gradientlair.com/post/101749673923/misogynoir-denyblack-women-joy (accessed 6 March 2018).

Weheliye, A. (2014). Habeas Viscus: Racializing Assemblages, Biopolitics, and Black Feminist Theories of the Human. Durham, NC: Duke University Press.

Wekker, G. (2016). WhiteInnocence. Durham, NCand London: Duke University Press.

Wilderson III, F. B. (2016). 'Afro-pessimism and the end of redemption', Humanities Futures. https://humanitiesfutures.org/papers/afro-pessimism-end-redemption (accessed 5 March 2018).

Wiman, B. (2011). 'Redan för 59 år sedan utspelade sig "Play" på Kornhamnstorg i Stockholm', Dagens Nyheter (4 December), www.dn.se/arkiv/kultur/bjornwiman-redan-for-50-ar-sedan-utspelade-sig-play-pa-kornhamnstorg-istockholm (accessed 1 March 2018).

Wiman, B. (2012). 'Vad blir det kvar av konsten om allt socker tas ur saften?', Dagens Nyheter (30 September), www.dn.se/kultur-noje/kronikor/bjorn-wiman-vad-blirdet-kvar-av-konsten-om-allt-socker-tas-bort-ur-saften (accessed 6 March 2018).

Wirsén, S. (2012). 'Mina kritiker har begränsad utblick', Dagens Nyheter (21 October), www.dn.se/kultur-noje/kulturdebatt/mina-kritiker-har-begransad-utblick (accessed 2 September 2018).

Wynter, S. (1994). 'No humans involved: An open letter to my colleges', Forum N. H. I: Knowledge for the 21st Century: Knowledge on Trial, 1:1, pp. 42-103. 


\title{
6 \\ VISIBILITY AND \\ VULNERABILITY \\ Translatina world-making in The Salt Mines and Wildness
}

\author{
LAURA HORAK
}

$\mathrm{M}$ idway through the documentary film Wildness (US, Wu Tsang, 2012), we see a montage of glowing night-time Los Angeles streets and a laughing and posing translatina woman. Over a pulsing beat, the husky, feminine voice of the Silver Platter, a half-century-old Latinx gay bar, testifies (in Spanish):

My ladies are strong ... But we all have our limits. Not only do they live in fear of being deported, they also have to deal with abuse from their families, their boyfriends, and strangers. Going to the police is not an option when you are afraid they will hurt you or deport you. If you are in the streets you risk being a target.

This scene condenses the key themes of this chapter: the structural forces that produce trans women of colour as vulnerable, how some trans activists have organised a political movement that centres the experiences and leadership of the most vulnerable, and how filmmaking can contribute to this project. What happens when we bring together a trans social justice politics attuned to the unequal distribution of vulnerability with a consideration of the ambivalences of transgender representation? How can documentary filmmakers encounter marginalised people ethically and help share strategies for survival, kinship, and world-making in the face of vulnerability? I will explore these questions using two documentaries about translatina world-making: The Salt Mines (US, Susana Aikin and Carlos Aparicio, 1990) and Wildness (US, Wu Tsang, 2012).

The Salt Mines, made on low-resolution video by cisgender SpanishAmerican documentary filmmakers Susana Aikin and Carlos Aparicio, 
portrays a group of homeless Latinx immigrants in New York City, many of whom present as transfeminine, who live in abandoned garbage trucks beside the building where the New York City Sanitation Department stores road salt, which they call the 'Salt Mines'. Wildness, a richly saturated and dreamy digital film created twenty-two years later by trans Chinese-American multimedia artist Wu Tsang, tells the story of Tsang's relationship with the Silver Platter, a Latinx bar in Los Angeles, and the many translatina women who go there. The films show how translatina women are building new forms of relation within conditions of vulnerability and imaginatively invite viewers into these worlds.

\section{TRANSGENDER VULNERABILITY}

As trans legal scholar and activist Dean Spade has written, the United States 'has always had laws that arrange people through categories of indigeneity, race, gender, ability, and national origin to produce populations with different levels of vulnerability to economic exploitation, violence, and poverty' (2015: 2). The police and legal system, together with racial capitalism, make trans and gender-nonconforming people who are of colour, poor, immigrants, and/or sex workers particularly vulnerable to violence, murder, incarceration, and deportation. Alongside black and indigenous trans women, translatina women are particularly vulnerable. ${ }^{1}$ A 2011 report conducted by the National Center for Trans Equality indicated that 'Latino/a Trans people often live in extreme poverty with $25 \%$ reporting a household income of less than $\$ 10,000 / y e a r$, which is 'nearly double the rate for Trans people of all races', 'five times the general Latino/a community rate', and 'seven times the general U.S. community rate' (as cited in The TransLatin@ Coalition et al., 2013: 3). In a 2013 national survey of translatina immigrants, 61 per cent reported being victims of sexual abuse, 78 per cent had experienced 'verbal insults and/or physical aggression for being a Trans Latina Immigrant', and 69 per cent had 'met another Trans Latina who was murdered because of her gender identity' (The TransLatin@ Coalition et al., 2013: 29). In these conditions of extreme precarity, surviving becomes a crucial political act. Translatina women cultivate survival through strategies of collective care, kinship, and world-making.

Following the insights of the Combahee River Collective, which argued that, 'If Black women were free, it would mean that everyone else would have to be free since our freedom would necessitate the destruction of all the systems of oppression' (1986), trans activists have argued that the most vulnerable trans people should be at the heart of trans politics and activism (Spade, 2015: 19). This political attention to vulnerability (e.g. to the structures that produce it, the people who are most impacted by it, what it feels like, and how people survive in the face of it) builds on a queer and 
transnational women of colour feminist tradition of interrogating 'vulnerability as a lived experience and diagnostic tool to point to asymmetrical distributions of power and violence', articulated by Cherríe Moraga, Gloria Anzaldúa, bell hooks, Chandra Mohanty, and others (Oliviero, 2016: 6).

Indeed, since the 20oos, trans people of colour who are poor, immigrants, sex workers, and/or formerly incarcerated have founded and led many grassroots trans organisations, campaigns, and actions, such as the TransLatin@ Coalition in Los Angeles, El/La Para TransLatinas and the TGI Justice Project in San Francisco, the Translatina Network and FIERCE in New York, Butterflies Trans Foundation in Puerto Rico, and the national Trans Women of Color Collective. The concept of vulnerability has become central to trans activism, in terms of both the political work of trans survival in the face of structurally enforced vulnerability and political organising that centres the experiences and leadership of the most vulnerable people.

\section{THE VICISSITUDES OF TRANS VISIBILITY}

One key tool of trans imagination, kinship, and world-making is audiovisual media. But where trans media 'visibility' is often hailed as an unalloyed good, it can also contribute to the vulnerability of trans women of colour. Trans filmmaker Sam Feder and the editors of a recent anthology on trans cultural production point out that the so-called 'transgender tipping point' (coined by a Time magazine cover story featuring black trans actor Laverne Cox [Steinmetz, 2014]) coincided with a marked increase in violence against and murders of trans women of colour (Feder and Juhasz, 2016; Gossett et al., 2017). Black trans activist Miss Major Griffin-Gracy argues that trans sex workers bear the brunt of this backlash because they are accessible and the legal and political system has already deemed them disposable. She observes that:

People all around the world were amazed by Laverne's cover story. However, for the girls who have to live on the streets and off their wits, this was not something that was beneficial to their existence. What I have noticed, since that happened, is that there are more girls being murdered or beaten up because the people who want to do these harmful things can't get to Laverne Cox. (Griffin-Gracy et al., 2017: 26)

Increased visibility has also sparked political backlashes in the form of bathroom bills, religious freedom laws, and religious proclamations (Allen, 2018; Tang, 2017: 364-5; United States Conference of Catholic Bishops, 2017).

Well-intended representations can also exploit their subjects, as critics of ethnographic documentaries and other representations of marginalised 
people have long pointed out (Rony, 1996; Spivak, 1988; Winston, 1988). Trans studies scholar Aren Aizura has criticised the spectacularisation and instrumentalisation of trans of colour suffering by LGBT non-profits in activist videos like Transgression (2011), created by Immigration Equality. Aizura cautions that LGBT non-profits place a 'symbolic burden' on trans women of colour 'to represent consistently as victims' (2016: 133). Aizura writes: 'Vulnerability becomes a method to extract value [from trans women of color] in the form of spectatorial sympathy' (2016:124). The films put these women's suffering on display but refuse to consider them as historical agents or experts in anything beyond their own personal experience. These audiovisual media strategies are part of the broader 'extraction of value from trans of color lives through biopolitical and necropolitics technologies' that trans scholars C. Riley Snorton and Jin Haritaworn have described (2013: 71).

The unequal distribution of economic resources and social capital have long put creative control of trans stories in the hands of white, middleclass, cisgender creators, which often results in 'aesthetically gentrified' representations directed at cisgender audiences (Keegan, 2016; Namaste, 2005). Black trans filmmaker Reina Gossett recently revealed that David Francis, an established white gay filmmaker, had stolen material and opportunities from her when they were both working on documentaries about black trans activist Marsha P. Johnson (Gossett, 2017).

But trans media need not be solely about 'visibility' as such (that is, about simply asserting trans people's existence and humanity); it can also be a form of collective world-making and radical imagination. Queer of colour scholar José Esteban Muñoz has described art as a crucial mode of queer world-making (2009). He writes:

Queerness is that thing that lets us feel that this world is not enough, that indeed something is missing. Often we can glimpse the worlds proposed and promised by queerness in the realm of the aesthetic. The aesthetic, especially the queer aesthetic, frequently contains blueprints and schemata of a forward-dawning futurity. (Muñoz, 2009: 1)

Similarly, queer black artist Kai Lumumba Barrow states, 'In imaginative space we have the freedom to create new worlds, counter-narratives, and new mythologies where daily realities are transformed, appropriated, subverted, destroyed, and refashioned' (Barrow et al., 2017: 335). The potential of audio-visual media to create new worlds is most clearly present when trans people themselves become media makers. However, I also want to hold out the possibility that films made through genuine collaboration between cis and trans people can contribute to this process. In this chapter, I argue that documentary films can be an essential way to present the survival and world-making strategies of marginalised trans people and 
to invite viewers into these worlds and networks of care. Documentary films that engage ethically with marginalised trans subjects can help us imagine, as Muñoz urges, 'new and better pleasures, other ways of being in the world, and ultimately new worlds' (2009: 1).

Despite the ambivalence of trans representation in general, The Salt Mines (1990) and Wildness (2012) demonstrate the potential for documentary films to stage largely respectful encounters with marginalised trans subjects and the worlds they have created, and to extend these words to new times and places. They are part of a small wave of translatina documentaries released over the past three decades. Several realist, talkinghead style documentaries focus on translatina women's political organising across the Americas, including Translatina (Peru, Felipe Degregori, 2010), TransVisible: Bamby Salcedo's Story (US, Dante Alencastre, 2013), and Mala Mala (Puerto Rico/US, Antonio Santini and Dan Sickles, 2014). Mala Mala also explores the world of trans and queer performance, as do Paris is Burning (US, Jennie Livingston, 1990), How Do I Look? (US, Wolfgang Busch, 2006), I am the Queen (US, Henrique Cirre-Lima and Josue Pellot, 2010), and Kiki (US/Sweden, Sara Jordenö, 2016). In contrast to films about political organisers and performers, The Transformation (US, Susana Aikin and Carlos Aparicio, 1995), a follow-up to The Salt Mines, follows the efforts of Christian missionaries to convert translatina sex workers, and revisits the protagonists of the previous film. A recent short documentary, Becoming Joanna (US, Jonathan Skirnik, 2016), shows the struggles of a translatina high schooler who is able to take advantage of trans and queer support networks in Los Angeles to get back on the path to graduation. In different ways, all these films present resilient communities of Latinx and black trans and gender-nonconforming people and their varied strategies of survival, organising, kinship, and creative world-making.

Paris is Burning, which has received the widest distribution and most critical attention, put some of the black and Latinx participants in New York's ballroom scene at the centre of scholarly conversations about gender performativity, racialised queer subcultures, and new queer cinema in the 1990s. However, some complained that the film sensationalised the performances as a modern-day freak show or minstrel show, and criticised the realist ethnographic style that absented the film's director, Jennie Livingston, a white lesbian filmmaker, from the diegesis (e.g. hooks, 1996; Reid-Pharr, 1990). In contrast, queer film scholar Lucas Hilderbrand argues that critics of Paris is Burning 'have repeatedly failed to imagine identification, appreciation or coalition in their claims of exoticization, exploitation, and "othering"' (Hilderbrand, 2013: 134). Black queer scholar Marlon Bailey asserts that the film has been important for contemporary house/ball participants (2011: 368). Paris is Burning invites spectators into the dynamic 
world-making practices of marginalised trans and queer people even as it raises ethical questions about the appropriate relationships between the film team, the film's subjects, and its varied audiences. Wu Tsang, the director of Wildness, has stated that she specifically wanted to avoid the ethical missteps of this earlier film (Oishi, 2015: 253, 263).

I use The Salt Mines and Wildness as my case studies because they both stage encounters with marginalised translatina subjects who come together in precarious urban spaces to create new forms of recognition, relation, and community through provisional collectivities, yet they are separated in time by twenty-two years and use very different formal strategies. They are also both excellent films that should be screened and taught more often. These two films can help us better see the possibilities and dangers of the documentary representation of vulnerable trans lives.

\section{ENCOUNTERING PRECARIOUS TRANSLATINA WORLDS IN THE SALT MINES}

José Esteban Muñoz has called The Salt Mines and The Transformation 'antidotes of sorts to the overexposed Paris is Burning' (1999: 162). He writes that the films 'have offered a narration of transgender communities of color in New York City that has resisted the impulse to glamorize the experience in the way that Paris is Burning does. Poverty and disease, for instance, have not been sacrificed in these videos for the sake of spectacle and style.' Released in 1990, the same year as Paris is Burning, The Salt Mines screened on US national public television via the Public Broadcasting Service (PBS). It also made the rounds of gay and lesbian film festivals, Latino film festivals, and, in 1997, played at one of the world's first transgender film festivals, Tranny Fest, in San Francisco. Lately, The Salt Mines and The Transformation have been rediscovered by today's trans activists.

In the film's first scene, Little Man, an energetic homeless Latino man, shows the filmmakers around the Salt Mines and names the people who live there the Salt People. Gigi, Giovanna, and Sara and their friends Little Man, JR, Bobby, Edwin, and Ruby ${ }^{2}$ talk to the filmmakers about their lives and hopes for the future, and make an assessment of the United States. Gigi, with dyed red hair and a leather jacket, is a cynical fast-talker from Puerto Rico, Giovanna a determined Afro-Latina from the Dominican Republic (see figure 6.1), and Sara a charismatic blond from Cuba with a Farrah Fawcett look.

Sara describes immigrating to the United States in the 1980 Mariel boatlift and the experience of being incarcerated in Cuba and the United 


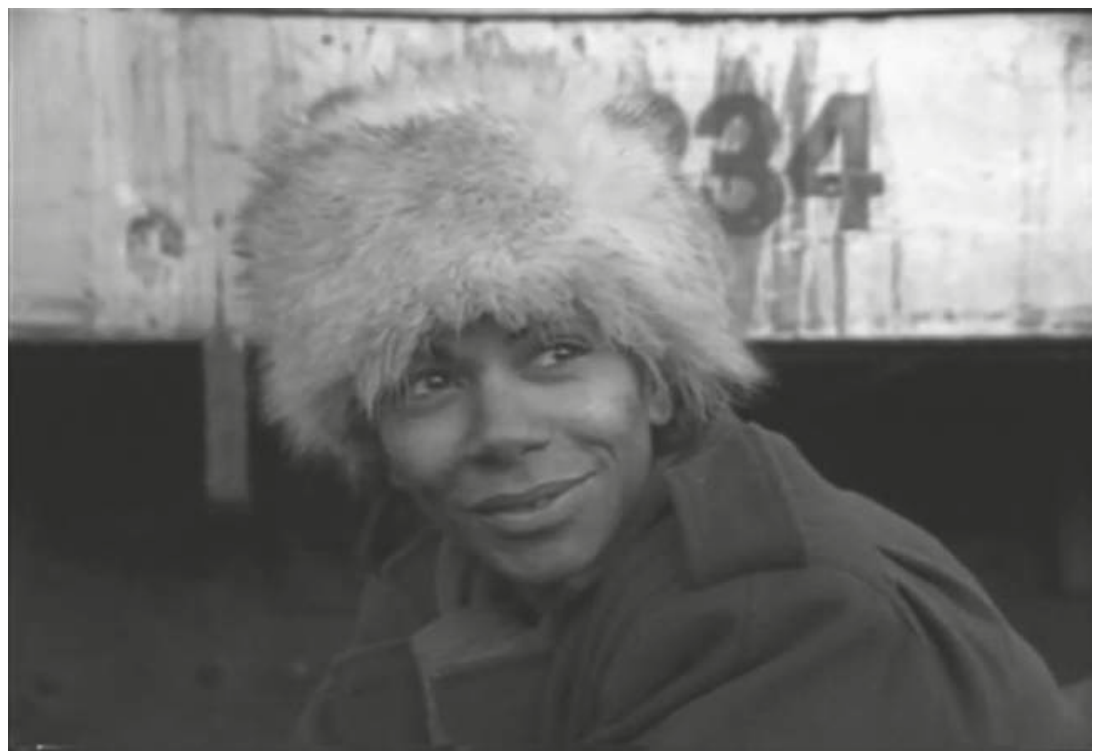

Figure 6.1 Giovanna in The Salt Mines.

States. The filmmakers observe Gigi, Giovanna, and Sara as they chat, cook food, show off new outfits, and argue. All three candidly discuss using crack and doing sex work, and Sara allows the team to film her picking up a trick.

Clearly, Gigi, Giovanna, and Sara are at the intersections of multiple forms of socio-politically generated vulnerability - they are immigrants, poor and homeless, drug users and sex workers, and at least one has been incarcerated. In the Salt Mines, they must work to fulfil their basic needs food, warmth, the ability to bathe. And yet, the point of the film is not the spectacularisation of their suffering, evocations of pity, or incitement of donations in the vein of the film Aizura critiques; rather, the film presents the world these women have created for themselves. Though their lives are hard, they have autonomy and are recognised and valued as their feminine selves. They have friends and lovers and seem to have a good time together. They don't seem troubled by their identities. They are not ashamed or guilty. The film does not romanticise their hard-scrabble lives, but it does attend to the value of what they have created together. Even though The Salt Mines was created by filmmakers who are outside the community they represent, it presents subjects who are living in relation to multiple forms of vulnerability without instrumentalising them.

The Salt Mines adopts a realist ethnographic documentary style. The filmmakers are outsiders to the community and they do not appear onscreen 
(although we do sometimes hear the filmmakers and subjects talking to each other). The film has a rough, lo-fi image and sound quality associated with a handheld video camera and footage shot on the fly. It primarily consists of long takes in which the subjects explain their lives and perspectives to the camera, as well as observational shots of the Salt People hanging out together. There is no voiceover narration and very little non-diegetic sound.

While critics of Paris is Burning have denounced the realist ethnographic documentary style as objectifying and a misguided attempt to obscure the constructed nature of all representation, The Salt Mines demonstrates the power of this form to centre the perspectives of marginalised subjects. It accomplishes this by giving these subjects centre stage in a series of long takes, and minimising music that might cue a simplistic emotional reaction by the audience. Alex Juhasz (1999) has described realist documentaries as an essential feminist tool for sharing the experiences and insights of marginalised subjects.

How does the film manage to represent translatina subjects living with vulnerability without re-victimising them? One key strategy is that the film stays close to its subjects. The long-take interviews give the subjects time and space to express themselves, rather than having their words cut up into soundbites. Aparicio asks the women neutral questions about where they're from, when they arrived at the Salt Mines, and where they sleep, and avoids probing questions about their identity, drug use, or sex work - anything prurient or moralising. With the exception of Aparicio's off-screen inquiries, the only voices we hear are of the Salt People themselves. No outside 'experts' are brought in to explain things. The only experts are the women themselves. There is no attempt to create an objective frame outside the women's testimonies, the type of frame criticised by documentary scholar Dijana Jelača (2016) as a 'humanitarian gaze' that fails to scrutinise its own partiality, positionality, and implication in inequality. Instead, we get a decidedly partial view and are well aware that we only see and hear what the women decide to show and tell us.

Viewers of the film never have the sense that we have transparent access to the Salt People's whole lives or innermost selves, or that we can see more than they do. While the women sometimes get emotional when speaking, they never break down or hold up a hand to shield their face from the camera (which have become almost stock shots in today's emotion-obsessed documentary culture). In other words, we generally stay at a friendly but polite distance from the subjects.

Although we never see Aikin or Aparicio onscreen, we are nonetheless aware of them through Aparicio's occasional questions and the Salt People's gazes towards Aparicio, who is holding the camera. Furthermore, as the filmmakers follow Little Man in the film's opening sequence, he glances back 
towards the camera and observes: 'He looks like a reporter. You look like a cop! I hate cops!' Through this remark, the filmmakers are written into the film as outsiders who are potentially on the side (at least socio-economically) of the authority figures who exploit and police the Salt People. And yet, as the films continues, it becomes clear that the filmmakers, despite their socio-economic position, do not approach the Salt People as police or traditional news reporters.

While there is a tendency to see documentaries as being more honest about their constructed nature and the relations between filmmakers and subjects when we can see the filmmakers on screen, that approach sometimes centers the voice of the filmmaker rather than that of their subjects. Perhaps seeing Aikin and Aparicio would reveal some of the disjunctures between them and their subjects, but we can still get some idea of the feelings of the subjects towards the filmmakers and vice versa. Based on Gigi, Giovanna, and Sara's body language, gestures, and speech, we get the sense that the women view the filmmakers as interested friends with whom they can be relatively candid. ${ }^{3}$

The film's sound also demonstrates respect for its subjects. For one, there is very little music. We mostly hear the subjects' voices and some ambient industrial sound. Music often cues particular emotional responses sadness, pity, hope, etc. - and is a key tool for inciting emotional responses to spectacularised suffering. This film's lack of music de-spectacularises the women's experiences and forces audiences to read the subjects' body language and tone of voice to cue their own emotional responses.

In the short sequences where there is music, usually during shots of the urban landscape, we hear a saxophone and sometimes bongo drums playing Charlie Parker-style melancholy bebop, and occasionally a dissonant Ornette Coleman-inspired screaming sax solo, all composed by New York musician Elliot Sharpe. This jazz music is associated with black metropolitan music culture. It connotes urbanity and world-weariness, and sometimes desperation, but also coolness, resilience, sophistication, and countercultural belonging. While one could critique the score as being a kneejerk convention of representing urban social outsiders, appropriating black cultural production to evoke a universalising sense of outsiderness, one could also read the music as making an argument for connecting the translatina women's experiences with the long American history of black oppression and resistance.

The subjects of The Salt Mines do not become political actors in the way the subjects of many later trans documentaries do. They do not form an organisation, protest, or raise money; in fact, they don't seem to think of themselves as part of a 'class' of people. One of the most interesting things about the film is that its subjects do not seem to have a coherent sense of 
'transgender' identity, let alone a sense that this identity is associated with a political movement. One of the film's great strengths is that it portrays this diversity of terms and concepts without trying to homogenise them under a single label or political project. Gigi, Giovanna, and Sara mostly use female pronouns and engage in some forms of body modification - in one scene, they inject black-market hormones, and in another Giovanna points out her breast implants. Yet they use many different words to describe themselves. At one point, Giovanna says 'I consider myself a transvestite' (Yo me considero un transvestista), using a part-English, part-Spanish version of the word 'transvestite' with a male pronoun (un instead of una). ${ }^{4}$ However, elsewhere she refers to herself using feminine nouns (e.g. cuando era pequeñita), and notes that most gay men 'do not like women like me' (la mujer como yo). She points out that even in the gay world (el mundo gay), 'We are the minority, the drag queens and transvestites' (las drag queens, las travestistes), using the English term 'drag queens' and a part-English, part-Spanish word for 'transvestite'.

Gigi, on the other hand, never calls herself a transvestite. She tells us that when she was young, a doctor told her parents that she was 'a woman trapped in the body of a man' (una mujer encerrada en el cuerpo de un hombre). She seems to agree with this assessment, though she never uses a specific term and later describes her relationship with Edwin as a relationship between 'two people of the same sex' (dos personas del mismo sex). When describing the dangers of street sex work, she implicitly calls herself 'a queen' (un queen), using the English word with a masculine pronoun. She refers to other people as homosexual, but never herself. Sara, on the other hand, calls herself un homosexual and later describes herself as una transformista, a word with varying meanings throughout Latin America, from female impersonators to people who transform their bodies through make-up, hormones, and surgery. When they want to be insulting, they call each other maricón (faggot).

The most likely reason for this proliferation of terms is that The Salt Mines was released right before activists began arguing for a coalition of gender-nonconforming people to organise under the banner of 'transgender' in the early 1990s (Stryker, 2017: 153-5; Valentine, 2007). The film thus provides a snapshot of the variety of terms and concepts used before this sea change. Its attentiveness to this linguistic variety also individualises the film's subjects, rather than labelling and classifying them. The film presents the kinship and care cultivated by translatinas for each other in the years before explicitly political organising around trans rights.

While the film does not portray its subjects coming into consciousness or intervening in the political order, they are still political actors. One of their key political acts is to survive in the face of multiple forms of oppression. In the opening sequence, Little Man tells the filmmakers: 'We survived! And 
that is the name of the shit!' His assertion echoes black lesbian poet Audre Lorde's famous reflection that for black women like her, 'self-preservation' is 'an act of political warfare' (2017: 130). Likewise, by keeping each other alive in the face of a system that has thrown them away, the Salt People's survival is a form of political resistance.

Key to their survival is the creation of community - one that is precarious and temporary, but nonetheless crucial. The trans and straight members of the Salt Mines alike have woven networks of care between each other. They recognise each other as they are, without trying to change each other, and offering what they have to each other. These genuine forms of relation are in a stark contrast to Christian missionaries who appear later in the film. The missionaries are quick to offer the Salt People kind greetings, warm clothing, and a hot meal, but only in exchange for the opportunity to convince the women to give up their feminine identity and accept Jesus as their saviour.

Another way the women become political actors is through critiques of American inequality and Christianity. In Spanish, Giovanna says:

This group of Christians, I think, is seeking recognition in their Church. Just imagine, good Samaritans who found a bunch of nomads ... that's us in this Salt Mine, sleeping in trucks in the worst possible conditions and they are going to make us straight and get us into religion ... Shit! What more could they do? That's worth a Nobel Prize each!

Like Aizura, Giovanna points out how this organisation tries to instrumentalise trans of colour suffering to benefit themselves. Giovanna and Sara are also sceptical of the promises of the United States. Sara says (in Spanish): 'I used to think the USA was the most beautiful place in the world where you could have anything you wanted ... But now I'm sorry I came. Because here without money you are nothing.' She is ambivalent about whether her combination of freedom and poverty in the United States is actually better than being imprisoned in Cuba.

The one part of the film that comes across as prurient is a three-minute sequence representing the women's sex work. It is shot from inside a car, thus from the point of view of a potential customer, curious tourist, or vice officer. Grainy and mostly in slow motion, this scene is the film's most stylised. First, we look out of a car window as dark, decaying urban streets go by in slow motion. We hear rhythmic, dissonant, jazz electronica. Then we spot a sex worker in a short dress walking by in grainy slow motion, then more sex workers standing around, then a cut to a woman leaning into a car (Aikin says that this is Sara, although we can't tell by looking). The saxophone goes crazy with a burbling, screaming cry as the camera zooms in on the grainy scene. We stare clandestinely at these fuzzy figures as Sara gets in the car, the car's lights brighten, and the shot freezes then slowly fades to 
black. This sequence is the film's most problematic, with its explicitly voyeuristic structure, identification with a customer's point of view, and sense that it is capturing a secretive and shameful thing. It is very different in tone from the candid daylight chats and observations of the rest of the film.

Perhaps because the film's only spoken words come from its subjects, The Salt Mines never openly considers the effect its production might have on its subjects. However, Aikin later published a book about the film's production in which she thinks through this question. She admits that the increased visibility that came with the film did contribute to its subjects' vulnerability. She recalls: 'There was no doubt in my mind that the closing of the Salt Mines had, if nothing else, been accelerated by our filmmaking' (Aikin, 2013: 137). She also learned that the parents of one of the film's subjects (Ruby) had discovered her HIV positive status from watching the film on television. Aikin berates herself, writing:

I had pushed relentlessly to film every detail of The Salt Mines and interviewed to probe deep into its people's hearts and minds. In my craze, I had been convinced that the world needed to have a close look at this reality to better understand the predicament of its inhabitants. But now I was wondering how all this information was going to benefit anyone at all. (Aikin, 2013: 137-8)

However, after seeing the film's effect on a conservative audience at a Long Island library screening, Aikin concludes that the film did make a positive impact, 'shaking up the comfortable patterns we live in' and 'questioning our prejudices', albeit on audiences assumed to be cisgendered.

The film has evidently impacted translatina activists as well. Recently, New York trans Latinx activist Bianey Garcia wrote that The Salt Mines and The Transformation are two of her favourite films. In a promotion for a screening, she wrote: 'When I saw these documentaries, it broke my heart to see how my trans sisters lived during that time. Nowadays, there are people like me who fight for a better life for our future generations!!' ('The Salt Mines \& The Transformation', 2017). The film has become part of today's trans movement through repeated screenings. It shows both how much the trans community has mobilised since 1990 but also how vulnerabilities are still disproportionally distributed to trans women of colour. While the film may have made its subjects more vulnerable in some ways, by bringing their lives to the notice of family members and the authorities, it also shared the survival and world-making strategies of these translatina women with audiences, including fellow translatina women like Garcia. Through a realist ethnographic approach, it keeps these women at its centre and allows the messiness of their language as well as their lives and community to show through. 


\section{CONFRONTING THE FISSURES IN TRANS WORLD-MAKING PROJECTS IN WILDNESS}

Wildness (2012), created twenty-two years after The Salt Mines, also explores the world-making of vulnerable trans subjects that coalesces around a particular place, but in a very different context and using different formal strategies. Wildness is a feature-length documentary written and directed by trans Chinese-American performance artist and filmmaker Wu Tsang and co-written by queer Persian film programmer Roya Rastigar. Wildness presents Tsang's discovery of the Silver Platter, a forty-nine-yearold Latinx gay bar near MacArthur Park in Los Angeles, and friendships with the translatina women who frequent the bar (see figure 6.2) and with the bar's co-owners and operators, Gonzalo, his sister Nina, his boyfriend Javier, and his ex-boyfriend Koky. Tsang performs a version of herself, 'Wu', which was scripted by Tsang and co-writer Rastigar. ${ }^{5}$ The Silver Platter itself, voiced by Guatemalan-American trans activist Mariana Marroquin, narrates the film. Wu and friends create a popular Tuesday night party called Wildness that combines dancing and performance art. The film explores the divisions between the bar's Spanish-speaking regulars and the predominantly English-speaking Wildness attendees, as well as Wu's attempts to bridge these divisions through friendships, artistic collaborations, and the creation of a legal aid clinic.

Eventually, when the party attracts too much outside attention and Gonzalo's death prompts a messy inheritance fight, Tsang and friends shut

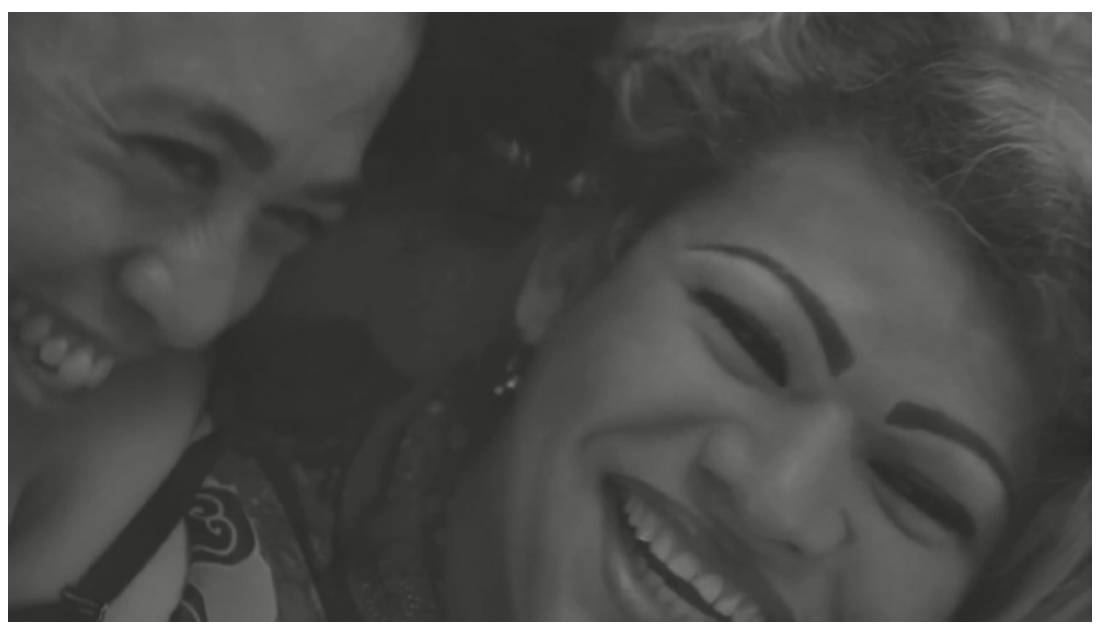

Figure 6.2 Wu and Erika in Wildness. 
the Wildness parties down. Wildness takes up the question of vulnerability head on, explicitly thinking through the effects of the Wildness party on the bar's regulars, who are vulnerable to deportation, incarceration, and violence, as well as the precarity of the bar itself and the entire Latino neighbourhood, which is undergoing 'revitalization'. The film invites the audiences to step into the communities that interlace the Silver Platter, if only temporarily and in fantasy, thus sharing the world-making of the bar's denizens with the cinema audience.

As an artistic, formally-innovative documentary that takes an unflinching look at queer and trans life, Wildness was well-received by art institutions and LGBT film festivals. It premiered at the New York Museum of Modern Art's Documentary Fortnight Festival and was included in South by Southwest and the Whitney Museum of American Art's Biennial. It also played at Los Angeles' Outfest LGBT Film Festival, with many of the film's subjects in attendance, where it won the Grand Jury Prize for documentaries.

Many queer and trans scholars have praised the film for its self-reflexive, self-critical examination of the difficulties of creating community across differences. Dean Spade, upon viewing a rough cut, wrote: 'the portrayal of the creation of Wildness and its impact on the Silver Platter engage a complexity and self-reflectiveness that is rarely represented in film and yet is a constant companion of activists, artists, and organizers' (2011: 29), and Finn Jackson Ballard likewise appreciates Tsang's willingness to criticise her own queer utopian project (2014: 464-5). Tavia Nyong'o (2013) helpfully calls the film 'a critical reimagining of "safe space". He writes: 'Rather than engage in the interminable analysis of the impossibility of ever doing interpersonal justice to one another - given the ways our communities are necessarily riven by difference - the film turns its attention to the structures that enable and condition our gathering in the first place.'

Like The Salt Mines, Wildness presents a community of translatina women who experience intersecting forms of state-enforced vulnerability and yet have created a space where their feminine selves are recognised and valued. One of the translatina women interviewed early in the film, Griselda, is deported midway through. Two of the regulars, Karen and a friend, discuss their fears (in Spanish): 'We've had deaths here, too. Yes, girlfriends. We've known people, who we could be with today, but tomorrow, we don't know. Karen's friend notes that they were, 'Murdered with guns. In the area. Because of discrimination', and 'That makes us really scared. The film documents a press conference about the murder of trans teen Paulina Ibarra, with signs that demand 'Stop Killing US!'

One major difference between the two films, though, is that while the feminine Salt People in 1990 did not share a coherent sense of identity, the women of the Silver Platter seem to share a sense of belonging to not just one but 
several nameable, politicised, collective identities - trans, Latina, and immigrant. This is one of the starkest markers of the twenty-two years that separate the films - the creation of specifically trans identities, communities, and political movements as a result of steadfast trans activism. Nevertheless, a variety of terms proliferate in the film in both Spanish and English, and the film makes space for this multiplicity. Tsang says that this strategy was intentional:

I feel like I barely even use the word 'transgender' in the film because that was another ideological category to me. I felt like life at the Silver Platter almost defied all categorisation in that way. It wasn't 'LGBT'; it was more complicated and messy than any of those categories. (King and Rivas, 2012)

Nonetheless, Nicol, the bar's host, calls the bar a 'living room' for 'the transgender community' (la comunidad transgénero). Alternately, one of the regulars, Karen, declares: 'I'm so proud that I'm a transexual' (transexual). Most commonly, the women refer to themselves simply as las chicas, translated as either 'the girls' or 'the ladies', and leave it at that. The community also includes men who perform as women only on stage, such as Morale, leader of the bar's weekly 'transvestite show' (show travestis).

Despite her reservations about categorisation, Tsang and her Englishspeaking friends mostly refer to the crowd at the Silver Platter as 'trans' and 'queer', words they likewise use for themselves. A flyer created by the Wildness organisers and featured in the film states: 'THE SILVER PLATTER IS A SAFE SPACE FOR TRANSGENDERED AND QUEER LATINO PEOPLE(S). WE, THE ORGANIZERS OF WILDNESS ... AS A COLLECTIVE BODY BEING THING ARE: 1) BROWN 2) QUEER 3) TRANS 4) CREATIVE.' While the terms 'trans' and 'transgender' seem unavoidable for the English-speaking activists, the film nonetheless demonstrates its commitment to the messiness of community building by maintaining space for all these labels at once.

While The Salt Mines presents a series of low-resolution long takes in the convention of 1980 os activist videos, Wildness has an arty, stylised, and polished feel. The images are high-resolution and the sound high fidelity. There is lots of quick cutting, many different camera angles, and colourful lighting. The film's seductive look recalls Jeannine Tang's description of the way Reina Gossett and Sascha Worzel's Happy Birthday, Marsha! (US, 2018) uses 'glamor as an optics of loving looks between queer and trans women' (2017: 382). Of that film, Tang argues that:

Gossett and Wurzel set out ... to make a luscious film as a form of aesthetic resistance to the ways in which trans bodies are so frequently featured on camera as mangled and murdered, their scenes often captured with lower production values, their characters presented as caricatures, tropes, or scenography. (Tang, 2017: 382) 
The 'luscious' formal qualities of Wildness similarly function as a form of 'aesthetic resistance'.

There is also a lot of music throughout the film, ranging from sparse electronic music to Latin cumbia. As the film's music was largely created by the same DJs who did the music for the Wildness parties (NGUZUNGUZU, aka Daniel Pineda and Asma Maroof; and TOTAL FREEDOM, aka Ashland Mines), this music brings the film spectators into contact with the rhythms and melodies that likewise moved the party's attendees.

The focus of Wildness is not on the stories and perspectives of translatina women per se, but rather on the challenges of coalition across class and linguistic differences within queer and trans communities. The protagonists are the Silver Platter itself and 'Wu', a version of the film's writer-director, whose quest for a place to create art and community drives the narrative. In interviews, Tsang says that she endeavoured not to exploit the film's subjects. Tsang states: 'Documentary is an inherently exploitative medium, literally because you are using people's lives to make art. The narrative structure of Wildness grew out of this question of responsibility' (Berardini and Tsang, 2013). Though Tsang says that she first approached the documentary through "more of an anthropological "this is what it's like to be a transgender immigrant" kind of story', she grew frustrated by the conventions of documentaries about immigrants and trans people she was watching, which she found to be 'a little bit exploitive' (King and Rivas, 2012). In response, Tsang says:

We made the bar the main character, who narrates the story. I also put myself in the film, which exposes me to vulnerabilities alongside my subjects. In a way I wanted to exploit myself, or put myself out front, because I would rather be the target than have my subjects be the target. (Berardini and Tsang, 2013)

These two strategies were intended to make Tsang's role as filmmaker 'really transparent' and call attention to the constructed and partial nature of the film. Tsang asserts: 'films simply cannot tell the whole "truth" about something - so the mythology was intended to eliminate any possibility that this film could be "about" the women of the Silver Platter, or transgender/immigrant experience in general' (Berardini and Tsang, 2013).

What is the effect of these strategies on the film? Having the bar narrate the film, through the compelling and seductive voice of Marroquin, does convey the element of fantasy and constructedness that Tsang aims at. The Silver Platter's voice also provides some of the positive functions of a narrator (e.g. it provides continuity, exposition, and context), without bringing in an external authority that might de-authorise the expertise of the trans subjects. It also quite helpfully concretises a relation of care between people and places. Having a translatina woman perform the voice of the Silver Platter puts the translatina experience of the bar at the centre of the 
bar's own identity, even though the business is owned by a cis gay man and cis straight woman. The personified bar is one of the film's most unique and compelling aspects - it's the thing that I remembered best when I first saw it.

The strategy of the filmmaker writing herself into the film does make visible the gaps and misunderstandings between $\mathrm{Wu}$ and the bar's regulars. In this, the film does not pull any punches. It shows how Wu's attempts to engage with the Latinx regulars do not always succeed and the community created by the Wildness parties is often fissured and contested. However, another effect of this strategy is that the translatina women are decentred and deindividualised. The film becomes primarily about Wu and her experience of the Silver Platter. The translatina women remain on the sidelines. They are first introduced to the viewer en masse, in a quickly edited montage that makes it impossible to name and differentiate one from the other. The film quickly introduces eighteen different translatina women who stand in front of a gold curtain, singly and in pairs, and announce, variously, their name, age, where they're from, and their thoughts about the Silver Platter. The film cuts between different women, with voices and bodies only occasionally in sync. We only hear seven names. Later, we get to know Nicol, Betty, and Erika a little better, but overall the translatina women are introduced as a barely differentiated mass. This approach conveys a sense of community, but not of each woman as an individual. While Tsang is interested in their stories and collaborating with some of them, their thoughts and feelings are ultimately filtered through Tsang. In her analysis of Tsang's attempts to counter Paris is Burning's 'mistakes', Eve Oishi similarly concludes that, 'While a self-conscious foregrounding of the filmmaker and the apparatus can open up a critical space for the viewer, the proliferation of autobiographical and self-reflexive representations means that this technique does not inoculate a film or a viewer from hegemonic forms' $(2015: 265,267)$.

Wildness's major achievement is to take a frank look at creative and activist queer and trans world-making and reveal the persistent fissures within queer and trans communities. Although $\mathrm{Wu}$ and the women of the Silver Platter are trans, they are nonetheless from different worlds - economically, educationally, linguistically, and otherwise. They can become friends and create networks of care, but the possibility of harm remains.

Tsang is both an insider and outsider to the community of Silver Platter regulars she portrays in the film. The film's trans subjects (Wu and the women of the Silver Platter alike) exert political agency by taking care of each other and surviving, but also through dancing, performing, and making themselves glamorous and beautiful (and expanding what those categories could mean). They also engage in more straightforward political actions, attending a march protesting the state's crackdown on undocumented immigrants. Wu and the Wildness crew establish a legal aid clinic 
near the bar to help trans immigrants acquire status in the United States and change their documentation to fit their gender identity.

Tsang clearly worries that increasing media attention on the Silver Platter due to the Wildness parties will put the bar's regulars at risk. At the same time, Gonzalo, the bar's co-owner, notes that when the crowds get unwieldly on Wildness nights, the police never intervene, unlike on regular nights. However, when the Los Angeles Times deems the bar 'LA's Best Tranny Bar', Tsang and friends ask the newspaper not to print the review, because 'there will be serious consequences for the safety of the people involved'. The newspaper prints the review anyway and some Silver Platter regulars lash out at the Tuesday night parties.

Unlike The Salt Mines, Wildness takes up the question of vulnerability and inadvertent harm as an explicit part of its politics. However, despite their many differences, the two films are alike in key ways: both share the survival and world-making strategies of precarious translatina women, both hold space for contesting and contradictory identity labels, and both invite viewers into these networks of care and community.

\section{WORKING THROUGH VISIBILITY AND VULNERABILITY}

Just as Nyong'o argues that the film Wildness attends to 'the structures that enable and condition our gathering' (2013), these films reveal how another kind of structure - cinematic structures - 'enable and condition our gathering. The films accomplish this task in different ways. The Salt Mines uses the conventions of realist ethnographic documentary to centre the perspectives of a community of homeless translatinas. While the film does not explicitly conceptualise its subjects' vulnerability as such, their resilience and the insights they have gained through survival are surely what drew the filmmakers to these individuals. Wildness likewise shares the survival and world-making strategies of two intersecting groups of trans people - las chicas of the Silver Platter and the queer and trans organisers of the Wildness parties - with film audiences. The film takes up the question of how Tsang, as party-planner (and, implicitly, as filmmaker), can engage ethically with las chicas of the Silver Platter in a way that contributes to the liberation of both communities. Tsang rejects a realist ethnographic style in favour of an overtly self-referential and lusciously fantastical style in order to complicate the traditional relationship of (powerful) filmmaker with (vulnerable) subject. Both films provide potent examples of how cinema can contribute to the political project of trans of colour survival and imaginative world-making, even as they demonstrate the potential dangers of documentary representation. Nevertheless, films 
like The Salt Mines and Wildness can help bring new worlds into being and stretch the kinds of coalitions - however fraught - that arise and disappear in these worlds.

\section{NOTES}

1 I use 'translatina' to identify 'transgender, transsexual, and transvestite individuals in Spanish-speaking parts of Latin America and elsewhere' (La FountainStokes, 2014: 237; see also Rodrígues de Ruíz and Ochoa, 2016). Trans- refers to the 'transing' of gender and of national boundaries (e.g. 'trans-latinoamericana').

2 In the film, Ruby uses the name Ruben. A year after the broadcast, Aikin ran into 'Ruben' and discovered that she now goes by Ruby (Aikin, 2013: 134-7).

3 While Aikin's account of the filmmaking process in a later book (2013) suggests that she is emotionally attached to the film's subjects, many passages of the book reveal a more condescending attitude towards them than is evident in the film itself. The film is actually better than its maker in this regard.

4. In correspondence with me, Javier García León writes: 'This word, as she says it, it is not recognized as part of the Spanish language by the Dictionary of the Real Academia de la Lengua Española. It seems to be an accommodation from English to Spanish. The Spanish words recognised by the Language Academy are travesti, travestido or travestista.'

5 While the film uses male pronouns for 'Wu', Tsang's most recent bio in Trap Door uses female pronouns, so I have chosen to use female pronouns for both Tsang and 'Wu'.

\section{ACKNOWLEDGEMENTS}

Muchas gracías to Javier García León, who translated the Spanish dialogue quoted in the article, provided context for the terms, and offered invaluable feedback.

\section{REFERENCES}

Aikin, S. (2013). Digging up the Salt Mines: A Film Memoir. New York: Ishta Press.

Aizura, A. Z. (2016). 'Affective vulnerability and transgender exceptionalism: Norma Ureiro in Transgression', in Y. Martínez-San Miguel and S. Tobias (eds), Trans Studies: The Challenge to Hetero/Homo Normativities. New Brunswick: Rutgers University Press, pp. 122-40.

Allen, S. (2018). 'These are the worst anti-LGBT bills planned for 2018'. The Daily Beast (17 January), www.thedailybeast.com/these-are-the-worst-anti-lgbt-billsplanned-for-2018 (accessed 29 August 2018).

Bailey, M. M. (2011). 'Gender/racial realness: Theorizing the gender system in ballroom culture', Feminist Studies, 37, pp. 365-86. 
Ballard, F. J. (2014). 'Wu Tsang's Wildness and the quest for queer utopia', TSQ, 1:3, pp. 461-5. https://doi.org/10.1215/23289252-2687555.

Barrow, K. L., Y. L. Cohen, K. Young and D. Spade (2017). 'Models of futurity', in R. Gossett, E. A. Stanley and J. Burton (eds), Trap Door: Trans Cultural Production and the Politics of Visibility. Cambridge, MA: MIT Press, pp. 363-92.

Berardini, A. and W. Tsang (2013). Wu Tsang 'Wildness.' Vdrome. www.vdrome.org/ wu-tsang-wildness.

Combahee River Collective (1986). The Combahee River Collective Statement: Black Feminist Organizing in the Seventies and Eighties. New York: Kitchen Table: Women of Color Press.

Feder, S. and A. Juhasz (2016). 'Does visibility equal progress? A conversation on trans activist media', Jump Cut, 57.

Gossett, R. (2017). 'Reina Gossett on transgender storytelling, David France, and the Netflix Marsha P. Johnson documentary', Teen Vogue (11 October), www. teenvogue.com/story/reina-gossett-marsha-p-johnson-op-ed (accessed 29 August 2018).

Gossett, R., E. A. Stanley and J. Burton (2017). 'Known unknowns: An introduction to Trap Door', in R. Gossett, E. A. Stanley and J. Burton (eds), Trap Door: Trans Cultural Production and the Politics of Visibility. Cambridge, MA: MIT Press, pp. xv-xxvi.

Griffin-Gracy, M. M., C. McDonald and T. Meronek (2017). 'Cautious living: Black trans women and the politics of documentation', in R. Gossett, E. A. Stanley and J. Burton (eds), Trap Door: Trans Cultural Production and the Politics of Visibility. Cambridge, MA: MIT Press, pp. 22-38.

Hilderbrand, L. (2013). Paris is Burning: A Queer Film Classic. Vancouver: Arsenal Pulp Press.

hooks, b. (1996). Reel to Real:Race, Sex, and Class at the Movies. New York: Routledge.

Jelača, D. (2016). 'Gendered visions in As If I Am Not There and in The Land of Blood and Honey: Female precarity, the humanitarian gaze and the politics of situated knowledge', Jump Cut, 57.

Juhasz, A. (1999). 'They said we were trying to show reality - all I want to show is my video: The politics of the realist feminist documentary', in J. Gaines and M. Renov (eds), Collecting Visible Evidence. Minneapolis: University of Minnesota Press, pp. 190-215.

Keegan, C. M. (2016). 'History, disrupted: The aesthetic gentrification of queer and trans cinema', Social Alternatives, 35:3, pp. 50-6.

King, J. and J. Rivas (2012). 'At SXSW: An honest look at a Latina transgender bar in transition', Colorlines, www.colorlines.com/articles/sxsw-honest-look-latinatransgender-bar-transition (accessed 29 August 2018).

La Fountain-Stokes, L. (2014). 'Translatinas/os', TSQ, 1:1-2, pp. 237-41. https://doi. org/10.1215/23289252-2400217.

Lorde, A. (2017). A Burst of Light and Other Essays. Mineola: Ixia Press.

Muñoz, J. E. (1999). Disidentifications: Queers of Color and the Performance of Politics. Minneapolis: University of Minnesota Press.

Muñoz, J. E. (2009). Cruising Utopia: The Then and There of Queer Futurity. New York: New York University Press.

Namaste, V. (2005). 'Beyond image content: Examining transsexuals' access to the media', in Sex Change, Social Change: Reflections on Identity, Institutions, and Imperialism. Toronto: Women's Press, pp. 41-59. 
Nyong'o, T. (2013). 'Wildness: A fabulation', S\&F Online. http://sfonline.barnard.edu/ activism-and-the-academy/wildness-a-fabulation (accessed 29 August 2018).

Oishi, E. (2015). 'Reading realness: Paris Is Burning, Wildness, and queer and transgender documentary practice', in A. Juhasz and A. Lebow (eds), A Companion to Contemporary Documentary Film. Malden, MA: Wiley-Blackwell, pp. 252-70.

Oliviero, K. E. (2016). 'Vulnerability's ambivalent political life: Trayvon Martin and the racialized and gendered politics of protection', Feminist Formations, 28:1, pp. 1-32. https://doi.org/10.1353/ff.2016.0013.

Reid-Pharr, R. F. (1990). 'The spectacle of blackness', Radical America, 24:4, pp. $57-66$.

Rodrígues de Ruíz, A. and M. Ochoa (2016). 'Translatina is about the journey: A dialogue on social justice for transgender latinas in San Francisco', in Y. MartínezSan Miguel and S. Tobias (eds), Trans Studies: The Challenge to Hetero/Homo Normativities. New Brunswick: Rutgers University Press, pp. 154-72.

Rony, F. T. (1996). The Third Eye: Race, Cinema, and Ethnographic Spectacle. Durham, NC: Duke University Press.

'The Salt Mines \& The Transformation' (2017). IFC Center, www.ifccenter.com/ films/the-salt-mines-the-transformation (accessed 29 August 2018).

Snorton, C. R. and J. Haritaworn (2013). 'Trans necropolitics: A transnational reflection on violence, death and the trans of color afterlife', in S. Stryker and A. Z. Aizura (eds), Transgender Studies Reader 2. New York: Routledge, pp. 65-76.

Spade, D. (2011). 'Wildness', make/shift, 9, pp. 28-9.

Spade, D. (2015). Normal Life: Administrative Violence, Critical Trans Politics, and the Limits of Law. Durham, NC: Duke University Press.

Spivak, G. C. (1988). 'Can the subaltern speak?', in C. Nelson and L. Grossberg (eds), Marxism and the Interpretation of Culture. Urbana and Chicago: University of Illinois Press, pp. 271-316.

Steinmetz, K. (2014). 'The transgender tipping point', Time (29 May), http://time. com/13548o/transgender-tipping-point (accessed 29 August 2018).

Stryker, S. (2017). Transgender History: The Roots of Today's Revolution. Berkeley: Seal Press.

Tang, J. (2017). 'Contemporary art and critical transgender infrastructures', in R. Gossett, E. A. Stanley and J. Burton (eds), Trap Door: Trans Cultural Production and the Politics of Visibility. Cambridge, MA: MIT Press, pp. 363-92.

The TransLatin@ Coalition, B. Salcedo and K. Padrón (2013). TransVisible: Transgender Latina Immigrants in U.S. Society. Los Angeles: The TransLatin@ Coalition.

United States Conference of Catholic Bishops (2017). 'Created male and female: An open letter from religious leaders', www.usccb.org/issues-and-action/marriageand-family/marriage/promotion-and-defense-of-marriage/created-male-andfemale.cfm (accessed 29 August 2018).

Valentine, D. (2007). Imagining Transgender: An Ethnography of a Category. Durham, NC: Duke University Press.

Winston, B. (1988). 'The tradition of the victim in Griersonian documentary', in A. Rosenthal (ed.), New Challenges to Documentary. Los Angeles and London: University of California Press, pp. 269-87. 


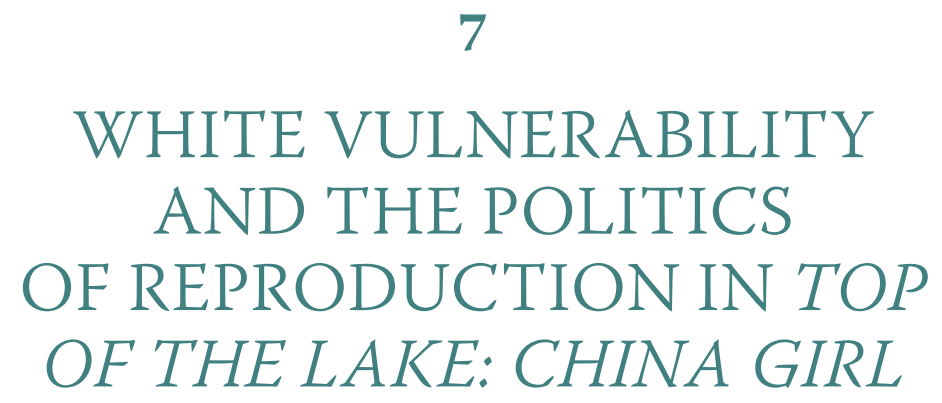

JOHANNA GONDOUIN, SURUCHI THAPAR-BJÖRKERT

AND INGRID RYBERG

7 Top of The Lake: China Girl (Australia, Jane Campion, 2017) is the sequel 1 to Jane Campion and Gerard Lee's crime series Top of the Lake from 2013, directed by Campion and Ariel Kleiman. After four years of absence, Inspector Robin Griffin (Elisabeth Moss) returns to the Sydney Police Force and comes to lead the murder case of an unidentified young Asian woman, found in a suitcase at Bondi Beach. The investigation connects Robin to a group of Thai sex workers, and a network of couples - including two of her closest colleagues - willing to pay these women large sums of money as surrogate mothers via illegal commercial arrangements. Moreover, on her return to Sydney, Robin makes contact with her now teenage daughter Mary (Alice Englert), whom she gave up for adoption at a young age. Worrying links between the murdered girl and Mary are revealed, as it turns out that one of the prime suspects is Mary's boyfriend Puss (David Dencik). The circumstances surrounding the adoption are revealed in season one, set in the fictional town of Laketop, New Zealand. Visiting her dying mother, Robin becomes involved in the investigation of the disappearance of a pregnant twelve-year-old, Tui. The case results in the exposure of a paedophile ring implicating a large number of men in the small community, among others the missing girl's father and the police officer in charge. In the process, Robin's traumatic past unfolds through flashbacks: the gang rape that she was the victim of as a teenager, and the following pregnancy and adoption.

The six episodes of approximately one hour each of China Girl were screened at the Cannes film festival in May 2017, and have since been shown on the BBC, Sundance TV, and Swedish national television (SVT), 
among others. The first season was a critical success, praised for its visual power, emotional depth, and outstanding acting. The second has also been well received, although slightly less enthusiastically. China Girl has been praised by feminist critics for its radical depiction of the experiences of women as well as its ambitious analysis of an insidious rape culture. It has been perceived as more about the complexities of gender politics than police work; as less a detective story than a thought-provoking meditation on motherhood and kinship (Balac, 2017; Budowski, 2017; Pulver, 2013; Vineyard, 2017; Wiegand, 2017). Campion herself has described the series as 'beyond feminism, as something "ovarian"'. She elaborates: 'I wanted to go deep into the uterus of a woman, and really tell the story from that point of view, from creation to appropriation' (Vineyard, 2017). The opening credits dramatically show the penetration of an ova and its subsequent formation into a foetus.

The focus on motherhood is bolstered by both the biographical background and public and fictional personae of Campion and the female leads of the series. The director has been explicit about her own thorny road to motherhood, including three miscarriages and a baby who died. In the series, Campion's real-life daughter Alice Englert plays the role of Mary. There is also the highly mediatised case of Nicole Kidman, cast as Mary's adoptive mother Julia. Kidman is an adoptive mother from her relationship with Tom Cruise and a mother through surrogacy with her current spouse, Keith Urban. In addition, one of Kidman's recent roles was that of the adoptive mother in Lion (Australia, Garth Davis, 2016). Elisabeth Moss has portrayed women with painful experiences of motherhood in two of her most acclaimed former appearances: as Peggy Olsen in the series Mad Men (US, Matthew Weiner, 2007-15) she has a child out of wedlock that she gives up for adoption, and as the surrogate Offred she is the main character of The Handmaid's Tale (US, Bruce Miller, 2017-), the television adaptation of Margaret Atwood's novel from 1985.

Moreover, Campion has pointed out that she was inspired by ongoing debates and specific cases in a different way to her previous work. In an interview in the New York Times, Campion mentions two incidents of surrogacy in Thailand that gained global media attention and prompted the government of Thailand to close its borders to foreign couples seeking surrogacy arrangements in the country. The first was the Baby Gammy case of 2014 involving an Australian heterosexual couple who contracted a surrogate in Thailand. The surrogate gave birth to twins - a boy and a girl but the couple only brought the daughter home with them since the boy was discovered to have Down's syndrome and a congenital heart defect (Howard, 2014). It was further revealed that the father was a convicted sex 
offender, having been found guilty of molestation of two girls aged seven and ten. The other case was that of a twenty-four-year-old Japanese businessman who fathered sixteen babies born from surrogates in Thailand in 2014, and planned to have another four. Commercial surrogacy is illegal in Australia, but instead of the usual recourse to offshore surrogacy in low-cost destinations, the arrangements in China Girl take place within the country. In the interview, Campion does not take a stance for or against transnational commercial surrogacy, but said she was driven by a curiosity to explore its complexities and highlight different perspectives (Vineyard, 2017). On the contrary, regarding sex work, Campion has been outspoken about her support for its legalisation, implemented in New South Wales since 1988 (Ellis-Petersen, 2017). Nonetheless, unlicensed brothels are estimated to outnumber registered brothels by four to one, and a recent study shows that almost half of those working in brothels are migrants having entered the country on a student visa (Ellis-Petersen, 2017). In the series, the women in the brothel, posing as students and contracted as illegal surrogates, speak to this joining of legal and illegal practices.

Revolving around charged issues such as surrogacy, adoption, and migrant sex workers, interconnecting these different forms of affective and biological labour and situating the notion of motherhood in a larger context of issues of reproductive work, the series offers a rich and complex reflection on the current debate about the global division of reproductive work across axes of gender, race, nationality, migration status, and class (Colen, 1995; Ginsburg and Rapp, 1995; Parreñas, 2000; Shanley, 2001; Vora, 2008; Yngvesson, 2010). However, while critics have recognised motherhood, misogyny, sexism, and gendered violence as central themes in China Girl, surprisingly few comments address the racial dynamics in the series (Jones, 2017; Kang, 2017). Swedish artist and activist Lisa Wool-Rim Sjöblom points out:

Even though the Asian women are victims of exactly the same cruel, patriarchal rape culture, and additionally find themselves both alienated and in serfdom, they remain stiff, onehanded decors in the series' background. Apparently indifferent to their life situations, they, as opposed to their white counterparts, do not break down. They neither cry nor bleed but populate the brothel in passive acceptance. We do not really know what they think of their lives in Australia, or how they feel about suddenly being brought out from the country, pregnant with genetically foreign children. Constantly naked, constantly sexually exposed, their bodies are rolled out like a carpet for the white women to walk on, where these can live out the whole complex register that being a human being entails. It's their feelings that are worth telling. It is when their bodies are raped, their lives risked, their life situations disturbed, that we are supposed to react. (Wool-Rim Sjöblom, 2017, authors' translation) 
Wool-Rim Sjöblom's criticism draws attention to the crucial and interconnected functions of emotions and agency in the series, but also to their unequal distribution between the white women and Thai women.

In this chapter, we set out to unpack these racial and emotional dynamics and the series' complex representation of the issue of surrogacy by shedding light on how it sets conflicting notions of vulnerability in motion. We show how articulating emotional vulnerability becomes a resource and springboard for agency and making citizen claims on the part of the series' white intended parents. The physical and material vulnerability and subordination of the Thai sex workers and surrogates, on the other hand, render them no other narrative function than that of passive, objectified victims to be used for the white characters' various purposes. These conflicting notions of vulnerability, we propose, evoke diverging positions in the current debate on transnational commercial surrogacy: a Western liberal notion of reproductive rights on the one hand, and a postcolonial critical notion of reproductive justice on the other. Ultimately, we argue, the series privileges the Western notion of reproductive rights by amplifying the emotional vulnerability of the white characters at the cost of the Thai characters, who remain flat and underdeveloped. Close reading the affective economy of this celebrated quality TV drama created by a white female auteur, our aim is to illuminate the crucial role of vulnerability in the ongoing debate as a vehicle for making transnational commercial surrogacy emotionally and ethically acceptable.

\section{REPRODUCTIVE RIGHTS VERSUS REPRODUCTIVE JUSTICE}

Since the late 20oos, transnational commercial surrogacy has developed into a booming global industry, with an increasing number of involuntarily infertile couples travelling from countries in the Global North, where commercial and altruistic surrogacy is either illegal or less affordable, to low-cost countries, where surrogate arrangements are offered for a fraction of the cost (Chavkin and Maher, 2010; Gupta, 2006; Pande, 2010; Sunder Rajan, 2007). As hubs in the Global South such as India and Thailand close their borders, the industry relocates to other countries; Nepal and Laos have recently become popular destinations for transnational surrogacy arrangements. The 'outsourcing' of reproductive labour to women of the Global South adds further layers of complexity to the already controversial practice of surrogacy (Nahman, 2008; Nussbaum, 1998; Ragone and Twine, 2000). In such a moment, cultural productions, such as China Girl with its high cultural visibility among audiences in the Global North, contribute 
to the cultural meaning making of surrogacy, and potentially shape the perceptions and decisions of those who are considering surrogacy (Riggs and Due, 2010; 2013; van den Akker et al., 2016), as well as surrogacy law and policy (Millbank, 2012).

In Western feminist thought, the notion of reproductive rights, centred around values such as choice and bodily autonomy, have primarily regarded the right to access birth control such as contraceptives and abortion. However, in the current context of declining fertility rates in the Global North, reproduction is increasingly valued (Eng, 2010), and new reproductive technologies (ARTs) enable new claims to reproductive rights (Cohen, 2005; Cooper and Waldby, 2008; 2014). Recent scholarship argues that reproduction is increasingly perceived as a marker of citizenship by providing the ground for social participation and claims to social resources (Turner, 2001; 2008: 46). In this context, reproductive rights, which are enshrined in the UN declaration of human rights, can be interpreted as having a child being a human right (Turner, 2008: 52). In China Girl, such an understanding of reproductive rights as human rights is explicitly expressed by the couple Felicity and Mike. The language of human rights is a potent discourse in the Global North, not only for straight couples but increasingly for marginalised groups fighting legal discrimination, such as LGBTQ people, disabled people, and single parents.

The notion of reproductive rights as a matter of individual choice has been heavily criticised in black and postcolonial feminism, by some deemed to constitute a new form of discursive colonialism (Bailey, 2011; Mohanty, 2003), which negates the ways in which socio-economic contexts and geopolitical locations shape women's reproductive options (Twine, 2015). 'For many women, contract pregnancy is one of the few routes to attaining basic social goods such as housing, food, clean water, education and medical care', Alison Bailey (2011: 722) argues. While infertility is more widespread in the Global South and marginalised communities in the Global North, privileged white women are the major beneficiaries of ARTs. In neo-liberal logic, the transformation of the desire to procreate into the right to reproduction is conceptualised as an issue of entrepreneurship and consumer rights. Examining neoliberal discourses in cases of transnational surrogacy, Krølokke and Pant develop the concept of 'repropreneur', whereby reproductive actors make choices that, 'maximize their chances of pregnancy and upward mobility, while simultaneously turning reproductive matter into particular types of commodities' (2012: 234). In China Girl, Felicity and Mike come across as paradigmatic examples of reproductive citizens able to draw on their 'entrepreneurial qualities' and financial capacities in order to invest both materially and emotionally in reproductive choices. 
Dorothy Roberts and other feminists of colour draw attention to how childbearing by wealthier women is encouraged and bolstered through the use of advanced technological interventions, while lacking financial resources, public policy measures, invasive and abusive medical and surgical procedures, or forced child removal prohibit the motherhood of poor women of colour (Roberts, 1996: 944). Furthermore, scholars such as Kalindi Vora (2012) and France Winddance Twine (2015) have drawn attention to how the current market in reproductive labour is prefigured by the US slave economy and other forms of colonial indentured labour.

Challenging and nuancing the Western liberal notion of reproductive rights, the concept of 'reproductive justice' was coined in the early 1990 os by SisterSong, a grassroots collective of women of colour in the United States. Merging reproductive rights with social justice, reproductive justice was launched in order to address 'how race- and class-based histories of population control, sterilisation abuse, high-risk contraception, poverty, and the effects of environmental pollution on fertility and maternal health shaped the reproductive lives of the third world (as well as women of colour in the first world)' (Bailey, 2011: 727; see also Rao, 2010; Scheper-Hughes, 2004). Going beyond liberal frameworks centred on women's individual autonomy and choice, this approach to ARTs and surrogacy extends the conversation to include the reproductive rights, social justice concerns, and human rights of women outside hegemonic feminism (Mohapatra, 2012). Taking India as an emblematic example, Twine - speaking of a 'fertility caste system' - and Vora argue that contemporary practices of transnational surrogacy extract and transfer value from poor, lower castes to wealthy nationals, foreigners and privileged upper castes (Banerjee, 2014; Twine, 2016; Vora, 2012). Reproductive rights and reproductive justice are conflicting perspectives, as 'the reproductive privileges of some women depended on the reproductive disciplining of other women in ways that did not challenge racism or other vehicles of inequality' (Ross and Solinger, 2017: 65). In both perspectives, the notion of vulnerability is central yet mobilised in different ways.

Literature focused on the surrogate mother and the child largely concerns the economic and educational vulnerability of surrogates, particularly their potentially limited alternative financial options (Damelio and Sorensen, 2008; Pande, 2010; Rao, 2004: 251; Rudrappa, 2012; Twine, 2015; Vora, 2009), as well as their medical vulnerability and exposure to the risk of maternal deaths (Bailey, 2011: 729). On the other hand, Damien Riggs and Clemence Due (2013; 2014) draw attention to the 'reproductive vulnerability' of intended parents, highlighting what they perceive as a lack of attention to the various intersections between 'differing vulnerabilities'. They build on the abovementioned increasing value attached to reproduction, and argue that people who are reproductively vulnerable are those who 
are unable to reproduce via heterosexual intercourse either due to medical infertility or 'social infertility' (Boivin et al., 2001). 'To be outside the norm of reproductive heterosex then is to be vulnerable to the diminishment of one's cultural capital as a reproductive citizen' (Riggs and Due, 2013: 957). In her analysis of the Norwegian debate on surrogacy, Unn Conradi Andersen (2012) points out how relatively privileged groups have picked up on the language of marginalised groups in their struggle for recognition and rights to reproduction. Positioning oneself as victim in relation to the state is also recurrent in Swedish ART discourses as well as in pro-surrogacy discourses (Arvidsson et al., 2015; Gondouin, 2015).

Our analysis draws from Judith Butler's understanding of vulnerability as both a common human condition and as relational and depending on one's positionality within a multilayered field of power (Butler, 2014: 5). Butler discusses how 'dominant groups can use the discourse of "vulnerability" to shore up their own privilege'. In this instance, 'it is their privilege which has become "vulnerable" to being undone by increasing demands for equality and freedom' (Butler, 2014: 16). Such use of vulnerability, Butler elaborates, effaces the condition of vulnerability in which precarious populations live, and constitutes an ideological seizure of the term to expand and rationalise inequalities. In our reading of Top of the Lake: China Girl, we demonstrate how the emphasis on the reproductive vulnerability of the white intended parents precisely effaces the precariousness of the Thai women's lives.

\section{PASSIVE VICTIMS AS NARRATIVE BACKDROP}

In both seasons of Top of the Lake, a pregnant Asian female is driving the narrative. In season one it is pregnant preteen Tui's attempt to drown herself that starts off the investigation leading to the exposure of the paedophile network. In season two, a dead Thai woman, Padma, found in a drifting suitcase, subsequently discovered to be pregnant, leads to the unravelling of migrant sex workers contracted as surrogate mothers. When asked if there is a deeper meaning to the depiction of these Asian women as victims, Campion claims she wanted to challenge the widespread idealisation of Asian femininity as 'more petite, more beautiful, more feminine than us big white women ... It's a common thing for some men who find women to be too difficult, to get what they hope will be a submissive woman. It doesn't really work out that way, because they aren't that submissive' (Vineyard, 2017). However, the portrayal of the Thai women in the series does very little to counter dominant stereotypes. Instead, we argue, it invokes a fetishising notion of the vulnerability of South East Asian female bodies as available, consumable for sexual and reproductive labour, and ultimately disposable. 
Aestheticised images of the suitcase floating in the water, with long black hair leaking out of it, are recurrent in the first episode. Examining the distorted corpse, it is this hair, determined by the forensic pathologist to be of Asian texture, that inspires the police operation's official code name - the exoticizing 'China Girl', which is also the name of the whole season. ${ }^{1}$ The objectification of Asian female bodies continues throughout the series, as pointed out by Sjöblom, with the young Thai women consistently seen halfnaked and sexually exposed. As commodities available for sexual consumption, they are recurrently rated in derogatory racist and misogynist terms by a group of young men reviewing the brothel's website in a café. Eager to serve whoever turns out to be the customer, the series reproduces the image of the sexually available, servile South East Asian woman-as-prostitute, a dominant stereotype of Asian women in Hollywood Cinema instated by iconic performances in Vietnam war films such as Michael Cimino's The Deer Hunter (1978) and Stanley Kubrick's Full Metal Jacket (1987) (Prasso, 2005). In addition to the submissive and hypersexual Thai prostitute, these young women also come across as another stereotypical image of the third world woman: the passive, silent victim, whose lack of agency allows the Western feminist subject to define herself as agentic and politically conscious and progressive (Mohanty, 2003). The women at the brothel form an anonymous, silent collective. It is telling that their names are rarely mentioned in the dialogue.

The main function of these women, we argue, is to serve as the background against which the white protagonists' profiles are drawn. Our reading hence resonates with the postcolonial critique of Campion's Palme d'Or winning film The Piano (Australia, 1993). Reshela DuPuis (1996: 62), among others, scrutinises the film's colonialist politics and representation of Maori land and characters primarily as a backdrop to the white characters and their relationships with each other. In China Girl, a case in point is a scene in which Puss, who lives in a room above the brothel where he offers the Thai women English lessons, has the women recite: 'No one ever gives away power, power has to be taken', before proceeding to phrases such as 'Wow, your cock is huge.' In another scene, one of the women explains: 'He [Puss] teach us we're victims, oppressed, we need to be strong.' The lessons function as a pretext for Puss to impose his political ideas. It is he, the white male, who informs these young women of colour about their precarious condition and the most efficient ways to deal with it, a condition that they are neither shown to be aware of and even less able to critically address themselves. They are not afforded any agency of their own, but have to be taught by the white saviour. Another example is one of the few scenes in which dialogue in Thai is translated into English: the women discuss Puss's confrontation with Mary's upper-middle-class parents, Julia and Pyke, who 
openly disapprove of their daughter's relation with a man of dubious social standing twice her age. The women express concern for him not having eaten for days and are worried that he might try to kill himself. The main function of the scene is to give crucial information about Puss by suggesting that his dismissiveness and contempt do not exclude sensitivity and feelings of hurt and pain.

The Thai women also function as a contrasting background against which Mary's white femininity appear as precious and in danger of violation. A key part of the drama regards Julia and Pyke's, as well as Robin's, worries about Mary's relationship with Puss and the suspicious environment of the brothel. In contrast to the representation of the Thai women as passively submissive and emotionally indifferent to their precarious situation, Mary is represented as vulnerable and at risk because of her love for the manipulative and erratic Puss. ${ }^{2}$ The difference between Mary and the girls at the brothel is further emphasised when Puss pushes Mary to prostitute herself on the eve of her eighteenth birthday, as an act of solidarity with the Thai women. Whereas the commodification and exposure of the Thai girls are normalised in the series, Mary's ventures into street prostitution are represented as terrifying, violent, and traumatic. In the end, however, she regains her agency and dignity, leaves Puss, and reunites with her parents. In contrast, the Thai women never question or challenge Puss but follow him passively in silence and without signs of hesitation or emotion. The stereotypical depiction of the Thai women evokes a notion of vulnerability as passive victimhood and aestheticised spectacle. Their physical and material precarity render them no other narrative function than that of backdrop for the white characters.

\section{EMOTIONALLY VULNERABLE INTENDED PARENTS}

After realising that the unidentified young woman is a surrogate, Robin starts searching for 'people who are neurotically fixated on having a baby', which, replies the physician at the IVF-clinic, 'sounds like everybody in here'. He describes the drive to reproduce as being like a 'vortex', and tells of a woman who died from her attempts to get pregnant, but died happy since she finally succeeded. In the series, the intended parents' desire to have children is portrayed as extremely emotionally charged, a drive that may drive you mad, as is the case of Felicity, who is introduced wandering in the middle of the street in a nightgown looking for her baby, which we learn is not yet born. Felicity has escaped from a psychiatric asylum where she ended up after twelve attempted pregnancies and eight miscarriages spanning several years, a process which also drained the couple's finances, 
forcing them to sell their house and leaving them unable to pay for a lawyer. In desperation, the couple has impregnated three surrogates. 'We want to be sure, we can't take any more disappointments. She really doesn't need this. She would be okay if she could just have a baby. It would make her ok', says Felicity's husband Mike. As mentioned earlier, Mike invokes the discourse on reproductive rights by stating that having a child is a human right. Crucially, however, in the series, the notion of reproductive rights is activated through an overemphasis on the emotional vulnerability of the intended parents and the suggestion that the desire to have a child is a force of nature, beyond the characters' control. This notion of the biological drive as a basis for rights claims exceeds notions of rational family planning and free choice that ground demands for birth control. The series manifests the decisive role that the articulation of vulnerability plays in justifying the practice of transnational commercial surrogacy. The emotional pain of the intended parents, including Robin's colleagues Miranda and Adrian, even justifies the fact that the arrangements are illegal, which does not lead to any consequences in the series (see figure 7.1).

As the intended parents of Padma's baby learn about her death, and the possibility of her being murdered, their only response is their need to see, acknowledge, and bury 'their child'. In the series, the intended parents, including Miranda and Adrian, claim such ownership to the babies inside the

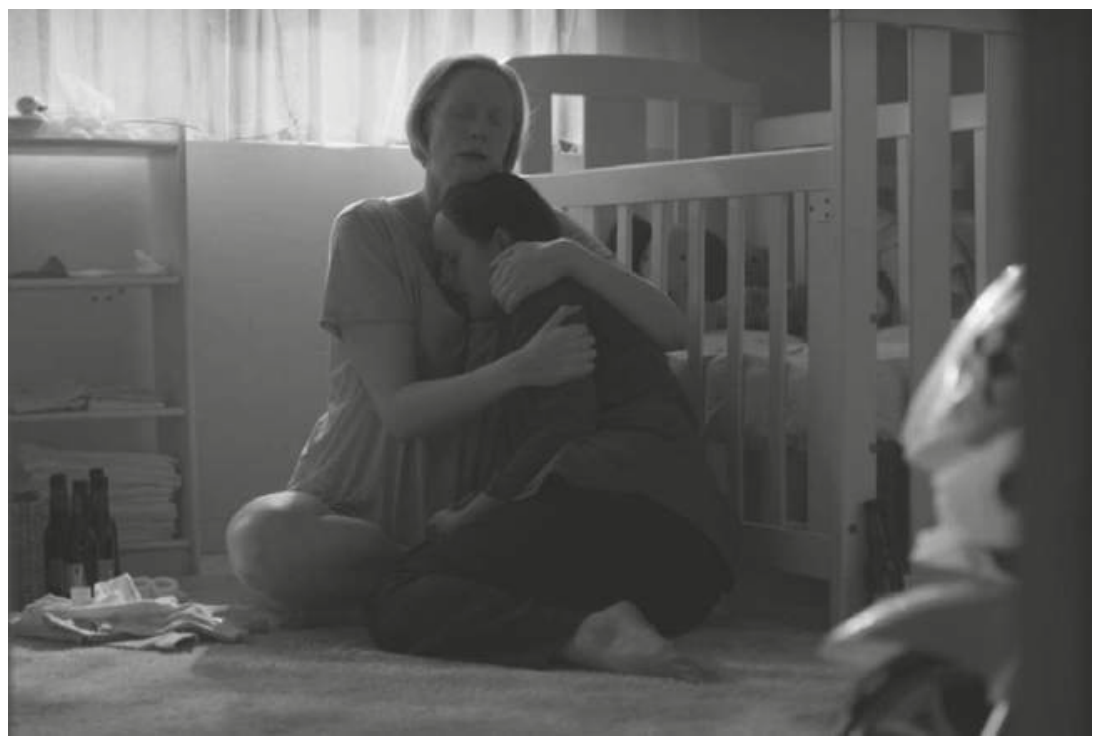

Figure 7.1 Robin and Miranda in Top of the Lake. 
surrogates' wombs. The different conceptions of kinship that are represented in the series illustrate how the nature/nurture divide is complicated by commercial surrogacy. In addition to the distinction between birthmother and adoptive mother, gestational surrogacy separates biological motherhood (the mother who gestates) from genetic motherhood (and in cases where the egg is sourced from an ova donor, social motherhood is added). In gestational surrogacy, genetics takes over the role of biology. For some couples turning to surrogacy rather than adoption, kinship as genetic relatedness (either through egg or sperm, or both) is a driving motive. Thus, the ways in which the intended parents in the series speak of 'their' children reproduces a dominant understanding of kinship made possible via surrogacy arrangements (Farrell Smith, 2005).

\section{WHITE SAVIOURS}

The representations of the Thai women and the white intended parents mobilise vulnerability in vastly different ways. A third narrative position is inhabited by the characters Robin and Puss, who both act as white saviours, if driven by different motifs. Puss's violent behaviour as well as his radical political ideas are inferred as originating in an abusive childhood. His class pathos and hatred are triggered by the encounter with Mary's upper-middleclass parents and her privileged upbringing. Puss not only teaches the women in the brothel about oppression and resistance, but also organises an escape of the surrogates back to Thailand. Through a recorded message left for the shocked intended parents as they discover the empty apartment where the surrogates lived, he formulates what could be described as a postcolonial critique of surrogacy:

For too long the West has exploited the poor and impoverished women of Asia. Girls as young as twelve years old are sold as virgins to gratify the appetite of the wealthy but what sort of life is that? Fucked to feed? Come on! And now you all want to grow your vile DNAs, your precious little babies, inside the slave wombs of enslaved women too poor to choose. But just one of these bundles of happiness gives enough money to support a whole village in the third world for years and years to come. Now the shoe is on the other foot. The tide has turned. Your babies have flown away and now it's your time to cry.

Here Puss connects sex work and surrogacy as two facets of the international division of reproductive labour and its racialised lines of stratification, while at the same time recognising the significance of the economic transaction involved in surrogacy. In another scene, he suggests that the 
comfortable middle-class lives led by Mary's adoptive parents are made possible by cheap child labour in the Global South. Thus, he connects the material and physical vulnerability of the Thai women with a postcolonial history of poverty and exploitation that leads up to contemporary neoliberal practices of unequal working and living conditions and disrupts notions of freedom and choice. Differently stated, he frames reproduction as a question of social justice and invokes the notion of reproductive justice. In Puss's view, flying the surrogates off to Thailand is presented as a way of empowering the powerless, of destabilising an unjust power relation. Puss not only provides a critical analysis of global inequality and gives proof of an awareness of class privileges but is also a proclaimed feminist. Yet, given his aggressive and manipulative personality, his political ideals in the end appear absurd and dishonest. He is shown to be provocatively sexist and even physically abusive towards both Robin and Mary. Using threats and physical abuse, he forces Mary to prostitute herself, and during a conversation on the beach suddenly bites Robin in the face, unprovoked. Thus, the postcolonial, reproductive justice-oriented critique articulated by Puss is easily dismissed as the intellectual meltdown of a bodily and emotionally detached white male.

In contrast to Puss's ideological analysis of power imbalances between the Global North and South, Robin's engagement with the pregnant Asian female victims, in both seasons of the series, turns deeply personal as the unfolding murder cases awaken her own trauma of sexualised violence, pregnancy, and giving up her child for adoption. Her empathetic desire to save these women can thus be read as a desire to potentially heal her own past injuries. Ultimately, though, Robin is driven by her desire to save her newly regained biological daughter Mary, who runs the risk of becoming the victim of similar assaults. Although the crime cases that both seasons revolve around regard the sexual exploitation and violation of Asian females, the trauma as well as the threat of sexual abuse are primarily attributed to and articulated by the white female lead and her daughter at risk. In the narrative logic of the series, the deadly patriarchal violence that the Asian characters are victims of can only be emotionally recognised from the point of view of the white character's experiences. The poster for the series shows Robin's naked back with cracks running across it, as though it were made of porcelain, clearly suggesting that the scars and vulnerability in the focus of China Girl are hers.

Moreover, in addition to the emotionally charged reproductive vulnerability articulated by the white intended parents, it is also Robin's experience of reproduction - of giving up her child at birth - that becomes a narrative focus, rather than the Asian females' experiences of their surrogate pregnancies. Although Robin and the surrogates are all birth mothers, 
it is telling that while it has deep emotional consequences for Robin, we are told nothing about the Thai sex workers' feelings about the foetuses growing inside them. There are many parallels between commercial surrogacy in its transnational form and adoption in its modern transnational and transracial form - with children of colour from the Global South being adopted by white parents in the Global North. Scholars within the field of critical adoption studies have placed attention on the historical and political dimensions of transnational adoption. In this perspective, transnational adoption becomes a paradigmatic example of how 'imperialist processes "over there" and social relations "over here" intersect' (Eng, 2010: 95); that is, in transnational adoption, private family and kinship dynamics are conflated with public histories of race, class, and gender. In the series, however, it is Robin, the white female protagonist, who gives up her child for adoption, an emotional drama bolstered by Elizabeth Moss's roles in Mad Men and The Handmaid's Tale. These narratives also place white women's experience of reproduction at centre stage and omit the historical and present role of race in adoption and surrogacy, hence whitewashing these experiences (Doane and Bonilla-Silva, 2003; Gibney and Askeland, 2017).

\section{CONCLUSION}

Top of the Lake: China Girl is a multilayered narrative addressing complex issues of sexualised and racialised power relations and vulnerabilities. In our reading, we have demonstrated how the series sets vulnerability in motion in terms of stereotypical and fetishising images of Asian femininity as exploitable and disposable, as well as in terms of an intense emotional drama about white women's experiences of sexual violence, reproduction, and motherhood. The affective economy of the series, we argue, privileges and attaches great value to white femininity as precious, emotionally fragile, and at risk of abuse - against the flat backdrop of passive and emotionally indifferent Asian sex workers. Only the white mothers are allowed to feel, whereas the feelings, thoughts, and desires of the surrogate mothers are not part of the story. Vulnerability, we argue, becomes a vehicle by which experiences of trauma and hurt in regard to sexual violence as well as reproduction are whitewashed in the series. Rather than focusing on the Thai women's material and physical vulnerability as illegally contracted surrogates exposed to the risk of being murdered, the series explores in depth the psychological injuries suffered by Robin having given up her child for adoption, as well as by the intended parents going mad from longing for children. Most clearly, we conclude, the series illuminates the crucial role of vulnerability in the ongoing debate about transnational commercial surrogacy and its conflicting 
discourses of reproductive rights and reproductive justice. It demonstrates how an idea of extreme emotional vulnerability of white intended parents can powerfully override concerns for the material and physical precarity of surrogates in the Global South.

\section{NOTES}

1 'China Girl' is also the title of a David Bowie hit single from 1983, which deals with stereotypes of East Asian women and racism.

2 Manipulative men are a recurrent theme in Campion's work: Isabel Archer's husband Gilbert in Portrait of a Lady (1996) and Ada's lover Baines in The Piano (1996) are other examples.

\section{REFERENCES}

Andersen, U. C. (2012). 'Offerposisjonens paradoks. Offentlig debatt om surrogati', Tidskrift for samfunnsforskning, 54:1, pp. 31-62.

Arvidsson, A., S. Johnsdotter and B. Essén (2015). 'Views of Swedish commissioning parents relating to the exploitation discourse in using transnational surrogacy', PLoS ONE, 10:5, e0126518. doi:10.1371/journal.none.0126518.

Bailey, A. (2011). 'Reconceiving surrogacy: Toward a reproductive justice account of Indian surrogacy', Hypatia, 26:4, pp. 715-41.

Balac, S. (2017). 'Den kvinnliga blacken är här, och den är inte nådig', Aftonbladet (10 June).

Banerjee, A. (2014). 'Race and a transnational reproductive caste system: Indian transnational surrogacy', Hypatia, 29:1, pp. 113-28.

Boivin, J., T. C. Appleton, P. Baetens, J. Baron, J. Bitzer, E. Corrigan, K. R. Daniels, J. Darwish and D. Guerra-Diaz (2001). 'Guidelines for counselling in infertility: Outline version', Human Reproduction, 16:6, pp. 1301-4. doi:10.1093/ humrep/16.6.1301.

Budowski, J. (2017). 'Top of the Lake: China Girl tackles trauma unlike any other show on television', Decider (13 September).

Butler, J. (2014). 'Vunerability and resistance revisited', presentation at Trinity College, Dublin (5 February).

Chavkin, W. and J. M. Maher (eds) (2010). The Globalization of Motherhood: Deconstructions and Reconstructions of Biology and Care. New York: Routledge.

Cohen, L. (2005). 'Operability, bioavailability and exception', in Aihwa Ong and Stephen J. Collier (eds), Global Assemblages: Technology, Politics and Ethics as Anthropological Problems. London: Blackwell Publishing, pp. 79-90.

Colen, S. (1995). " "Like a mother to them": Stratified reproduction and West Indian childcare workers and employers in New York', in F. D. Ginsburg and R. Rapp (eds), Conceiving the New World Order: The Global Politics of Reproduction. Berkeley, Los Angeles and London: University of California Press, pp. 78-102. 
Cooper, M. and C. Waldby (2008). 'The biopolitics of reproduction: Post-Fordist biotechnology and women's clinical labour', Australian Feminist Studies, 23:55. http://dx.doi.org/10.1080/08164640701816223.

Cooper, M. and C. Waldby (2014). Clinical Labor: Tissue Donors and Research Subjects in the Global Bioeconomy. Durham, NC and London: Duke University Press.

Damelio, J. and K. Sorensen (2008). 'Enhancing autonomy in paid surrogacy', Bioethics, 22:5, pp. 269-77. doi:10.1111/j.1467-8519.2008.00629.

Doane, A. and E. Bonilla-Silva (2003). White Out: The Continuing Significance of Racism. New York: Routledge.

DuPuis, R. (1996). 'Romanticizing colonialism: Power and pleasure in Jane Campion's The Piano', The Contemporary Pacific, 8:1, pp. 51-79.

Ellis-Petersen, H. (2017). 'Jane Campion: My Top of the Lake research involved sneaking into brothels', Guardian (18 July), www.theguardian.com/tv-and-radio/ 2017/jul/18/jane-campion-my-top-of-the-lake-research-involved-sneakinginto-brothels (accessed 18 December 2017).

Eng, D. L. (2010). The Feeling of Kinship: Queer Liberalism and the Racialization of Intimacy. Durham, NC: Duke University Press.

Farrell Smith, J. (2005). 'A child of one's own: A moral assessement of property concepts in adoption', in S. Haslanger and C. Witt (eds), Adoption Matters: Philosophical and Feminist Essays. Ithaca, NY and London: Cornell University Press, pp. 112-34.

Gibney, S. and L. Askeland (2017). 'Race, interxectionality and the end of the world: The problem with the Handmaid's Tale, The Nerds of Color, https:// thenerdsofcolor.org/2017/05/10/race-intersectionality-and-the-end-of-theworld-the-problem-with-the-handmaids-tale (accessed 14 December 2017).

Ginsburg, F. and R. Rapp (eds) (1995). Conceiving the New World Order. Berkeley: University of California Press.

Gondouin, J. (2015). 'Global feminist motherhood: On single mother adoption and white feminity in a Swedish media context', in C. Kroløkke, L. Myong, S. Willum Adrian and T. Tjørnhøj-Thomsen (eds), Critical Kinship Studies: Kinship (Trans) Formed. London: Rowman \& Littlefield International, pp. 101-16.

Gupta, J. A. (2006). 'Towards transnational feminisms: Some reflections and concerns in relation to the globalization of reproductive technologies', European Journal of Women's Studies, 13:1, pp. 23-38.

Howard, S. (2014). 'Taming in international surrogacy industry', British Medical Journal, 349:633, pp. 1-3.

Jones, E. E. (2017). 'Empty nests: Why has TV become obsessed with surrogate mothers?', Guardian (14 August).

Kang, I. (2017). 'Bottom of the list: The return of Top of the Lake is only 2017's second best wrenching Elisabeth Moss drama', The Village Voice (13 September).

Krølokke, C. and S. Pant (2012). " "I only need her uterus”: Neo-liberal discourses on transnational surrogacy', NORA - Nordic Journal of Feminist and Gender Research, 20:4, pp. 233-48.

Millbank, J. (2012). 'From Alice and Evelyn to Isabella: Exploring the narratives and norms of "new" surrogacy in Australia,' Griffith Law Review, 21:1, pp. 101-36.

Mohanty, C. T. (2003). Feminism Without Borders: Decolonizing Theory, Practicing Solidarity. New Delhi: Zubaan. 
Mohapatra, S. (2012). 'Achieiving reproductive justice in the international surrogacy market', Annals of Health Law, 21:1, pp. 190-200.

Nahman, M. (2008). 'Nodes of desire: Romanian egg sellers, "dignity" and feminist alliances in transnational ova exchanges', European Journal of Women's Studies, 15:2, pp. $65-82$.

Nussbaum, M. (1998). "Whether from reason or prejudice”: Taking money for bodily services', Journal of Legal Studies, XXVII, pp. 693-724.

Pande, A. (2010). 'Commercial surrogacy in India: Manufacturing a perfect motherworker', Signs: Journal of Women in Culture and Society, 35:4, pp. 969-92.

Parreñas, R. S. (200o). 'Migrant Filipina domestic workers and the international division of reproductive labor', Gender E Society, 14:4, pp. 560-80.

Prasso, S. (2005). The Asian Mystique: Dragon Ladies, Geisha Girls, and Our Fantasies of the Exotic Orient. New York: Public Affairs.

Pulver, A. (2013). 'Top of the Lake: first look review', Guardian (9 February).

Ragone, H. and F. W. Twine (eds) (200o). Ideologies and Technologies of Motherhood: Race, Class, Sexuality, and Nationalism. New York and London: Routledge.

Rao, M. (ed.) (2004). The Unheard Scream: Reproductive Health and Women's Lives in India. New Delhi: Zubaan.

Rao, M. (2010). Markets and Malthus: Population, Gender and Health in Neo-liberal Times. New Delhi: Sage.

Riggs, D. W. and C. Due (2010). 'Gay men, race privilege and surrogacy in India', Outskirts Online Journal, 22. www.outskirts.arts.uwa.edu.au/ volumes/volume22/riggs (accessed 10 September 2017).

Riggs, D. W. and C. Due (2013). 'Representations of reproductive citizenship and vulnerability in media reports of offshore surrogacy', Citizenship Studies, 17:8, pp. 959-69. doi:10.1080/136210 25.2013.851145.

Riggs, D. W. and C. Due (2014). "The contented faces of a unique Australian family": Privilege and vulnerability in news media reporting of offshore surrogacy arrangements', Feminist Media Studies, 14:5, pp. 869-72.

Roberts, D. (1996). 'Race and the new reproduction', Hastings Law Journal, 47, pp. 935-49.

Ross, L. and R. Solinger (2017). Reproductive Justice: An Introduction. Oakland: California University Press.

Rudrappa, S. (2012). 'India's reproductive assembly line', Contexts, 11:2, pp. 22-7. doi:10.1177/1536504212446456.

Scheper-Hughes, N. (2004). 'The last commodity: Post-human ethics and the global traffic in "fresh" organs', in A. Ong and S. Collier (eds), Global Assemblages. London: Basil Blackwell, pp. 145-68.

Shanley, M. L. (2001). Making Babies, Making Families: What Matters Most in an Age of Reproductive Technologies, Surrogacy, Adoption, and Same-Sex and Unwed Parents. Boston: Beacon Press.

Sunder, Rajan, K. (2007). 'Experimental values: Indian clinical trials and surplus health', New Left Review, 45, pp. 67-88.

Turner, S. B. (2001). 'The erosion of citizenship', The British Journal of Sociology, 52:2, pp. 189-209. 
Turner, S. B. (2008). 'Citizenship, reproduction and the state: International marriage and human rights', Citizenship Studies, 12:1, pp. 45-54.

Twine, F. W. (2015). Outsourcing the Womb: Race, Class and Gestational Surrogacy in a Global Market. New York: Routledge.

Twine, F. W. (2016). 'The fertility continuum: Racism, biocapitalism and postcolonialism in the surrogacy industry'. Paper presented at the workshop 'Making Families: Transnational Surrogacy, Queer Kinship \& Reproductive Justice', Center for Genetics and Society, UC Berkeley (19 February).

van den Akker, O., P. Fronek, E. Blyth and L. Frith (2016). 'This neo-natal menage a trois: British media framing of transnational surrogacy', Journal of Reproductive and Infant Psychology, 34:1, pp. 15-27.

Vineyard, J. (2017). 'Top of the Lake: China Girl: Jane Campion on her "ovarian" series', New York Times (12 September).

Vora, K. (2008). 'Others' organs: South Asian domestic labor and the kidney trade', Postmodern Culture, 19:1. doi:10.1353/pmc.0.0036.

Vora, K. (2009). 'Indian transnational surrogacy and the commodification of vital energy', Subjectivity, 28:1, pp. 266-78. doi:10.1057/sub.2009.14.

Vora, K. (2012). 'Limits of "labor": Accounting for affect and the biological in transnational surrogacy and service work', South Atlantic Quarterly, 111:4, pp. 68170o. doi:10.1215/o0382876-1724138.

Wiegand, D. (2017). 'Stunning perfomances elevate new Top of the Lake season', San Francisco Chronicle (4 September).

Wool-Rim Sjöblom, L. (2017). ‘̈̈ven kvinnor förslavar kvinnor, Flamman (10 November).

Yngvesson, B. (2010). Belonging in an Adopted World: Race, Identity and Transnational Adoption. Chicago and London: Chicago University Press. 


\title{
8 \\ SPECTACULARLY WOUNDED \\ White male vulnerability as heterosexual fantasy
}

\author{
SUSANNA PAASONEN
}

$\mathrm{I}^{\mathrm{n}}$ n a 2012 interview, E. L. James, the author of the massively popular Fifty Shades novel series, describes its male protagonist Christian Grey as 'the ultimate fantasy guy. And that's the point: As long as you accept that fantasy guy - fantasy sex, fantasy lifestyle, a broken man who needs fixing through love - what woman could resist that?' (in Thomas, 2012.) Grey is a twenty-seven-year-old, white, cis-gendered, Seattle-based multi-billionaire businessman CEO firmly representative of the one per cent. As the most privileged, he is nevertheless depicted as also being spectacularly broken and scarred by childhood trauma. Starting from and revolving around James' articulation of a hurt, damaged man as an irresistible object of heterosexual desire, this chapter inquires after the intermeshing of privilege, vulnerability and desirability in the narrative fantasy of Fifty Shades.

Written as fan fiction online and launched as e-books in 2011-12, James' trilogy gained viral popularity and was published through Vintage as Fifty Shades of Grey (2012a), Fifty Shades Darker (2012b) and Fifty Shades Freed (2012c). Despite the notably and unequivocally negative critical reception that the series continues to enjoy, it has been translated into more than forty languages and sold over 125 million copies worldwide (Deller et al., 2013; Grigoriadis, 2015). The trilogy has spawned a film trilogy as well as a literary spin-off trilogy - comprising Grey (2015), Darker (2017) and the forthcoming Freed - which recounts the narrative from Christian Grey's perspective in order to shed further light on his inner life (see Flood, 2015).

The first volume introduces the main couple: Christian Grey and Anastasia Steele - a twenty-one-year-old English literature undergraduate student - the blossoming of their mutual passion, her introduction to sexual pleasure and his kinky tendencies, and the childhood traumas and 
desire for control that haunt the couple's newly acquired bliss. At the end of the first book Anastasia leaves, only for the couple to be reunited in the beginning of the next one. Following the classic romance narrative formula of 'boy meets girl, boy loses girl, boy gets girl', the two remaining books focus on the couple's growth haunted by past shadows, threats of external intervention and violence. These events intersect with Christian's initiation to loving care and gradual recovery from trauma, as well as the couple's passage into monogamous matrimony and parenthood (Pääkkölä, 2016: 14). Despite thinking of his heart as having been 'savaged beyond recognition a long time ago' (James, 2015: 10), romance makes it possible for Christian to reveal his inner softness and uproot early experiences of hunger, violence, hurt, death, abandonment and neglect in ways enabling therapeutic healing.

This chapter asks what makes the traumatised and vulnerable super-rich white man appealing as a heterosexual fantasy figure. In order to unravel vulnerability as both a fantasy that lends the series much of its commercial power and a narrative instrument deployed in character building, I first examine the use of generic romance and erotica conventions (e.g. Radway, 1984; Snitow, 1983) as well as the gendered forms of affective labour that the figure of the broken, rich, sad white man entails, motivates and fuels. Second, and in connection with Eva Illouz's (2014) analysis of Fifty Shades as self-help, I inquire after the interconnections of trauma and sexual fantasy within the novels' broad appeal. Third, bringing these strands of discussion together, I ask how male vulnerability of the spectacular kind works in relation to social and economic privilege, the dynamics of BDSM and gendered relations of power - namely, how the narrative centrality of a privileged yet broken white man attunes the imagery of material opulence, limitless wealth, kink play and heterosexual fulfilment in a markedly depoliticised vein. Vulnerability, as examined in this chapter, is primarily a narrative instrument crucial to the dynamics of romance as a story of growth, transformation and intimacy.

\section{ROMANCE REMIXED}

Christian's hidden vulnerability and brokenness are presented as key components to the overall fantasy scenario, and it is Anastasia's task to rescue and fix him through romantic love. According to the generic romance formula that is dutifully followed here, the virginal, younger heroine is the one with the special capacity to soften, tame and heal the romantic hero whose hard shell hides his insecurities and fragilities (Snitow, 1983: 249). The heroine's capacity to do this renders her exceptional and forms a specific, exclusive bond between the couple. As Janice Radway (1984: 128-9) points 
out in her classic analysis of popular romance novels and their avid readers, heroines need to be able to 'translate male reticence and cruelty into tenderness and devotion' by bringing 'to the surface traits and propensities that are part of the hero's most basic nature'. Faithfully conforming to this script, Anastasia - 'good and innocent and courageous' (James, 2015: 511) - is able to rescue Christian from his nightmares of childhood abuse. Meanwhile,

\begin{abstract}
The hero of the romantic fantasy is always characterized by spectacular masculinity. Indeed, it is insufficient for the author to remark in passing that the romantic hero has a muscular physique. The reader must be told, instead, that every aspect of his being, whether his body, his face, or his general demeanor, is informed by the purity of his maleness. Almost everything about him is hard, angular, and dark. It is, however, essential to add the qualifying 'almost' here because, in descriptions of the ideal romantic hero, the terrorizing effect of his exemplary masculinity is always tempered by the presence of a small feature that introduces an important element of softness into the overall picture. (Radway, 1984: 128)
\end{abstract}

First coined as Twilight fan fiction on an online forum, Fifty Shades is essentially a sexed-up variation of romantic genre fiction that borrows from familiar tropes, scenes and characters. In Twilight, the dark hero is literally a vampire - a pale immortal teenager - whose passion, should it be unleashed, would be the romantic heroine's undoing. In Fifty Shades, the hero is a white elite businessman described as an 'elegant, beautiful, Greek god' (James, 2012b: 183) with 'unruly dark copper colored hair and intense, bright gray eyes' (James, 2012a: 7). Thus his darkness - central to the romantic hero - is not lodged in physical features inasmuch as in the heavy shadows of trauma, deep dark secrets and sexual tastes ringing with risk (Harrison and Holm, 2013). An avid athlete, Christian is sketched out as a physical joy to behold, and Anastasia is frequently lost in visual contemplation of his overpowering, magnetic good looks: 'My mouth goes dry as he casually strolls around the piano toward me. He has broad shoulders, narrow hips, and his abdominal muscles ripple as he walks' (James, 2012a: 112). In a fully Gothic vein, Christian, filled with self-doubt and self-hate, nevertheless thinks of himself as nothing short of a monster with a 'dark, twisted', 'ugly, torn' soul, and can only feel relieved for Anastasia not to know the depths of his depravity that lurks beneath the handsome surface (James, 2015: 43, 501, 504-5, 545).

The romantic couple's relationship is rife with traumas and frictions, yet these rarely extend to their scenes of sexual play. In fact, frictions and tensions of all kinds are lubricated with and overcome through abundant, mutual and easily available sexual pleasure. Their relationship is initially designed as a contractual one under Christian's scripting, but unfolds as 
a highly compatible, intense and mutually gratifying one. Despite his inner darkness and nightly regressions into traumatised infancy, Christian remains in control as endlessly skilled and knowledgeable about carnal pleasures. As the resident sexual expert, he knows Anastasia's body and desire much better than she does, and guides her through experimentations of all kinds. In fact, as Meg-John Barker (2013: 898) notes, 'Anastasia rarely communicates any desires of her own but rather Christian orchestrates their scenes completely'. Consent is therefore 'inevitably complicated under such conditions wherein one person does not know their desires and is restricted from articulating some possibilities, whilst the other automatically knows what they both want' (Barker, 2013: 890). Scenes of sexual play do not, for the most part, involve much activity from Anastasia. It is Christian who sets the scene and coins and explains the rules, which may or may not be negotiable. He does so according to his own preference while also mastering the secrets of Anastasia's pleasure, which, consequently, turn out to be not secret at all.

There is no room in their scenes of sexual submission and domination for the reversal of or play with roles. Consequently, scenes of female submission and male domination are mapped onto a gendered dynamic of unequal social status and agency, where Christian's desire for control extends beyond the 'red room of pain' to the details of Anastasia's diet, exercise, birth control and social life. His tendencies for stalking and jealousy are depicted as ultimately in her best interest, while possessiveness and jealousy translate as love and commitment. In this sense, the books explicitly prop up the gendered hierarchies of control and privilege that frame and structure the couple's relationship, and find support from the broader social dynamics of privilege. These dynamics come wrapped up in a fantasy scenario of youth, white physical beauty and abundant wealth, manifesting in lavish apartments, private planes, helicopters, yachts, new cars, expensive jewellery, designer fashions, fine dining and exclusive holidays. The fantasy on offer is unburdened by scarcity or need other than that of the emotional and physical kind, the gradual yet constant fulfilment of which comprises the main narrative tension.

\section{KINK IN THE ROMANCE PATTERN}

The ingredient of BDSM initially marked Fifty Shades apart from other competing romantic erotica titles and afforded it with a specific edge. The series is naughty, yet its transgressions occur safely within the confines of heterosexual romance, commitment and passion (Dymock, 2013). Like Ann Summers parties promoting sex toys and other paraphernalia to women, 
the novels chart out the boundaries of 'the acceptably kinky' within the marshes of the 'plain perverted', while foregrounding female pleasure throughout (Storr, 2003: 208-11). In fact, it is the separation between the acceptably and the unacceptably kinky that guides the narrative as a negotiation between the partners' different preferences, expectations and boundaries of comfort. While Christian's BDSM preferences are motivated as trauma play allowing for a sense of control that he so craves, for Anastasia this remains both a fascinating and uneasy testing ground for what her body may or may not like, and what practices of pleasure the world may generally hold. As their relationship develops, Christian removes the paraphernalia undesired by Anastasia from his playroom, and the couple constantly negotiate what toys or scenes to experiment with. In the course of this all, the playroom shifts from being the centre of Christian's sexual routines to an additional spice. Meanwhile, their more-or-less kinky patterns of play leak into the other rooms of his vast penthouse, hotels, elevators, boats and private planes.

In accordance with the conventions of romance (Snitow, 1983: 247), Anastasia's perspective is emphasised in the first three books through the uses of the first-person point of view and the description of sensory intensities that it affords. The echoes of transgression connected to Christian's kinky bent and Anastasia's curiosity about her bodily capacities, combined with the couple's insatiable lust for one another, revolve in the registers of excess characteristic of pornographic fiction. The flood of sexual desire comes across as a visceral force that fills their lives with enchantment, liveliness and meaning: 'I am just sensation. This is what he does to me - takes my body and possesses it wholly so that I think of nothing but him. His magic is powerful, intoxicating. I'm a butterfly caught in his net, unable and unwilling to escape. I'm his ... totally his' (James, 2012b: 79).

As Ruth Deller and Clarissa Smith (2013: 937) point out, the fact that the Fifty Shades series is, with the exception of Grey, 'Written by a woman, from a woman's point of view and for a female audience', the books have been 'discursively fabricated as potentially revelatory so that to read them was to engage in public debate about female sexuality'. As a media phenomenon, the series is tightly entangled with the notion of women's culture as an iconic piece of 'mummy porn' that has been often defined as a compendium of E. L. James's own sexual fantasies (e.g. Dymock, 2013: 883). Here, Christian - 'a broken man who needs fixing through love' - stands for the penultimate heterosexual fantasy figure who, despite his shell of privilege, remains but a fragile husk of a man.

Despite Christian's extraordinarily exclusive lifestyle that the novels so attentively detail, the quotidian reverb of 'raising the ordinary to the extraordinary' (James, 2015: 16) cuts through the books, from the couple's first 
encounter when Anastasia makes the remark about an artwork in his office, to scenes where her orgasms unfold similarly to the spin cycles of a washing machine, and where the act of cooking a chicken fry-up transforms into an intensely sexual scene. Romantic and sexual desire elevates Christian's sombre moods from 'flat and gray as the weather' into ones of heightened aliveness, and shifts his monotonous and monochrome world 'into one rich with color' (James, 2015: 4, 518). His world rotates 'on a different axis' as Anastasia brings his heart back to life (James, 2017: 127, 231). For her part, Anastasia has 'never felt so alive, so vital' (James, 2012b: 359, 375). According to the generic defaults of romance fiction, 'The body of the heroine is alive and singing in every fiber, she is overrun by sexuality that wells up inside her and that she cannot control' (Snitow, 1983: 254). This all results from the immediate attraction between the couple that galvanises their bodies and makes them flourish.

Ann Snitow (1983: 256) associates the sex-saturated liveliness of romance fiction with the generic features of pornography that explore the explosion of the boundaries of the self and where social constraints are overwhelmed by a flood of sexual energy'. For Snitow, romance fiction differs from pornography mainly in how it negotiates, or balances, the visceral force of sex with romantic magnetism and the goal of domestic security (Snitow, 1983: 259; also Smith, 2007: 201). This magnetism and security ultimately make it possible for Christian to have his body touched and change his routines of sexual play from the singularly kinky towards vanilla. As love making, sex becomes an arena for the production of intimacy and trust.

In contrast to the plenitude of bodies and desires, abundant satiation and 'enjoyment in sensuous material reality' that, according to Steven Marcus $(1964,22)$, form the basis of the pornographic narrative realm, Fifty Shades narrows down the availability of sexual partners to just one person while tying desire to monogamous commitment. At the same time, a plenitude of enjoyment is taken in access to exclusive goods. The frame of propriety is highlighted and eroticised throughout the main couple's relationship where repetitive declarations of ownership fuel desire for both parties involved: “"You are mine," he whispers. "Only mine. Don't forget it." His voice is intoxicating, his words heady, seductive. I feel his growing erection against my thigh' (James, 2012a: 119). In the state of matrimony, the wedding ring, as a symbol of possession, becomes something of an arousing fetish object in its own right: 'I reach for his left hand and plant a kiss on his wedding ring, a plain platinum band matching my own. "Mine," I whisper' (James, 2012c: 119). 'His wedding ring clinks against the glass as he takes another sip of wine. Now that is a sexy sound' (James, 2012C: 240). In these instances, sexual desire, ownership and romantic love are glued into a fantasy scene of proprietary and monogamous bliss. 
The core story of Fifty Shades is one of overwhelming, possessive heterosexual desire set in the surroundings of exclusive white privilege. With the exception of Claude, Christian's black, kickboxing champion trainer, José, Anastasia's photographer friend who sometimes fails to respect her boundaries of bodily integrity, and José's father, the gallery of characters is firmly white. Within the novels' heterosexual realm, there are no other directions for fantasies and attachments to ripple. During the first encounter, Anastasia, interviewing Christian on her best friend Kate's behalf, asks if he is gay. In Grey's first-person narration, this misrecognition makes it possible to more clearly outline his sexual palates: 'How dare she! I have a sudden urge to drag her out of her seat, bend her over my knee, spank her, and then fuck her over my desk with her hands tied behind her back. That would answer her ridiculous question' (James, 2015: 12). References to this fundamental misunderstanding of Christian's celibate public image re-emerge as jokes, given his evident, steadfast heterosexuality: 'I wrap my arms around him, marveling at the ridiculousness of Christian being gay' (James, 2012C: 280).

Heterosexual coupling abounds in the series more widely: in addition to Anastasia and Christian marrying, Kate marries Christian's brother Elliot while their sister Mia pairs up with Kate's brother Ethan. This somewhat claustrophobic, quasi-incestuous pattern of coupling keeps things firmly in the family while allowing for undisturbed sociability within the couple format. Meanwhile, queer people appear as liberal accents at the margins of the story as gay male hairdressers and massage therapists, as well as Ros Bailey, the lesbian Vice President of Grey Enterprises Holdings, Inc. Intimacy in Fifty Shades is framed as both heterosexual and familial. In the broader narrative arc, the Grey family both grows with new daughters and brothers in law and becomes increasingly whole as Christian opens to being physically touched and emotionally expressive.

\section{TRAUMA AND EMOTIONAL LABOUR}

Christian's journey of self-discovery and healing, as narrated by James, closely follows a popular Freudian route where sexual preferences and behaviours are rooted in childhood events, relationships and traumas. In other words, Freudian trauma functions here as a narrative template that runs parallel to and supports the genre conventions of romance and erotica. Christian dominates young brown-haired women, having witnessed the abuse and death of his young and brown-haired drug addict mother by her pimp, who hit, kicked and burnt him with cigarettes. The stuff of trauma emerges as a key explanation for both Christian's BDSM interest and 
discomfort with physical intimacy in ways that position his kink preference as an outcome of harm, and therefore a problem to be solved.

Anastasia, who becomes the only woman allowed to touch the scars on Christian's muscular, sculpted torso, finds herself thinking of them as a 'stark physical embodiment of a horrific childhood and a sickening reminder of what mental scars he must bear' (James, 2012b: 125). Figuring out the routes of trauma, she soon charts their connections with 'his control freakery, his possessiveness, his jealousy, his overprotectiveness ... I can even understand why he doesn't like to be touched - I've seen the physical scars. I can only imagine the mental ones, and I've only glimpsed his nightmares once' (James, 2012b: 422). This specific product of 'mummy porn' then positions the female protagonist as an emotional caretaker for whom nursing the broken rich white man through trauma is a labour of love. Initially, Anastasia's life starts to revolve around the mystery of Christian's trauma. Once the roots of trauma are uncovered, the emotional labour needed for working through it becomes her central mission. In other words, the gendered demands of affective labour - of reproductive care, emotional support, as well as positive affective amplification (Hochschild, 2003) - become the elementary stuff of romance. Framed as a female heterosexual fantasy, the task and requirement of emotional labour positions Christian, a figure of privilege condensed, as a 'lost boy' acutely dependent on feminine acceptance and care.

Childhood trauma - recounted in several flashback snippets of nightmare - explains Christian's compulsion to control and punish Anastasia, as well as keep her safe. These aspects then fold into BDSM play as a form of DIY therapy (James, 2015: 425). In his recurrent nightmares, Christian regresses into childhood, observing his frightening surroundings from the perspective of an infant, and with the emotional registers of one.

It is dark now, and my mommy is gone. I can reach the light when I stand on the stool.

On. Off. On. Off. On. Off.

Light. Dark. Light. Dark. Light.

I'm hungry. I eat the cheese. There is cheese in the fridge. Cheese with blue fur.

When is Mommy coming home?

Sometimes she comes home with him. I hate him. I hide when he comes. My favorite place is in my mommy's closet. It smells of Mommy. It smells of Mommy when she's happy. When is Mommy coming home?

My bed is cold. And I am hungry. I have my blankie and my cars but not my mommy. When is Mommy coming home? (James, 2015: 216)

Unlike the sad blue-collar men of contemporary American film that Jack Halberstam (2017) identifies as being sad due to low pay, the uncaring 
women around them and the broader, oppressive conditions of contemporary life, Christian is sad in a cocoon of wealth with a very caring and attentive woman indeed. There is little to the trimmings and resources of his life that calls for audience empathy or pity. Yet, similarly to the cinematic depiction that Halberstam explores, audience empathy is requested, or even demanded, for the figure of the sad white man on whose hurt narrative attention clusters. Childhood trauma provides an origin story that circumvents Christian's uber-privileged circumstances by revealing the deeper, persistent current of damage and vulnerability at his core that he so tries to hide. In other words, vulnerability amounts to an inner truth concerning Christian's character.

Christian lives haunted by an engulfing darkness, frightened by feelings of love and affection. Becoming animated by romantic love means becoming subject to the potential of further emotional harm, which makes love terrifying as such: 'That strange feeling swells in my chest. Scarier than the darkness, Bigger. More potent. It has the power to wound' (James, 2017: 206). 'I'm a lost boy, standing before you. Unloved. Abandoned by the one person who was supposed to protect me, because I'm a monster' (James, 2017: 218).

Since this partly infantilised, privileged sad white man is also the 'ultimate fantasy guy', trauma is central to the fantasy that the series caters for. Within this narrative realm, Christian's vulnerability makes it possible to communicate interiority and personal depth, as well as chart his passage of growth. White male vulnerability creates an acute demand for the female heroine and her emotional labours while also investing them with immeasurable value - for, as James repeatedly points out, Anastasia is doing nothing less than saving him. The versatile emotional labour that fixing the wounded, tormented man requires spans from maternal care to romantic intimacy and sexual athletism. In a pattern more than subtly suggestive of Freudian patterns of trauma, the transformations afforded by romance shift Christian's painful dreams to happy ones where the smell of the lost mother blends into the sweet scent of his new girlfriend and bride-to-be:

Mommy sits looking at me in the mirror with the big crack.

I brush her hair. It's soft and smells of Mommy and flowers ...

And she turns around and smiles at me.

Today, she's happy.

I like it when Mommy is happy.

I like it when she smiles at me.

She looks pretty when she smiles.

Let's bake a pie, Maggot.

Apple pie. 
I like when Mommy bakes.

I wake suddenly with a sweet scent invading my mind. It's Ana. (James, 2015:320-1)

The Freudian model of sexual desire is rooted in primary trauma as the child comes to realise their separateness from 'the caretaking environment/ mother/breast that she relies on for nurturance and pleasure' (Berlant, 2012: 27). The mother's body, and the lost breast in particular, is the object of both desire and trauma. In this narrative of loss, lack and melancholy, 'to love an object is to attempt to master it, to seek to destroy its alterity or Otherness' (Berlant, 2012: 25). Love is not antithetical to aggressiveness if sadism and masochism are seen as integral to human attachment. Meanwhile, 'Love enables the pressure of desire's aggression to be discharged within a frame of propriety' (Berlant, 2012: 25). All this finds an incarnation in the damaged, needy Christian haunted by memories of his mother, practising structured BDSM routines as a means of self-therapy and moving into the security of proprietary monogamy in the course of romance.

\section{FANTASY BEYOND TRAUMA}

In her analysis of the series, Illouz identifies it as a genre hybrid combining Gothic romance with self-help. For Illouz (2014: 30), it primarily offers a social fantasy rather than a sexual one, providing guidelines for navigating the tensions of heterosexual gender relations in late capitalist culture. Understood in this vein, the remarkable success of Fifty Shades, like that of other bestsellers, is indicative of its providing solutions to social tensions and guidelines towards a happier life - a point made earlier by both Radway and Snitow, who see Harlequin narratives as negotiating and possibly compensating for the discrepancies and unresolvable tensions of heterosexual relationships. In addition to improving sexual lives with the aid of practical tips, Fifty Shades, according to Illouz, also promises to pave the way to happier relationships and self-discovery.

Illouz deploys the term 'resonance' to describe how books that become bestsellers encapsulate something of that which Raymond Williams (1977: 133-4) identified as structures of feeling, namely common yet partly emergent and hence possibly ephemeral qualities and experiences of life characteristic for specific generations, contexts or locations. For Illouz, it is that which resonates among readers, striking a chord in its familiarity but also formulating something that they have not quite found the means to express: 'Resonate here means that a narrative is able not only to address a social experience that is not adequately understood, named, or categorized 
but also to "frame" it in adequately explanatory ways' (Illouz, 2014: 23, emphasis in the original). Illouz's analysis focuses on the social experiences of heterosexuality in late capitalist cultures without extending to those connected to race or class. Anastasia's upward mobility from modest means to extravagant riches, as facilitated by romantic coupling, is smoothed over by her whiteness: while she may not always feel like belonging to her novel settings, in the eyes of those around her the fit is nothing short of perfect. The social experiences that the series frames and that possibly find resonance in its readers are impossible to decouple from the tiers of social privilege connected to and afforded by whiteness.

Since Illouz sees Fifty Shades primarily as a social fantasy speaking to women in relationships, she does not frame it as pornographic stimulation as such. There is nevertheless no need to see these two modes of reading - of advice and of sexual arousal - as mutually exclusive. In the case of Fifty Shades, such a division in fact turns attention away from the centrality of sexual fantasy as its key content and attraction. The novels' success among readers can be connected to the pleasurable circulation of sexual fantasies that intensify and animate bodies. Such circulation cannot be neatly reduced to functionality or instrumentality of the kind implied by the explanatory framework of self-help.

In his discussion of sexual fantasies, Martin Barker (2014: 145) maintains a critical distance from Freudian and post-Freudian psychoanalytical theories that treat fantasies as compensatory 'playback for real traumatic experiences' and the 'distorted management of childhood problems and traumas, almost always family generated', such as those driving Christian Grey. Instead, Barker is interested in the diverse work that sexual fantasies do in peoples' lives as a means of trying 'out versions of self-in-sexual-society, reimagining themselves through others' reimaginings' (2014: 146). He offers a five-fold conceptualisation of sexual fantasy as 'a conscious accentuation of desire'; 'a means to look at our responses to things'; 'a world of possibilities to be explored and thought about'; 'a visitation to a distant realm of desires and fantasies' and an imagining of 'what I might or might not be' (2014: 155). Understood in this vein, fantasies contribute to the creation of novel connections, the imagining of scenarios, the build-up of desire and the emergence of bodily pleasure. Rather than being rooted in trauma, sexual fantasy is reframed as the productive exploration of bodily horizons of possibility. Fifty Shades is both a sexual and a social fantasy for the reason that it is not possible to separate the two - that is, to somehow ply the sexual apart from the social. It then follows that vulnerability, as it cuts through the fabric of romance, is connected to negotiations of dependency, trust and need within intimate relationships as Illouz suggests - as well as the discovery of bodily liveness and enchantment that sexual play affords in the framework of romance. Despite the 
centrality of trauma to Christian's orientation in the world, Anastasia's sexual discovery is a narrative of pleasure, even ecstasy. The first volume in particular - the most successful in the entire series - frames female sexuality as a realm of possibility and adventure, rather than one of healing or trauma.

E. L. James herself describes how, in the feedback she receives, women write of having discovered previously unknown aspects of themselves: 'They're quite freaked out by it, but in a good way. They're thinking, "Wow, this is amazing. Why has it taken me so long to discover this?"' (in Thomas, 2012). Such discovery can be understood through any of Barker's five conceptualisations of the productivity of sexual fantasies, but much less through the template of trauma. Writing on masochistic erotica, Smith (2009: 29) argues that its readers engage in an empathetic relation with the narration - this is how sex can feel, how it works on the body. It is a relation of co-animation. The pleasures of Fifty Shades can therefore be associated with 'corporeal intensification which requires going beyond the limits of "ordinary, nice, well-behaved sex"; submitting to feeling, letting go; letting oneself experience sexual desire' (Smith, 2009: 30).

Such zones of intensity engendered in acts of reading are resonant points of contact between personal sexual fantasies, and those rendered public through their publication and circulation. These then push and open up the perceived horizons of bodily possibility as that which readers can imagine doing, experimenting with or enjoying. Conceptualised in this vein, rather than in connection with social tensions and experiences à la Illouz, resonance describes instances of being moved, touched and affected by that which is tuned to the right frequency. Such attunement emerges as certain bodies, images, texts or figures of fantasy attract attention, fascinate and possibly stick. Resonance is descriptive of the momentary connection between bodies that varies in intensity and shape over time (Paasonen, 2011: 16-18; 2013). The resonance of Fifty Shades can be seen as coming from not only its power to address the complexities of heterosexual coupling but also its force to capture attention through the embodied reverbs that its narrative of sex and romance sparks. Written in the first-person point of view, the books describe in minute detail what is happening to the narrator's body and how all this feels. As is the case with pornography, these accounts of physical intensity, of bodies moving and being moved, aim to move the bodies of those reading within resonant moments.

\section{PLEASURES OF PRIVILEGE}

Fifty Shades is a story about personal fulfilment through sexual learning and intimacy. The positioning of the sad, white, damaged man in need 
of saving as an ultimate heterosexual fantasy figure attunes the available circuits of desire in particular ways. Christian's brokenness, trauma and vulnerability, narrated in accordance with a popular Freudian template, serve a key narrative function as a means of balancing the unequal relations of power between the main couple. It is Anastasia, and no other, who has the unique ability to heal Christian through emotional labour and sexual experimentation. In the course of all this, the books adopt and appropriate the language of vulnerability in ways that detach it from considerations of racialised, class-related and gendered structures of privilege and subordination. Rather, James frames vulnerability as a personal property emerging from tragic, under-privileged circumstances of hunger and neglect. Connected to trauma, it becomes exclusively an inner, individual condition detached from the current material conditions of Christian's life. This vulnerability then works to humanise his character as a representative of the global business elite as well as motivate romance as techniques of healing as his primary focus and priority.

Christian's wealth is initially presented as something of a dilemma for the romantic heroine to solve in ways assuring that Anastasia is no golddigger, yet its comforts soon overpower her hesitancy. Despite the abundant pleasures that the purchase of services, objects and other commodities afford, the cocoon of wealth does not suffice to keep out the harms and risks of the surrounding world. Christian employs therapists, a private security and private investigators, buys the safest of high-end German cars and dwells within the isolation of his luxury penthouse, yet none of this is enough to keep his inner turmoil at bay, or keep other people from infringing on his privacy in violent ways. Both inner and outer security then come across as elusive but valuable, while the lack of the former in particular tints Christian's life in unhappy shades. In contrast, romantic love provides therapeutic healing and emotional security of the kind that money cannot buy.

As is not particularly rare or surprising in erotica and romance, Fifty Shades veers away from addressing structural inequalities that give rise to the forms of privilege that it so carefully conveys. Rather, the series reinforces them through the perennial white saviour fantasy where Africa becomes a space for a white person to 'become a godlike savior or, at the very least, have his or her emotional needs satisfied' (Cole, 2012). Due to his childhood experiences, Christian is committed to fighting hunger in Africa by developing innovative agricultural techniques and renewable energy sources, and directly shipping food to the needy. His philanthropy is motivated by experiences of personal suffering that translate as and call for degrees of empathy. None of this is connected to the global structures of privilege and exploitation, or to the circulation of materials, goods and resources within which Christian's enterprises deal. Avoiding publicity 
for his charitable actions, Christian operates under no external pressure, encouragement or need; hence, the project of fighting world hunger is reimagined and refocused as being about the emotional drama of a rich white man. The activities of a white saviour soften Christian's character and provide it with some degree of depth and roundness. While the generosity of a super-rich American man towards the less fortunate functions as proof of his inner goodness and genuineness, the people to whom this help is targeted remain nowhere present or named as individuals speaking for themselves. Since the white saviour fantasy is both of and about white people, and their agency and emotional life (Cole, 2012), the less privileged and the starving function as narrative props in and ephemeral background for the construction of Christian Grey as the ultimate fantasy guy.

Written by James, a British author, the series caters for fantasies of American wealth and luxury decoupled from politics of race or issues of social justice. Given the books' massive global appeal, this fantasy resonates well beyond the United Kingdom or the United States. The setting of white wealth would then seem to involve a certain invisibility as a transnational fantasy template that translates easily from one language and social context to another. Zooming in on the inner vulnerabilities and emotional authenticity of Christian Grey makes it possible to efface some of his privilege, even when it is constantly being highlighted. White, straight, male privilege and vulnerability are therefore not mere trimmings to the overall fantasy catered for but central to its dynamic. The striking edge of privilege is rounded up by trauma and romance, which both soften the male hero and elevate the heroine to his equal as an exceptional and irreplaceable love object and emotional labourer.

Christian's position as the fantasy guy revolves around his divine looks, success, clout, sexual skill and inner softness. Critics have, however, regularly identified his character as 'an utter psychopath', 'a cut-price $\mathrm{Mr}$ Darcy in nipple clamps', 'a million different shades of sexist' and 'a deeply unpleasant, insecure asshole, whom readers are nevertheless called on to pity (Biederharn, 2015). As is obvious on the basis of the extended critiques squared against Fifty Shades, there is no universal resonance to this romantic hero or the ways in which James sketches out his inner life. At the same time, the stuff that the guy is made of - including the formulas of romantic fiction, the fleshy intensities of BDSM erotica, the shivers of Freudian sexual trauma, obsessive and possessive monogamous desire, extraordinary richness and white straight male privilege - boils down into a heady mixture with global market value and appeal. This stuff frames and orients the scenes of bodily transgression and sexual ecstasy, while also enclosing them in predictable patterns, hierarchies and dynamics. 
In the midst of this all, vulnerability has particular value as a narrative tool that grants Christian interiority, and provides Anastasia with the challenge and labour of saving him from the lingering shadows of trauma, in doing so providing a solution to the couple's unequal positions of wealth, privilege and power. At the same time, the value of white male vulnerability remains dependent on the depths of Christian's trauma being sealed up, his sweaty nightmares evaporating and his more hardcore kink preferences being abandoned for matrimonial vanilla. The main story, or fantasy, of Fifty Shades revolves around the transformations afforded by romance and sexual discovery wrapped up in a proprietary couple format. This narrative of transformation is set in a fantasy frame of white American super-richness where the issues causing suffering and vulnerability are personal rather than societal, and solvable through the freely given affective labour of loved ones. The attraction of the novels' fantasy is directly dependent on the imagined subject in question - Christian Grey - being worth the care, love and attention that is so richly endowed on him. As a subject and fantasy figure, the super-rich, white, straight cis-man described as a Greek god incarnate then comes across as valuable indeed.

\section{REFERENCES}

Barker, M. (2013). 'Consent is a grey area? A comparison of understandings of consent in Fifty Shades of Grey and on the BDSM blogosphere', Sexualities, 16:8, pp. 896-914.

Barker, M. (2014). 'The "problem” of sexual fantasies', Porn Studies, 1:1-2, pp. 143-6o.

Berlant, L. (2012). Desire/Love. New York: Punctum Books.

Biederharn, I. (2015). 'Reviews of E.L. James' "Grey": Christian is a psychopath', Entertainment Weekly (18 June), http://ew.com/article/2015/o6/18/greyreviews-el-james.

Cole, T. (2012). 'The white-savior industrial complex', The Atlantic (21 March), www. theatlantic.com/international/archive/2012/03/the-white-savior-industrialcomplex/254843.

Deller, R. A. and C. Smith (2013). 'Reading the BDSM romance: Reader responses to Fifty Shades', Sexualities, 16:8, pp. 932-50.

Deller, R. A., S. Harman and B. Jones (2013). 'Introduction to the special issue: Reading the Fifty Shades "phenomenon"', Sexualities, 16:8, pp. 859-63.

Dymock, A. (2013). 'Flogging sexual transgression: Interrogating the costs of the "Fifty Shades Effect", Sexualities, 16:8, pp. 880-95.

Flood, A. (2015). 'Fifty Shades of Grey sequel breaks sales records', Guardian (23 June), www.theguardian.com/books/2015/jun/23/fifty-shades-of-greysequel-breaks-sales-records.

Grigoriadis, V. (2015). 'The rocky road to making The Fifty Shades of Grey movie', Vanity Fair (February), www.vanityfair.com/hollywood/2015/01/fifty-shadesof-grey-sex-scenes. 
Halberstam, J. (2017). 'White men behaving sadly', Bully Bloggers (22 February), https://bullybloggers.wordpress.com/2017/02/22/white-men-behavingsadly-by-jack-halberstam.

Harrison, K. and M. L. Holm (2013). 'Exploring grey zones and blind spots in the binaries and boundaries of E. L. James' Fifty Shades trilogy', Feminist Media Studies, 13:3, pp. 558-662.

Hochschild, A. (2003 [1983]). The Managed Heart: Commercialization of Human Feeling. Berkeley: University of California Press.

Illouz, E. (2014). Hard-Core Romance: 'Fifty Shades of Grey', Best-Sellers, and Society. Chicago: University of Chicago Press.

James, E. L. (2012a). Fifty Shades of Grey. New York: Vintage.

James, E. L. (2012b). Fifty Shades Darker. New York: Vintage.

James, E. L. (2012C). Fifty Shades Freed. New York: Vintage.

James, E. L. (2015). Grey. London: Arrow Books.

James, E. L. (2017). Darker. London: Arrow Books.

Marcus, S. (1964). The Other Victorians: A Study of Sexuality and Pornography in Mid-Nineteenth-Century England. New York: Basic Books.

Pääkkölä, A.-E. (2016). Sound Kinks: Sadomasochistic Erotica in Audiovisual Music Performances. Turku: Annales Universitatis Turkuensis, series B, vol. 422.

Paasonen, S. (2011). Carnal Resonance: Affect and Online Pornography. Cambridge, MA: MIT Press.

Paasonen, S. (2013). 'Grains of resonance: Affect, pornography and visual sensation', Somatechnics, 3:2, pp. 351-68.

Radway, J. (1984). Reading the Romance: Women, Patriarchy, and Popular Fiction. Chapel Hill: University of North Carolina Press.

Smith, C. (2007). One For the Girls! The Pleasures and Practices of Reading Women's Porn. Bristol: Intellect.

Smith, C. (2009). 'Pleasing intensities: Masochism and affective pleasures in short porn fictions', in F. Attwood (ed.), Mainstreaming Sex: The Sexualization of Western Culture. London: I. B. Tauris, pp. 19-35.

Snitow, A. (1983). 'Mass market romance: Pornography for women is different', in A. Snitow, C. Stansell and S. Thompson (eds), Powers of Desire: The Politics of Sexuality. New York: Monthly Review Press, pp. 245-63.

Storr, M. (2003). Latex E Lingerie: Shopping for Pleasure at Ann Summers Parties. Oxford: Berg.

Thomas, M. (2012). 'Fifty shades of success: Behind the (sex) scenes with E. L. James', The Huffington Post (10 April), www.huffingtonpost.com/marlo-thomas/fiftyshades-of-success_b_1923039.html.

Williams, R. (1977). Marxism and Literature. Oxford: Oxford University Press. 


\section{Part III}

\section{VULNERABILITY AND \\ CULTURAL POLICY}





\title{
9 \\ THE INVULNERABLE BODY OF COLOUR \\ The failure and success of a Swedish film diversity initiative
}

\author{
MARA LEE GERDÉN
}

$\mathrm{I}^{\mathrm{n}}$

n 2016, the Swedish Film Institute launched the Fusion Programme, the aim of which was to promote diversity in Swedish film production. The announcement of the Fusion Programme emphasised innovation, intersectional analysis, and feminist and anti-racist perspectives on artistic practices. The question of representation is also central, which is reflected in the guidelines for the applicants: 'Applicants must identify himself [sic] as a woman and have experience of [processes of] racialisation in Sweden.' ${ }^{1}$ The application form addressed 'Professional's [sic] creators in the artistic field', stressing an overall artistic expertise and excellence, combined with challenging ideas for film. As a writer and a novelist, I have relentlessly addressed questions of race, gender and power structures, always aiming at producing counter-narratives, but I have also been inspired by the impact of visual forms of art, intrigued and attracted by the directness and force of the film medium. So, I submitted an application that included a synopsis of my idea for a TV series - the main character being a strong woman of colour working as a personal trainer at a gym - and it was accepted. This is how I ended up as one of the participants of the Fusion Programme of 2016.

In this chapter, I examine the affective politics of the Fusion Programme, focusing on tensions between participant motivations and a film policy which, I argue, balanced conflicting frameworks: an outspoken effort to attain goals for gender equality, the desire to implement a perspective on diversity, a notion of quality informing Swedish film policy since the 1960s, and a Swedish self-image expressed as a need to 'implement Swedish values'.

In what follows, I discuss the paradox that arises when, paraphrasing Audre Lorde, the master actually summons you to dismantle his house (Lorde, 1996). While launched in the name of advancing diversity in Swedish 
film, there was a clear tension between the quality film rhetoric of the Swedish Film Institute and the participants' insistence on making race play a major role in the respective projects. In my reading, what emerged can be termed 'affective indigestion'. According to a theory of affective labour as metabolisation (Whitney, 2016), the main task of the affective worker is to harbour and 'swallow' the by-products of her work, for instance sadness, disgust or anger, not being allowed to display these kinds of feelings. In my reading, the participants of the Fusion Programme ended up being such affective workers. While emotionally draining for the participants, I will argue that this indigestion made visible the question of affective privilege - which emotions can be articulated, and by whom - and materialised the figure of what I term 'the invulnerable body of colour', i.e. the illusory but common belief that a brown or black body is less sentient/sensitive than a white body. Thereby, it enabled a reconceptualising of pain as a 'racial emotion', which I consider as one of the major outcomes of the Fusion Programme. This reconceptualisation in the context of the arts allows a further exploration of how to avoid the commodification of 'the pain of others' (Sontag, 2003) and instead the turning to a language of vulnerability, thus disclosing a political and creative potential that stresses agency and embodiment.

\section{FUSION AS A DIVERSITY INITIATIVE}

The background of the Fusion Programme was the 2013 reform for film financing in Sweden. ${ }^{2}$ This reform aimed at reaching actual and literal gender equality: to divide funding evenly between men and women. In comparison, the diversity goal expressed in the same plan was spineless. Diversity was described as a 'perspective': 'funding shall be given based on the perspective of diversity.' The same phrasing is found in the bill presented to parliament in 2016. While the 50/50 gender equality mandate of Anna Serner is by now famous all over the film world, putting Sweden on the map as a leading country regarding gender issues, we are definitively lagging behind as far as diversity issues are concerned. A 'perspective' is not binding in any way and entails few obligations, and is thus easily reducible to mere surface, or, in the words of Sara Ahmed, a form of 'institutional polishing' (2017: 102). The problems with diversity initiatives have been closely scrutinised over the years, and the objective of this chapter is not to offer any systematic analysis of them. Instead, I want to focus on one specific aspect of this Swedish initiative: how diversity and quality, in terms of rhetoric, feed into each other.

One of the assumptions of the Fusion Programme was that an increase of minorities in the cultural industry would improve both quality and equality. This assumption may be contested in various ways, but a major objection is 
that 'diversity is also a technology of power, a means of managing the very difference it expresses' (Grey, 2016: 242). As such, there is a great risk that diversity remains a 'difference that doesn't make a difference', as Angela Davis puts it. ${ }^{5}$ In such case, race becomes a commodity to consume, drawing from the notion of 'racial capitalism', which 'then leads to the exploitation of nonwhite racial value' (Leong, 2013: 2198). In Living a Feminist Life, Ahmed pinpoints how diversity work pinions the diversity worker: 'Doing diversity work has taught me that agreeing to something is one of the best ways of stopping something from happening' (Ahmed, 2017: 137). Another problem is that 'diversity' only seems to encompass 'the good stuff', leaving all the difficult issues out. Sara Ahmed argues that 'the fact that diversity is not a scary word is part of the problem: if it is detached from scary issues, such as power and inequality, it is harder for diversity to do anything in its travels' (2012: 66).

As an exclusively positive term, diversity accumulates 'positive affective value' and becomes a 'feel good politics', ready at any time to consume the other (Ahmed, 2012: 67f.). It can thus easily be reduced to a means that allows for immense pleasure and consumption while at the same time creating the illusion of equality. As a consequence, a question arises: what happens to the negative affects that diversity projects might entail? The 'bad feelings', the discomfort, the calling into question, the call outs, the pain that it may cause? Are they simply swept under the carpet? Where and with whom do these negative affective residues end up?

Despite the vagueness of the diversity goal in the film agreement, Baker Karim, a Swedish film director who was appointed a public film commissioner in 2013, set out to make a difference: 'We have a chance to make a Swedish film that is internationally relevant, quality driven and urgent, contributing to the glory yet to come, of Swedish film, Karim says in the press communiqué released at the time of his appointment. ${ }^{6}$ Finding new voices was the means by which to achieve this, and Karim emphasises that 'diversity and gender equality is a quality criterion'? Earlier that year, as a member of Tryck, an organisation for Swedish cultural workers from the black diaspora, Karim initiated the Black List project, a catalogue consisting of black cultural workers aiming at directing attention to black invisibility in Swedish culture. ${ }^{8}$ In the wake of this initiative, he received 10,ooo letters and emails of hate, some of them claiming that he excluded white people (Kulturnytt, 2013a). In 2014, within the frame of the Swedish Film Institute, he continued the diversity work with the launch of 'Black is the new black', a combined screenplay contest and seminar, aiming at highlighting film and creative work that challenge stereotypes of Africa and blackness (Svenska Filminstitutet, 2014). Finally, in November 2015, Karim and the Swedish Film Institute presented 'Beyond the new black', a seminar that focused on the newly invented term 'norm creativity' (Svenska Filminstitutet, 2015). 
Norm creativity was introduced to replace 'norm criticism', by now a well-established conceptual tool in Swedish diversity policies. It has been implemented over the past ten years in order to discern power structures and unpack the categories of normal and desirable, on the one hand, and deviating and undesirable on the other (Bromseth and Darj, 2010; Elmeroth, 2012; Martinsson and Reimers, 2014). It has been a critical tool for analysing normativity in relation to gender, sexuality, functionality and ethnic variation. As a diversity policy tool, norm critical pedagogy and methods have been implemented at Swedish schools, institutions and kindergartens by certified norm critical consultants. In film policy language, the change from 'norm criticism' to 'norm creativity' signalled a shift of focus from the analysis of discourses of power to creative practices and change. ${ }^{9}$ Hence, the 'Beyond the new black' seminar reframed questions of diversity and representation in an empowering context, and it was also the occasion when the Fusion Programme was presented.

The gender equality goal of the Swedish Film Institute had previously been met by suspicion and critique, ${ }^{10}$ but the loudest criticism coincided with the launch of the Fusion Programme in late 2015 (see figure 9.1). In an article in Dagens Nyheter, several persons questioned what they termed 'identity politics' pursued by Anna Serner, the present CEO of the Swedish Film Institute, and public film commissioner Baker Karim. These critics saw Serner and Karim as responsible for the 'identity politics' that is supposedly

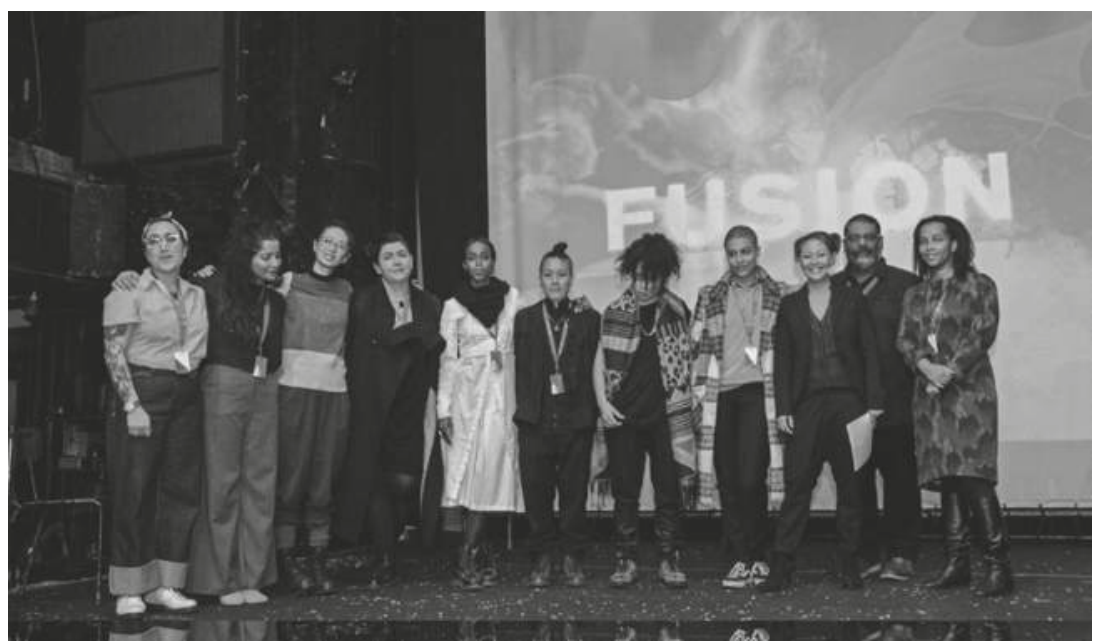

Figure 9.1 Launching the Fusion Programme in January 2016 with participants Aida Chehrehgosha, Saadia Hussain, Mara Lee Gerdén, Farnaz Arbabi, Farah Yusuf, MyNa Do, Nikeisha Andersson, and Saleen Gomani together with jury members Klara Grunning, Baker Karim, and Sara Waldestam. 
'a threat against both economy and artistic quality in Swedish film'. In their view, achieving the policy goals has become more important than the actual films being made (Nordström, 2015).

\section{FUSION AS A QUALITY FILM INITIATIVE}

When launched, Fusion was described as a 'research and development program with financial support, technology and network[ing]' that offered its participants the possibility to develop a film project over one year. Seven projects were chosen. We were artists, directors for stage and film, photographers and one writer (me).

In my project, I wanted to work with a comedy set in a sports environment. My ambition was to go straight to the heart of Swedishness (sports, comedy), but at the same time defying and fighting racial stereotypes (casting an Asian-looking Swedish woman in the leading role, performing Swedishness perfectly). Artist and art pedagogue Saadia Hussain worked on a project about Muslim women and feminism, turning the tables by displaying religious devotion not as subordination but as strength, community and sisterhood. Music video director Nikeisha Andersson worked on a feature film, a genre movie with strong women in the leading roles. Then there was the artist duo Mahoyo, consisting of Farah Yusuf and MyNa Do. They were working on a film project in several parts, documenting the cultural scenes in parts of the world that are often named 'the global south' The whole Mahoyo 'experience' is about contesting stereotypes and exploring cutting-edge cultural expressions in music and the arts, turning their back on the white gaze. Saleen Gomani worked with a virtual reality project addressing non-normative desire, such as fetishism and BDSM, especially oriented towards rewiring the sexual agency of women of colour. Theatre director Farnaz Arbabi worked on a project addressing mental health among immigrants, and how this phenomenon is made invisible and thus extremely difficult to approach. And lastly, the project of artist Aida Chehrehgosha could be seen as part of an ongoing artistic project of hers approaching the family, this time with a focus on the intra-generational aspects through which histories of pain and love are handed down.

The ambitious aim of developing a film project over one year was to be realised with a series of rapid and professional networking encounters, workshops and seminars. The budget was minimal, entailing less than 300,000 euros for seven film projects, so consequently there was an emphasis on speed and risk, as opposed to slow development and low risk.

When publicly criticised for trying to 'control artistic processes' and pursuing identity politics in the Swedish film industry, Karim stressed over and again how the new creative perspective of the Swedish Film Institute, 
which also made the Fusion Programme possible, had nothing to do with 'regulating' or 'controlling' the film industry. Instead, Karim reassured that 'affirmative action is a means to fight mediocrity. We have to make sure that the mediocre isn't accepted, [just] because they are men' (Nordström, 2015).

The rhetoric of avoiding mediocrity invokes the 1963 film policy plan conceived and initiated by the former head of Swedish Film Institute Harry Schein - which introduced a new concept of artistic quality that ever since has been repeated and thus validated by the film industry (Lantz, 2009; Snickars, 2010: 159). One of Schein's arguments was that quality would enable film to find new international markets (Snickars, 2010: 167). In Schein, 'quality' was constructed as not necessarily satisfying the popular taste, ${ }^{11}$ but rather something that lay 'one step ahead', even defying popularity (Snickars, 2010: 163).

The 1963 film policy plan states that the purpose of the newly founded Swedish Film Institute is to 'support valuable Swedish film production, to support artistic and technological development as well as education and research within the area of film' (Schein, 1970: 235). The definition of quality, and how to assess quality, is defined by:

renewal of the means of expression and formal language of film, the degree of urgency in its message, the intensity or freshness of its perception of reality or its criticism of society, the degree of psychological insight and spiritual level, playful imagination or visionary strength, epic, dramatic or lyrical values, the technical skill displayed by the screenplay, directing, acting and other artistic components in film. (Schein, 1970: 235) ${ }^{12}$

The relevance and impact of these few lines on the Swedish film industry cannot be understated. Today, the public film commissioners still use this definition as a guideline in their evaluation of which projects will or will not receive financial support (Elwin Frenkel, 2010: 236). Also, its relative vagueness makes it easy to adapt to various purposes, including using it as an instrument to preserve the status quo and the existing power structures. ${ }^{13}$

In his rhetoric, Karim comfortably referenced the Schein perspective of quality where exclusion of the mediocre is one of the fundamental aspects. ${ }^{14}$ But, at the same time, he employed the Schein language to implement a new agenda, thus turning the tables. Schein would probably not agree that affirmative action or state interference would enhance quality, as he repeatedly and firmly stated that the arts are inherently undemocratic (Vesterlund, 2013: 57).

This 'new' take on Schein's argument on quality was also found in the 2015 government memorandum 'Framtidens filmpolitik' (which anticipated the final cancellation of the 1963 film agreement) and the subsequent 2015/16 bill 'Mer film till fler - en sammanhållen filmpolitik' presented to the Swedish 
government. In the memorandum, equality and diversity are 'not only an end in [themselves], but the very premise for quality' (Kulturdepartementet, 2015: 4). In the final bill, 'a crucial element for consolidating the quality and relevance of Swedish film in the future is the increase of diversity and equality' (Prop. 2015/16:132: 17). In the memorandum, the ambition to support equality and diversity was however combined with yet another perspective displayed later on in the document: 'In our effort to promote Swedish film culture internationally, the Film Institute works actively with implementing Swedish values concerning democracy, freedom of speech, equality and representation' (Kulturdepartementet, 2015: 16). Implicitly, Swedish values were presented as potentially enhancing human rights such as freedom of speech, but also democratic rights, gender equality and anti-racism, of which it is incumbent upon the Swedish culture to implement internationally.

The instances where the quality concept of Harry Schein coincides with the language used in the Fusion Programme are too many to overlook. The expression 'the intensity or freshness of its perception of reality' from the Schein plan is found more or less to the letter in the application form for Fusion: 'Applications are evaluated by the jury based on ... the freshness of the candidate's perception of reality, or ... the creative intensity of the candidate's creative process. ${ }^{15}$ After the applicants were chosen, the motivations of the jury were publicly displayed in a language that continued to echo Scheinian rhetoric: expressions such as 'technical skill', 'renewal' of the art form and 'criticism of the society' reiterate the language of the 1963 policy plan. Of the remaining expressions, some coincide with the goals of the new bill from 2013, and most importantly the one aiming at full gender equality and the ambition to implement 'Swedish values' around the world. Thus, expressions like 'feminist voice' as well as 'democracy' and 'freedom of speech' were found in the motivations. The remaining words expressed either professional expertise or qualities that could be interpreted as challenging existing norms: 'norm-creative', 'rebellious', 'challenging artistic expressions' and 'norms', and 'stereotypes'. The last category of words clearly bore the mark of the diversity initiatives introduced by Baker Karim, testifying to a diversity-oriented 'Karim-paradigm' of the Swedish Film Institute.

The jury motivations hence echoed a range of historically traceable attempts at reforming the Swedish film industry. So, even if Fusion was, on the surface, presented as a wholly new feminist and anti-racist (even separatist) venture accepting only women of colour working in the arts as members, its construction and very premise were, at a closer look, built on the foundation of the norms, values and powers that it was supposed to challenge.

Summarising the aesthetic and political outset of the Fusion Programme, the main and defining premises that emerge were the following: (1) a fiftyyear-old quality concept forged by a 'Social Democratic cultural aristocrat' 
(Snickars, 2010: 164, 172); (2) a newly adopted effort to attain gender equality goals and also bring about a 'perspective' of diversity, that was in fact a reformulation of an old quality concept; (3) a certain Swedish selfimage expressed by a desire to 'implement Swedish values'; and (4) seven film projects that, while at first sight fed into the 'diversity/quality project' of SFI, soon turned out to be not the least interested in supporting a vague or generalised 'quality concept' or a diversity initiative in which real and lived difference runs the risk of being domesticised and reframed as manageable difference - i.e. as commodities.

We were a group of eight women of colour. Our 'diversity' was supposed to feed into the quality notion of SFI, strengthening and validating its legitimacy. Instead, the collective force of the projects actually seemed to question the very foundations on which this quality concept was forged. From our very first meeting onwards, there was a feeling of something opening up, something being destabilised. My initial thought was that we could actually change something for real. It sounds like an impossible feat but, at the same time, if ever the master's house were to be dismantled, why not now?

\section{REPRESENTING PAIN}

Our introductory meeting took place during the Gothenburg Film Festival in January 2016. It was the first time I had found myself in a room with only women of colour, including the two project managers Sara Waldestam and Klara Grunning. During this first seminar, all of us presented our respective projects. One of the most important discussions that arose, and that, in my view, became key throughout the Fusion year, was the question of pain. First of all, pain emerged as a central - if not always explicit - theme in the majority of the participants' projects, but also as a recurring emotion that circulated in the room as a consequence of the affective clash between the institutional desire to produce diversity and the participants' refusal to submit to that desire.

I presented my project as a counter-narrative insisting on avoiding depictions of the pain of others, explicitly turning away from the image of the brown woman as constantly victimised and in need of rescue. My decision to situate my main character at the heart of the health industry as a personal trainer at a gym was a way to wire her directly into a certain kind of health-conscious, middle-class Western lifestyle, thus fighting racial stereotypes and instead stressing the potential for identification by downplaying differences. It was also a way for me to overtly avoid the very common hyper-feminisation and sexualisation of Asian women (Cho, 1997: 178-211; Chou, 2012; Parrenas, 2007). As a personal trainer, your body is indeed 
central, but not necessarily the object for (sexual) consumption, and instead a physical authority with the power to define and sculpt other bodies. I wanted to challenge the depiction of women of colour as the permanent victims, tired of representations and images that perpetuate the violence against us and normalise our pain, turning our wounds into a consumer spectacle. The contemporary representations of brown and black women as either hyper-sexualised or victims of trafficking, rape and abuse (or forever smiling contently), domestics, maids and nannies, invariably subjugated under either God or man, ${ }^{16}$ are variations of stereotypes of the subjugated brown and black woman handed down for centuries in Western culture. These images are closely connected to the civilising missions of colonial rule, as any white saviour or rescue narrative requires the construction of a brown or black victim to be saved. Historian and gender studies scholar Anne McClintock explains: 'North African, Middle Eastern and Asian women were, all too often, trammeled by the iconography of the veil, while African women were subjected to the civilising mission of cotton and soap. Arab women were to be "civilised" by being undressed (unveiled), while sub-Saharan women were to be "civilised" by being dressed' (McClintock, 1995: 31). In the Fusion Programme, some of us intended to challenge these stereotypes by creating new images: feminist Muslim women, Asian nonconforming femininity, and women of colour forging solidarity across borders, with an emphasis on agency, sisterhood and empowerment.

From the perspective of pain, the other tendency amongst the participants was strikingly different, in fact seemingly almost the opposite - a redirected attention to our wounds, as in the project of theatre director Farnaz Arbabi. The premise of this project was that the pain of others was rarely recognised at all, leading to escalating mental ill health among immigrants. Her project wanted to explore and make visible this pain and the voices of those who are rarely heard.

At first sight, our respective views seemed incompatible, even contradictory, resulting in a 'tie' which could be articulated as the impossible questions: do we need to pay more or less attention to our wounds? Do we need to emphasise or downplay affects such as pain? Representing the pain of others can sometimes become an empowering tool; a way to acknowledge and recognise wounds that for decades have been silenced. But the pain of others can also be used as visual pleasure, a consumer spectacle that risks perpetuating the wounds, turning these images into permanent features. My point, though, is that these views are not incompatible at all, but complementary. How? How can the need to avoid depictions of 'the pain of others' coexist with the need to stress 'the pain of others'?

The need to stress our wounds is grounded in history, but also in contemporary social reality. An interesting experimental study raises the question 
of whether black people are believed to feel less pain than white people (Trawalter et al., 2012). In a series of experiments, a team of psychology scholars wanted to illuminate questions of racial bias in the perception of others' pain. The participants consisted of psychology students (who were given course credit for their participation), nurses and nursing students (who were given gift certificates for their participation) and people recruited on an online marketplace called Mechanical Turk (who were paid a small symbolic sum for their participation). Except from in experiment $2-$ which used all black participants - the vast majority of the participants were white. The results of the study indicated that the participants responded more intensely when watching white people in pain than they did when watching black people in pain. One of the conclusions of the researchers was that racial bias could not explain the participants' lack of empathy with black bodies, but rather 'that people assume that, relative to Whites, Blacks feel less pain because they have faced more hardship. So, the researchers conclude, even if it is not racial bias per se that instigates the lack of empathy, the sheer underestimating of black bodies' pain will have 'potentially disastrous outcomes' (Trawalter et al., 2012).

Even though the Fusion Programme took place in Sweden and our racial reality differs from the American experience, '[n]umerous Swedish studies have reported that mental ill health is more common among immigrants than among native-born', according to social scientist Petter Tinghög, implicating that 'immigrants' mental health can be regarded as one of the most urgent health issues in Sweden today' (2009: 1). In addition, statistics show that immigrant women are overrepresented in suicide rates (de Noli, 2014), and that among transnational adoptees suicide attempt rates are as much as 3.6 times higher when compared to the overall population (Hjern et al., 2002: 443), and as much as 4.7 among male adoptees from South Korea. And just as in the experiments above where people reacted less to pain inflicted on black people, the attempts at explaining these numbers mostly leave out race as a factor. For instance, the researchers behind the study on transnational adoptees and suicide comment on the high suicide rates in a newspaper article, suggesting that they are grounded in the separation that took place in the toddler's earlier years', referring to 'attachment issues.' This explanation erases the following twenty or so years of social reality in the toddler's life, as if these years had nothing to do with the high suicide rates and the risk of everyday racism was wholly insignificant (Letmark, 2003). ${ }^{17}$

These statistics and the findings of the American experimental study indicate that people of colour endure an increase in lived pain but at the same time a reduction of recognised pain, which in turn might explain the profuse occurrences of visual depictions of people of colour in pain. In order to evoke empathy for the black or brown body in pain, the violence 
must increase, it seems, as the viewer basically requires more blood to spark an emotional response (while, at the same time, the excessive violence may always be rationalised by referring to the statistics and thus concealing the underlying mechanisms of a lack of empathy). This suggestion partly coheres with Lauren Berlant's observation 'that scenes of vulnerability produce a desire to withhold compassionate attachment', and even 'to refuse engagement with the scene or to minimise its effects; to misread it conveniently' (2004: 8). And maybe, Berlant suggests, compassion and cruelty are not opposites at all, but instead point towards a relation between compassion and sadism (2004: 8-9).

As for the Fusion Programme, the 'conflicting' aspirations of us participants turned out to be not so conflicting. On the one hand there was an ambition to create counter-narratives fighting the overrepresentation of lived pain, and on the other was the aim to tell the truth about this pain by not under-evaluating it. Some of us aimed at recognising the wound in the first place, saying clearly that we exist and that our wounded histories exist, while some of us felt a need to tend to this wound, trying to heal it. It became clear that these two aims where in fact one, facing and fighting one of the most problematic stereotypes - namely the invulnerable body of colour.

\section{DIVERSITY WORK AND THE INVULNERABLE BODY OF COLOUR}

The affective clashes between the Fusion Programme and the participants were in part a result of our not embracing the idea that 'the promise of diversity is the promise of happiness', as Ahmed puts it (2012: 165). Instead, we insisted not only on histories of pain, but also that pain is an actual, present and heightened risk in the lives of people of colour. In other words, we refused the 'feel good', the 'overing', of racism, which is the inherent logic of the diversity initiative (2012: 179), and especially we rejected the figure of 'the invulnerable body of colour'.

The paradox that played out through the whole Fusion Programme consisted of the tension between our respective projects that addressed and elaborated aspects of pain and emotional labour (but also creativity and agency) in relation to people of colour, and on the other hand the figure of 'the invulnerable body of colour'. We participants wanted to explore counter-narratives in depth but at the same time the construction of us, and so the participants, as 'invulnerable bodies of colour', informed the whole framing of the programme. The paradox in being discursively situated as 'invulnerable bodies of colour' yet 'chosen' to fight this very same figure became a central issue during the Fusion Programme. 
At the beginning of the year we were asked to make suggestions for guests who were professionals in the creative fields. We made our suggestions, being mostly people of colour working in film or the arts. However, none of the guests we suggested were invited. Instead, the project managers invited guests of their choice. Out of these, none was a person of colour. All of them were extremely competent but our suggestions were completely overlooked, leaving us with the impression that our voices did not count and that the whole procedure of asking us to make suggestions was only a formality. The reason why the project managers did not meet our wishes cannot be explained by lack of funding (as they could obviously fund other guests), access (as they could obviously find other guests) or time. Instead, one possible explanation could be found in the implicit institutional requirements. As the Film Institute and the Fusion Programme itself were saturated by the legacy of the quality guidelines forged by Harry Schein, everything that we tried to articulate that did not fit into them became illegible, and as such not noticed or overlooked.

Our encounters with the invited guests were at best interesting, and at worst disastrous. One of the guests, an accomplished documentary filmmaker, was working on an exceedingly interesting project involving Roma children. The encounter started out well - she discussed ethics, power structures, and checked every box that implied that she was aware of structural inequalities based on race. She was also an avid listener as well as an enthusiastic speaker. But suddenly, out of nowhere, she said the n-word, and not only once but three times, like she had suddenly lost her mind. It took only a few moments for her to recover her composure, realising what she had done and apologising, but the harm was already done. The room had changed. She was so obviously the only white woman in a room full of women of colour.

Thinking about it afterwards, how the most hurtful racist slur suddenly materialised amidst us, served as a reminder of how its emergence in fact cannot be described as coming 'out of nowhere' or as a sudden manifestation, but is to be regarded as quite the opposite. Slurs and hate speech are handed down and repeated as a part of language, and according to Judith Butler acquire their performative force through the acts of iteration and citation, a 'long string of injurious interpellations' that came before (1997: 49). Though elsewhere questioned in terms of responsibility and legal culpability (Mills, 2003: 253-72), Butler's assertion that the speaking subject is the consequence of that very citation' (1997: 50) may shed some light over the invited guest's excuse that she 'did not mean any harm. This utterance displays the difficult distinctions between intention and effect, and also highlights questions of subjective responsibility. The utterance 'I did not mean any harm' performs as an excuse and thus as a performative utterance - it does 
something, namely it tries to undo the previous performative, the slur. But the swift attempt to undo, in this situation, is exactly where the harm lies. A person who does not mean any harm is actually saying 'I did not think this would cause you any harm'. Uttering the worst racist slur that exists thinking that it would not cause any harm to a room filled with black and brown women does not necessarily imply bad intentions, but it does imply racial bias. It implies the perception of us as invulnerable, conjuring up the figure of 'the invulnerable body of colour'.

Even though the other guests did not quite evoke 'the invulnerable body of colour' to that same extent, many of the encounters amounted to very little because the guests refused to meet us where it really mattered for us. For instance, a senior film advisor was brought in to comment on our work, but by leaving out race from his language entirely he had absolutely no tools to assess what we were doing or aiming at. As guests quite literally consecrated their time to persuade us that they were not racists, we ended up with their emotional residues.

\section{AFFECTIVE INDIGESTION/INDIGESTIBLE EMOTIONS}

The emotions evoked by the Fusion Programme recall bell hooks's description of writing a film review:

That will ... to write, to put other things aside to write, to sit at my computer and key in the Beasts of the Southern Wild piece while I am sitting there crying because I just can't take another image of an abused black child being represented as entertaining, and I am sitting there and I am writing, but I am also hurting, I'm hurting because we can't get past the construction of black children as little mini-adults whose innocence we don't have to protect, who we can consider cute if they're being slapped around by an alcoholic father. (The New School, 2013)

There is something very odd in this description. Usually, writing a film review is not associated with profound feelings, and it is not seen as typically laborious. But in hooks's description the emotional investment is huge, and the labour she puts into it enormous. Crying at her keyboard, hurting, her emotional labour seems immeasurable (Hochchild, 1983). And for what? Not a seven-volume novel, not her collected works, but a review of a film that she, on top of everything, hates.

Importantly, it is not just pain or the appalling depictions of black subjects that make bell hooks cry. In my interpretation, the tears are also legible as an expression of unnoticed emotional labour, having to incorporate indigestible emotional residues. Discussing sociologist Encarnación 
Gutiérrez-Rodríguez's research on the affective dimension of the domestic work performed by racialised migrant women in European homes, philosopher Shiloh Whitney uncovers a language of indigestion (GutiérrezRodríguez, 2010: 128; Whitney, 2016). Whitney suggests that understanding the threat of exploitation involved in affective labour 'requires understanding the metabolisation of their by-products' (2016: 285). This affective metabolisation includes absorbing unwanted affects in the environment, for instance if the employer denigrates or insults the worker. 'Just as it becomes part of Elena's job to choke back her anger and Karin's to soak up anxiety, it is part of Carmen's job to swallow her pride' (2016: 286). Their employers use them as containers for affective dumping, whereas the workers themselves are not allowed to express any emotions: 'It is their job to swallow these feelings: to absorb them into their own depths of feeling and contain them there, without allowing them to surface in gesture or posture' (2016: 286). Whitney suggests that this sort of labour 'also produces ... racialisation and gendering. It is women of color who are expected to do this sort of work, and what it means to be a woman of color is being constructed in this practice' (2016: 287). In other words, the affective economy of indigestion affects not only racialised domestic workers, but all women of colour: 'Certain types of bodies are marked for this sort of use, leaving them with the after-hours "dirty work" of metabolising these unwanted affects and with the inevitable affective indigestion from the unexpressed by-products' (2016: 287).

As another example of both a language of affective work and that of metabolisation, Whitney invokes Audre Lorde's text 'Eye to eye: Black women, hatred, and anger'. In this text, Lorde describes how: 'As children we absorbed that hatred, passed it through ourselves' (Lorde, 1996: 146). Despite everything, however, hatred in Lorde is perceived not only as an indigestive by-product but as fuel, because from hatred anger may emerge, and anger is fuel, a negative passion (1996: 154).

For me, the notions of affective metabolisation and indigestible affects adequately and accurately describe what the Fusion Programme made visible and evoked among the participants. The emotional labour that took place (from my part, at least, but I think from almost all of us) in the interaction with the guests included downplaying ignorance concerning racial matters, overlooking the more-or-less constant underrating of our artistic expertise, smoothing out misunderstandings that involved race, excusing or pretending not to notice ignorant remarks, 'saving' embarrassing situations or remarks, feeling nervous about them and possible racist remarks, reassuring ourselves that we were not hurting their feelings, and lastly, of course, trying to process the indigestible slur that the filmmaker had left on the table, trying not to make her feel too uncomfortable and saving the situation again. On an emotional level, we were constructed as the invulnerable 
and the guest as the vulnerable, and thus he or she inhabited the double privilege of being the one with discursive, social and racial power, but still constructing themselves as the emotionally (and by all means physically, even if this never arose) vulnerable.

In my reading, the film review 'No love in the wild' by bell hooks referred to above also describes affective indigestion (hooks, 2012). The affective indigestion not only means that bell hooks disagrees with the overall positive reception of the film ${ }^{18}$ and its 'crude pornography of violence', but has to do with the film inflicting images on her, and how this leads to an enforced embodiment of unwanted affects. For instance, in the review bell hooks clearly states that the film put images inside of her head that she did not want there, and she refers to this as 'eating', meaning the images' overwhelming power to affect the viewer. She also says that she saw something that others - judging from the great reviews - did not, which means that she is left alone with both the unwanted violent images of the film and the unrecognised affects that these images evoke in her; lingering inside as affective indigestion, impossible to metabolise.

In other words, in the encounter with artistic representations - and perhaps visual representations in particular - the faculties involved for a woman of colour exceed the merely aesthetic. They may imply having to grapple with the fact that a poetics of violence (against our bodies) is assumed as a quality criterion. It may also situate her in a political economy of affects, leaving her with affective waste products that are indigestible.

This affective violence actualises, in Whitney's words, how 'white privilege is an affective privilege' (2016: 290). This is also the reason why I will now turn to the concept of 'racial emotions' in an attempt to investigate how the double situatedness of pain in the Fusion Programme - both as a representational problem and challenge, but also as an affect produced in the room as a consequence of the collision with the institutional desire enabled a retooling of it in its entanglement with creativity.

\section{RACIAL EMOTIONS}

At the first gathering of the Fusion participants in February 2016, when each and every one presented their projects, the turn of artist Aida Chehrehgosha came. Throughout her career, Chehrehgosha has worked with the family trope, as well as with her own biological family. She told us that she would continue working on this theme, digging even deeper into the family history, going further back in time, beyond her own upbringing and childhood.

She became silent for a moment. We, the other participants, listened carefully to this silence. Then she continued talking, telling us that she and her 
two brothers underwent constant abuse growing up. In her home, domestic violence was a standard procedure - her mom hit her and her brothers, and her father hit her mom. But despite this abuse, or because of it, she had to continue digging. She would look for the sources of this abuse, namely the precariousness of her parents and their vulnerability as newly immigrated Iranians - her father, a former fighter pilot, ending up as a blueberry picker in the Swedish woods. She would work with authentic documents: journals and records of their respective histories. At this point, Chehrehgosha burst into tears, and some things were torn apart in the room - things like decorum and restraint. We immediately left the rules of propriety behind, and instead stepped into a space of deeply felt affinity; a sense of creativity that the same time bordered on immense pain and necessity. I claim that it was at this moment that the Fusion Programme was forged on an affective level. It was then the participants understood that in this room we would never have to take it from the beginning, from the letter A, every time we needed to address questions that were relevant between us, but start at $\mathrm{W}$, at $\mathrm{O}$, or at $\mathrm{C}$ - i.e. from our own specific situatedness. The account of Chehrehgosha immediately brought the group to the burning affective core of the project, and everybody in that room knew that it was a significant moment.

Importantly, it was not the moment of revelation that forged us together. The abuse that Chehrehgosha told us about was not a secret, as she had mentioned it in interviews before. What happened had nothing to do with providing us with a spectacular piece of pain to be consumed. Quite the contrary, what happened was vulnerability, a shared affective intensity that brought us together as a collective. It was a display of precise artistic integrity combined with vulnerability before a very painful task. In the account of Chehrehgosha, at this moment pain came across as a racial emotion.

Law professor Janine Young Kim suggests that there are emotions that are so closely tied to the experience of race that 'they can be said to demonstrate and typify an emotional dimension of the concept of race' (2016:497). Kim argues that race is something that we not only do or think but also feel (439). Emotions are, however, not restricted to a strictly personal realm. As a discursive expression, they can be understood as both political and social. Therefore, it is reasonable to argue that constructions of race are also performed along emotional lines. Kim concludes that if race is partly affectively constructed then we also have to begin to rethink race (497).

In order to demonstrate the emergence and range of racial emotions, Kim turns to W. E. B. Du Bois, Frantz Fanon and Lorde (again). I share her and many other scholars' understanding of these writers as making a powerful case for the profoundness of the emotions of grief, rage, anger, disgust and hatred as intimately connected to the experience of racial subjectivity. In a passage in The Souls of Black Folk, Du Bois recounts the birth of his first 
son - an event that in most circumstances would provide pure joy. But here, the joy is immediately dampened: 'I saw the shadow of the Veil as it passed over my baby' (Du Bois, 2007: 100). The veil, at the same time the incarnation of grief and the metaphor that Du Bois uses for a life lived behind the colour line, turns joy into grief. A similar emotional pattern recurs later in the book when Du Bois describes his child's premature death, and once again displays strongly ambivalent feelings: grief, of course, but also: 'All that day and all that night there sat an awful gladness in my heart', and 'Not dead, not dead, but escaped; not bond, but free' (Du Bois, 2007: 102). Thinking about the racial destiny that awaits his first born, his emotions do not follow the book. At first sight, they may resemble 'mixed emotions': two conflicting emotions harboured in one body. At a closer look, however, they are nothing like mixed emotions because those expressed by Du Bois at the death of his beloved son - both grief and joy - are utterly incomprehensible and ungraspable without a key reference to race. The context of racial segregation is required for the emotions to make sense. This makes them racial emotions.

Another, more contemporary example that displays the devastating force of racial emotions is Ta-Nehisi Coates' Between the World and Me, where he addresses his young son in a narrative about racial America. In a very personal (and painful) reflection on domestic violence, he shows how even the most intimate emotions are soaked with race:

\begin{abstract}
Now I personally understood my father and the old mantra - 'Either I can beat him or the police'. I understood it all - the cable wires, the extension cords, the ritual switch. Black people love their children with a kind of obsession. You are all we have, and you come to us endangered. I think we would like to kill you ourselves before seeing you killed by the streets that America made. That is a philosophy of the disembodied, of a people who control nothing, who can protect nothing, who are made to fear not just the criminals among them but the police who lord over them with all the moral authority of a protection racket. (Coates, 2015: 82)
\end{abstract}

Here, it becomes clear how the intimate sphere always has been and still is highly political. This should not be read as a condoning of child abuse, but as an attempt at illuminating how race affects the most intimate things, and that not even the love between parent and child will stay untainted by racial oppression.

If race, in Ta-Nehisi Coates, can be said to be the reason why love is intercepted with violence, and, in the case of Du Bois, grief with joy, then the case for racial emotions becomes clearer - sometimes, emotions are not graspable without thinking through race, and sometimes they signify something else in a context of race. If race can turn grief into joy and love into violence, even love into death (as, for instance, in Toni Morrison's Beloved), 
it is obviously not a sign of inherent racial difference but the emotional manifestation of a history of non-acknowledged oppression.

The notion of racial emotions may shed light on certain aspects of the deeply felt vulnerability that we, the Fusion participants, felt and were forged together by at our first meeting. As mentioned, the abuse that Chehrehgosha and her siblings endured during their childhood had been brought up before, and especially in relation to the highly acclaimed and prize-winning series of photographs entitled To Mom, Dad and My Two Brothers, where Chehrehgosha staged the death of her parents. In an interview, she has explained how this project was grounded in affects of anger and hate, but also love:

My upbringing consisted of abuse and constant fear ... My anger was so immense, many times I wanted to see my dad dead. My anger towards my mom was just as strong, mostly when she hit me because of her own frustrated situation. I hated them so much. But it was a very complicated anger. I also loved them. (Chehrehgosha, 2011)

Her photographs capture the ambivalent feelings of 'the eternal, strong hate and the connection that we have, despite everything. Here, the affective impact of 'mixed emotions' dominates. In her new work presented at the Fusion Programme, however, Chehrehgosha seemed to turn her back on hate, instead approaching the affective realm of pain. In my understanding, the pain articulated in her new project was construed as a racial emotion: the violence that was handed down by her parents was not a personal heritage but a racist legacy, a product of a social, structural and racist violence. Recognising this difference also meant acknowledging pain as an intergenerational affect in this context, suturing her and her parents' wound as a mutual experience that had to do with race. At the moment of recognition, a language of vulnerability emerged as a key to issues of pain and violence; there are injuries that extend over time, and we are in this together. As such, pain was constituted as a racial emotion in the moment that we recognise ourselves as vulnerable subjects. It was almost as if her work was adhering to Ahmed's words: 'To speak about racism is to labor over sore points' (Ahmed, 2012: 171). Perceiving pain through vulnerability as a racial emotion was, to me, the most impactful outcome of the Fusion Programme, allowing us all to approach a language of vulnerability both as a collective and as individual artists.

\section{CONCLUSIONS}

The Fusion Programme had many problems: the historically determined context that turned out to be discursively shaped by the 1960 os quality 
concept, the ridiculously low budget, and, most importantly, the paradox of us participants being discursively situated as invulnerable bodies of colour', yet 'chosen' to fight this very same figure. Nevertheless, we were able to approach aspects of racial emotions challenging this figure, both in our respective projects and the way we struggled to inhabit our discursively determined situatedness in the white rooms of Swedish film industry. Each and every one of us of course employed different strategies in the confrontation with the singular events, but, seen from the point of view of a collective effort, the outcome of the Fusion year was both surprising, instructive and creatively productive. While the institutional frame was saturated with tradition and at times constituted an impediment, it also mirrored the predicaments and obstacles that a woman of colour in the arts confronts on a daily basis. At the same time, the programme provided us with a space to disentangle and address these obstacles - a space that would hardly survive outside of a separatist diversity initiative. This space managed to initiate a retooling of the racial emotions of pain into creativity by highlighting the connections between race, creativity and quality. It also showed how the figures of brown and black pain inconsistently but insistently knit together with 'the invulnerable body of colour' in racist discourse. Not as an antonym but as a variation of the figure of the black or brown victim, the invulnerable body of colour' appears as a viable figure depending on how whiteness chooses to fashion itself. In this programme - and probably as a function of the encounter with us as a collective, i.e. we outnumbered them in our encounters - whiteness chose mostly to inhabit vulnerability, which is why the figure of the invulnerable body of colour became so dominant.

In one sense, the Fusion Programme was a failure. From day one, the affective clash between, on the one hand, the institutional desires/ expectations, and on the other the participants' refusal to submit to these very same desires, became an impediment to the intended 'diversity work' that we were supposed to perform. The benevolent intentions of the diversity policy had a contrary effect that, instead, perpetuated certain wounds and pains, and situated us as affective workers having to clean up the emotional mess and indigestive residues of their diversity goal. In another sense, however, it was a success. We participants managed to install a creative environment where fixed and static figures of pain, anger and hatred most blatantly expressed through the figure of the invulnerable body of colour - were constantly negotiated through the language of vulnerability. This language would never again content itself with two binary takes on the representation of 'the pain of others' as either victim or perpetrator. Instead, the most fruitful outcome was discovering how approaching pain as a racial emotion entailed the responsibility to trace the emotion back in time, until its roots of vulnerability could be grasped. 
A last thought: I fully agree with Sara Ahmed, who says that the brick walls encountered in diversity work are material, real obstacles that testify to the materiality of race and gender (2017: 147). She explains how the mere mentioning of the wall will make you come across as a 'wall maker', as if you were the one who put the wall there, making things 'harder' than necessary (141f.). Drawing from the image of the wall, the figure of the invulnerable body of colour turns out to be even more disturbing. This figure implies that we are not even conceived of as wall makers anymore. Instead, we have become the very wall that was blocking us. In this figure, invulnerability confers neither strength nor resistance, and neither empowerment nor agency. The intricate connections between power, vulnerability and privilege are rarely as evident as when the other, for whom these qualities aren't accessible, is constructed as a less sentient being.

\section{NOTES}

1 Swedish Film Institute. Fusion Programme, www.focal.ch/medici-training/ reports/docs/Medici_W6_Module_6_Fusion.pdf.

2 In Sweden, film financing is organised through 'the film agreement', which also includes a policy and agreement on what films should be produced.

$3 \mathrm{Ku}$ 12:004, English translation of the 2013 Film Agreement. www.regeringen.se/ 4.9bb9d/contentassets/cd4178254.cb843f2a3f1b2febb3e52db/2013-ars-filmavtal, p. 2.

4. Prop. 2015/16:132. Mer film till fler-en sammanhållen filmpolitik, www.regeringen. se/49481 b/ contentassets/ 7c57dagffe184d7cbeo0278f929c5f81/15161320o webb.pdf, p. 8 .

5 This is one of Davis' recurring slogans, repeated over the years, for instance in Davis (2012) which also includes a full transcript.

6 Quote from the press communique of the appointment of Karim as public film commissioner in (Svenska Filminstitutet, 2013). An appointment lasts for three years. Baker Karim took office in November 2013 and departed at the appointed time in 2016.

7 Karim concludes the interview saying that he will try to 'stir Swedish film into mutiny' by taking risks (Kulturnytt, 2013b).

8 The catalogue eventually changed its name to Kulturarbetarkatalogen Push.

9 This term was especially useful for practitioners in education and communication, rather than for scholars. For further information about this term see Vinthagen and Zavalia (2014).

10 This critique has been voiced ever since the film agreement of 2006, aiming at strengthening gender equality, guaranteeing that at least 40 per cent of a film production team supported by the Swedish Film Institute should be gendered as women. See, for instance, Redvall (2006).

11 According to Schein, the quality of TV and radio programmes could not be defined in terms of 'the ability to attract a bigger audience', furthermore 
suggesting that quality only refers to 'valuable and not audience-oriented shows' (Snickars, 2010: 163).

12 My translation, and henceforth all translations of Swedish sources will be mine unless otherwise indicated.

13 For instance, in the discussions following the new film policy plan of 2006 , quality was allegedly at stake. The object of controversy around this plan concerned its aim to strengthen gender equality, guaranteeing that at least 40 per cent of a film's production team supported by the Swedish Film Institute should be gendered as women. As expected, the discussion that followed revolved around the pros and cons of affirmative action, and the opponents voiced more or less the same argument that is standard in any field where steps towards gender equality or diversity goals are taken: quality, not gender (or race), should determine your opportunity, meaning that affirmative action would lower the quality (Redvall, 2006).

14 'I said that the concept of quality, the raison d'être of the film reform, was not non-controversial ... for those who were not gifted enough to make quality film ... the possibilities would be curtailed' (Schein, 1970: 25).

15 Swedish Film Institute Fusion Programme, https://focal.ch/medici-training/ reports/docs/Medici_W6_Module_6_Fusion.pdf.

16 The tradition of portraying Asians as objectified sex victims to be rescued or discarded in popular culture is overpowering, but the appetite for brutality committed against black bodies seems to be unceasing at present. See Top of the Lake and its follow up China Girl, by the same white female director, 12 Years a Slave, Precious, and most recently Detroit and Orange is the New Black. For further reading see Shimizu (2016) and hooks (2015).

17 I should add that in the actual study the researchers do mention 'discrimination and prejudices against children and youths with a non-Swedish appearance' as a possible explanation for why the researchers found similar results between transnational adoptees and immigrant children, but not as a direct explanation for the increased numbers per se. I should also mention that the word 'race' is not mentioned once in the study.

18 This film was nominated for best picture, best actress, best director and best adapted screenplay.

\section{ACKNOWLEDGEMENTS}

The research for this chapter was financed by the Swedish Research Council.

\section{REFERENCES}

Ahmed, S. (2012). On Being Included: Racism and Diversity in Institutional Life. Durham, NC and London: Duke University Press.

Ahmed, S. (2017). Living a Feminist Life. Durham, NC and London: Duke University Press. 
Berlant, L. (2004). 'Introducing compassion (and withholding)', in L. Berlant (ed.), Compassion: The Culture and Politics of an Emotion. New York and London: Routledge, pp. 1-14.

Bromseth, J. and F. Darj (eds) (2010). Normkritisk pedagogik: makt, lärande och strategier för förändring. Uppsala: Centrum för genusvetenskap, Uppsala universitet.

Butler, J. (1997). Excitable Speech: A Politics of the Performative. New York and London: Routledge.

Chehrehgosha, A. (2011). 'till mamma, pappa och mina två bröder 5/3-3/4 2011', http://galleriformat.nu/2011/aida-chehrehgosha-till-mamma-pappa-och-minatva-broder-53-34-2011 (accessed 16 February 2018).

Cho, S. K. (1997). 'Converging stereotypes in racialized sexual harassment: Where the model minority meets Suzie Wong', Journal of Gender, Race and Justice, 177, pp. $178-211$.

Chou, R. S. (2012). Asian American Sexual Politics: The Construction of Race, Gender, and Sexuality. Lanham, MD: Rowman \& Littlefield.

Coates, T.-N. (2015). Between the World and Me. New York: Spiegel and Grau.

Davis, A. (2012). 'Social justice in the public University of California, reflections and strategies teach-in, keynote address \& student discussion', UC Davis (23 February), https://video.ucdavis.edu/media/Angela+Davis+Teach-InA+Angela +Davis+\%26+Student+Panel/o_g1t9aewg (accessed 16 February 2018).

de Noli, M. F. (2014). 'Självmord bland invandrare ökar', Läkartidningen (January), www.lakartidningen.se/Klinik-och-vetenskap/Kommentar/2014/01/Sjalvmordbland-invandrare-okar (accessed 16 February 2018).

Du Bois, W. E. B. (2007 [1903]). 'Of the passing of the first-born', in H. L. Gates Jr. (ed.), The Souls of Black Folk: The Oxford W. E. B. Du Bois. Oxford and New York: Oxford University Press.

Elmeroth, E. (ed.) (2012). Normkritiska perspektiv: i skolans likabehandlingsarbete. Lund: Studentlitteratur.

Elwin Frenkel, C. (2010). 'Harry och jag', in L. Olshammar, P. Snickars and P. Vesterlund (eds), Citizen Schein. Värnamo: Mediehistoriskt arkiv 14, Kungliga biblioteket, pp. 224-37.

Grey, H. (2016). 'Precarious diversity: Representation and demography', in M. Curtin and K, Sanson (eds), Precarious Creativity, Global Media, Local Labor. Oakland: University of California Press, pp. 241-53.

Gutiérrez-Rodríguez, E. (2010). Migration, Domestic Work and Affect: A Decolonial Approach on Value and the Feminisation of Labour. New York: Routledge.

Hjern, A., F. Lindblad and B. Vinnerljung (2002). 'Suicide, psychiatric illness, and social maladjustment in intercountry adoptees in Sweden: A cohort study', The Lancet, 360:9331, pp. 443-8.

Hochschild, A. R. (1983). The Managed Heart: Commercialization of Human Feeling. Berkeley: University of California Press.

hooks, b. (2012). 'No love in the wild', www.newblackmaninexile.net/2012/og/bellhooks-no-love-in-wild.html (accessed 16 February 2018).

hooks, b. (2015). Black Looks: Race and Representation. New York and London: Routledge.

Kim, J. Y. (2016). 'Racial emotions and the feeling of equality', University of Colorado Law Review, 87:2, pp. 438-500. 
Kulturdepartmentet (2015). Framtidens filmpolitik. Kulturdepartementets promemoria. Ds 2015:31. www.regeringen.se/49b74.2/contentassets/7e111809096 e45bfbo96ed555ce39dc2/ds-2015_31-inl_web-2.pdf (accessed 16 February 2018).

Kulturnytt (2013a). 'Baker Karim fick 10000 hatmejl', Sveriges Radio (12 March), http:// sverigesradio.se/ sida/artikel.aspx? programid $=478 \&$ artikel $=5470613$ (accessed 16 February 2018).

Kulturnytt (2013b). 'Baker Karim vill ge svensk film en ny storhetstid', Sveriges Radio (7 October), http://sverigesradio.se/sida/artikel.aspx? programid=478\&ar tikel $=5667195$ (accessed 16 February 2018).

Lantz, J. (2009). 'Kvalitet', FLM (15 March), http://flm.nu/2009/o3/kvalitet-2.

Leong, N. (2013). 'Racial capitalism', Harvard Law Review, 126:8, pp. 2151-226.

Letmark, P. (2003). 'Självmord vanligt bland adopterade', Dagens Nyheter (15 October).

Lorde, A. (1996 [1984]). Sister Outsider: Essays and Speeches by Audre Lorde. Freedom, CA: The Crossing Press.

Martinsson, L. and E. Reimers (eds) (2014). Skola i normer. Malmö: Gleerup.

McClintock, A. (1995). Imperial Leather: Race Gender and Sexuality in the Colonial Contest. New York: Routledge.

Mills, C. (2003). 'Contesting the political: Butler and Foucault on power and resistance', The Journal of Political Philosophy, 11:3, pp. 253-72.

The New School (2013). 'Black female voices: Who is listening - a public dialogue between bell hooks + Melissa Harris-Perry'. The New School (8 November), www.youtube.com/watch?v=5OmgqXao1ng (accessed 16 February 2018).

Nordström, A. (2015). 'Många kritiska röster mot Filminstitutets identitetspolitik', Dagens Nyheter (27 November).

Parrenas, S. (2007). The Hypersexuality of Race, Performing Asian/American Women on Screen and Scene. Durham, NC: Duke University Press.

Redvall, E. (2006). 'Manliga filmare kritiserar kvotering' ['Male directors criticise affirmative action']. Sydsvenskan (27 August).

Schein, H. (1970). I själva verket. Sju års filmpolitik. Stockholm: Norstedts.

Shimizu, C. P. (2016). 'Equal access to exploitation and joy: Women of color and Hollywood stereotype', Quarterly Review of Film and Video, 33:4, pp. 303-21.

Snickars, P. (2010). 'Vad är kvalitet?', in L. Olshammar, P. Snickars and P. Vesterlund (eds), Citizen Schein. Värnamo: Mediehistoriskt arkiv 14, Kungliga biblioteket, pp. $158-73$.

Sontag, S. (2003). Regarding the Pain of Others. New York: Picador.

Svenska Filminstitutet (2013). 'Baker Karim ny långfilmskonsulent' (7 October), www.filminstitutet.se/sv/om-oss/press/pressmeddelanden/2013/baker-karimny-langfilmskonsulent (accessed 16 February 2018).

Svenska Filminstitutet (2014). 'Black is the new black- manustavling-och-seminarium' (17 September), www.filminstitutet.se/sv/om-oss/press/pressmeddelanden/2014/ black-is-the-new-black--manustavling-och-seminarium (accessed 16 February 2018).

Svenska Filminstitutet (2015). 'Beyond the new black' (9 October), www.filminstitutet. se/sv/se-och-samtala-om-film/filmrummet/evenemang/evenemang/beyondthe-new-black (accessed 16 February 2018). 
Svenska Filminstitutet (2016). Riktlinjer för det redaktionella arbetet med digitaliseringen av filmarvet. 2014/rev. 2016. www.filminstitutet.se/globalassets/2.-fakunskap-om-film/digitala-filmarvet/diverse-bilder/riktlinjer-for-det-redaktionellaarbetet-med-digitaliseringen-av-filmarvet.pdf (accessed 30 December 2016).

Tinghög, P. (2009). Migration, Stress and Mental Ill Health: Post-Migration Factors and Experiences in the Swedish Context (diss.). Linköping: Linköping Studies in Arts and Science.

Trawalter, S., K. M. Hoffman and A. Waytz (2012). 'Racial bias in the perceptions of others' pain', Plos One, 7:11 (14 November): e48546. https://doi.org/10.1371/ journal.pone.0048546.

Vesterlund, P. (2013). 'Vägen till filmavtalet - Harry Scheins filmpolitiska aktivitet innan 1963', Nordisk Kulturpolitisk Tidskrift, 16:1, pp. 45-67.

Vinthagen, R. and L. Zavalia (2014). Normkreativ. Stockholm: Premiss.

Whitney, S. (2016). 'Affective indigestion: Lorde, Fanon, and Gutiérrez-Rodríguez on race and affective labor', The Journal of Speculative Philosophy, 30:3, pp. 278-91. 


\title{
NAMING, SHAMING, FRAMING?
}

\author{
The ambivalence of queer visibility in \\ audio-visual archives*
}

\author{
DAGMAR BRUNOW
}

$\mathrm{T}$ his chapter looks at the dynamics of visibility and vulnerability in audiovisual heritage. It analyses how film archives in Sweden and the UK, following their diversity policies, address and mobilise the notion of queer, recognising and making visible queer lives, history and cinema, and how they negotiate the risks of increased visibility. In this approach, the archive is positioned as an object of analysis, shifting the focus on the archive as a site of knowledge retrieval to a site of knowledge production (Foucault, 1972; Stoler, 2002). Instead of examining how sexual minorities as a priori identities are included in the archives, I suggest studying the processes of regulation according to which different lifestyles and experiences become 'acknowledgeable' (Schaffer, 2008; Thomas et al., 2017). Archival practices enacting recognition and regulation include the choice of metadata, the modes of selection for public screenings and online exhibition and the curation and contextualisation of online content. The case studies will be the BFI Player, the online portal of the British Film Institute, and the Swedish website Filmarkivet.se, which has created access to some of the digitised collections from the Swedish National Film Archives, administered by the Swedish Film Institute (SFI) and the National Library of Sweden (KB). As points of contrast and comparison, I will draw in the findings of my research on two queer 'minor archives': ${ }^{1}$ Bildwechsel, based in Hamburg, and the Lesbian Home Movie Project in Maine (Brunow, 2015; forthcoming).

Heritage institutions, such as museums, galleries or archives, have been increasingly attempting to acknowledge LGBTQ pasts, often guided by diversity policies (Axelsson and Åkerö, 2016; National Trust, 2017; Sandell and Nightingale, 2012; Steorn, 2012). They are some of the stakeholders in the process of heritage construction during which different interest groups

* This study was funded by the Swedish Research Council. 
negotiate political recognition (Smith, 2007). Creating visibility for previously hidden narratives is based 'on the premise that queer lives ought to be worth preserving' (Stone and Cantrell, 2015: 7). The recognition of queer pasts is relevant for both political goals in terms of equal rights and legislation and the purpose of community-building. In this struggle for LGBTQ recognition, the trope of 'visibility' has been crucial. Visibility can provide role models and counter stereotypical representations, for instance via forms of self-representation, such as home movies or amateur videos (Brunow, 2017). Although often understood as empowerment for marginalised groups, dynamics of visibility and recognition also increase the risks of vulnerability (Foucault, 1990; Schaffer, 2008). ${ }^{2}$ Johanna Schaffer (2008) pointed out this 'ambivalence of visibility' while studying the representation of minorities in visual culture. As representation is pervaded by hegemonic power structures, visibility does not immediately lead to empowerment. For queer individuals, visibility comes with an increased risk of vulnerability in forms of surveillance, governmentality, policing, pathologising, homophobic or transphobic violence, stereotyping and/or modes of shaming (Munt, 2008). Throughout history, exposing LGBTQ persons via 'outing' has been the cause of scandals and violence (Sedgwick, 1990). The fear of exposure has resulted in the desire for safe spaces or the need to be invisible within dominant society. Remaining unmarked within dominant society can thus be a means of protection, leaving only a thin line between archival neglect and recognition.

There has not been much attention given to the connection between film archives, digitisation and the recognition of LGBTQ pasts. Film historiography, media archaeology and archivology tend to neglect questions of archiving LGBTQ-related films, whereas studies on queer archives often ignore the specific requirements involved when archiving audio-visual footage. Studies on queer exhibition practice in museums tend to come to the conclusion that its production of knowledge, of inclusions and exclusions, is in need of further analysis (Museerna och hbtq, 2015; Steorn, 2010; 2012). While conceptualisations of queer perspectives on the archive and archival exhibition practice (Cvetkovich, 2003; Danbolt, 2010; Halberstam, 2005; Muñoz, 2009; Stone and Cantrell, 2015) have outlined a number of relevant aspects for curating LGBTQ-related content, research on the recognition and interpretive framing of gender and sexuality is lacking. The focus on national archives implies that I will be reading along, not against, the archival grain (Stoler, 2002). The recognition of queer lives in the archive is not automatically a means of 'queering' collections, but can produce and perpetuate normative meanings (Edenheim, 2014; Steorn, 2010). ${ }^{3}$ In fact, it is the disciplined recognitions of sexuality and gender that are produced through these signifying practices that make the knowledge they constrain 
and preserve searchable and archivable', as the editors of a special issue on 'Queering archives' note in their introduction (Marshall et al., 2014: 4).

Attempts to counter the previous marginalisation of queer lives in collection and exhibition practice have coincided with diversity politics and the digital turn. Not least for film archives, which had to limit public access to the easily damageable analogue film stock, digitisation has had an enormous impact for the renewed circulation of archival content. These developments imply new challenges for archivists, in terms of not only legal issues but also metadata management and the curation of online content (Brunow, 2017). Metadata helps to make archival content searchable and findable, as well as creates the content by defining and categorising it. Rather than being neutral and objective, metadata entail values and norms which shape the content by defining what is worth searching for and what is not. While the materiality of metadata and analogue film or video is clearly distinct, digitised films and metadata are based on the same digital code. Their relation erodes the previous hierarchy of the 'original content' and the data describing the 'content'. Inextricably linked to the content it creates and therefore no less important than the films themselves, metadata is crucial for conditioning queer visibility. 'Naming' is inextricably linked to the notion of the archive as an instrument of power (Derrida, 1996; Foucault, 1972), highlighting some narratives while marginalising others. Understanding archival practices as performative acts (Brunow, 2017), this chapter argues that cataloguing, tagging and classifying LGBTQ-related content opens up questions about the ambivalence of visibility. As a consequence, it also makes a case for an increased self-reflexivity of the archive, inspired by Joan Schwartz's and Terry Cook's (2002: 1) suggestion that ' $\mathrm{t}$ ] he power of archives, records, and archivists should no longer remain naturalised or denied, but opened to vital debate and transparent accountability'. In view of the risk of queer vulnerability, heritage institutions such as national film archives are in need of a thoughtfully conceived and ethically executed archival practice.

Arguing for the need of archival openness and accountability, this chapter discusses examples of archival practices which are especially sensitive with regards to the risk of queer vulnerability. While Schaffer's focus lies on visual representation, I would like to expand her notion of the 'ambivalence of visibility' towards archival practices of creating metadata and contextualisation. ${ }^{4}$ In the following, three aspects will be explored in relation to queer visibility. The first section, Naming, examines practices of cataloguing and the use of metadata as politics of recognition. The second section, Shaming, discusses the ambivalences of visibility and poses the question of whether visibility should be strived for at any cost, for example when curating online access. The third part, Framing, looks at challenges for online curation in 
term of contextualisation and targeting audiences. Finally, this chapter will outline how national film archives could foreground their own role in the production of (normative) knowledge.

\section{BET WEEN DIVERSITY POLICIES AND MINOR ARCHIVING}

During the last decade, the notion of diversity has gained importance for heritage institutions, such as the Swedish and the British film institutes. ${ }^{5}$ The BFI policies draw on the UK Equality Act of 2010, in which the following characteristics are worth protecting: 'Age, Disability, Gender reassignment, Marriage and civil partnership, Race, Religion of belief, Sex, Sexual orientation'. In more recent policy documents, a rhetorical shift has occurred towards regarding diversity as an asset rather than a means to protect marginalised groups. To illustrate this, the BFI Film Fund Diversity Standards (BFI, 2016) understands diversity as a means not to empower marginalised groups in the first place, but to strengthen the film industry as part of the creative industries: 'Diversity is not just about doing what's right: it's good for creativity, supports economic growth, taps into underserved audiences and makes good business sense ... That's why our definition of diversity is to recognise and acknowledge the quality and value of difference.' ${ }^{6}$ According to the policy documents of the Swedish Film Institute (SFI, 2016), works by female filmmakers, producers, scriptwriters and cinematographers should be prioritised when selecting the one hundred films to be digitised each year. The same goes for films about the Sami and other officially acknowledged ethnic minorities in Sweden. Although the Swedish Film Institute very successfully works for a more even gender balance - an effort which is ground-breaking internationally - sexual minorities are not explicitly mentioned in guidelines and regulations. ${ }^{7}$ In contrast, the British Film Institute is actively promoting diversity, both in terms of film production, distribution and exhibition as well as in relation to LGBTQ people. These different strategies in implementing diversity issues influence the archival practice of both national film institutes, for instance when curating access to their archival collection on their internet platforms Filmarkivet.se and the BFI Player.

Launched in 2011, the Swedish website Filmarkivet.se provides free global access to a selection of films archived at the Swedish Film Institute and the National Library's Division of Audio-visual Media, as well as programmes provided by Sweden's public service broadcasting corporation Sveriges Television. Setting out to show 'the transformation of Swedish society over the last century' (www.filmarkivet.se), the 1,500 films accessible via Filmarkivet.se are mainly Swedish documentaries, such as industrial, city 
or election films, as well as short films, animations, or experimental filmmaking. Although access to the exhibited material is not limited by geoblocking, knowledge of Swedish is required when navigating the site, since both the films and their paratexts, such as metadata and contextual information, are available in Swedish only. Unlike Filmarkivet.se, the BFI Player is geo-blocked, prohibiting access outside the UK. Providing the interface for feature films available via VOD and S-VOD, the BFI Player is divided into three sections, Subscriptions (S-VOD), Rentals (VOD) and Free, which holds non-fiction material from the National Archives. The Free section in turn can be accessed through a number of curated collections, ranging from Railways on Film and Punk to Black Britain, Chinese Britain on Film and LGBT Britain. More than thirty films can be found in the free collection LGBT Britain, but the label is also used within the VOD and SVOD sections.

Arguing that national archives could learn from queer minor archives, I will draw comparisons to the archival practice of the Lesbian Home Movie Project (LHMP) in Maine (Brunow, forthcoming) as well as to the international archive for female and trans visual artists, Bildwechsel in Hamburg (Brunow, 2015). The term 'minor archives', drawing on the notion of 'minor cinema' (Brunow, 2015), is used as an umbrella term for such grassroots, independent or community archives founded as a reaction to archival neglect. This form of archival activism set out to make personal memories visible and accessible within the (semi-)public sphere. While queer minor archives and national heritage institutions are facing similar challenges in the wake of digitisation, they have different approaches to recognising queerness and navigating the ambivalence of queer visibility. First, archivists might lack an insight into LGBTQ subcultures and fail to acknowledge these; second, the politics of representation at work in the archival footage itself can differ to a high degree (Kirste, 2007). To illustrate, the films and tapes found in queer minor archives, for instance home movies or amateur filmmaking, tend to 'portray LGBT people as complex individuals rather than stereotypes, offer a diversity of race, age, ethnic background, politics, gender identification, and other qualities, and show LGBT people in the context of our relationships, families, and communities', as Lynne Kirste (2007: 134) points out. Such complex representations are rarely found in national film archives, and even if they are, archivists might not recognise or acknowledge them. Moreover, both Bildwechsel and the LHMP are highly reflective about their archival practice and are actively seeking the dialogue with the queer community about archival decisions, on location, via social media or via interactive art installations (Brunow, 2015; forthcoming). Minor queer archives' participatory approaches and their involvement in the communities they serve can provide a role model for heritage institutions. 


\section{NAMING}

Archival practices of cataloguing and choosing metadata always imply a 'naming time' (Marshall et al., 2014: 4). Naming provides the discursive framework for the articulation of non-normative sexualities. Therefore, archivists need to understand cataloguing, not as a neutral, descriptive activity, but as a performative act of power. Search terms might 'appear unbiased and universally applicable - but they actually hide their exclusions under the guise of neutrality' (Olson, 2001: 640). This is why archives need to foreground their operations of classification as being transparent and acknowledge the interrelatedness of queer visibility and governmentality. For example, the National Archives in the UK advises researchers how to look for LGBTQ lives in criminal records, searching for 'relevant criminal offences': 'buggery, disorderly house, gross indecency, importuning, indecency, obscenity, sexual offences, sodomy, soliciting, street offences, unnatural offences, unnatural acts. ${ }^{8}$ Through self-reflexive acts like these, the archive acknowledges that metadata and search terms are historically situated. Moreover, archives need to navigate the risk of defying the subversive, evasive quality of queerness (Muñoz, 2009; Steorn, 2012). Single catalogue terms cannot grasp the complexities of shifting sexualities or variable gender expressions. As Patrik Steorn points out: 'It is important to keep in mind that reclassifying and tagging objects not only makes them available for database searching, it also adds new historical layers and forces objects to fit established categories', thus restricting 'queer possibilities' (2012: 359). Overall, archivists might be hesitant to classify the persons portrayed in the footage in terms of their sexual identity. Given the history of criminalising or pathologising LGBTQ persons, the reluctance to tag archival holdings as LGBTQ-related is quite understandable. The scepticism about the usefulness of 'naming' can either be the result of latent or manifest homophobia among archivists or a means to acknowledge the risk of 'naming' as a way of reducing shifting identities to a single classification.

The metadata on Filmarkivet.se is mainly derived from the Swedish Media Database and the Swedish Film Database, an online catalogue containing information on almost 80,0oo Swedish films and international productions screened in Swedish cinemas. Because the archivists do not work with single tags but on the basis of a full text search, LGBTQ-related terms need to be part of the text that describes the film. Since this text is often retrieved from older information to be found in the databases mentioned above, the discursive space for the articulation of LGBTQ identities is very limited. For instance, before 2017, when an updated version of the Swedish Film Database was relaunched, the search term 'lesbisk' ['lesbian'] did not lead to any results on Filmarkivet.se whatsoever. In contrast, 
the BFI Player uses tags, such as 'Gay people' or 'Lesbians', 'Gay pride' and 'Gay activists', and can even take an intersectional perspective by combining these with, for example, 'Cultural identity', 'ethnic minorities' or 'Afro-Caribbean community in Great Britain'. Also in 2017, Filmarkivet.se launched the subject category 'Queer.' Two films in the section represent instances of cross-gender performance: the three-minute silent film Skilda tiders danser [Dances Through the Ages] (Walfrid Bergström, 1909) and an ad for shaving foam (Hylins Rakin, 1940), showcasing a male to female crossdresser and including a sequence parodying Greta Garbo's notorious hat in Ninotchka (Ernst Lubitsch, 1939). The choice of these two films exemplifies the challenges of curating the trans archive (Halberstam, 2017; Rawson, 2010; Stryker and Currah, 2015) in view of a broad variety of queer subject positions, such as 'transsexual, transvestite, cross-dresser, transman/ transwoman, genderqueer, androgyne, female-to-male (FTM), and male to female (MTF)' (Rawson, 2010). According to Laura Horak (2017), more than ninety films containing cross-gender performances can be traced in the history of Swedish cinema, but 'these performances were not necessarily subversive or queer' (Horak, 2017: 378). Of these ninety films, only one, Skilda tiders danser, can be currently seen on Filmarkivet.se. Trans in the archive epitomises the challenges queer visibility implies for archivists, both with regards to the lack of self-representation and the choice of metadata.

The category 'Queer' currently (November 2017) contains six films, from the aforementioned Skilda tiders danser to the collective gay film project Bögjävlar [Damned Queers] (1977) and the award-winning short Längs vägen [Along the Road] (2011) about the secret love of two truck drivers. ${ }^{9}$ While the selection of films categorised under the header 'Queer' seems to be quite eclectic, a conceptualisation of the concept 'Queer' is missing both on the website itself and in the policy documents provided by the SFI (SFI, 2017; Svenska Filminstitutet, 2016). Unlike other themes on the platform, such as 'Football' or 'Radio', the category 'Queer' does not yet have introductory text. On what grounds the films are selected thus remains unclear for the users. To compare, the BFI Player introduces its theme 'LGBT Britain' by explaining:

British cinema boasts a long history of carefully coded queerness, but for much of the 2oth century explicit depictions of gay life in drama or documentary were more or less taboo. Gay men were subject to vicious statesanctioned persecution, while lesbians were socially ostracised and the transgender community ignored and misunderstood. Cinematic and smallscreen breakthroughs in the 1950 s and 6 os played their part in the public debate ... From early glimpses of 'queer' characters, this collection charts the path towards ' 67 and beyond, through responses to the AIDS crisis to diverse reflections on queer life today. 
The explanatory text gives an overview of the different historical contexts which have shaped the representations of LGBTQ lives in the British National Film Archives. This self-reflexive stand helps to widen the discursive space for the articulation of queer sexualities in the archive.

Along with visibility, invisibility also affects the risk of queer vulnerability. Instead of being binary oppositions, the notions of visibility and invisibility are interrelated (Schaffer, 2008). Queer lives which remain unmarked, unnamed or untagged might not be visible within the archive's dominant heterosexual structure, but their invisibility can protect them. As a consequence, archivists need to be aware that naming or 'outing' some individuals might put many others back into the closet. Choosing a category such as 'Queer' for only a small number of films while at the same time ignoring other works which could provoke queer readings or which could be considered part of a LGBTQ heritage produces new exclusions and perpetuates heterosexuality as the norm. I will briefly discuss the archival presentation of two queer Swedish icons: Selma Lagerlöf and Greta Garbo. Filmarkivet.se presents two newsreels on the Noble prize laureate: 'Ett besök hos Selma Lagerlöf' ['Visiting Selma Lagerlöf'] (1926) and 'Selma Lagerlöf 8o år' ['Selma Lagerlöf's 8oth Birthday'] (1938), as well as three films on Greta Garbo: Garbo as a fashion model in a commercial from 1921 for the store PUB, a 1929 newsreel about Garbo's voyage from Hollywood to Sweden, and a screen test from 1948 for the projected film adaptation of Balzac's La Duchesse de Langeais, which was never realised. None of these five films is included in the section 'Queer', and the metadata and newly written editorial contextualisation do not relate the footage to LGBTQ heritage.$^{10}$ As a result, Garbo and Lagerlöf are not legible as the queer icons they have become. In order to perceive the films as part of LGBTQ heritage, users need to bring their previously acquired knowledge to the viewing of the footage. The archivists might have wanted to avoid reductive classifications, but the lack of any hint to queerness risks 'unqueering' Garbo and Lagerlöf. The often-observed reluctance by archivists to tag or classify queer persons as LGBTQ-related can be a means of protecting their integrity. Yet, as Lynne Kirste points out: 'Without a subject heading or descriptive word to search on, a researcher or archive staff member must resort to searching film titles or the names of filmmakers, actors, or personalities, one by one' (Kirste, 2007: 137). This is especially difficult, if not impossible, in an archival collection such as Filmarkivet.se which grants access to newsreel footage and other non-canonised material. To compare, the National Trust's project Prejudice \& Pride: Celebrating LGBTQ Heritage is described by Alison Oram and Matt Cook as 'not looking for gays and lesbians in history, but for signs of same sex relationships and desires and their different configurations' (National Trust, 2017: 5). This approach can prove useful for 
film archives as well because it helps to create a self-reflexive take on archival practices of selecting and 'naming' and highlighting their repercussions on queer visibility.

\section{SHAMING}

As the visibility of queer lives is linked to notions of pride and shame (Munt, 2008; Sedgwick, 1990), the lack of metadata can be either a symptom of archival neglect or a sign of archival responsibility. In terms of the latter the lack of metadata can be considered as a way to acknowledge the vulnerability of LGBTQ people and a means to protect them from homophobia or transphobia.

Collection policies have had repercussions on queer archival visibility. As LGBTQ-related footage is rarely recognised by national film archives, queer filmmakers of home movies or amateur videos have often been reluctant to hand over their material. This is why works of queer selfrepresentation are highly absent in national archives (Brunow, forthcoming; Kirste, 2007). Many filmmakers have been hesitant to expose the queer lives portrayed in their works to society's 'disapproving gaze' (Munt, 2008: 219), and have been suspicious of institutions, of being the potential target of homophobia or transphobia, or of being misrepresented. Another contributing factor to the lack of LGBTQ self-representations in official archives is the materiality of the analogue stock, especially with regards to video productions from the late 1970 os and 1980s. Since not all film archives have included video into their collection policies, 'LGBT independent and amateur productions are typically stored in media-unfriendly conditions in filmmakers' homes rather than in archives' (Kirste, 2007: 134). As a result, the audio-visual memory of a whole generation is at risk of disappearing. Therefore, minor archives are currently urging queer filmmakers to hand over their home movies and amateur films so that they can be digitised and stored in climate-controlled vaults (Thompson, 2015). Handing over such private material is still a matter of trust, especially in times of political crisis. LGBTQ people have been confined to queer minor archives as safe havens for their material, to be taken care of in a spirit of love, affection and solidarity (Cvetkovich, 2003). Meanwhile, the idea of queer archives as safe spaces is challenged by the increasing possibilities to access archival footage online. Online access comes with a challenge: what happens when films leave the semi-public sphere of the minor archive and start circulating within the heteronormative public sphere? ${ }^{11}$

Negotiating the binaries of secrecy and disclosure (Sedgwick, 1990: 11), of safe space and public access, and of pride and shame has become a crucial 
task for minor queer archives in the wake of digitisation. As one of such minor archives, Bildwechsel was founded in 1979 in the wake of the political video movement. It houses more than 7,000 videotapes on nineteen different formats, of which about 10 per cent have been digitised. Among them are collections from the feminist film festival Feminale in Cologne (1999-2006), the West Berlin queer art space Pelze Multimedia (1986-90) or the lesbian television show Lesben in Sicht, broadcast on Hamburg's Open Channel (1994-98). Other works include film and videos donated by the artists themselves and productions by the Bildwechsel collective, such as travelogues, documentations of queer/feminist events or interviews with female artists from Martha Rosler to Pipilotti Rist (Brunow, 2015: 11825; Maule, 2016). In 2015, Bildwechsel launched its website Videoschloss [Video Castle] as a streaming device for selected videos from the archival collections. A mixture of Tove Jansson's Moomin house and a classical art gallery, the video castle guides users through the online exhibition. The other minor archive to be highlighted is the Lesbian Home Movie Project (LHMP) in Maine, which was founded after a collection of $16 \mathrm{~mm}$ home movies by New York schoolteacher Ruth Storm surfaced in 2008 (Thompson, 2015). As its board members are 'rooted within multiple lesbian communities', the project's focus on lesbian filmmaking is both 'affectionate and pragmatic' (Thompson, 2015: 115). Since its inception in 2009, the LHMP has acquired more than twenty collections which are digitised and contextualised, for example via oral history interviews. Just like Bildwechsel, the LHMP actively engages with the filmmakers or their circle of friends.

Ethical considerations play an important role for minor archives, such as Bildwechsel or the LHMP. Their archival practice of curating archival exhibitions (online or in specifically programmed screenings) is ethically executed, recognising the risk of queer vulnerability. Acknowledging the cultural sensitivity of the films and videos in their collections, both archives are keen on respecting donor and participant concerns. Therefore, contracts with the individual donors include detailed information on to what extent the archived films or videos can be made accessible. This can range from access on location only to online access to selected clips. For each of the various collections archived within the LHMP, different modes of access are in use. For example, the 'Anonymous' collection consists of $8 \mathrm{~mm}$ reels and VHS tapes shot by a Maine painter and her circle of family and friends. From this collection, only one half-hour segment is allowed to be shown. Other collections have restrictions, such as, 'Donor notification required. Donor retains right to also use the material \& intends to collaborate on edit', 'Donor \& other permissions required for any public use' or 'DVD \#6 cannot be shown at the present time.' Currently, the LHMP has limited access via DVD or public screenings in queer/feminist contexts, but has only recently 
started to upload any of the material. We can now find a number of films from the various LHMP collections online on Vimeo, for instance three films from the Ruth Storm Collection, Corky Culver's 'Prairie Journal' or an interview with Audre Lorde (1975), for which none other than Michelle Citron operated the portapak.

The 1970 s feminist slogan 'the personal is political' involves another challenge for queer minor archives. Aiming at turning vulnerability into resistance, the notion of the personal being political deliberately disrupts the boundaries between the private and public spheres. This becomes especially relevant for amateur films and home movies, especially those made during the 1970 s in the context of social movements. To what extent can or should - these films or videos be made accessible online? Even if online exhibition has been granted by donors, queer minor archivists would tend to refrain from uploading footage which they consider too personal to be exposed to the public (Brunow, forthcoming). Examples would be footage from feminist separatist events, such as summer camps or music festivals, or lesbian bars and clubs. Unlike Bildwechsel, which refrains from exhibiting such footage online, the LHMP was debating whether or not to upload home movie footage of topless lesbians at a feminist festival on their Vimeo portal in 2017. While no decision has been reached at the time of writing (November 2017), the upload would be an act of exposure which can turn into agency. These examples show that minor archivists are highly reflective when navigating the ambivalence of queer visibility. Queer minor archives are also able to engage with their respective communities when trying to find solutions for archival challenges.

\section{FRAMING}

The shift from analogue footage to digital data requires new contextualisations when curating online access. Titles, descriptions, search filters and suggestions for 'related content' provide a framework for the reception of the films. One of the earliest lesbian self-representations on film in Sweden, the 1983 production Eva and Maria (dirs. Mary Eisikovits, Marie Falksten and Annalena Öhrström) serves as an example of how contextualisation creates or prevents queer visibility. Meanwhile, the film has gained scholarly attention (Ryberg, 2015; Chapter 11, this volume) and has been circulated again. Since it was uploaded on Filmarkivet.se in 2015, its contextual information given on the website has changed three times. This makes it a case worth exemplifying on what grounds queer lives are acknowledged in the archive.

Eva and Maria is the first Swedish feature 'by, with, and about open lesbians' (chapter 11, this volume), publicly funded by The National Board of 
Health and Welfare (Socialstyrelsen), the very organisation which classified homosexuality as a mental disorder in 1968. This makes the film an important historical source. Ryberg details how the filmmakers deliberately avoided the use of terms such as 'homosexual' or 'lesbian' when applying for funding. Such strategic decisions need to be foregrounded when contextualising the film on Filmarkivet.se. In the Swedish Media Database (SMDB), Eva and Maria is categorised as a 'fiction film,' 'short film', 'feature' and 'drama.' The lesbian content is not mentioned in these subject categories, and even the description 'the L-word' (lesbian) is never used. Thus, the film could not be found by using search terms, such as 'lesbian' or 'queer', until 2017, when the category 'Queer' was introduced on Filmarkivet.se and these terms became part of the full text. In 2015, the Swedish Film Database described the film as follows:

It is important that heterosexuals understand that the love between Eva and Maria is based on true and worthy emotions. This love has the same obvious right to be respected as the love between woman and man. Many people are provoked when they see homosexuals kiss or cuddle. It is experienced as strange and disgusting. The script writers hope that those who have seen the film, and talk about it, can react in a less prejudiced manner when they will encounter homosexual men and women from now on. ${ }^{12}$

The text stems from a fact sheet provided by the distribution company Filmo AB, which is credited on the website. It states that homosexuals often do not consider their sexuality to be a problem, but that the problems are caused by the society that surrounds them - a description evoking Rosa von Praunheim's film Nicht der Homosexuelle ist pervers, sondern die Situation, in der er lebt (Germany, 1971). Including the information from the fact sheet echoes Ingrid Ryberg's contention that Eva and Maria and Bögjävlar 'mark a significant shift in focus, from regarding homosexuality as problematic to critiquing and deconstructing homophobia and gender roles' (Ryberg, 2015: 147). The contextual information provided by the distribution company highlights the historical understanding of homosexuality from the perspective of LGBTQ activism in late 1970s Sweden: not as a timeless 'problem, but as an identity which is created in relation to and by the surrounding society and its discursive frameworks.

Contextualisation can contribute to the queer visibility - or can prevent it, as the example of Eva and Maria shows. For the presentation on Filmarkivet.se in 2016, a much shorter text was chosen. Taken from the filmmakers' description (see chapter 11, this volume), it reads: 'A film about love between two young women. They meet understanding and tolerance, but also prejudice and lack of understanding by family and friends. ${ }^{13}$ The source of the text, however, is not credited on the 
website. The lack of contextualisation and the thus missing terms 'lesbian', 'queer' and 'homosexual' has had at least two consequences: first, an online search for these terms failed to find the film. Second, with this new version not only the historical context has disappeared but also the critical perspective on the Swedish society as a decisive factor of defining 'homosexuality' or 'lesbian identity'. Instead of offering an analytical perspective on contemporary politics, the focus is on the individual. At the same time the notions of 'understanding and tolerance' as well as 'prejudice and lack of understanding' appear as timeless conditions that homosexual couples will have to face. As Ryberg (2015:144) details, after both the Swedish Film Institute and the left-wing Filmverkstan declined, Eva and Maria was funded by the National Board of Health and Welfare in 1977, remarkably enough from its budget for birth control education. When Eva and Maria was screened in Japan at a UNESCO health conference, it was distributed alongside guidelines for teaching, which state:

Homosexuals often feel that, rather than their sexual or emotional preferences being problematic, the attitudes in the surrounding world cause difficulties ... The few times homosexuality is represented in media, criminality and illness are often part of the picture. We want to turn the debate to focus on homophobia (fear of homosexuals) instead. (Ryberg, 2015: 145)

This approach, however, was considered as conveying a too positive message (Ryberg, 2015: 144). While Swedish television, especially the second channel, was usually open to left-wing progressive content, it refused to broadcast the film without an accompanying on-air discussion. As the filmmakers did not want to comply with these conditions, Eva and Maria was never broadcast on television (Ryberg, 2015: 144). Embedding contemporary material into today's online presentation, which contextualises the information, can illustrate the discursive framework in which the film has been circulating. At the same time such an approach can help the users to understand as to what extent filmmaking can be regarded as an intervention in hegemonic representation. A broader historical overview is provided by the latest version of the accompanying text, published in December 2017.14 It contextualises Eva and Maria in the events around the occupation of the National Board of Health and Welfare in 1979, which was a protest against the classification of homosexuality as a mental disorder. ${ }^{15}$ The example illustrates how the choice of metadata and paratexts not only can be seen as an attempt to recognise lesbian lives, but how it can also foreground the politics of exclusion at work in film production, distribution and reception. The film's contextualisation can help to understand on what grounds lesbian or homosexual identity could be articulated in history. 
As a situated practice, the work of the archivist is defined by multiple discursive frameworks. In Sweden, notions of equality and cultural homogeneity are part of the hegemonic master narrative of the nation, whereas in the UK heritage institutions do not shy away from representations of social inequality and political struggle (Axelsson and Åkerö, 2016). However, a perspective on heritage which glosses over conflicts and political struggle can lead us to believe that our democratic rights can be taken for granted. Instead, these rights are the result of intense political struggle, which is why historical exhibitions should highlight that democratic rights are not won forever, but need to be continuously defended (Eivegård and Furumark, 2017: 13). Therefore, film archives, when curating access, could make use of a conflict perspective in favour of homogenising the past. For example, the BFI Player offers a number of examples for the recognition of the LGBTQ struggle. One is the current affairs report 'Oxford Housing' (1982). Tagged as 'Council housing' and 'Gay people', the film is contextualised with the following text:

\begin{abstract}
Another small step towards equality came in 1982 when same sex couples in Oxford were able to register for council housing. There were conditions of course: couples had to be over 35 years old and able to demonstrate that they had a 'stable' relationship, a vague sounding stipulation that heterosexual applicants did not have to adhere to. Even this small concession was contested by the conservative group on the council, which was hoping to reverse the decision once in power. ${ }^{16}$
\end{abstract}

In this text, different political opinions are not glossed over but addressed and foregrounded. The archival clip is historicised, while at the same time showing the relevance of the past struggle for LGBTQ lives today. The case of Eva and Maria, discussed above, illustrates how different ways of contextualising the film can either avoid or implement a conflict perspective, which can point to the role of LGBTQ activism in the struggle for democratic rights.

Alternative ways of contextualising archival footage can be found in minor archives, for instance by including oral history interviews with the filmmakers or their circle of friends or family. The LHMP, for example, actively encourages donors to participate in the documentation of the material and its contexts (Thompson, 2015). In national archives, oral history interviews could also be employed to obtain different versions of an event, for instance by countering stereotypical representations in archival footage. Here, the use of oral history narratives could be a means of adding forms of LGBTQ self-representation to the archive. Oral histories could also be employed to generate knowledge about queer readings or queer (re)appropriations of specific films. Another way to contextualise online 
archival exhibitions would be to add digitised print material providing background information on the production, distribution or exhibition context. ${ }^{17}$ National film archives and queer minor archives tend to host impressive collections of books, fanzines, press cuttings, flyers and posters, which would provide a historical context for the film footage, embedding it in its (sub)cultural framework.

\section{CONCLUSION}

The archival recognition of LGBTQ pasts leads to an increased queer visibility, but requires an ongoing reflection about the resulting risk of vulnerability. This chapter has examined this ambivalence of visibility faced by national film archives when trying to create a more inclusive heritage in relation to queer pasts. It has also shown that metadata management is of high importance in times of digitisation. Visibility, as a result of 'naming' practices, such as tagging and cataloguing, can be both understood as a way to recognise and empower sexual minorities and at the same time expose LGBTQ lives. Archivists need to acknowledge, reflect upon and negotiate these contradictions, navigating the epistemological challenges. Discussing the ambivalence of queer visibility, this chapter has shown how national film archives are in need of analysing 'queer' as a category. They should be able to share their reflections on archival decisions to the users. Furthermore, to acknowledge their agency in knowledge production, archives should: (1) date the descriptions, (2) credit the author(s) of the text, even if it was written by one of the archivists themselves, and (3) draw on scholarly film expertise, therefore (4) collaborating with scholars and members of the LGBTQ communities. These strategies can contribute to a contextualisation of queer-related content which historicises the material, while at the same time showing its relevance for today's audiences. ${ }^{18}$

Regarding the politics of queer recognition in the wake of diversity policies, national film archives would do well to learn from the experiences and reflections of minor archives. Collaborations between national heritage institutions and minor archives could be a way to employ the expertise assembled in these often longstanding community-based projects. To illustrate, the National Trust's Prejudice \& Pride project mentioned above has been working in tandem with 'a number of communities, artists and creative practitioners to breathe life into our places, collections and stories' (National Trust, 2017: 4). For national film archives, such collaborations would be relevant in view of access policies and collection practices, especially with regards to home movies and amateur filmmaking. An example of a successful archival cooperation is the Outfest UCLA Legacy Project 
for LGBT Moving Image Preservation, founded in 2005, a collaboration between the Outfest Los Angeles LGBT Film Festival and the UCLA Film and Television Archive. The Legacy Project has been a ground-breaking initiative for the restoration and renewed circulation of queer film classics, independent film productions or home movie collections. ${ }^{19}$ An option worth considering for national heritage institutions in Sweden would be to team up with projects such as the Swedish Archive for Queer Moving Images, initiated by curator and filmmaker Anna Linder and funded by the Swedish Arts Grants Committee from 2017. ${ }^{20}$ Building relationships between official heritage institutions and other nodal points for queer knowledge can prove fruitful for the recognition of queer narratives and experiences.

The question remains as to what extent the current efforts to chronicle queer lives can be regarded as a means of counterbalancing the longstanding neglect of heritage institutions. Despite well-meaning efforts to integrate a queer perspective, 'the queer eye will always see its presences elsewhere and collect the neglected', as Patrick Steorn (2010: 136) points out. Steorn is also sceptical about the capacity of heritage institutions to capture the complexities of queer experiences and affect. Heritage institutions, he states, need to critically examine their own role as producers of knowledge, thereby addressing the power relations involved in the politics of inclusion and exclusion: 'They should allow for queer presences to occur on their own terms rather than co-opt LGBT culture as a way to seem more radical than they really are' (Steorn, 2010: 136). At the same time, critical museum studies have shown that museums' efforts to target ethnic minorities do not automatically lead to an appellation of these groups (Dewdney et al., 2013). Archives should therefore provide a space for multiple identifications, I argue, instead of creating limiting classifications. And, of course, the perspective needs to be intersectional, taking other categories, such as 'race' or ability, into account (Han, 2007). It is my contention that LGBTQ-related visibility in the archives might be at best regarded as a form of a strategic essentialism and a means of reaching audiences, but not a means in itself. Archivists will still need to face the challenge of how to navigate the ambivalences of queer visibility in order to walk the fine line between surveillance and empowerment.

\section{NOTES}

1 The notion of 'minor archives', just like the concept of 'minor cinema', is derived from the Deleuzian understanding of 'minor literature'. See Brunow (2015: 16) for an overview of the concept of 'minor cinema.' 
2 I understand vulnerability as a relational practice, always situated in a specific sociohistorical and discursive context. Neither is it a subjective disposition (Butler, 2016: 25) nor an essentialist concept. In this sense, when speaking of 'queer vulnerability' I am well aware of the social inequalities which pervade the various queer communities.

3 As Sara Edenheim (2014) points out, the extent of subversion is limited: LGBT lives, made 'visible', will still be embedded in a heterosexual logic of reproduction.

4. This contribution draws on some of the findings from my current research project 'The Cultural Heritage of Moving Images' (Swedish Research Council, 2016-18), in which I examine the ways digital film heritage is curated and contextualised in online collections (Brunow, 2017).

5 The concept of 'diversity' entails a number of epistemological problems which cannot be discussed here. For heuristic reasons the use of the term in this article will follow its use in official policies dedicated to the recognition of minorities within a national framework.

6 www.bfi.org.uk/sites/bfi.org.uk/files/downloads/bfi-diversity-standardsleaflet-2016-05-11.pdf.

7 See SFI (2017), Svenska Filminstitutet (2016). See also the website Nordic Women in Film. www.nordicwomenfilm.com (accessed 10 August 2017).

8 www.nationalarchives.gov.uk/help-with-your-research/research-guides/gaylesbian-history/ (accessed 8 January 2017).

9 After a workshop which I conducted with some of the archivists at the Swedish Film Institute in May 2018, more films were added to the category 'Queer' on Filmarkivet.se, including selected footage of Selma Lagerlöf and Greta Garbo.

10 See note 9 above. The films included in May 2018 are 'Ett besök hos Selma Lagerlöf' (1926) and 'Testfilm Greta Garbo' (1948).

11 Such decisions are not made by the archivists alone, though. Online accessibility to audio-visual content is limited due to strict national copyright regulations (unlike in the US, in Europe the notion of 'fair use' does not exist), including property rights issues and neighbouring rights, such as music rights (Brunow, 2017). No matter how good the intentions of the archivists are, legislation can be an obstacle to unlimited online access.

12 The Swedish original: 'Det är viktigt att de heterosexuella i gruppen förstår att kärleken mellan Eva och Maria bygger på sanna och värdiga känslor. Denna kärlek har samma självklara rätt till respekt som kärleken mellan kvinna och man. Många människor blir provocerade den första gången de ser homosexuella kyssas eller hålla om varandra. Man upplever det som främmande och motbjudande. Manusförfattarna hoppas att de som sett och talat om filmen ska kunna reagera mindre fördomsfullt när de senare i livet möter homosexuella män och kvinnor. (Beskrivning i faktablad från Filmo AB)'. www.filmarkivet.se/ movies/eva-och-maria (accessed 20 October 2017).

13 My translation. Swedish original: 'En film om kärlek mellan två unga kvinnor. De möter förståelse och tolerans men också fördomar och oförståelse från släkt och vänner'. www.filmarkivet.se/movies/eva-och-maria (accessed 20 October 2017).

14 www.filmarkivet.se/movies/eva-och-maria (accessed 18 December 2017). In the meantime the film description has been revised while taking Ryberg's research findings into account. 
15 See Ryberg's chapter in this volume for a historically detailed version of the events.

16 https://player.bfi.org.uk/free/film/watch-oxford-housing-1982-online.

17 The Swedish website Filmarkivforskning.se can be regarded as an attempt to compensate for the lack of contextualisation on Filmarkivet.se. It is the result of a three-year grant (RJ 2013-2016). From 2017, it has been administered by the National Library of Sweden (see also Snickars, 2015).

18 However, in times of right-wing populism the vulnerability of national archives dedicated to liberal identity politics is likely to increase.

19 www.cinema.ucla.edu/collections/outfest-ucla-legacy-project-lgbt-movingimage-preservation (accessed 20 February 2017).

20 Meanwhile, the Swedish Archive for Queer Moving Images and Filmarkivet.se have initiated a collaboration in 2018.

\section{REFERENCES}

Axelsson, B. and K.-E. Åkerö (2016). 'LHBTQI-perspektiv och kulturarv. Aspekter på urval, överväganden och tillrättalägganden', Nordisk Museologi, 2, pp. 3-19.

BFI Film Fund Diversity Standards (2016). www.bfi.org.uk/sites/bfi.org.uk/files/ downloads/bfi-diversity-standards-leaflet-2016-05-11.pdf (accessed 9 August 2017).

Brunow, D. (2015). Remediating Transcultural Memory: Documentary Filmmaking as Archival Intervention. Berlin and Boston: deGruyter.

Brunow, D. (2017). 'Curating access to audiovisual heritage: Transnational memory and polyvocality in European film archives', Image and Narrative, 18:1, pp. 98-110.

Brunow, D. (forthcoming). 'Queering the archive: Amateur films and LGBT-memory', in I. Stigsdotter (ed.), Making the Invisible Visible. Stockholm: Stockholm University Press.

Butler, J. (2016). 'Rethinking vulnerability and resistance', in J. Butler, Z. Gambetti and L. Sabsay (eds), Vulnerability in Resistance. Durham, NC: Duke University Press, pp. 12-27.

Cvetkovich, A. (2003). An Archive of Feelings: Trauma, Sexuality, and Lesbian Public Cultures. Durham, NC and London: Duke University Press.

Danbolt, M. (2010). 'We're here! We're queer? Activist archives and archival activism', Lambda Nordica, 15:3-4, pp. 90-118.

Derrida, J. (1996). Archive Fever: A Freudian Impression, tr. Eric Prenowitz. Chicago: University of Chicago Press.

Dewdney, A., D. Dibosa and V. Walsh (2013). Post-Critical Museology: Theory and Practice in the Art Museum. London and New York: Routledge.

Edenheim, S. (2014). 'Lost and never found: The queer archive of feelings and its historical property', A Journal of Feminist Cultural Studies, 24:5, pp. 36-62.

Eivergård, M. and A. Furumark (eds) (2017). 100\% kamp: mänskliga rättigheter $\mathcal{E}$ kulturarv. Stockholm: Boréa bokförlag.

European Commission (2014). 'Implementation of the 2005 European Parliament and Council Recommendation on Film Heritage. Progress report 2012-2013, 
https://ec.europa.eu/digital-single-market/en/news/european-commissionsreport-film-heritage (accessed 9 August 2017).

Fossati, G. (2009). From Grain to Pixel: The Archival Life of Film in Transition. Amsterdam: Amsterdam University Press.

Foucault, M. (1972). The Archaeology of Knowledge. London and New York: Routledge.

Foucault, M. (1990). The History of Sexuality. Vol. 1: The Will to Knowledge. Harmondsworth: Penguin.

Halberstam, J. (2005). In a Queer Time and Place: Transgender Bodies, Subcultural Lives. New York and London: New York University Press.

Halberstam, J. (2017). Trans*: A Quick and Quirky Account of Gender Variability. Oakland: University of California Press.

Han, C. (2007). 'They don't want to cruise your type: Gay men of color and the racial politics of exclusion', Social Identities, 13:1, pp. 51-67.

Horak, L. (2017). 'Cross-dressing and transgender representation in Swedish cinema, 1908-2017', European Journal of Scandinavian Studies, 47:2, pp. 377-97.

Kirste, L. (2007). 'Collective effort: Archiving LGBT moving images', Cinema Journal, 46:3, pp. 134-40.

Legislation.gov.uk (2010). Equality Act 2010, www.legislation.gov.uk/ukpga/2010/15/ contents (accessed 9 August 2017).

Marshall, D., K. P. Murphy and Z. Tortorici (2014). 'Editors' introduction: Queering archives: Intimate tracings', Radical History Review, 122, pp. 1-10.

Maule, R. (2016). 'Mobilizing women+'s art: bildwechsel, a global archive', European Journal of Women's Studies, 23:4, pp. 381-40o.

Muñoz, J. E. (2009). Cruising Utopia: The Then and There of Queer Futurity. New York: New York University Press.

Munt, S. (2008). Queer Attachments: The Cultural Politics of Shame. Aldershot: Ashgate.

Museerna och hbtq (2015). En analys av hur museer och andra utställare kan belysa perspektiv rörande homosexuella, bisexuella, transpersoner och queera personer. Visby: Riksutställningar. www.riksutstallningar.se/sites/default/files/documents/ MUSEERNA\%20OCH\%20HBTQ\%202015.pdf (accessed 9 August 2017).

National Trust (2017). Prejudice and Price: Celebrating LGBTQ Heritage. Text by Alison Oram and Matt Cook. National Trust.

Olson, H. A. (2001). 'The power to name: Representation in library catalogs', Signs, 26:3, pp. 639-68.

Outfest UCLA Legacy Project. www.cinema.ucla.edu/collections/outfest-uclalegacy-project-lgbt-moving-image-preservation (accessed 20 February 2017).

Pride of Place. https://historicengland.org.uk/research/inclusive-heritage/lgbtqheritage-project/our-approach (accessed 10 April 2017).

Rawson, K. J. (2010). 'Archiving transgender: Affects, logics, and the power of queer history'. Writing Program - Dissertations. Paper 1.

Ryberg, I. (2015). 'Between positive representation and camp performance: Three films from the Swedish lesbian and gay liberation movement', Journal of Scandinavian Cinema, 5:2, pp. 137-54.

Sandell, R. and E. Nightingale (2012). Museums, Equality and Social Justice. London and New York: Routledge. 
Schaffer, J. (2008). Ambivalenzen der Sichtbarkeit. Über die visuellen Strukturen der Anerkennung. Bielefeld: Transcript.

Schwartz, J. M. and T. Cook (2002). 'Archives, records, and power: The making of modern memory', Archival Science, 2:1-2, pp. 1-19.

Sedgwick, E. K. (1990). Epistemology of the Closet. Berkeley: University of California Press.

SFI (2017). Hit och ännu längre. Jämställdhetsrapport 2017. Stockholm: Svenska Filminstitutet.

Smith, L. (2007). 'Empty gestures? Heritage and the politics of recognition', in H. Silverman and D. F. Ruggles (eds), Cultural Heritage and Human Rights. New York: Springer, pp. 159-71.

Snickars, P. (2015). 'Remarks on a failed film archival project', Journal of Scandinavian Cinema, 5:1, pp. 63-7.

Steorn, P. (2010). 'Queering the museum: Methodological reflections on doing queer in museum collections', Lambda Nordica: Queer Methodologies, 15:3-4, pp. $119-43$.

Steorn, P. (2012). 'Curating queer heritage: Queer knowledge and museum practice', Curator. The Museum Journal, 55:3, pp. 355-65.

Stoler, L. A. (2002). 'Colonial archives and the arts of governance', Archival Science, 2:1-2, pp. 87-109.

Stone, L. and J. Cantrell (eds) (2015). Out of the Closet, into the Archives: Researching Sexual Histories. New York: SUNY Press.

Stryker, S. and P. Currah (2015). 'General editors' introduction', TSQ: Transgender Studies Quarterly, 2:3, pp. 539-43.

Svenska Filminstitutet (2016). Policy of the digitization selection committee. December 2016. www.filminstitutet.se/globalassets/2.-fa-kunskap-om-film/digitalafilmarvet/diverse-bilder/policy-of-the-digitization-selection-committee.pdf (accessed 9 August 2017).

Thomas, T., E. Grittmann, L. Brink and K. de Wolff (eds) (2017). Anerkennung und Sichtbarkeit in Medienkulturen. Bielefeld: transcript.

Thompson, S. (2015). 'Urgent: The lesbian home movie project', Journal of Lesbian Studies, 19:1, pp. 114-16.

UNESCO (2016). Audiovisual Archiving Philosophy and Principles by Ray Edmondson. Bangkok: UNESCO Bangkok. 


\title{
ABORTION PREVENTION \\ Lesbian citizenship and filmmaking in Sweden in the 1970 s
}

\author{
INGRID RYBERG
}

Tn the late 1970s, in the midst of the so-called gay liberation era, two pivotal lesbian films were shot in Sweden: the documentary short The Woman in Your Life Is You [Kvinnan i ditt liv är du] (1977), directed collectively by members of the organisation Lesbisk Front [Lesbian Front] in Stockholm, and the short educational fiction Eva and Maria [Eva och Maria] (Marie Falksten, Annalena Öhrström and Mary Eisikovits, 1983), directed by three women who ran a company called Tjejfilm ['Chick Film'] in Gothenburg. Both were funded by the state agency Socialstyrelsen [The National Board of Health and Welfare] and are the first cases of publicly funded films made by, with and about open lesbians in Sweden. Paradoxically, the same state agency was at this time also in charge of the official classification of homosexuality as a mental disorder (Socialstyrelsen, 1968). However, just a few years later the classification would be dropped and an official government report, 'Utredningen om homosexuellas situation i samhället' (1984) ['Investigation about the situation of homosexuals in society'], would put homosexuality on the official political agenda as a legitimate social and civil rights issue in Sweden, paving the way for cohabitation, antidiscrimination, parental and marital rights during the following decades. The two rare lesbian films examined in this chapter, largely forgotten and overlooked in Swedish film history as well as in feminist and queer historiography, anticipate these crucial shifts in the official medical, legal and social understanding of homosexuality in Sweden in the 1970s and 1980s.

Undertaking a close reading of the two films' funding processes in this chapter, I investigate the ambiguous sexual citizenship (Bell and Binnie, 2000; Evans, 1993) shaped by the interplay between formal sexual policymaking and lesbian film production in Sweden at a moment in time when 
homosexuality was on the threshold of becoming recognised as a civil rights issue. Drawing from original archival research and interviews, I shed light on the rhetorical twists and euphemisms through which lesbian filmmaking was inserted into the National Board of Health and Welfare's budget and administered as an issue of birth control education. Looking closer at the two films' representation of lesbianism, noting how they downplay sexual desire, I argue that rather than simply exemplifying the transnational lesbian feminist movement's alleged anti-sex politics, this articulation of lesbian identity should be understood as shaped by the interaction with official sexual policymaking in Sweden at this crucial moment in time. These neglected films and their production histories, I contend, are unique cases illuminating the official shift from regarding homosexuality as a mental disorder to regarding homosexuals as a vulnerable group exposed to prejudice and discrimination. The notion of vulnerability, I demonstrate, plays an instrumental and multifaceted role in the production of lesbian citizenship and audio-visual self-presentation at this time.

\section{AFFIRMATION FILMS: EVA AND MARIA AND THE WOMAN IN YOUR LIFE IS YOU}

In Sweden, like in other Western European countries, the LGBT movement grew more radical and visible in the 1970s, influenced by the Stonewall riots in New York in 1969 (Silverstolpe and Söderström, 1999: 667). In addition to Riksförbundet för sexuellt likaberättigande [the National Organisation for Sexual Equality] (RFSL), that had been formed in 1950, new groups like Homosexuella Socialister [Homosexual Socialists], Gay Power Club and Lesbian Front also emerged (Ahlberg, 200o).

The documentary amateur short The Woman in Your Life Is You was directed in 1977 by a group of women active in the newly proclaimed organisation Lesbian Front in Stockholm. The names of the filmmakers are not credited in the film. Instead, the closing credits read: 'In front of the camera: us'; and: 'Behind the camera: us'. According to one of the women who formed part of the team, Birgitta Olsson (2014), about five to seven women were involved in the production, which was rather improvised as none of them had any previous filmmaking experience. Documentary scenes, shot on a shaky Super-8 camera, show women taking part in a photography workshop and self-defence sessions, attending a women's summer camp, demonstrating in the streets, and executing direct action against sex-shops in the centre of Stockholm (see figure 11.1). The political analysis behind and aims of these activities are pedagogically explained in voiceover, stating for instance that self-defence strengthens women's 


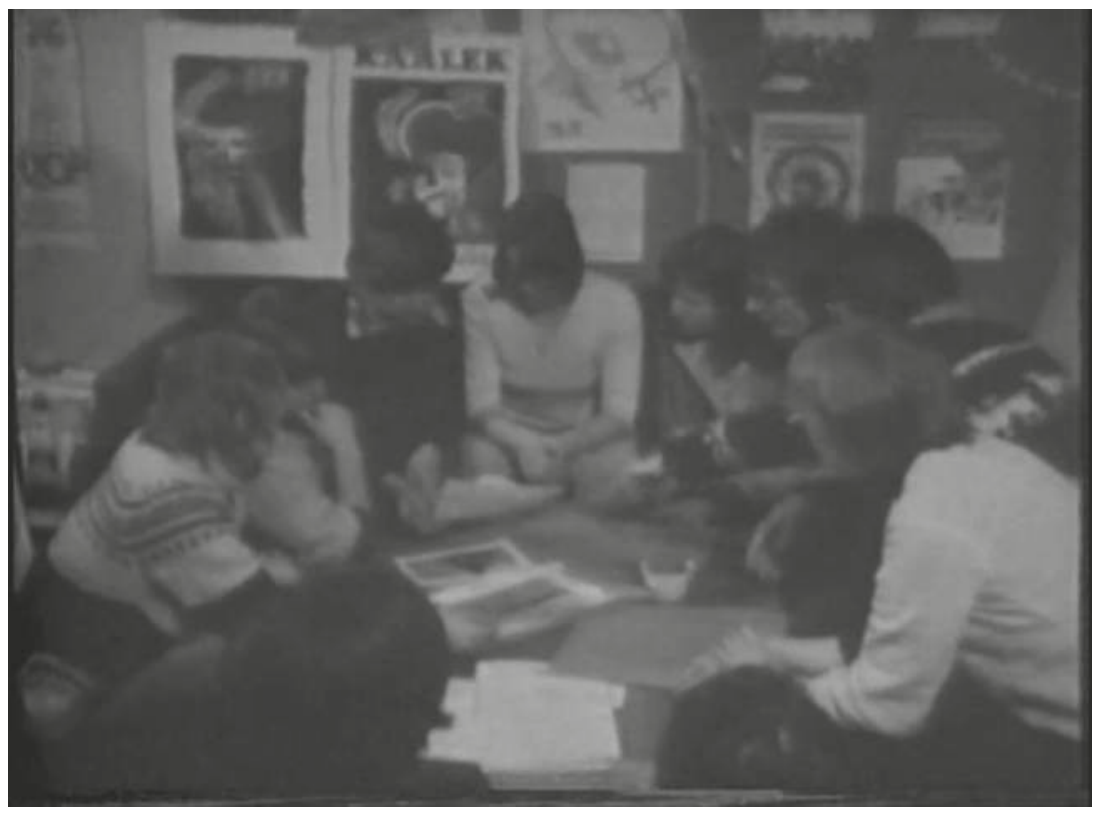

Figure 11.1 Lesbian Front meeting in The Woman in Your Life Is You.

self-esteem, that women are allowed to be themselves at the summer camps and that 'pornography is capitalism's opium for the male population' (author's translation). One woman also tells a more personal story about how before she met the group she did not know that other lesbians existed. 'True, it really is possible to live as a lesbian, I now dare to feel what I do' (author's translation), she declares.

With its documentary insistence on the very existence of lesbians and the very possibility to live as a lesbian, the film fits into the category of transnational filmmaking emanating from the liberation movement that Richard Dyer has called 'affirmation films', characterised by the key aim to represent homosexuality as 'a positive thing to be' (2003: 217). Affirmation films, he contends, were informed by the practices of lesbian and gay organising of the time, such as coming out, consciousness raising, analysis/activism and the creation of positive images (see also Ryberg, 2015; 2017).

The narrative short Eva and Maria was directed by three women in Gothenburg, Marie Falksten, Mary Eisikovits and Annalena Öhrström, and shot by an entirely female crew. Unlike The Woman in Your Life Is You, the film was carefully scripted and shot on $16 \mathrm{~mm}$ film during the summers of 1977 and 1978. The editing was completed in 1983. The film tells the story of Eva and Maria, two young women who fall in love during their driver's 


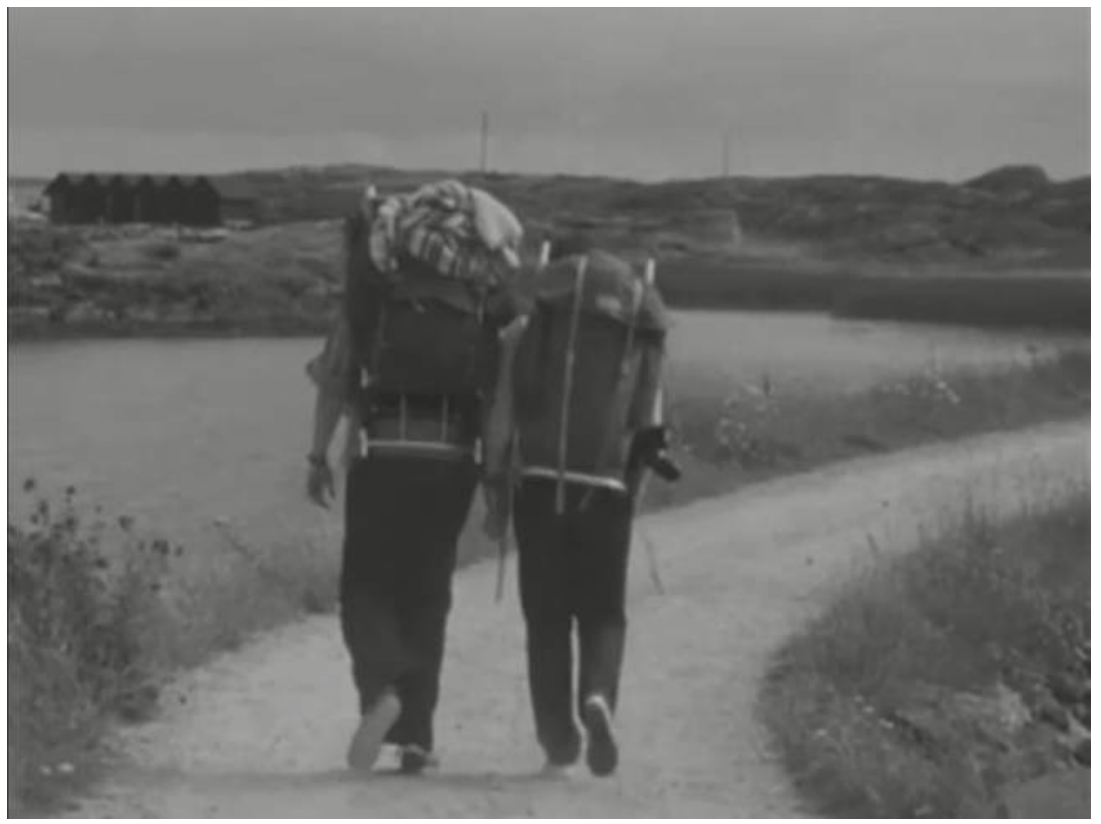

Figure 11.2 Eva and Maria go to the archipelago.

education course. The focus is largely on the interaction between the women and with Maria's parents. The couple face homophobic comments from friends and Maria's father, but also acceptance from Maria's mother who supports them and encourages them to go on a romantic trip to the archipelago (see figure 11.2).

With its emphasis on the romantic couple, beautiful images of the natural landscape and a happy end stressing the women's self-confidence, pride and joy, this film also fits well into Dyer's categorisation of affirmation films as essentially being about 'exchanging negative feelings about homosexuality with positive' (2003: 201; see also Ryberg, 2015).

In addition to fitting well into Dyer's category of affirmation films, and albeit their aesthetic differences, the two films share other similarities. Both insert quotations from Norwegian writer and activist Gerd Brantenberg's book Opp alle jordens homofile [Arise You Homosexuals of the World], published in 1973 and translated to Swedish in 1981. According to literary scholar Karin Lindeqvist (2007: 14), the book epitomised the new unapologetic attitude of lesbian activism at the time by fiercely attacking gender roles, homophobia, capitalism and the prevailing idea that homosexuality was an illness. The book differed significantly from other available representations of homosexuality, including those by LGBT authors and press, Lindeqvist 
argues. The fact that both films include quotations from the book, at a time when it was not yet translated from Norwegian to Swedish, is also an indication of its popularity and impact at the time (Ryberg, 2015). The passage that both films quote accounts for a range of contradictory psychological explanations of the origins of homosexuality. Homosexuality is claimed to be caused by growing up in a family with a single mother; with a dominant father and submissive mother; with a dominant mother and submissive father; with brothers only; with sisters only; without parents, and so on. By juxtaposing such mutually exclusive explanations, the book undermines the very idea that homosexuality is caused by some unfortunate family constellation. Hence, by quoting this passage, both films take issue with the notion of homosexuality as a deviance in need of explanation.

As already mentioned, the two films were shot more or less parallel to each other during the years 1977-78. At the same time, a gay male short was also produced in Sweden: Damned Queers [Bögjävlar] (Gunnar Almér et al., 1977), supported by Filmverkstan [the Film Workshop], an organisation funded by the Film Institute and Swedish Radio, supporting amateur and less-established filmmakers (Andersson and Sundholm, 2014; Ryberg, $2015 ; 2017)$. The three films are unique not only as the first known examples of publicly funded lesbian and gay self-presentation (by which I here refer to films explicitly made by, with and about open homosexuals) on film in Sweden, but also because no other such films were publicly supported in Sweden until the 1990s (e.g. Väninnor [Girlfriends] (Bergström and Neant-Falk, 1996)). This moment in time around 1977, which was also the year of the first liberation march in Stockholm, evidently provided fortunate, unprecedented conditions for lesbian and gay filmmaking in Sweden (Ryberg, 2015). It is important, however, that in the case of the two lesbian films, these conditions were not provided by the regular contexts of moving image production and distribution. Eva and Maria, the more professionally made film of the two, was rejected when the team applied for support from institutions such as the Swedish Film Institute, the Film Workshop and the Swedish Arts Grants Committee (Falksten, 2013). Damned Queers, on the other hand, was supported by the Film Workshop and broadcast on Swedish Television, whereas Eva and Maria was not.

The realisation of the two films instead depended on the National Board of Health and Welfare, the same government agency that upheld the classification of homosexuality as a mental disorder. Both films were funded by the National Board of Health and Welfare's department Nämnden för hälsoupplysning [the Committee for Health Education], a committee responsible for issues of diet and exercise (notoriously recommending the Swedish population six to eight slices of bread a day), addictive substances, sex and cohabitation and other health issues. Both films were funded by the 
Committee's division for sex and cohabitation issues, and their specific subdivision for contraceptives and birth control (Riksarkivet [hereafter RA], n.d.a; RA, 1977b). Eva and Maria was supported under the banner 'collaboration with cultural producers', an allocated budget post that formed part of the division's information work about contraceptives that had begun in 1973 (RA, n.d.a; Utredningen om homosexuellas situation i samhället, 1984: 20912). The Woman in Your Life Is You was funded by a budget allocated for the purpose of 'abortion prevention' that the National Board of Health and Welfare received from the parliament when free abortion was legalised in Sweden in 1975 (RA, 1974b). The purpose was to support sex education work within youth and women's organisations in order to prevent unwanted pregnancies and abortions.

As much as the two films are characteristic products of the liberation era and lesbian activist organising - as affirmation films making lesbianism publicly visible, shot the same year that the first liberation march paraded in Stockholm, and in their invocation of new lesbian literature and music I propose that their articulation of lesbianism was not only enabled but also shaped by the interaction with the National Board of Health and Welfare and their official policymaking around sexuality and birth control. Before shedding light on this, a more detailed historical contextualisation is necessary.

\section{HOMOSEXUAL CITIZENSHIP: FROM CRIMINALISATION AND MEDICALISATION - TO VICTIMISATION?}

Despite a widespread and self-celebratory idea of sexual liberalism and progressiveness in Sweden since at least the 1950 os (e.g. Lennerhed, 1994), the National Board of Health and Welfare upheld its classification of homosexuality as a 'mental disorder' (Socialstyrelsen, 1968) until the end of the 1970s. The classification had come into existence when homosexuality was decriminalised in 1944, following a decade of investigations (Promemoria angående ändringar $i$ strafflagen beträffande straffsatserna för särskilda brott m.m., 1936; Strafflagberedningen, 1941) drawing from medical expertise influenced by German sexologists such as Richard von Krafft-Ebing and Magnus Hirschfeld (Edenheim, 2005; Rydström, 2003). Homosexuality, it was argued in these investigations, was to be understood as a medical condition and not as a matter of criminal acts to punish. Rydström (2003: 330, also $164,166)$ points out that this shift comprised a mobilisation of vulnerability as the basis for calls for compassion and empathy for 'the unhappy few'. The investigations shaped a notion of homosexual identity as an inherent 
property in some people, forming the basis both for medical attempts to cure it and the organised struggle for acceptance and rights that began in Sweden when the RFSL was founded in 1950. According to Rydström (2003: 325), the 'medicalization of homosexuality comprised at least three important areas, the explanation of homosexuality, its diagnosis, and its possible cure.' Explanations of homosexuality were influenced by the notion of 'sexual inversion' and diagnosing involved evaluating bodily and behavioural signs of inversion (Rydström, 2003: 326). Whether or not homosexuality was able to be successfully cured was debatable, but applied treatments included psychoanalysis and hypnosis, as well as surgery. Castration, however, was advocated as a method not so much for curing homosexuality as for inhibiting the drive. This treatment was voluntary but, according to Rydström (2003: 327), often coerced. In the history of sexual reform work in Sweden, such notions of voluntarism and choice also informed the forced sterilisation programme that ran between the years 1935 and 1975 (1997 års steriliseringsutredning, 2000). Lena Lennerhed (2000a) demonstrates how, in the 1930s and 1940s, sterilisation, but also contraceptives and abortion, were debated and advocated from the points of view of both authoritative regulation on the basis of what was beneficial for society and individual rights on the basis of helping people.

When the RFSL was founded in 1950, the organisation proposed a slightly different view to the dominant medical classification of homosexuality as an illness. According to Andréaz Wasniowski (2007: 223), the RFSL advocated an understanding of homosexuality as not essentially different from heterosexuality, but as a matter of degree on a continuous scale. The organisation's goals included 'humanitarian, social and legal equality', which meant that homosexuals should have the same civil rights and obligations as heterosexuals (Wasniowski, 2007: 93). The RFSL defined the main problem as intolerance due to lack of knowledge and advocated enlightenment (Lennerhed, 200ob). The organisation, however, did not have any significant impact on the public debate until it became more radical and visible in the 1970s. In August 1979, activists occupied the National Board of Health and Welfare's office building in Stockholm, demanding that the illness classification be removed. The board had previously rejected these demands, but the newly appointed director general Barbro Westerholm declared that the classification would be dropped (Svensson, 2001). Preceding this crucial change and indicative of the shift towards regarding homosexuals as equal to rather than deviant from heterosexuals was the 1978 legal reform that lowered the age of consent for homosexual sexual relations from eighteen to fifteen, the same age that already applied to heterosexuals.

This was also the year when the official government investigation that would be published as the report 'Utredningen om homosexuellas 
situation i samhället' in 1984 began. This report put the issue of homosexuality on the political agenda by proposing that 'homosexuals are to be given equal status with other minority groups who through legislation are given particular protection against unfavourable legislation and discrimination' ('Utredningen om homosexuellas situation i samhället', 1984: 271). The proposal is motivated by the statement that 'the only certain difference between homosexuals and heterosexuals is that homosexuals are emotionally attracted to persons of the same sex', and therefore should 'not be discriminated against' (271). In the report, vulnerability is mobilised in descriptions of homosexuals as a group experiencing many 'difficulties' and 'complications'; and it is even stated that 'discovering one's homosexuality can be a shattering experience for a young person' (271). Such difficulties, the report stresses, are not caused by being homosexual, but by 'the expectation on the part of society and the general public that one should live in a heterosexual fashion' (272). In addition to legislation, the report also advocates information and improved education - just like the RFSL did in the 1950 .

Critically analysing this and other official government reports regarding 'deviant sexuality and gender', Sara Edenheim (2005) contends that the main difference between early reports concerning the decriminalisation of homosexuality and those from 1984 onwards is the shift from regarding homosexuality as a deviance and illness in need of treatment to regarding homosexuals as victims of discrimination and prejudice. In the reports from 1984 onwards, the position of the victim becomes the basis and prerequisite for proposing rights and legal reforms, Edenheim (2005: 131) argues. Recognition and rights are from now on based on the idea that homosexuals should be seen as the same as heterosexuals, which presumes the exclusion of same-sex desire and non-binary gender.

\footnotetext{
An individual can ... demand certain rights as a homosexual only if homosexuality is destitute of independent values or specific significations, i.e. only if homosexuality is victimized and ascribed a will to adopt to a heterosexualized lifestyle. As a consequence, a homosexual individual can only be recognized by the law if that individual simultaneously repudiates any abject desire different from heterosexual desire; in other words, the homosexual subject is perceived as an impossibility before the law. (Edenheim, 2005: 243)
}

Moreover, the reports are based on male-centred definitions of body and sexuality, Edenheim shows. There is a recurrent inability to address and handle lesbianism and lesbian desire, which is either 'inconsequentialized or excluded from the reports altogether' (Edenheim, 2005: 242). Only in sections dealing with monogamous love relationships and parenthood does lesbianism become part of the discussion (Edenheim, 2005: 115). 
Edenheim addresses several critical aspects of the discursive shift towards an official recognition of homosexuality in Sweden that are relevant for the understanding of how the films Eva and Maria and The Woman in Your Life Is You were administered by the National Board of Health and Welfare. However, these lesbian films manifest that this discursive shift also opened up for other, if unexpected, opportunities and creative forms of agency than the picture of self-extinctive assimilation and interpellated victimhood that Edenheim paints of homosexual citizenship allows for. In what follows, I demonstrate how making strategic use of the language of vulnerability at this crucial moment in time resulted in unique cases of selfpresented lesbianism on film that would most likely not have been made otherwise.

\section{EVA AND MARIA: STATE-APPROVED LOVE BETWEEN WOMEN}

The production of Eva and Maria was granted funding in 1977, more than a year after the three filmmakers' initial contacts with the Health Committee (Marie Falksten's private archive [hereafter MF], 1976b), indicating that the decision to provide funding was not made quickly on the part of the Committee. In June 1976, the filmmakers were invited to a conference where they gave a lecture about 'lesbian love' (Falksten, 2013; MF, 1976a). The conference, and the ensuing support of the film, formed part of the Committee's collaboration with cultural producers for the purpose of education about contraceptives that had been initiated through an allocated budget in 1973 (RA, n.d.a). In 1977, the production was granted 70,0oo SEK (RA, 1977d); in 1978 an additional sum of 50,00o SEK was given to the project (RA, n.d.b); and in 1983 the film was granted a last small sum of 5,00o SEK (MF, 1983). Whereas the filmmakers' lecture in 1976 was explicitly about 'lesbian love', decision and budget protocols in the National Board of Health and Welfare's archive describe the project as 'a film about love between women' (RA, n.d.a; 1977d, author's translation of all archive documents). Lesbianism or homosexuality are not explicitly mentioned. Letters from the filmmakers to the Committee also employ a vocabulary avoiding these words (MF, 1976b).

In one paragraph motivating the funding, it is stated that the Committee has received many requests about 'material about love between people of the same sex' (RA, n.d.a). According to the paragraph, there is a lack of material about 'this subject' and a need for 'discussion material'. The purpose of the project, it is stated, is to 'shed light on love between women and with this theme as a starting point initiate a discussion about the concept 
of love, sexuality and relationships between people'. It is suggested that the film will be very useful at youth centres, but also in the Committee's own education of counsellors.

These notes from the Committee's protocols show how lesbianism could find its way into the official records when described in terms of love, just as in the case of the official government reports that Edenheim investigates. Moreover, it is addressed not as essentially different from other types of relationships, but as a useful starting point for a general discussion about 'the concept of love'. The fact that the words 'lesbianism' and 'homosexuality' are not used by the National Board of Health and Welfare at a time when the illness classification was still running is perhaps not surprising, but still noteworthy. The editing and postproduction of Eva and Maria stretched over several years and the film was not completed until 1983 the year before the report 'Utredningen om homosexuellas situation i samhället' was published and after the illness classification was dropped. In protocols, correspondence and other archive material from the later parts of the film's production as well as distribution, lesbianism and homosexuality are spelled out explicitly (e.g. MF, 1983), and notions of discrimination and prejudice come into focus, reflecting the ongoing shift towards a new official vocabulary for addressing the issue.

For instance, an information sheet from Skolöverstyrelsen [the National Board of Education] includes a paragraph about Eva and Maria under the heading 'Health education - cohabitation' (MF, 1984). The film is now called 'a film about love between two girls', and the presentation states that 'homosexuality is a taboo area for many people' and that fear and insecurity of the unknown and society's view on homosexuality result in many teachers' avoidance of the issue. It is stressed that the audience is invited to relate to the feelings of love and tenderness between the girls in the film. The statement is largely in agreement with how the need for information and improved education is highlighted in the 1984 official government report. Again, the universal aspects of the feelings between the girls are emphasised, implying that these are not essentially different. Importantly, an agreement between the filmmakers and the National Board of Health and Welfare states that both the film and the accompanying education material should be approved by the National Board of Health and Welfare (RA, 1977e). Another document states that the teacher's guidelines will be elaborated in collaboration with the National Board of Education (MF, n.d.e).

The above statement reappears in other information brochures (MF, n.d.b; n.d.c) that were distributed with the film. In one fact sheet it is also stated that homosexuals do not experience difficulties because of their homosexuality but because of prejudice and homophobia - again in agreement with the report. 'The film is about ordinary people. Through the 
warmth and the low-key humor one can easily relate to the feelings and situations in the film', it is stated in one brochure (MF, n.d.d). Furthermore, the brochure argues against associating homosexuality with tragedy. 'The film concentrates on the happiness and joy in a lesbian relationship, not on the possible problems and conflicts', it is stated. Another brochure argues that in contrast to negative role models such as tragic lesbian and gay artists, like Oscar Wilde, Karin Boye and Pjotr Tjajkovskij, that make young homosexuals see themselves as tragically different, 'one should highlight happy and successful homosexuals' (MF, n.d.a).

Produced during the same years that the official government investigation that would ultimately put homosexuality on the official political agenda in Sweden was ongoing, and collaborating with state agencies for health and welfare as well as education, Eva and Maria's production and distribution history clearly evokes the shift from an official understanding of homosexuality as an illness and of homosexuals as worthy of compassion on the basis of being deviant and hence vulnerable, to an understanding of homosexuals as a vulnerable group exposed to society's prejudice and discrimination due to misconceptions that homosexuals are different and unhappy. This shift is also evoked in the film.

As mentioned already, one of the ways in which dominant misconceptions about homosexuality is addressed and discarded in the film is the inclusion of Brantenberg's book. While spending time together in the archipelago, Eva reads out loud from the book in a theatrical voice, quoting the passage where the origins of homosexuality are explained in a number of contradictory ways. The girls laugh about the different theories. Another scene taking issue with the official view on homosexuality as a deviance takes place in the classroom at Maria's high school. The teacher awkwardly explains that homosexuals have distorted relations with different groups in society, such as with family and friends. The scene is parodic, but Maria gets upset after class when a classmate comments on homosexuality as being disgusting and the teacher's voice echoes in her head as she takes the bus home. In a later scene, Maria is confronted with her father's prejudice when finding out that the two girls share a bed in the cottage in the archipelago. 'You have always been a real girl', the father says, and Maria yells back: 'Are you a real girl only if you fuck boys?' (author's translation of the film's dialogue). The mother defends Maria when the father says that Eva and Maria's relationship is sick and unnatural: 'Maria has the right to love whoever she wants, the right to one's feelings is important', she pedagogically states. The film shows that Maria is unhappy only when confronted with people's prejudice, not when she is with Eva. In only one scene does she express doubts about her feelings, asking her mother: 'Is it wrong if two women love each other?'. The mother replies: 'It can never be wrong for people to 
love each other', stressing the general aspects of love. The dialogue takes place in the kitchen while Maria and her mother set the table for dinner. Several other scenes also take place in domestic settings, emphasising the characters' ordinariness.

The interaction between the two girls Eva and Maria is gentle, caring and sexually innocent. The scene where Eva reads from Brantenberg's book is followed by a scene where the women lie naked on a blanket in the grass in front of the cottage. Eva caresses Maria's back, they kiss gently, touch feet and roll around laughing. Although the images do not show any further sexual passion or action, the music rises to a climax, suggesting that sex possibly does happen. This is also implied through the invocation of a well-known trope in the history of moving image sex in Sweden - that of the young couple's escape to nature in order to live out an attraction condemned by societal norms. Just like in iconic scenes from Hon dansade en sommar [One Summer of Happiness] (Arne Mattsson, 1951) and Sommaren med Monika [Summer With Monika] (Ingmar Bergman, 1953), Eva and Maria go skinnydipping and enjoy relaxed and healthy nudity in the natural landscape, far away from those who see their love as sinful or wrong. The film inscribes itself into this cinematic legacy and into a national narrative of sexual enlightenment that has progressively come to see 'sin', such as pre-marital sex in Bergman's and Mattsson's films, as good and sound. Now, homosexuality should be afforded the same kind of enlightened acceptance, I propose the scene suggests. The film's softening of sexual desire and emphasis on romantic love and 'the right to one's feelings', I argue, are instrumental in the articulation of a notion of lesbianism that could be recognisable and legible in the context of Swedish sexual policymaking, cultural imaginary, and medical, legal and social discourse in which lesbian desire is constructed as an impossibility (Edenheim, 2005: 110).

\section{THE WOMAN IN YOUR LIFE IS YOU: LESBIAN DESIRE BELOW THE RADAR}

According to two of the filmmakers, Birgitta Olsson (2014) and Sonja Rosenqvist (2014), the production of The Woman in Your Life Is You began when members of Lesbian Front learned about the National Board of Health and Welfare's budget for abortion prevention that was allocated on occasion of the new law granting women free abortion. Altogether, 7.4 million Swedish crowns were allocated for information work within youth and women's organisations between 1974 and 1978 (Ryberg, 2015). The notion of 'abortion prevention', it is stated in a memo that was distributed to women's and youth organisations (RA, 1974b; see also 1980 års abortkommitté, 1983), 
should not be interpreted too narrowly, but understood in a larger context of issues such as cohabitation and gender roles. This invitation to a broad interpretation of the purpose of the budget was evidently perceived as an opportunity for the members of Lesbian Front. The group submitted its application in late 1976 and received funding in the beginning of 1977. The original application did not indicate any plans for a film production (RA, 1976). The group applied for a relatively large sum of 220,0oo SEK for organising a Nordic women's camp and an information campaign including work in schools and youth centres, consciousness-raising groups and conferences. The goals of the application are stated as: 'to inform women in order to fight prevailing gender roles'; 'to conduct enlightening activities about alternative forms of cohabitation'; and 'to raise women's consciousness about the right to their own body' (RA, 1976, author's translation of all archive documents), hence invoking one of the key slogans of the new women's movement. 'Women's rights to their own bodies' was the broad heading under which women demanded free contraceptives, free abortion, pain-free childbirth, and a ban of the objectification of women in pornography and advertising (Isaksson, 2007: 79; Lennerhed, 2008: 182).

Lesbian Front was granted only a small part of the sum it applied for $-30,000$ SEK. The official decision from the Committee states that Lesbian Front was granted this sum for the purpose of information about contraceptives and issues of sex and cohabitation (RA, 1977c). The letter also states that the Committee paid attention particularly to the goal to 'produce information material with the purpose of education about alternative forms of cohabitation and raise women's awareness of the right to their own body'. Hence, informing 'women in order to fight prevailing gender roles' is not encouraged here. 'The support is not meant to cover costs for camps', it is also stated. This same statement was also published in a press release (RA, 1977a).

Like in the protocols regarding the funding of Eva and Maria, there is no explicit mention of lesbianism or homosexuality in Lesbian Front's application or official statements about the support from the Committee - aside from the organisation's name. The declaration that the support is intended for an information campaign and not a women's camp indicates that education is considered valid and in line with the purpose of the budget. Whatever assumed activities that a Nordic summer camp for women organised by Lesbian Front might enable, however, are considered to fall outside of the scope of the Committee's budget. The Committee hence explicitly regulates how Lesbian Front can use the funding. Like in the case of Eva and Maria, lesbianism is covered by generalised concerns such as 'women's right to their own bodies' and 'alternative forms of cohabitation' - concerns that also fitted within the notion of 'abortion prevention'. 
The very combination of the terms (free) 'abortion' and 'prevention' epitomises the entanglement of regulation and rights claims in the history of sexual reforms in Sweden (Lennerhed, 2000a). Produced under the banner of abortion prevention, The Woman in Your Life Is You reactivates both a notion of the individual woman's right to free abortion without having to motivate her choice, as well as the regulatory, eugenic, medical and educational approach to sexual policymaking in Sweden in the twentieth century. I contend that inserting lesbianism into this equation implies, on the one hand, acknowledging lesbians as women entitled to reproductive rights by their exposure to the risk of unwanted pregnancies ('women's rights to their own body'); and, on the other, acknowledging lesbianism as birth control ('alternative forms of cohabitation'). Lesbianism in itself, as Edenheim shows in the case of official government reports, is an impossibility within this framework. Even more absurd therefore is the criticism that the report 'Utredningen om homosexuellas situation i samhället' aims at the National Board of Health and Welfare for not explicitly including and addressing homosexuality in its work with abortion prevention ('Utredningen om homosexuellas situation $\mathrm{i}$ samhället', 1984: 211-12). Not only is the fact that the illness classification was still running at this time disregarded, but Lesbian Front's project and approved application also appear to have been undetectable and invisible even to the government investigators evaluating the Committee's commissions. Eva and Maria, on the other hand, is mentioned in the report (212). Significantly, Lesbian Front had also been approached by the investigators, but declined to participate as study objects in the report (538). The fact that the perspectives of lesbians are largely absent in the report is only commented upon briefly (Edenheim, 2005: 109). Hence, in these instrumental official records dealing with sexual policymaking and homosexuality, lesbianism is erased and rendered invisible on multiple levels (Edenheim, 2005: 118).

However, when Lesbian Front supplemented its application with a report about the progress of the project in 1978, one year after receiving the funding, it not only declared that it had made a film, but fiercely put the issue of lesbianism back on the agenda. Lesbian Front wrote:

We've worked from the premise that there is a lack of information about lesbians, by lesbians, for lesbians and that many lesbians live alone and isolated. Society uses us as bad examples by calling us mannish, man-haters, frustrated bitches, sexually abnormal - in order to reproduce the myth about women as womanly, motherly, surrendering, dependent, leading to submission to men. An active lesbian manifestation is a necessary part of the liberation movement that is necessary in order to break down society's oppression. (RA, 1978, author's translation)

This unapologetic statement largely differs from the first application's emphasis on generalised goals and evokes a different, more confrontational 
politics than in the case of Eva and Maria. While lack of information motivates both films, Lesbian Front here claims that its work is intended for a lesbian audience rather than an allegedly misinformed and prejudiced majority that needs to learn that homosexuals are not so different, and hence should be accepted. The statement that many lesbians live alone and isolated can be read as confirming a negative image that Eva and Maria explicitly rejects as part of its aim to "highlight happy and successful homosexuals'. Lesbian Front does not claim that lesbians are just the same as heterosexuals, but instead attacks dominant gender roles and notions of femininity as such. The function of homophobic descriptions of lesbianism, it is suggested here, is to reinforce oppressive ideas about women's role in society. Rather than positive images of ordinary people, this statement advocates 'an active lesbian manifestation'.

In stark contrast to the production of Eva and Maria which, as I have shown, is largely in agreement with the language of the then-ongoing government investigation about homosexuality, the politics of The Woman in Your Life Is You falls outside of the framework of official recognition. One striking difference between the two films is that the romantic couple is absent from The Woman in Your Life Is You's articulation of lesbianism. The film instead emphasises collective activities such as consciousness-raising, self-defence and demonstrations, evoking notions of 'women-identification' and sisterhood that Hanna Hallgren (2008: 290) shows were central in lesbian feminist discourse production at the time. In the closing sequence, three women go skating together, holding each other's hands, again stressing lesbian sociality as something other than an issue of love between a couple.

In contrast to how Eva and Maria mobilises vulnerability in accordance with the emerging official view that homosexuals are a minority exposed to prejudice, The Woman in Your Life Is You rather mobilises vulnerability as a matter of women's oppression at large. Women's vulnerability to patriarchal oppression is addressed recurrently, for instance in regard to the fashion industry and the limited set of roles available for women in society. 'The housewife, the whore, the fashion girl and the little kind, quiet and sweet one; these roles are so narrow, they shatter me' (author's translation of the film's voiceover), the voiceover states over images of mannequin dolls in department store windows and women walking in high-heels. 'Self-defence is a method for heightening women's self-esteem in order to cope with the pressure', it is stated. Here, vulnerability is not about being recognised as vulnerable and therefore worthy of protection and rights. Instead, vulnerability is instrumental in collectively organising against oppression, both in terms of supporting and caring for each other and for outwards manifestations. Vulnerability forms the basis for demanding rather than deserving rights. One scene shows how the women prepare for a demonstration, sewing and painting banners. The voiceover reads the slogan out loud: 'We demand the 
right to our own bodies and sexuality', and continues: 'Women have been deprived of this right for centuries'.

In another scene, the women paint slogans on porn shops in central Stockholm. The voiceover criticises how women's bodies are seen as goods to consume. 'This is how the male society sees us, it has nothing to do with women-love', it is stated as the camera pans over porn tabloids about 'female homosex' and 'lesbian games'. The notion of 'women-love', I propose, here implies another meaning than the notion of 'love between women' in the case of Eva and Maria. Contrasting the porn tabloid's objectifying image of lesbianism, 'women-love' contributes to an articulation of lesbianism as not simply about sex, but about sisterhood and love among women rather than between just two women (Hallgren, 2008: 156-9). Unlike Eva and Maria, where the word 'lesbian' is never mentioned in the film, lesbianism is stressed throughout in The Woman in Your Life Is You, from the opening sequence where one woman jumps up from a bed exclaiming: 'I am a lesbian!' while the others cheer, to the closing credits including still photographs of women to the sound of American lesbian singer-songwriter Sue Fink's 'The leaping lesbians'.

According to Hallgren (2008: 159-63), the lesbian feminist politicised notion of lesbianism was articulated in opposition not only to a notion of the 'pornographic lesbian' but also the 'mannish lesbian'. Just as the figure of the 'pornographic' lesbian is rejected, The Woman in Your Life Is You also takes issue with the figure of the 'mannish' lesbian. In an early sequence, the various family constellations that Brantenberg mockingly suggests cause homosexuality are enacted by the women in the film. Impersonating the roles of fathers, mothers and children, they pose in front of the camera as if to have their family photograph taken. The sequence, however, opens with the enactment of yet another constellation associated with lesbianism: a butch-femme couple. This constellation is also presented as a false, outdated and ridiculous stereotype, emphasised by theatrical outfits and exaggerated acting. The ironic voiceover classifies lesbians as either 'not real women, more like men' or 'bored upper-class women'. Nevertheless, the enactment paradoxically also enables a lustful and campy performance of lesbian desire and seduction. Unlike the family constellations where the women pose for the camera, the butch-femme couple interacts with each other in a small role-play sequence ending in an embrace where the entangled couple slowly sinks out of the picture frame, clearly taking great delight in the action. The very act of playing out - in order to reject and disown the negative stereotype creatively turns into the film's only opportunity to explore lesbian desire (Ryberg, 2017) in much the same way that the regulatory framework of 'abortion prevention' unexpectedly enables 'an active lesbian manifestation'. 


\section{CONCLUSION: VULNERABILITY AS A STRATEGIC KEY TO SEXUAL CITIZENSHIP AND AGENCY}

Eva and Maria and The Woman in Your Life Is You are unique cases of lesbian filmmaking in Sweden in the 1970s. As the first known publicly funded Swedish films by, with and about lesbians, they both foreshadow the removal of the illness classification and official recognition of homosexuals as a discriminated group in need of legal protection. Anticipating this crucial shift in the public view on homosexuality, they both take issue with the dominant medical understanding of homosexuality as something abnormal in need of an explanation and cure. Such views are criticised in scenes quoting Brantenberg's fierce parody of theories of the origins of homosexuality; mocking sex education in schools; rejecting the figure of the 'mannish' lesbian that informed sexological notions of 'gender inversion'; and the figure of the 'pornographic' lesbian. The main aim of this chapter has been to illuminate how this lesbian criticism was paradoxically enabled and supported by the very same state agency in charge of the classification of homosexuality as a mental disorder.

By excavating the films' production histories and highlighting the interplay with the National Board of Health and Welfare, I have read the films not simply as examples of oppositional and autonomous lesbian feminist cultural production and politics, but as shaped by official sexual policymaking in Sweden at the time. While the de-emphasising of sexual desire in both films could well be read as manifesting a 'woman-identified' lesbian feminist politics focusing more on sisterhood and love among women than on sex, a politics that Hallgren (2008: 314-27) shows was articulated in the movement at the time, I claim that the two films are more exclusive cases illuminating where the borders for public recognition and inclusion were drawn and where the loopholes were located in Sweden in the 1970s. The official handling of the two films in the National Board of Health and Welfare's records demonstrates how lesbian filmmaking could be inserted into the budgets and protocols under the guise of generalised notions of information about sex and cohabitation and through a strategic use of euphemisms. The board's assigned mission to raise the population's awareness about contraceptives on the occasion of the legalisation of free abortion, but also situate the information in a 'social and psychological context' (RA, 1974a), was broad enough to include the production of these rare films, although lesbianism in itself was not possible to spell out or motivate support for at the time they received funding.

I propose that the rhetorical twists through which the films entered into the official records and earned their funding are far from random, but significantly strategic. They show that, in both cases, vulnerability is the very 
key to inclusion and legibility, although set in motion in different ways in the two films. Formally recognised as a film about 'love between women' that can provide the backdrop for general discussions about 'the concept of love' and 'relationships between people', Eva and Maria, as I have shown, mobilises vulnerability in large agreement with the government report that shortly followed in understanding homosexuals as victims of discrimination and prejudice due to lack of knowledge and misconceptions that they are deviant and different from heterosexuals. The Woman in Your Life Is You, on the other hand, was not formally handled or recognised as a film about lesbians but as about 'women's rights to their own bodies', invoking one of the key slogans of the new women's movement at the time. Vulnerability is here set in motion in terms of women's oppression under patriarchy and as the basis for organising and resistance. As I have shown, these two different takes on vulnerability enable different politics and articulations of lesbianism and lesbian desire. I argue that the striking fact that two lesbian films were able to find funding from the same Committee at almost the exact same time - the official decisions to fund the projects are dated February 1977 in the case of The Woman in Your Life Is You and April 1977 in the case of Eva and Maria depends precisely on these two separate ways of mobilising vulnerability, and hence testifies to the multiple potential of this language at the time.

Finally, however, it is important to point out that this potential and the loopholes through which the two films entered the state agency's administration did not remain open for long. The removal of the illness classification and publication of the official government report 'Utredningen om homosexuellas situation i samhället' did not entail any new inclinations to support LGBT filmmaking in Sweden. To this day, Swedish film culture remains firmly heteronormative, despite an officially embraced idea of 'LGBT friendliness'. In this chapter about the fascinating and rich cases of Eva and Maria and The Woman in Your Life Is You, I have shed light not only on the key function and unexpected productivity of the language of vulnerability, but also on the brilliantly strategic and creative agency and success of lesbian activism against the odds at a crucial moment in the history of sexual policymaking in Sweden.

\section{ACKNOWLEDGEMENTS}

The author would like to cordially thank the filmmakers Birgitta Olsson, Sonja Rosenqvist, Annalena Öhrström and Marie Falksten for generously sharing their memories of the production of the two films, Falksten for sharing her private archive and documentation of the production and distribution of Eva and Maria, and the archivists at Riksarkivet Arninge. The author would also 
like to thank Professor Lisa Henderson for her generous response to a draft of this chapter, presented at the SCMS conference in Atlanta in 2016.

\section{REFERENCES}

1980 års abortkommitté (1983). Familjeplanering och abort: erfarenheter av ny lagstiftning: betänkande. Stockholm: Liber/Allmänna förl.

1997 års steriliseringsutredning (2000). Steriliseringsfrågan i Sverige 1935-1975: historisk belysning, kartläggning, intervjuer: slutbetänkande. Stockholm: Fritzes offentliga publikationer.

Ahlberg, E. (200o). 'Homo-Sverige utanför RFSL: en historisk exposé', in M. Andreasson (ed.), Homo i folkhemmet. Göteborg: Anamma, pp. 76-91.

Andersson, Lars Gustaf and John Sundholm (2014). 'Hellre fri än filmare': Filmverkstan och den fria filmen. Lund: Nordic Academic Press.

Bell, D. and J. Binnie (200o). The Sexual Citizen: Queer Politics and Beyond. Malden, MA: Polity Press.

Brantenberg, G. (1973). Opp alle jordens homofile. Oslo: Gyldendal.

Dyer, R. (2003 [1990]). 'From and for the movement', in Now You See It: Studies on Lesbian and Gay Film. London: Routledge, pp. 201-64.

Edenheim, S. (2005). 'Begärets lagar: moderna statliga utredningar och heteronormativitetens genealogi'. Diss. Lund: Lunds universitet.

Evans, D. T. (1993). Sexual Citizenship: Material Construction of Sexualities. London: Routledge.

Falksten, M. (2013). Interview by Ingrid Ryberg, Gothenburg 16 April.

Hallgren, H. (2008). 'När lesbiska blev kvinnor: lesbiskfeministiska kvinnors diskursproduktion rörande kön, sexualitet, kropp och identitet under 1970- och 1980- talen i Sverige'. Diss. Linköping: Linköpings universitet.

Isaksson, E. (2007). 'Kvinnokamp: synen på underordning och motstånd i den nya kvinnorörelsen'. Diss. Stockholm: Stockholms universitet.

Lennerhed, L. (1994). 'Frihet att njuta: sexualdebatten i Sverige på 1960-talet'. PhD thesis. Stockholm: Stockholm University.

Lennerhed, L. (2000a). 'Sex reform in the 1930s and 1940s: RFSU, the Swedish Association for Sex Education', in Lars-Göran Tedebrand (ed.), Sex, State and Society: Comparative Perspectives on the History of Sexuality. Umeå: Nyheternas tryckeri KB i Umeå, pp. 403-7.

Lennerhed, L. (200ob). 'Rätten att vara annorlunda: homosexualitet i sextiotalets debatt', in Martin Andreasson (ed.), Homo i folkhemmet. Göteborg: Anamma, pp. 132-41.

Lennerhed, L. (2008). Historier om ett brott: illegala aborter i Sverige på 19oo-talet. Stockholm: Atlas.

Lindeqvist, K. (2007). “"Gi dem som spør et skikk'lig svar!”: en diskursanalytisk läsning av Gerd Brantenbergs "Opp alle jordens homofile”, Lambda Nordica, 12:1/2, pp. 7-25.

Olsson, B. (2014). Interview by Ingrid Ryberg, Stockholm, 18 September.

Promemoria angående ändringar i strafflagen beträffande straffsatserna för särskilda brott m.m. (1936). Stockholm. 
Rosenqvist, S. (2014). Interview by Ingrid Ryberg, Stockholm, 10 October.

Ryberg, I. (2015). 'Between positive representation and camp performance: Three films from the lesbian and gay liberation movement', Journal of Scandinavian Cinema, 5:2, pp. 137-54.

Ryberg, I. (2017). 'Otidsenliga känslor i 1970-talets homosexuella frigörelsefilmer', in Helena Bergman, Christina Florin and Jens Ljunggren (eds), Känslornas revolution: kärlek, ilska och lycka på 1970-talet. Stockholm: Appell, pp. 127-54.

Rydström, J. (2003). Sinners and Citizens: Bestiality and Homosexuality in Sweden, 1880-1950. Chicago: University of Chicago Press.

Silverstolpe, F. and G. Söderström (eds) (1999). Sympatiens hemlighetsfulla makt: Stockholms homosexuella 186o-196o. Stockholm: Stockholmia.

Svensson, M. (2001). '“... och sedan gick det fort att ändra ...”: ockupationen av Socialstyrelsens trappa 1979', Lambda Nordica, 7:4, pp. 32-42.

Socialstyrelsen (1968). Klassifikation av sjukdomar 1968.

Strafflagberedningen (1941). Strafflagberedningens utlåtande med förslag till lagstiftning angående åtgärder mot homosexualitetens samhällsfarliga yttringar. Stockholm.

'Utredningen om homosexuellas situation i samhället' (1984). Homosexuella och samhället: betänkande. Stockholm: Liber/Allmänna förl.

Wasniowski, A. (2007). 'Den korrekta avvikelsen: vetenskapsanvändning, normalitetssträvan och exkluderande praktiker hos RFSL, 1950-1970'. PhD thesis. Umeå: Umeå universitet.

\section{FILM REFERENCES}

Bögjävlar [Damned Queers] (Gunnar Almér, Nils Gredeby, Lars Gustafsson, Staffan Hallin, Håkan Hede, Sten Åke Hedström, Olle Holm, Anders Näslund and Pelle Pettersson, 1977).

Eva och Maria [Eva and Maria] (Marie Falksten, Mary Eisikovits, Annalena

Öhrström, 1983).

Hon dansade en sommar [One Summer of Happiness] (Arne Matsson, 1951).

Kvinnan i ditt liv är du [The Woman in Your Life Is You] (Uncredited members of Lesbian Front Stockholm, 1978).

Sommaren med Monika [Summer with Monika] (Ingmar Bergman, 1953).

Väninnor [Girlfriends] (Nina Bergström and Cecilia Neant-Falk, 1996).

\section{ARCHIVE MATERIAL}

\section{Riksarkivet Arninge, Stockholm (hereafter RA)}

RA (n.d.a), SE/RA/420267/420267.67/A I a/4, Nämndens protokoll, 1976-1977, 'Disposition 1976/77 'Kostnadssammanställning, sex och samlevnad', date unspecified.

RA (n.d.b), SE/RA/420267/420267.67/A I a/4, Nämndens protokoll, 1976-1977, Dispositionsanhållan för området sex- och samlevnad budgetåret 1977/78, 'Disposition Projektplan', date unspecified. 
RA (1974a). SE/RA/420267.67/F V/3, Handlingar rörande sex och samlevnad, Anslag till ungdoms- och kvinnoorganisationer, Dnr A 5 III 121/232/74, Pressrelease 26, 'Anslag till ungdoms- och kvinnoorganisationer', Nils Östby, 1974.

RA (1974b). SE/RA/420267.67/F V/3, Handlingar rörande sex och samlevnad, Anslag till ungdoms- och kvinnoorganisationer, 'PM ang upplysning i samband med ny abortlagstiftning,' October 1974.

RA (1977a). SE/RA/420267.67/F V/3, Handlingar rörande sex och samlevnad, Anslag till ungdoms- och kvinnoorganisationer, Dnr SN/h 195/232/76, 'Pressrelease nr 7/77, 4 February 1977.

RA (1977b). SE/RA/420267/420267.67/F V/1, Handlingar rörande sex och samlevnad, Anslag till ungdoms- och kvinnoorganisationer, 'Referensgruppens förslag till fördelning av anslaget till ungdoms- och kvinnoorganisationernas information om sex- och samlevnadsfrågor', 1977-01-17.

RA (1977C). SE/RA/420267/420267.67/E I/47, Korrespondens, 1976, 195:2, 121, E1:47, 'Kvinno och Ungdomsorganisationer, fördelning av anslag till kvinno och ungdomsorganisationer', SN7h 195/232/76, 'Delgivningsbesked', 21 February 1977.

RA (1976). SE/RA/420267/420267.67/E I/47, Korrespondens, Ansökan Lesbisk Front, 1976, 195:2, 121, E1:47.

RA (1977d). SE/RA/420267/420267.67/A II/2, Föredragningslistor 1977, Diarienr SN/h 243/233/76, 'Föredragningslista nr 55', 15 April 1977.

RA (1977e). SE/RA/420267/420267.67/A II/2, Föredragningslistor 1977, Diarienr SN/h 243/233/76, 'Avtal', 15 April 1977.

RA (1978). SE/RA/420267/420267.67/E I/47, Korrespondens, 1976, 195:2, 121, E1:47, 'Kompletterande upplysningar och information från Lesbisk Fronts Projekt angående informationsmaterial och film projekt. Lesbisk Front Stockholm, Kerstin Karlsson, 10 October 1978.

\section{Marie Falksten, private archive, Gothenburg (hereafter MF)}

MF (n.d.a). 'Eva och Maria. Faktahäfte', Marie Falksten, Nils Weijdegård, Stina Sundberg, date unspecified.

MF (n.d.b). 'Eva och Maria. Lärarhandledning med diskussionsförslag', Marie Falksten, Nils Weijdegård, Stina Sundberg, date unspecified.

MF (n.d.c). 'Eva och Maria,' info sheet in Swedish, date unspecified.

MF (n.d.d). 'Eva and Maria. In love with each other!', information sheet in English, date unspecified.

MF (n.d.e). 'Skolöverstyrelsen informerar: Eva och Maria, kära i varandra!', information sheet in Swedish, date unspecified.

MF (1976a). 'Bekräftelse på medverkan i h-nämndens utbildnings och konferensverksamhet', 10 June 1976.

MF (1976b). DNR SN/h 243/233/76, 'Målsättning', Mary Eisikovits, Marie Falksten, Annalena Öhrström', 21 January 1976.

MF (1983). DNR 3409-107/83, 'Föredragningslista', Gunilla Hollander, 31 October 1983 .

MF (1984). 225-84:1362, Skolöverstyrelsen, information material, 'Eva och Maria', 24 July 1984. 


\title{
THE CARING NATION \\ Don't Ever Wipe Tears Without Gloves as a reparative fantasy
}

\author{
A N U KOIVUNEN
}

Tn February 2013, Swedish author and comedian Jonas Gardell was awarded the prize of 'Homo of the Year' by the Swedish Crown Princess Victoria, who was the first ever member of the royal family to attend the annual QX gay gala. An enthusiastic gala audience welcomed her appearance on the stage with cheers and a standing ovation. In her short award speech, Crown Princess Victoria proclaimed a wish: 'Your message is clear. Straighten your back. Reach out your hand. We shall dry each other's tears. We shall dry each other's tears with open hearts and our bare hands.' With these words, she paraphrased the title of Jonas Gardell's novel and TV drama Don't Ever Wipe Tears Without Gloves, which for the first time in the Swedish mainstream public sphere addressed the trauma of HIV/ AIDS, and for which Gardell was awarded the prize. Accepting the award, Jonas Gardell responded cheekily: 'You may be the Crown Princess, but tonight, I am the Queen' (see figure 12.1). The gala was televised nationally and Princess Victoria's presence was widely publicised (Backlund, 2013a; Engman, 2013a; 2013b; Lagerwall, 2013; TV4, 2014). 'There is no clearer way for the future sovereign of Sweden to show support and affirmation', summarised the chair of Stockholm Pride regarding the widely felt public enthusiasm (Rimsby, 2013).

The 2013 QX gala award ceremony, this chapter suggests, marked a moment whereby what in the 1980 os had been addressed as a 'gay plague' was now reframed as a national trauma. When awarding the prize to Jonas Gardell, Crown Princess Victoria enacted an imaginary trauma resolution, symbolically healing past wrongs - the blaming and offending of AIDS victims in the 1980 os public discourse on the epidemic, the inhumane treatment of patients, and the subsequent long silence. As the embodiment 


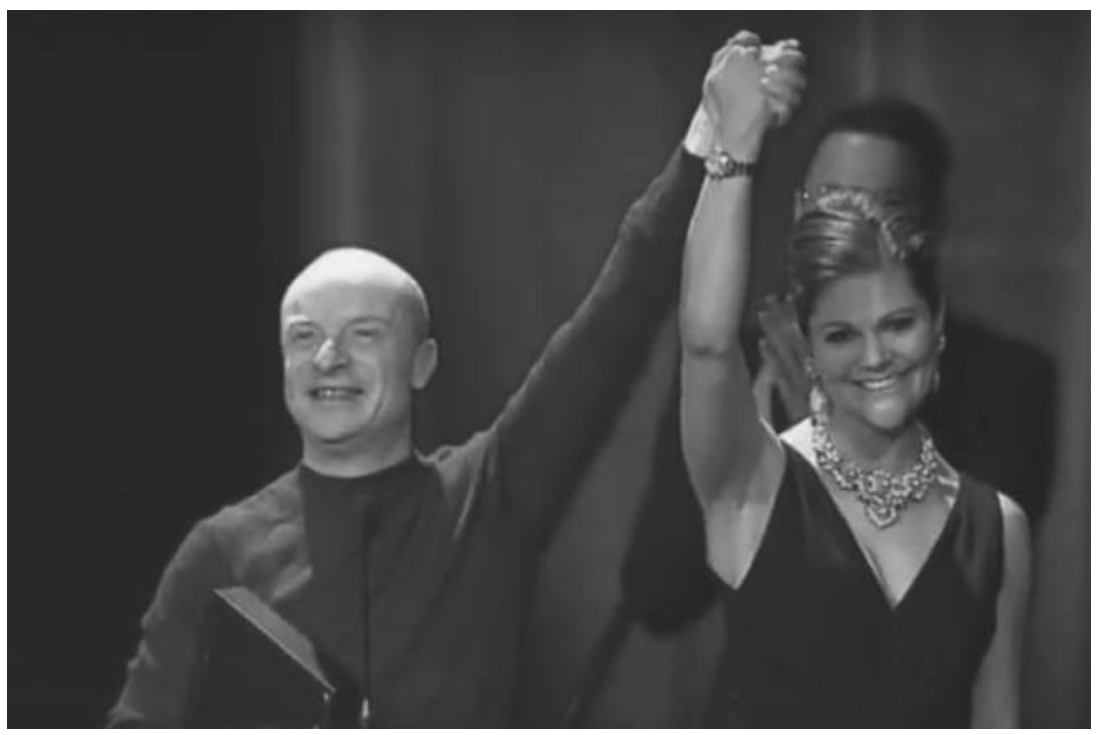

Figure 12.1 Swedish Crown Princess Victoria awarded the prize of 'Homo of the Year' to Jonas Gardell at the annual QX gay gala, 4. February 2013.

of the state of Sweden, the Crown Princess retrospectively offered both recognition and care. In the 'we' of the royal speech, the gay community, once regarded as 'not-us', was called upon as one with the nation. At the same time, the nation of 'us' was redefined as a community of compassion, and a historical notion of Swedish welfare state as caring was regenerated. The vulnerability of gay men during the epidemic and their suffering were recognised, the national self-image healed, and a new community of proper feeling envisioned (Berlant, 1999).

\section{GAY EPIC TO NATIONAL EPIC}

Released over a year between August 2012 and August 2013, Jonas Gardell's trilogy of novels (2012a; 2013a; 2013b) and a three-part TV drama Don't Ever Wipe Tears Without Gloves [Torka aldrig tårar utan handskar], scripted by Gardell and directed by Simon Kaijser, had immense success in Sweden. When Swedish public service television SVT aired the threepart drama series in October 2012, 1.2 million viewers, a third of the adult population, were seated for the premiere, and \#torkaaldrigtårar trended on Twitter. Both the novel - which sold over 100,00o copies - and the TV series received a very favourable public reception and exceptional 
media coverage in the national media, crossing over between the highbrow cultural pages and the entertainment sections of tabloids as well as receiving editorial commentary and massive acclaim. ${ }^{1}$ In the upcoming months, Jonas Gardell - a national gay celebrity since the 1980 s - was given a range of awards: the Swedish TV prize Kristallen for the best TV drama of the year in 2012, the Swede of the Year award 2012 from the weekly politics magazine Fokus for 'reminding us of how human dignity is never a self-evident fact but needs constant defending', an honorary doctorate in medicine at Linköping University in 2013 for 'depicting a dark chapter in the Swedish history of medicine', and the 2013 Bellman Prize from the city of Stockholm for 'depicting the greatness and the vulnerability, the shortcomings and the radiance of human beings' (Brevinge, 2012; Karlsson, 2013; Lundgren, 2013).

More than a novel or a television drama, Don't Ever Wipe Tears Without Gloves is better understood as a media event: a series of works and a serial narrative unfolding and evolving on many media platforms over two years, from August 2012 onwards. As a transtextual event, it comprised not only the three-part novel and television drama but also extensive media publicity in 2012-13 as well as Jonas Gardell's performances in his stage show (Mitt enda liv) and national radio and TV programmes ( $P_{1}$ Sommar, Allsång på Skansen, En helkväll med Jonas Gardell). They all recirculated material - lines, events, scenes, and songs - from the novel and the TV drama, amounting to a web of versioning, repetition, and recurrence. The different instances were joined together by Jonas Gardell as an author, performer, and public persona. His status as a celebrated artist in the eyes of the mainstream public as well as the transtextuality entailing both intensity and duration were crucial in making Don't Ever Wipe Tears Without Gloves a popular success.

The three-part novel and TV drama were received as a long-awaited revisiting of a forgotten traumatic past and enabling a belated but important occasion for public mourning and communicating of the trauma (Caruth and Keenan, 1995). At last, the lives of AIDS victims would be commemorated in Sweden (Butler, 2004; Sturken, 1997; Svensson, 2007; Warburton, 2014; 2016). At last, the homophobic reactions of media and society at large would be recognised and the experiences of repressive state health policies and legislation accounted for. When HIV was in 1983 included under the Infectious Diseases Law, HIV-positive persons were, in the name of public health, obliged to regularly report sexual encounters and partners to a physician. Furthermore, and even today, the HIV disclosure obligation is very strict: as stipulated by Swedish law, people with HIV must disclose their condition to their partners before sex, and they cannot have unprotected sex in any circumstance. Failure to comply can result in a prison sentence, 
even if the virus is not transmitted (Kulick, 2005; Thorsén, 2013; Warburton, 2016). Like in the United States and many European countries, in Sweden the introduction of protease inhibitors in 1996 led to a relative silence around HIV/AIDS in the public sphere (Sörberg, 2008). The doctoral thesis by ethnologist Ingeborg Svensson on Swedish AIDS victims' funeral practices was published in 2007, but in the broad public sphere the topic of HIV/AIDS was virtually untouched before Gardell, despite the gay-friendliness and high cultural visibility of LGTBQ issues in Swedish publicity since the mid1990s (Svensson, 2007; 2013; Warburton, 2014; 2016). ${ }^{2}$ Sweden, unlike many other countries, had no AIDS activist visual media (Juhasz, 2006; Sendziuk et al., 2010) which would have raised these issues. In 2012, a documentary called Infected - When HIV came to Sweden [Smittad - när hiv kom till Sverige] was released and broadcast on primetime television as a follow-up to Gardell's TV drama.

While Gardell's novel did not receive any of the prestigious literary prizes and was criticised for structural or stylistic fallacies by some critics, it was embraced by the most influential cultural journalists and critics as a significant and urgent documentary novel making a forgotten history visible. It was, furthermore, written into the national literary canon through comparisons with well-known epic historical novels. Wilhelm Moberg's tetralogy The Emigrants [Utvandrarna] (1949-59), about Swedish migration to the United States in the nineteenth century, and Per Anders Fogelström's (1917-1998) series of novels depicting Stockholm from the 1860s onwards (Liljestrand, 2012; Milles, 2013; Utbildningsradion, 2013). The trilogy was hailed as 'witness literature' (Wiman, 2012a), as a 'triumph of political literature' (Guillou, 2013), and a depiction of 'a civilisation process' of the Swedish society (Larsmo, 2013). While welcomed as a 'gay men's national epic' (Brandel, 2012) and 'a loving depiction of gay promiscuity' (Wilson, 2012), the novel was also framed as a mirror image for the general public, calling forth 'pain over what many have experienced and pride over how we in Sweden have progressed' (Ludvigsson, 2012). The mainstream acclaim for Don't Ever Wipe Tears Without Gloves concluded in 2014 when the readers of the newspaper Dagens Nyheter voted it the third 'most significant cultural event' in Sweden since 1964 (Hilton, 2014). ${ }^{3}$

The public acclaim of both the novel and the TV series evokes the 1990s US reception of Tony Kushner's play Angels in America (1991) which has also had many productions in Swedish theatres since the early 1990s. Even if Swedish critics were not 'stumbling over each other in adulatory stupor' to celebrate 'a masterpiece' (Savran, 1995), the broad popular embrace of Don't Ever Wipe Tears Without Gloves as significant history and an epic for the nation echoes how Kushner's play engaged with the national imagination and worked, in David Savran's (1995) words, to reconstruct the nation 
(see also Kekki, 2003). Whereas Kushner's play articulated a Mormonist notion of America as a promised land, Gardell's epic re-narrativised the nation's recent past through Christian language: the general public, in its ignorance and prejudice about the HIV/AIDS epidemic, violates the Great Commandment and ethical rule of loving one's neighbour as oneself. Like Kushner's play, Gardell's epic was accommodated with 'remarkable ease' into the national canon (Kekki, 2003; Savran, 1995: 226) as it turned around the pathologising gaze of the past. While gay men, in public discourse on HIV/AIDS, were excluded from the national 'we' during the epidemic and othered as bearers of 'the new plague', Gardell's epic projects the chosen family of gay friends as the true family which provided the acceptance, support, and care the biological families and the imaginary national family denied. In this manner, the epic - like Angels in America - depathologised 'gay men as a class' (Savran, 1995: 227) and, instead, pathologised the national past.

In her study of the politics of remembering and nation-building, Marita Sturken (1997: 14) compares the AIDS epidemic to the Vietnam War, arguing that these two historical moments have profoundly affected cultural memory. In her analysis, they have both disrupted 'previously held popular beliefs about the United States' as well as experiences of nationality. Gardell's epic suggests the same in the case of Sweden, despite a very different historical and political context: that the trauma in Sweden, beyond the epidemic itself, was not about denied access to healthcare or medication, but about social rejection and stigmatisation. The trauma resided in 'the severance from the national body' (Wiegman, 1997: 4; Yingling, 1991; 1994), in being marked as not belonging to the national 'we'. It is this trauma that Don't Ever Wipe Tears Without Gloves promised to repair.

Beyond addressing a trauma within gay male culture, Don't Ever Wipe Tears Without Gloves simultaneously engaged in a politics of nation. While enabling mourning work for gay audiences, it attempted to rewrite the national history by projecting the nation's near past of the 1980 os as an age of homophobia and intolerance against the contemporary, official self-image of Sweden as 'gay-friendly' (Swedish Institute, 2018). In other words, Don't Ever Wipe Tears Without Gloves resignified vulnerability, the injury of the HIV/AIDS epidemic on gay men, as a productive resource for the national self-image, thus enabling the integration of gay history into the 'national symbolic' (Berlant, 1991). While issuing a fierce accusation of homophobia against past Swedish society, through processes of resignification and transference, Don't Ever Wipe Tears Without Gloves reframed the HIV/AIDS-stricken bodies as objects of compassion, restoring the self-image of Sweden as a caring nation - a welfare state and folkhem, a people's home. 


\section{TESTIMONIAL SPACE: RE-NARRATIVISING THE NATION}

In its revisiting of the HIV/AIDS crisis of the 1980s, Don't Ever Wipe Tears Without Gloves coincided with several US documentary films about AIDS activism (United in Anger, 2013; How to Survive a Plague, 2012; Vito, 2011; We Were Here, 2010; Sex in an Epidemic, 2010). Instead of commemorating past political and social mobilisation, Don't Ever Wipe Tears Without Gloves, as a novel and a TV series, foregrounded public mourning over the loss of lives and communities during the HIV/AIDS epidemic by depicting a circle of gay friends: Rasmus, Benjamin, Paul, Seppo, Lars-Åke, Bengt, and Reine. The three-part structure of both the novel and the television drama enacts a tragic trajectory as the first part is subtitled 'love', the second 'illness', and the third 'death'. The narration moves between different temporal layers: the now of narration with a voiceover reminiscing on the past, the childhood of Rasmus and Benjamin, their journey to the circle of gay friends, their romance, Rasmus and other friends falling ill and dying, and Benjamin surviving them as a witness of the era. As an AIDS-narrative, the novel and the TV series echo three decades of literary, cinematic, and televisual representations of the epidemic, the legacies of 'AIDS media' (Hallas, 2009; Román, 2006; 2009; Sendziuk et al., 2010), and what Monica Pearl (2013: 8ff.) has termed the 'legacy of gay grief' (see figure 12.2).

In mobilising a sense of national renewal, the narrative structure of Don't Ever Wipe Tears Without Gloves played a crucial role. The TV series opens with an extreme close-up of Rasmus's (Adam Pålsson) eyes, conveying

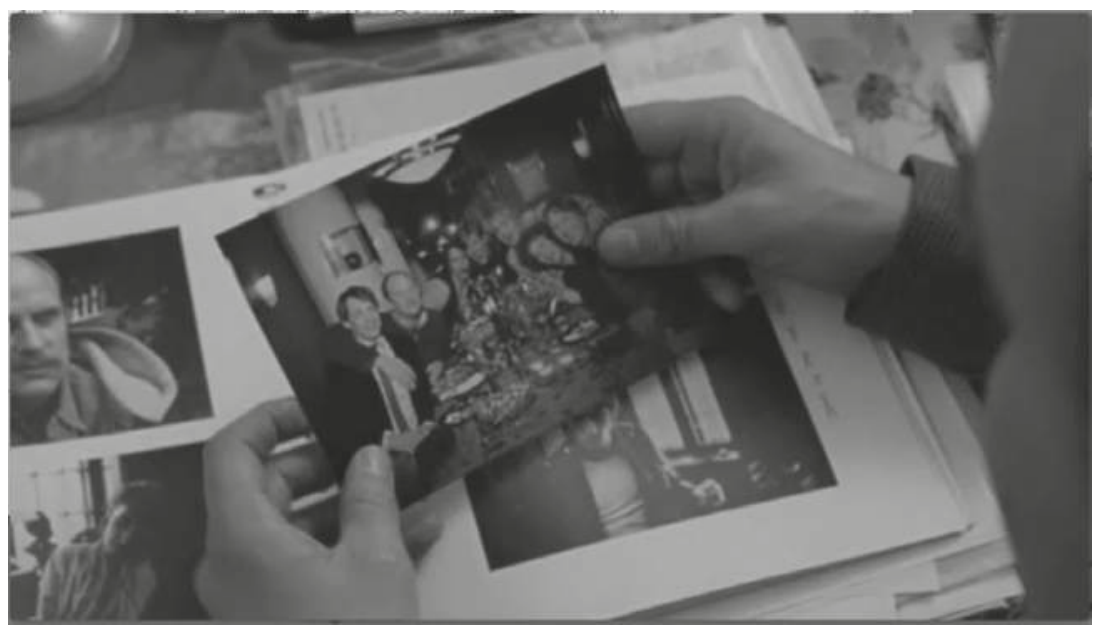

Figure 12.2 Remembering friends and lovers. 
a sense of panic and agony. He is in hospital, in pain and undergoing treatment. This opening scene introduces the viewers to the prototypical imagery of the HIV/AIDS epidemic, showing 'emaciated gay men in hospital beds' (Hallas, 2009: 12). An object of intense debate since the early years of the epidemic, these deathbed images have been fiercely criticised for sustaining 'stigmatizing ideological narratives about homosexuality's "innate pathology"', instead of persuading 'readers to demand a greater political and medical response to the AIDS crisis' (Crimp, 2002; Hallas, 2009: 12; Treichler, 1988; Watney, 1987; 1996). Nevertheless, the opening shot also has a particular narrative function. As Rasmus's eyes look straight into the camera, they serve as an injunction to the viewer: you are seeing this, and you are hailed as a witness.

With its narrative structure, Don't Ever Wipe Tears Without Gloves invites its viewers into what Roger Hallas has termed an 'intersubjective space of testimony' (Hallas, 2009). Documentary footage is used to enhance a sense of historical accuracy. Each episode features a title sequence in which documentary footage of everyday life in Stockholm is mixed with dramatic scenes from the television drama. On the soundtrack, an omniscient voiceover narrator (Björn Kjellman) addresses the viewer: 'The story you are about to see is true. And it happened here. In this city.' These pregnant words and the injunction to remember are repeated at the beginning of each episode, and they also reoccur throughout the three-part novel. The voiceover narrator is curiously ambivalent. He is anonymous in the openings of the first and the third episode, describing the diegetic events as an omniscient narrator: 'It was like a war fought in peacetime. In a city where most people went on as if nothing had happened, young men fell ill. They grew emaciated, withered away, and died.' In the second episode, however, the narrator identifies himself as Benjamin: 'We were like a family ... Paul, Bengt, Reine, me and Rasmus, Lars-Åke and Seppo. We'd spend Christmas at Paul's place. That's where Rasmus and I met.' Here, Benjamin reframes himself in the testimonial space as a witness to the epidemic and a survivor: 'We were so young. We loved each other so very much. And that's when this sickness came to our city. "The new plague", the papers called it.' In the third episode, the omniscient narrator enters the image track, becoming a protagonist who through first-person address embodies the remembrance. Visiting Rasmus's grave he recounts the tale of the 'plague' to a relative, a closeted gay man, recalling Rasmus's 'two years of sheer hell' entailing mistreatment and denied benefits as well as being 'met with contempt everywhere'. In this scene, he becomes a representative of those who survived: thanks to inhibitor drugs, 'eventually, you thought that you just might live', while having difficulty to accept 'that you weren't going to die'. 
The narration in the TV series operates in two registers. On the one hand, the voiceover frames the story as retrospection and a historical exposé. Short sequences using documentary footage and voiceover step out of the lives of Benjamin, Rasmus, and their friends to inform the viewer about gay culture in Stockholm. ${ }^{4}$ In the novel, even more distinctively, the fiction is punctuated by factual, essay-like sections where the omniscient narrator informs the reader about the history of the Swedish gay movement, gay life and press in the 1980s, attitudes towards homosexuality in Sweden and elsewhere, media coverage of HIV/AIDS, state policies, politicians' reactions, and changes in legislation. Through these passages, the lives of Benjamin, Rasmus, and their friends are explicitly framed as representative of larger histories.

On the other hand, the narration of Don't Ever Wipe Tears Without Gloves engages the viewer in emotional turmoil by contrasting scenes of happiness, lust, romance, and community with powerful, stereotypical imagery of 'AIDS victims'. With a flashback structure, whereby Benjamin (Adam Lundgren) is first met when sitting by the deathbed of Rasmus, the narration constantly cuts between the pre-epidemic happiness and the present loss, showing the devastating effects of the epidemic on the circle of friends. As a recurrent shock image (see figure 12.3), the title sequence of the series features a close-up of a zip-up plastic body bag with the sign 'biohazard' [smittorisk], another key trope of representations of 'AIDS victims' (Watney, 1987: 80). In this 'spectacle of AIDS', as Simon Watney argued in 1987, homosexual male bodies are identified with death: 'the homosexual

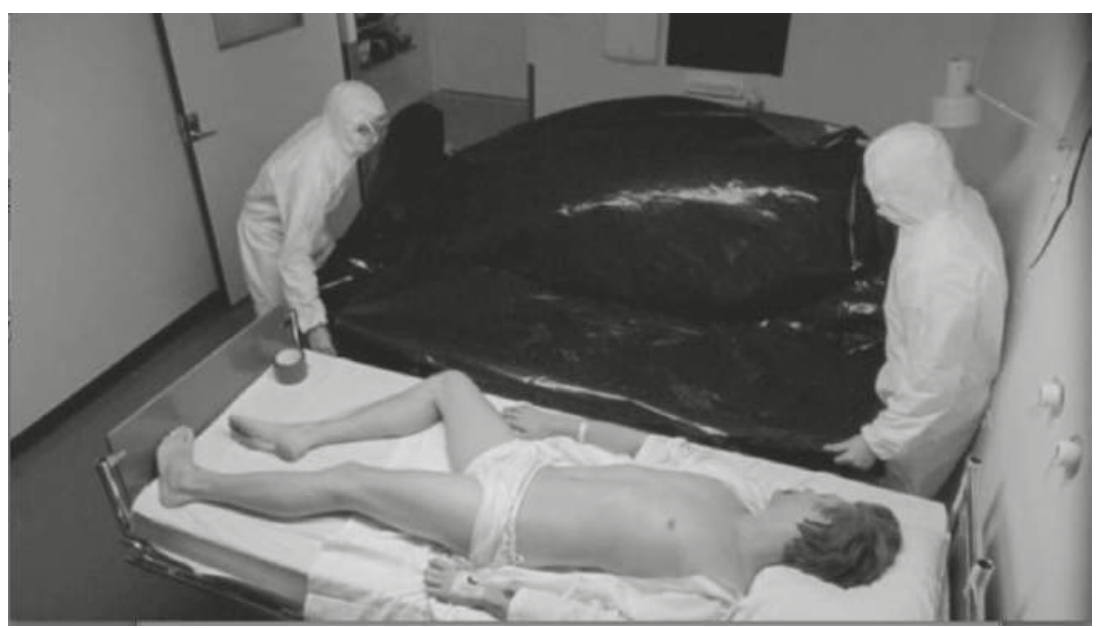

Figure 12.3 The spectacle of AIDS. 
body', he argued, 'must be publicly seen to be humiliated, thrown around in zip-up plastic bags, fumigated, denied burial, lest there be any acknowledgement of the slightest sense of loss' (Watney, 1987: 80).

The readers and viewers of Don't Ever Wipe Tears Without Gloves are addressed in the second person and called upon to perceive themselves as witnesses (Hallas, 2009: 9-10). Through engagement with the epic, the general public is offered an opportunity to look back to see and acknowledge the lives and losses that passed unmarked thirty years earlier. As a testimonial space, fiction thus enabled a re-enactment of the original trauma, functioning as a mode of affective historiography (Koivunen, 2016) and foregrounding felt connection and a sensory dimension of conceptualising the past. Feelings of fear, anger, and grief were reframed as a concern for a national collective, and indeed both social media and other public commentaries celebrated the television drama for 'tearful viewing' (e.g. Gentele, 2012; Hagström, 2012; Roos, 2012).

As discussed by Roger Hallas (2009), testimony is a relational act that, psychoanalytically speaking, effects a transference between the witness and the listeners. To receive a witness account entails becoming a secondary witness, but it also entails becoming affected, undergoing a transformation: 'The witness begins to come to terms with the event, to truly experience it for the first time, while the listener shares the burden and, with it, the responsibility to participate in the struggle produced by the experience of the event' (Hallas, 2009: 12-13). While Hallas focuses on queer AIDS media and experimental film and video, his description of transference in testimony points to a more general logic. In the case of Don't Ever Wipe Tears Without Gloves, the broad popular embrace testifies to a smooth and successful process of transference: the burden that was imaginarily transferred was not rejected but accepted with enthusiasm. In this affective historiography, gay and national histories were rewritten through one another, resulting in a reparative fantasy for both.

\section{AUTHORITATIVE WITNESSING: JONAS GARDELL}

The affective effect of a public testimony, in Hallas's reading, depends on the coincidence of two corporeal presences: a person who was physically present at the event and who is physically present at the moment of testimony: 'the alignment of these two corporeal presences in the singular body of the testifying witness provides the necessary enunciative condition for the listener to sense - both cognitively and affectively - the magnitude of the event' (Hallas, 2009: 11). In the case of Don't Ever Wipe Tears Without Gloves, the key element defining this corporeal presence was the author 
and scriptwriter Jonas Gardell, particularly considering his long-term star status. For the re-narrativisation of the HIV/AIDS epidemic as a national trauma, Gardell mobilised his whole public persona as well as his signature modes of sentimentality, melodrama, and Christian language.

In the many interviews Gardell gave in 2012-13, he recurrently called himself a witness (Brandel, 2012; Brevinge, 2012; Engström, 2012; Gustavsson, 2012; Henriksson, 2013a; 2013b; Öhrman, 2012; Torén-Björling, 2012). 'I was there, it was my time, my city, and I am a writer. It is my obligation to write, a kind of honorary task', he stated (Torén-Björling, 2012). He repeated how the story, despite its fictive characters, drew on true events and experiences shared by him and his friends. In these interviews, he told over and again that everything in the books was true, that the events, insults, and injuries happened - and he knew it, beyond extensive research, because he was there and he survived (Brandel, 2012). He placed himself in the scenes of his novels - for example, he described hanging around Norra Klara kyrkogata as a fourteen-year-old, 'where the difference between pickup and prostitution was fluid' (Brandel, 2012).

While Jonas Gardell never appears on-screen in the diegetic space of Don't Ever Wipe Tears Without Gloves, nor is he the omniscient voiceover narrator of the novel, in the broad transtextual event the narrator of his novels and his public persona converge. First, it is Gardell's hypervisibility in the Swedish mainstream media since the mid-1980s that gives him the position of authoritative witness - as someone having been there - and someone bearing witness - testifying in the present moment. Second, while not autobiographical, Don't Ever Wipe Tears Without Gloves reiterates many familiar themes of Gardell's writing and stage performances since the late 1980s: growing up as a queer child in a religious home, being harassed at school, bearing social stigma, and experiencing and living with the threat of violence. These topics as well as the use of the autobiographical self are the very core of Gardell's oeuvre. Third, in interviews on Don't Ever Wipe Tears Without Gloves, Gardell often speaks with the lines of his novels, citing them, and in discussing the HIV/AIDS epidemic and gay history he puts himself in the scene by speaking in the name of a 'we' (Gardell, 2013c). As an effect, Gardell recalls the omniscient narrator of his novel and the TV series, instructing the reader, listing names and providing references.

Furthermore, a year after the television drama Gardell upgraded his role as the embodied storyteller and survivor-witness with his new stage show My Only Life [Mitt enda liv], whose title reiterated a song from Paul's funeral in the concluding episode of the TV series. In this scene, an AIDS funeral is turned into a celebration of life, with lyrics confirming the lived life as a choice ('My one life. The only life I'm going to get. The only life I've ever wanted. My one life'), and the staging of the song as a joyous spectacle, 
a celebration of the chosen family and a sense of gay community (Backlund, 2013b). The aesthetics of the number recall a Pride parade, featuring a crowd, dancing, and drag queens. This number reframed the HIV/AIDS epidemic as a story about life rather than death, and was performed by Gardell as a music number in several TV programmes (Allsång på Skansen, 2013; En helkväll med Jonas Gardell, 2013). The stage show My Only Life, which premiered in Stockholm in October 2013, was sold out for two years, toured around the country, and was also broadcast on national network television. In this performance, Gardell explicitly inserted himself into the narrative of Don't Ever Wipe Tears Without Gloves. Using background projections from the TV footage and a first-person narrative ('my life'), he presented himself as a witness and survivor, the show concluding with the anthem from the television series. ${ }^{5}$

Important for Gardell's functioning as an authoritative witness was his long-term status as a national gay celebrity, and a face for both gay marriage and gay parenting. He himself commented upon his particular role as a 'domesticated' gay man, embraced by the straight mainstream rather than the gay subculture (Voss, 2007). When awarded the prize of 'Homo of the Year' in 2012, the jury praised Gardell for succeeding in making 'the average Swede understand and embrace the thought that homosexuality too is an ingredient of the Land of Mellanmjölk'. The notion of 'the Land of Mellanmjölk [Middle Milk]' refers to a joking self-image of Swedes, describing themselves as being average, 'in the middle', and anxiously not too much of anything, including fat in milk. In other words, Gardell was praised for his integrationist politics and mainstreaming homosexuality (cf. Warner, 1999).

Thanks to this exceptional status as 'gay of the nation' [riksbög], Gardell was, in his many stage performances and My Only Life [Mitt enda liv], also able to present himself as an embodiment and representative of Sweden. Proclaiming 'I am Sweden' or referring to his family as 'It is us who are Sweden, he explicitly took issue with the right-wing populist Sweden Democrats' attempt to hijack nationalist language and imagery. His defiant and bold gestures echoed the rebellious and jubilant rhetoric of the Queer Manifesto - 'We're Here. We're Queer. Get Used to It' - but also of the Queer Nation as a project of 'new nationality' which attempted to reoccupy 'the space of national legitimation' (Berlant and Freeman, 1992: 170).

\section{TIME OF AFFECT, TIME OF NATION}

Don't Ever Wipe Tears Without Gloves reframed the 1980s HIV/AIDS epidemic not only figuratively but also in a more literal sense, as Gardell 
returned to his own writing of the $198 \mathrm{os}$. He had indirectly thematised the epidemic in his debut novel Passion Play [Passionspelet] (1985), featuring a religious framing, and the main characters of Don't Ever Wipe Tears Without Gloves, Rasmus and Benjamin, were already there in his TV play Tenderness [Ömheten], along with a number of key dialogues. Significantly, the play originally broadcast by national public service television SVT in 1989 and produced for stage in 2012 following the success of Don't Ever Wipe Tears Without Gloves (Aschenbrenner, 2012; Håkansson, 2012; Waaranperä, 2012) was very different in its mode and aesthetics: an intimate chamber play and a family drama with a focus on homophobia and HIV/AIDS as a social problem. When versioned in 2012 for Don't Ever Wipe Tears Without Gloves, the core plot of the play was reframed as a question of national trauma.

Both versions have a flashback structure that focuses on Rasmus dying of AIDS in hospital in 1989, with his lover Benjamin by his bedside and his parents visiting. What was additionally preserved for 2012 is the charged dialogue between Benjamin and Rasmus's parents: Rasmus's parents deny Benjamin the presence at his funeral, rejecting him and proclaiming 'You don't belong to the family'. Beyond this, the two versions of Rasmus and Benjamin are very different. While in Tenderness we meet an ordinary gay couple, an un-dramatic everydayness framing the dramatic illness, in Don't Ever Wipe Tears Without Gloves the gay characters are cast as melodramatic virtuous victims: gorgeous young men who wanted to love, who - to quote the rhetoric of the series - had 'such capacity to love' but who faced death.

The melodramatic tone in 2012 is further emphasised by the ways in which Rasmus's and Benjamin's biological families treat them. Benjamin's parents are Jehovah's Witnesses who reject their son once he comes out as gay. Whereas in the 1989 television play Rasmus's parents react to the knowledge of their son being ill with frustration - 'first you ask us to be tolerant, to accept and to respect the demands of gay rights movement, and now this' - in the 2012 version the parents are depicted as lacking empathy. This withholding of compassion (Berlant, 2004) is further emphasised as a significant symbolic gesture, as the hospital personnel are singled out as refusing a human touch. The title of the series is explained in the introductory scene of the first episode as an explicit warning of one nurse to another: 'don't ever wipe tears without gloves'. The drama opens with denying or withholding compassion, signalled by both the parents' reactions and the hospital personnel's isolation routines. ${ }^{6}$ In 1989 the gay couple lives in social isolation, but in 2012 Rasmus and Benjamin are depicted as surrounded by their chosen family of gay friends and a vibrant gay community. In other words, the contrasting of the chosen family against societal abandon that is crucial to the narrative of Don't Ever Wipe Tears Without Gloves is notably absent in Tenderness. 
In reframing the 1989 drama of parental betrayal into an exposé of the nation's past mentality and lack of empathy, Don't Ever Wipe Tears Without Gloves invokes a community of feeling (Berlant, 2008). It establishes a particular sense of time - a time of affect beyond history in a conventional sense. The temporal distance that enables historicising the epidemic and returning to the past trauma in the first place is disavowed, and the repetition of betrayal appears as an original wound, as if of a different temporal order. The time of affect - a synchronic time - is the homogeneous, empty time of the nation described by Benjamin Anderson (1993) in his famous reading of Walter Benjamin. In this time or timelessness of affect, the viewers of the 2012 TV series as secondary witnesses are invited to revisit and share the trauma, the previously unrecognised loss. The synchronic time of affect as a mode of affective historiography enables a transference and reframing of the narrative about AIDS trauma as one about the nation.

And it is this trauma that is resolved in the scene where Jonas Gardell was crowned as the 'Homo of the Year' by the Swedish Crown Princess. In that moment, the community of compassionate viewers constructed by Don't Ever Wipe Tears Without Gloves coincided with the idea of Sweden as a nation, and the national self-image was reformed. If the TV series in its first episode introduced the narrative as a war drama - 'It was like a war that was fought in a time of peace' - it took six months for the drama to be crowned as a national narrative, and the AIDS victims recognised as soldiers of a nation, fighting for love but killed in action (Gould, 2002).

The war metaphor in Don't Ever Wipe Tears Without Gloves and the idea of AIDS victims as veterans associate with the US discussions of the HIV/AIDS epidemic as a national trauma comparable to the Vietnam War (Sturken, 1997). However, in Sweden the metaphors are not anchored in any contemporary or recent war experiences. Rather, they are a part of Gardell's melodramatic pathos: an invitation for the witness-viewer to feel sympathy for virtuous victims. In Don't Ever Wipe Tears Without Gloves, HIV/AIDS epidemic reads not only as a war but also a destruction of innocence. In the final scene of the television drama, the aged Benjamin is sitting at a café by Kungsträdgården and on the soundtrack we hear his internal monologue: 'And they were those who loved the most. Those who were obsessed with love. They were the ones who fell to the frost.' On the image track we see a flashback, private memory or a fantasy of afterlife: slow-motion images of the 'family', the circle of gay friends, enjoying the blossoming of cherry trees in that very same place, Kungsträdgården: 'There are cracks in my foundation, though. Sometimes, I'm on the verge of collapse when I think of Rasmus and the others. The ones who faded away. Somehow I'm only half a person without them'

This rhetoric of 'early frost' - echoing the title of the first US AIDS drama An Early Frost (John Erman) from 1985 - and of victims as 'those who loved 
the most' equates loving with being killed in action. When described as young, beautiful, and innocent, Rasmus and the other characters are portrayed, in classic melodramatic manner, as virtuous victims or victimheroes (Williams, 1998: 42, 66). In the melodramatic imagination, suffering signifies virtue and 'instants of weakness and vulnerability', 'emblematic of their moral goodness' (Williams, 1998: 54). In Don't Ever Wipe Tears Without Gloves, the omniscient narrator serves as a witness, asserting the virtue.

In Gardell's epic, furthermore, the depiction of vulnerability as a virtue draws on Christian morality underlying the notion of the nation as a community of compassion. The very title of Don't Ever Wipe Tears Without Gloves echoes a Bible quote cited by Benjamin in the first and the last episodes of the TV series. In the Revelation of St. John, it is God who is doing the wiping: 'God shall wipe all tears from their eyes. There shall be no more death, neither sorrow, nor crying, neither shall there be any more pain. For the former things are passed away.' Benjamin first cites this Bible quote at Paul's Christmas dinner when meeting Rasmus for the first time. In the TV drama, the quote is followed by a cut to the frame narrative Benjamin waking by Rasmus's death bed at the hospital - and a repetition of the quote. In this way, the hospital personnel's treatment of AIDS patients, the biological families' rejection of their gay lives, and the homophobic reactions of the general public are framed as violations of Christian morality. At the same time, the Bible quote and the Jehovah's Witnesses' image of an afterlife are removed from their homophobic uses and resignified as affirmative of the gay community (see figures 12.4 and 12.5).

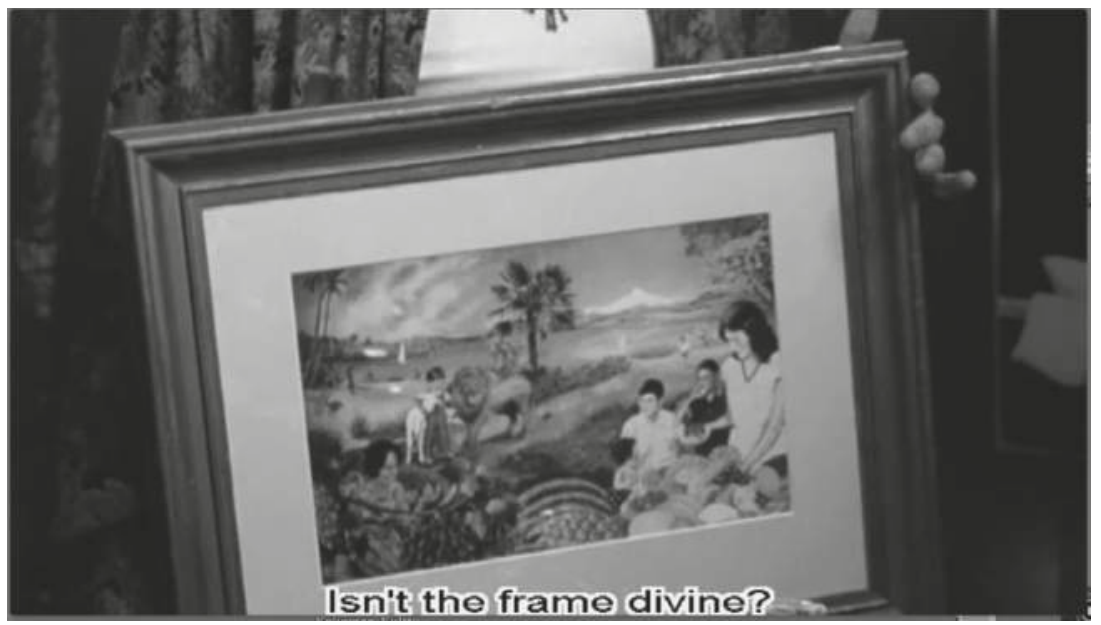

Figure 12.4. Jehovah's Witnesses' image of an afterlife. 


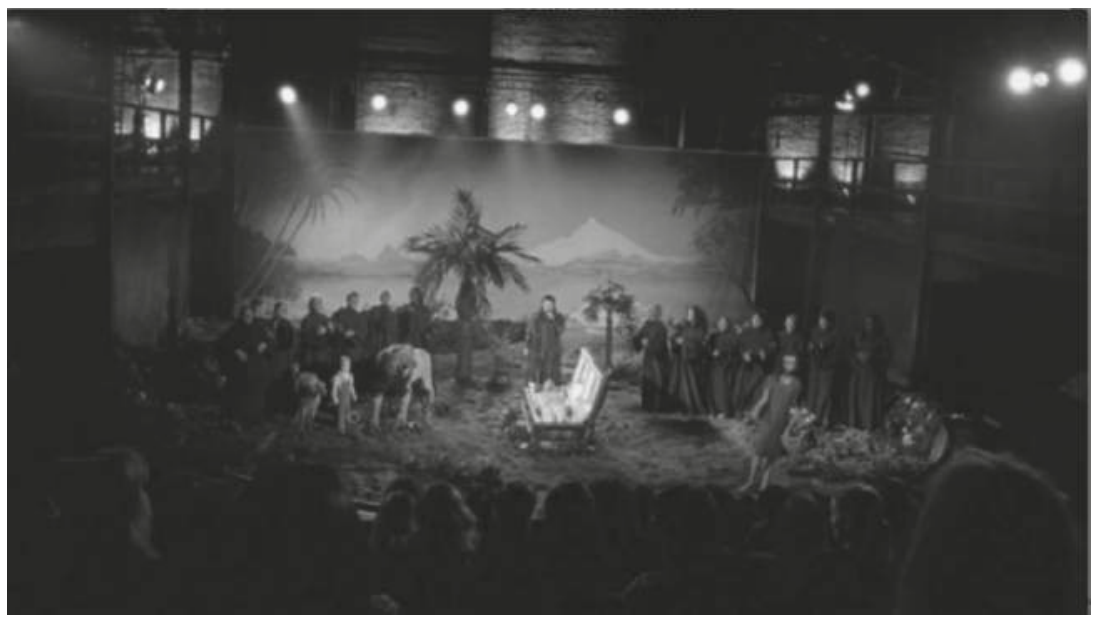

Figure 12.5 Paul's funeral.

Both the My Only Life number and the final scene in Kungsträdgården with cherry blossoms enact a Christian dream of redemption for queer subjects - celebration in life, turning of shame into pride - as well as the nation, provided that 'we all wipe each other's tears without gloves. This temporal structure, featuring a time of affect, an empty time of nation, and a futurity in an afterlife, confirms the overall re-narrativisation of the HIV/ AIDS epidemic: while focusing on dying and death, such a history concludes and invests in life. Writing history as something that enables futurity is a familiar move in recent queer politics, as described by Jasbir Puar in her discussion of homonationalism - the role of gay-friendliness in the construction of contemporary nation-states and discourses of citizenship (Puar, 2013).

\section{LIMITS OF MOURNING}

In 1989, Douglas Crimp famously described the activist response to AIDS as ambivalently torn between mourning and militancy. A similar tension between grief and defiance can be detected in the reframing of the HIV/ AIDS epidemic twenty years later with Don't Ever Wipe Tears Without Gloves. There is a militancy in Jonas Gardell's interviews where he stubbornly voices the injuries of the past as well as in the accusations explicitly presented by the omniscient narrator in his novel:

It happened here. Those doctors, journalists, editors in chief, editorial writers, politicians, policemen, priests, lawyers, and civil servants were guilty of this 
abuse - not one of them has ever been held accountable for the suffering and despair they incurred on an already marginalised group. (Gardell, 2013a: 58)

The Swedish Green party Miljöpartiet (2012) responded to this accusatory rhetoric by proposing that the Swedish government would issue an official apology to gay men who were offended, blamed, and treated with disrespect by the Swedish society during the epidemic. While this issue was raised by the prime minister with explicit reference to Gardell's epic, no official process or public debate ensued (Marmorstein, 2012), and Gardell himself declined to enter into discussions about apologies (Gardell, 2013d). ${ }^{7}$ An apology may, as Sara Ahmed (2004) has argued, be just a speech act that, instead of opening dialogues, stops the conversation.

In many interviews, Gardell made wry comments about his own popularity. While using his exceptional access to the public sphere to promote his issues and projects, he simultaneously pointed out the conditions and limits of mainstream acceptance and tolerance (see also Warner, 1999). With the HIV/AIDS epidemic the sense of liberation of the early gay movement was lost, with promiscuity outlawed and gay bathhouses prohibited by law in 1987. Instead, homosexuals were included in the cohabitation law in 1988, and the Registered Partnership Act was passed in 1995, offering acceptance through assimilation into the straight mainstream (Rydström, 2016).

When inviting its viewers and readers into a mourning work, a testimonial space and a community of feeling (Berlant, 2008), Don't Ever Wipe Tears Without Gloves disavowed the militancy and institutional critique. Focusing on the denial of human touch by the nurses, the epic bracketed the state policies that defined gayness as an illness in Sweden during the epidemic, demolishing the victories of the gay liberation movement by then. As a drama about a lack of compassion and a crisis of basic humanity, instead of a critique of institutions or still-existing policies, Don't Ever Wipe Tears Without Gloves and its reception redefined the nation around vulnerability. LGBTQ issues were mobilised to build an image of a compassionate, caring nation, and hence to revitalise a sense of the welfare state.

The 2013 QX gala award ceremony reads as a peak moment of an invitation to mourning and a process of imaginary trauma resolution. It became a public memorial and monument (Sturken, 1997) to the lives lost and devalued, now retrospectively honoured and, in an imaginary gesture of rehabilitation, incorporated by the royal family into the national 'we'. In that moment, it seemed as if Don't Ever Wipe Tears Without Gloves had enabled the gay community to publicly mourn the victims of AIDS, to revisit the injuries of the epidemic, and to narrativise gay life in 1980 os Stockholm. ${ }^{8}$ At the same time, through a process of transference and healing, the transmedial epic of Don't Ever Wipe Tears Without Gloves had also engendered a new, 
'healthier' nation that no longer ignored or repressed its past and the violence and exclusions it was founded on (Cvetkovich, 2003: 119).

The exclusion was however brought up by some critical voices (Edenheim, 2012a; 2012b; 2013; Warburton, 2014) and Gardell himself. The celebration of the nation as a caring community, engendered by Don't Ever Wipe Tears Without Gloves, coincided with another kind of nationalism, more concerned with how to delimit the scope of compassion. In 2013, the Swedish Migration Board responded to the escalation of the Syrian crisis by granting permanent residence to all Syrian asylum seekers, and in August 2014, Prime Minister Fredrik Reinfeldt gave a famous speech in which he urged Swedes to 'open their hearts' to refugees seeking shelter. In September 2014, however, the right-centre government lost the election and Sweden Democrats, with their anti-immigration and anti-Islam agenda, changed the Swedish political landscape.

In 2012, Gardell was active in articulating the limits of the narrative of the caring, compassionate nation. Together with another LGTBQ activist and two high-profile politicians, Gardell published an appeal to grant a residence permit to an HIV-positive gay man from Uganda (Gardell et al., 2012). With 'Let us wipe Karim's tears', Gardell and his companions highlighted the paradox of increasing LGTBQ rights in Sweden and an accelerating amount of threats, injuries, and hate in many parts of the world, including Russia, Belarus, Hungary, Iran, Iraq, and many African countries. Significantly, both this call for testing the limits of compassion as well as Gardell's militancy regarding the domestication of gay life were ignored in the public embrace of Don't Ever Wipe Tears Without Gloves and the focus on the shared national trauma and reinvention of the caring nation.

\section{NOTES}

1 For positive or even rave reviews see Folkhammar (2012), Helgeson (2012), Liljestrand (2012), Svensson (2012), and Wilson (2012). For editorial page commentary on the relevance of the series, see Franchell (2012), Ludvigsson (2012), and Kjöller (2012). For a cultural pages debate about identity politics see Edenheim (2012a; 2012b; 2013), Gardell (2012b), Hilton (2013a; 2013b), Nordenhök (2012), and Wiman (2012b), and a friendly exchange between Gardell and a critic (Gardell and Hilton, 2013). For tabloid publicity see Fårsjö (2012), Fjellborg (2012), Lindberg (2012), Lundberg (2012a), Schulman (2012), and Virtanen (2012).

2 In his preface to a reprint of her dissertation, Gardell (2013c) refers to his epic as a fictionalisation of Svensson's research.

3 Pippi Longstocking being number one, and classic 1973 children's TV programme Fem myror är fler än fem elefanter second.

4. Croneman (2012) described the TV series as a 'guided tour in the gay mileus of the 1980s'. 
5 Many of these narrative tropes were also reiterated in a 2016 episode of primetime talk show Min Sanning (2016), in which Jonas Gardell was interviewed to tell 'his truth'.

6 For protests against this framing of hospital personnel as inhumane see Kjöller (2012).

7 Gardell's rhetoric in interviews, novels, and public writings of 'how editors-inchief, priests and doctors incited hate against the diseased' (Gardell, 2012C; 2013d) caused no major discussions and provoked only few responses by journalists (Kjöller, 2012; Nycander, 2013) and the responsible medical authorities (Britton, 2012; 2013). Professor of infectious diseases Sven Britton argued the Swedish government acted responsibly in the 1980s, but even he regrets the forced isolation of AIDS patients, in particular young female prostitutes and drug users.

8 For gay readings of Gardell's epic, see Brandel (2012), Folkhammar (2013), Hilton (2014), Öhrman (2012), Voss (2013), and Wilson (2012).

\section{REFERENCES}

Ahmed, S. (2004). The Cultural Politics of Emotion. Edinburgh: Edinburgh University Press.

Anderson, B. (1993). Imagined Communities (Rev. ed.). London: Verso.

Aschenbrenner, J. (2012). 'För många tårar', Aftonbladet (15 December).

Backlund, A. (2013a). 'Allt från QX-galan, kronprinsesschocken, minut för minut', QX.se, www.qX.se/noje/gaygala/22919/allt-fran-qX-galan-kronprinsesschockenminut-for-minut/ (accessed 1 February 2018).

Backlund, A. (2013b). 'Gardell är upprättelsens apostel', QX.se (4 October), www.qx.se/ noje/kultur/24867/gardell-ar-upprattelsens-apostel (accessed 1 February 2018).

Berlant, L. (1991). The Anatomy of National Fantasy: Hawthorne, Utopia, and Everyday Life. Chicago and London: Chicago University Press.

Berlant, L. (1999). 'The subject of true feeling: Pain, privacy, and politics', in A. Sarat and T. Kearns (eds), Cultural Pluralism, Identity Politics, and the Law. Ann Arbor: University of Michigan Press, pp. 49-84.

Berlant,L. (2004). 'Compassion(and withholding)', in L. Berlant(ed.), Compassion: The Culture and Politics of an Emotion. New York and London: Routledge.

Berlant, L. (2008). The Female Complaint. Durham, NC: Duke University Press.

Berlant, L. and E. Freeman (1992). 'Queer nationality', Boundary 2, 19:1, pp. 149-80. Brandel, T. (2012). 'Jag var med och jag överlevde', Svenska Dagbladet (5 August).

Brevinge, N. (2012). ‘Årets svensk', Fokus (7-13 December), pp. 20-9.

Britton, S. (2012). 'Det behövs inga ursäkter för hiv-hanteringen', Svenska Dagbladet (29 December).

Britton, S. (2013). 'Det finns alla skäl att inte glömma lidandet', Svenska Dagbladet (3 January).

Butler, J. (2004). Precarious Life: The Powers of Mourning and Violence. London:Verso.

Caruth, C., and T. Keenan (1995). 'The AIDS crisis is not over: Conversation with Greg Bordowitz, Douglas Crimp, and Laura Pinsky', in C. Caruth (ed.), Trauma: Explorations in Memory. Baltimore: Johns Hopkins University, pp. 256-71. 
Crimp, D. (2002). Melancholia and Moralism: Essays on AIDS and Queer Politics. Cambridge, MA: The MIT Press.

Croneman, J. (2012). 'Jonas Gardell bjuder på en guided rundtur i 8o-talets bögmiljöer', Dagens Nyheter (9 October).

Cvetkovich, A. (2003). An Archive of Feelings: Trauma, Sexuality, and Lesbian Public Cultures. Durham, NC and London: Duke University Press.

Edenheim, S. (2012a). 'Gardell gråter bara för männen', Dagens Nyheter (21 November).

Edenheim, S. (2012b). 'Vantolkningar: Kritiken riktade sig huvudsakligen mot journalister', Dagens Nyheter (30 November).

Edenheim, S. (2013). 'Johan Hilton projicerande gör att debatten går över styr', Dagens Nyheter (25 September).

Engman, P. (2013a). 'Tårarna efter Victorias tal', GT (5 February).

Engman, P. (2013b). 'Victoria möttes av gråt och jubel på QX-galan', Expressen. se, www.expressen.se/noje/victoria-mottes-av-grat-och-jubel-pa-qx-galan/ (accessed 1 February 2018).

Engström, E. (2012). 'Skriver om skulden', Göteborgs-Posten (19 August).

Fårsjö, T. (2012). “Jag gråter själv varje gång”, Jonas Gardell varnar för trådrypande seriefinal', Expressen (16 October).

Fjellborg, K. (2012). 'Helt enkelt underbar!', Aftonbladet/Nöjesbladet (5 October).

Folkhammar, K. (2012). 'Blodigt allvar', Aftonbladet (27 August).

Folkhammar, K. (2013). 'Fler att sörja för', Aftonbaldet (26 January).

Franchell, E. (2012). 'När moralpaniken drabbade Sverige', Aftonbladet (3 September).

Gardell, J. (2012a). Torka aldrig tårar utan handskar: 1. Kärleken. Stockholm: Norstedts.

Gardell, J. (2012b). 'Stolthet och fördom', Aftonbladet (3 August).

Gardell, J. (2012C). 'Så skapades hatet mot de aidssjuka', Dagens Nyheter (30 December).

Gardell, J. (2013a). Torka aldrig tårar utan handskar: 2. Sjukdomen. Stockholm: Norstedts.

Gardell, J. (2013b). Torka aldrig tårar utan handskar: 3. Döden. Stockholm: Norstedts.

Gardell, J. (2013C). 'Förord', in I. Svensson, Liket i garderoben: bögar, begravningar och 8o-talets hivepidemi. Stockholm: Ordfront.

Gardell, J. (2013d). 'Varför bagatellisera det lidande som var?', Svenska Dagbladet (1 January).

Gardell, J. and J. Hilton (2013). 'Hej Johan! Hej Jonas!', Dagens Nyheter (4 August).

Gardell, J., M. Lodalen, J. Paulsson and M. Sahlin (2012). 'Torka Karims tårar', Aftonbladet (21 November).

Gentele, J. (2012). 'Djupt gripande katastrofskildring', Svenska Dagbladet (8 October).

Gould, D. (2002). 'Life during wartime: Emotions and the development of act up', Mobilization: An International Quarterly, 7:2, pp. 177-200.

Guillou, J. (2013). 'Ett storverk', Expressen (25 August).

Gustavsson, M. (2012). 'Först av allt är kärleken', Sydsvenskan (19 August).

Hagström, J. (2012). 'Tidstypiskt och viktigt', Göteborgs-Posten (8 October).

Håkansson, A. (2012). 'I svenska hjärtans djup', Expressen (15 December).

Hallas, R. (2009). Reframing Bodies: AIDS, Bearing Witness, and the Queer Moving Image. Durham, NC and London: Duke University Press. 
Helgeson, P. (2012). 'Arg Gardell angelägen från början till slut', Svenska Dagbladet (27 August).

Henriksson, S. (2013a). 'Jag är ute efter att få vittna', Norrbottens-Kurir (3 January).

Henriksson, S. (2013b). 'Gardell vill vittna om sanningen', Bohusläningen (4 January).

Hilton, J. (2013a). 'Luften i debatten är unken och instängd', Dagens Nyheter (17 September).

Hilton, J. (2013b). 'Sara Edenheim blandar effektiv bort korten', Dagens Nyheter (25 September).

Hilton, J. (2014). 'Äntligen har 'de som älskade mest' fått sin upprättelse', Dagens Nyheter (31 December).

Juhasz, A. (2006). 'Video remains: Nostalgia, technology, and queer archive activism, GLQ, 12:2, pp. 319-28.

Karlsson, S.B. (2013). 'Jonas Gardell blir hedersdoktor', LiU-nytt (19 February), https:// liu.se/liu-nytt/arkiv/nyhetsarkiv/1.44.2142? l=sv (accessed 1 February 2018).

Kekki, L. (2003). From Gay to Queer: Gay Male Identity in Selected Fiction by David Leavitt and in Tony Kushner's Play Angels in America. Bern: Peter Lang.

Kjöller, H. (2012). 'Torka alltid tårar', Dagens Nyheter (4 December).

Koivunen, A. (2016). 'Affective historiography: Archival aesthetics and the temporalities of televisual nation-building', International Journal of Communication, 10, pp. 5270-83.

Kulick, D. (2005). 'Four hundred thousand Swedish Perverts', GLQ, 11:2, pp. 205-35.

Lagerwall, K. (2013). 'Kronprinsessan hyllas efter gaygalan', DN.se (5 February), www. dn.se/kultur-noje/kronprinsessan-hyllas-efter-gaygalan (accessed 1 February 2018).

Larsmo, O. (2013). 'Gardell tar en stor tugga av vår samtid', Dagens Nyheter (24 August).

Liljestrand, J. (2012). 'Historien om aidsepidemin får episka vingar', Dagens Nyheter (27 August).

Lindberg, K. (2012). 'Nu glömmer vi aldrig den serien', Aftonbladet (23 October).

Ludvigsson, M. (2012). 'Förakt vid förälskelse', Svenska Dagbladet (1o October).

Lundberg, Z. (2012a). 'Jag överlevde - vännerna dog', Aftonbladet/Nöjesbladet (8 October).

Lundgren, J. (2013). 'Jonas Gardell årets mottagare av Bellmanpriset', QX.se (20 June), www.qx.se/noje/23910/jonas-gardell-arets-mottagare-av-bellmanspriset/ (accessed 1 February 2018).

Marmorstein, E. (2012). 'Reinfeldt säger nej till regeringsursäkt till 8o-talets aidsoffer', Politikerkollen, Aftonbladet.se (12 December), http://bloggar.aftonbladet.se/ politikerkollen/2012/12/reinfeldt-sager-nej-till-regeringsursakt-till-8o-taletsaidsoffer (accessed 5 June 2018).

Miljöpartiet De Gröna (2012). 'MP kräver en offentlig ursäkt till alla som kränktes under den försts tiden hiv var känt i Sverige' (1 December), news.cision.com/ se/miljopartiet-de-grona/r/mp-kraver-en-offentlig-ursakt-till-alla-somkranktes-under-den-forsta-tiden-hiv-var-kant-i-sverige,c9342939 (accessed 1 February 2018).

Milles, U. (2013). 'Utvandrarna', Expressen (23 January).

Nordenhök, H. (2012). 'Vulgarisering. När debatten går föraktets ärende', Dagens Nyheter (26 November). 
Nycander, S. (2013). 'DN-kampanj? Kraven på tvångslagstiftning gällde narkomaner', Dagens Nyheter (3 January).

Öhrman, A. (2012). 'Det var en gång två killer ..., QX.se, https://issuu.com/qxtra/ docs/qX-september-2012 (accessed 1 February 2018).

Pearl, M. (2013). AIDS Literature and Gay Identity: The Literature of Loss. New York and London: Routledge.

Puar, J. (2013). 'Rethinking homonationalism', International Journal of Middle East Studies, 45:2, pp. 336-9.

Rimsby, P. (2013). 'Alla måste föra kampen för hbtq-personers rättigheter', Dagens Nyheter (3 August), www.dn.se/debatt/alla-maste-fora-kampen-for-hbtqpersoners-rattigheter/ (accessed 5 June 2018).

Román, D. (2006). 'Remembering AIDS: A reconsideration of the film The Longtime Companion', GLQ, 12:2, pp. 281-301.

Román, D. (2009). Acts of Intervention: Performance, Gay Culture, and AIDS. Bloomington: Indiana University Press.

Roos, M. (2012). 'Tv:s tårkalas', Aftonbladet (21 October).

Rydström, J. (2016). 'Legalizing love in a cold climate: The history, consequences and recent developments of registered partnership in Scandinavia', Sexualities, 11:1-2, pp. 193-226.

Savran, D. (1995). 'Ambivalence, utopia, and a queer sort of materialism: How Angels in America reconstructs the nation', Theatre Journal, 47:2, pp. 207-27.

Schulman, A. (2012). 'Galant, Gardell', Aftonbladet/Nöjesbladet (29 December).

Sendziuk, P., R. Hallas, Jim Hubbard and Debra Levine (2010). 'Moving pictures: AIDS on film and video', GLQ: A Journal of Lesbian and Gay Studies, 16(3), pp. 429-49.

Sörberg, A.-M. (2008). Det sjuka. Stockholm: Atlas.

Sturken, Marita (1997). Tangled Memories: The Vietnam War, the AIDS Epidemic, and the Politics of Remembering. Berkeley: University of California Press.

Svensson, I. (2007). Liket i garderoben: en studie av sexualitet, livsstil och begravning. Stockholm: Normal.

Svensson, I. (2013). Liket i garderoben: bögar, begravningar och 8o-talets hivepidemi. Stockholm: Ordfront.

Svensson, P. (2012). 'I pestens tid', Sydsvenskan (27 August).

Swedish Institute (2018). 'Working for a gay-friendly Sweden', https://sweden.se/ society/working-for-a-gay-and-equal-sweden (accessed 1 February 2018).

Thorsén, D. (2013). 'Den svenska aidsepidemin: ankomst, bemötande, innebörd'. Diss. Uppsala: Uppsala universitet.

Torén-Björling, S. (2012). 'Jonas Gardell: Jag var med, det är min tid, min stad. Det är min plikt att skriva', Dagens Nyheter (5 August).

Treichler, P. (1988). 'AIDS, homophobia, and biomedical discourse: An epidemic of signification', in D. Crimp (ed.), AIDS: Cultural Activism/Cultural Analysis. Cambridge, MA: MIT Press, pp. 31-70.

$\mathrm{TV}_{4}$ (2014). 'Kronprinsessan Victoria delar ut pris till Jonas Gardell. (QX Gaygalan 2013)', TV4 (14 March), www.youtube.com/watch?v=kMWpmy6WcgE (accessed 1 February).

Utbildningsradion (2013). 'Fullbordat - Torka aldrig tårar utan handskar', UR Samtiden. Bok och bibliotek 2013, http://urskola.se/Produkter/178388-URSamtiden-Bok-och-bibliotek-2013-Fullbordat-Torka-aldrig-tarar-utan-handskar (accessed 1 February 2018). 
Virtanen, F. (2012). 'Tack gud för Jonas Gardell', Aftonbladet/Nöjesbladet (8 October).

Voss, J. (2007). 'Makalöst möte med Jonas Gardell', QX.se (13 November), www.qx.se/ nyheter/5622/makalost-mote-med-jonas-gardell (accessed 1 February 2018).

Voss, J. (2013). 'Verktyg för minnen', Sydsvenskan (25 August).

Waaranperä, I. (2012). 'Drabbande om ung kärlek och hiv', Dagens Nyheter (16 December).

Warburton, T. R. (2014). 'From AIDS to assimilation: Representations of male homosexuality in Swedish literature. PhD diss., University of Washington. https://digital.lib.washington.edu/researchworks/bitstream/handle/1773/27582/ Warburton_washington_0250E_14069.pdf?sequence=1 (accessed 1 February 2018).

Warburton, T. R. (2016). 'Cultural amnesia and AIDS: Breaking the silence in Sweden', in J. Björkund and U. Lindqvist (eds), New Dimensions of Diversity in Nordic Culture and Society. Newcastle upon Tyne: Cambridge Scholars Publishing, pp. 2-22.

Warner, M. (1999). The Trouble with the Normal: Sex, Politics and the Ethics of Queer Life. Cambridge, MA: Harvard University Press.

Watney, S. (1987). 'The spectacle of AIDS', October, 43, pp. 71-86.

Watney, S. (1996). Policing Desire: Pornography, Aids and The Media. Minneapolis: University of Minnesota Press.

Wiegman, R. (1997). 'Introduction', in T. Yingling, AIDS and the National Body. Edited by R. Wiegman. Durham, NC and London: Duke University Press.

Williams, L. (1998). 'Melodrama revised', in N. Browne (ed.), Refiguring American Film Genres: History and Theory. Berkeley: University of California Press 1998, pp. 42-88.

Wilson, R. (2012). 'Ogarderat', Expressen (26 August).

Wiman, B. (2012a). 'På den gamla begravningsplatsen möts den gula stjärnan och den rosa triangeln', Dagens Nyheter (4 November).

Wiman, B. (2012b). 'Det gjordes skillnad mellan homosexuella män och kvinnor', Dagens Nyheter (23 November).

Yingling, T. (1991). 'AIDS in America: Postmodern governance, identity, and experience', in D. Fuss (ed.), Inside/Out: Lesbian Theories, Gay Theories. New York: Routledge, pp. 291-310.

Yingling, T. (1994). 'Wittgenstein's tumour: AIDS and the national body', Textual Practice, 8:1, pp. 97-113.

\section{TV AND RADIO}

Allsång på Skansen (2013). Episodes 6-8. First broadcast 31 July by SVT1.

En helkväll med Jonas Gardell (2013). First broadcast 5 April by SVT1.

Min sanning: Jonas Gardell (2016). Episodes 1-5. First broadcast 20 November by SVT2.

Mitt enda liv (2015). First broadcast 6 January by SVT1.

Ömheten (1989). First broadcast 30 October by SVT1. Directed by Annika Silkesberg and written by Jonas Gardell.

P1 Sommar (2013). Jonas Gardell (22 June), Sveriges Radio. 
Smittad - när hiv kom till Sverige (2012). First broadcast 29 October by SVT1. Directed by Dylan Williams.

Torka aldrig tårar utan handskar (2012). Episodes 1-3. First broadcast 8 October by SVT1. Directed by Simon Kaijser and written by Jonas Gardell.

Torka aldrig tårar utan handskar (2012). Episodes 2-3. First broadcast 15 October by SVT1. Directed by Simon Kaijser and written by Jonas Gardell.

Torka aldrig tårar utan handskar (2012). Episodes 3-3. First broadcast 22 October by SVT1. Directed by Simon Kaijser and written by Jonas Gardell. 


\section{INDEX}

$9 / 117,14$

À ma soeur! [Fat Girl] (2001) 42

abjection 7,8

able-bodiedness 9, 36

Aboriginal 60

abortion 20, 120, 195, 200-1, 206-8, 210-11

abuse $1-3,18,42-3,55,85,95-6,120-1$, $126-8,136,139,159,163,166-8,231$

activism 1, 9, 11, 13-14, 16, 18-19, 36, 57, 96-7, 109, 179, 186, 188, 197-8, 212,221

adoption 46, 116-18, 126-8

affect $3-5,7-10,12,14-15,18-20,30$, $36-7,40,55,62,64-5,85-6,118-$ $19,128,134,140,151-3,158-9,163-$ 9, 190, 224, 226-30

affective labour 118, 134, 139-41, 147, 152,164

see also emotional labour

Affleck, Casey 15

afro-pessimism 9, 16, 71, 78-80, 88-9

agency $1,3,5-6,9-12,32,42,81,83-4$, $89,111,119,123-4,136,146,152,155$, 159, 170, 185, 189, 203, 205, 211-12

Ahmed, Sara 5, 10, 14-18, 30, 37, 47, $59-65,86,152-3,161,168-70$

AIDS 9, 20, 181, 206, 216, 218-31

AIDS activism 19-20, 219, 221, 231-2

AIDS media 219, 221, 224

see also HIV

Aikin, Susana 14, 95, 99, 102-3, 105, 106, 113n.1, 113n.2

Aizura, Aren 98, 101, 105

Andersen, Unn Conradi 122

Andersson, Nikeisha 154-5, 199

Angels in America (1991) 219-20

anger $7,15,18,31,43,60,85,87-8,152$, 164, 166, 168-9, 224

see also rage anti-feminism $5,17,30-1,34,44-7$, $62-3,65 n .2$

anti-racism/anti-racist 2, 4, 13, 16, 18-19, 29-30, 36-7, 61, 66n.4, 73, $82-3,86-9,151,157$

anxiety $3,11,14,35,41,76,164,226$

Anzaldua, Gloria 90n.8, 97

Aparicio, Carlos 14, 95, 99, 102-3

Arbabi, Farnaz 154-5, 159

archive 4, 20, 54, 175-90, 196, 203-4.

archival activism 179, 189

archival practices $175-80,183-4$

artificial intelligence 14

audience $31,42,53-4,98,100,102-3$, 106, 108, 112, 120, 137, 141, 170n.11, 178, 189-90, 204, 209, 216, 220

Australia 117-18

autobiography $61,71,111,225$

auto-ethnography 71-2

Bailey, Marlon 99

Ballard, Finn Jackson 108

Barker, Martin 42, 143-4

Barker, Meg-John 136

Barrow, Kai Lumumba 98

BDSM 134, 136-7, 139-40, 142, 146, 155

Beasts of the Southern Wild (2012) 17,163

Berlant, Lauren 3, 10, 11, 15, 17-18, 142, $161,217,220,226-8,231$

BFI see British Film Institute

Bildwechsel (Hamburg) 175, 179, 184-5

bioethics 5

birth control 120, 125, 136, 187, 196, 200, 207-8

Black List project 153

blackface 73

\#BlackLivesMatter 2-4, 7, 9, 21n.1

blackness 2, 7-8, 16-17, 39, 41, 43, 6o-1, 63, 71-9o, 159-60, 163-4, 167 
black bodies 3, 7, 39, 81, 84, 152, 160, 169, 170 . 16

black social death $71,80-2$

black suffering 17, 80, 159-6o, 169

see also stereotype, black stereotype; women, black women

blogs $15,16,29$, 33, 37, 42, 45, 62, $73,85,90$

body $3,5,7-12,14,17,32,37-8,40-3,56$, 59-62, 84, 103-4, 109, 111, 118-19, $122-3,136-8,142-4,152,158-61$, $163-5,167,169-70,202,207-8,210$, 212, 220

see also embodiment

Bögjävlar [Damned Queers] (1977) 181, 186, 199

Bonilla-Silva, Eduardo 80, 128

Braidotti, Rosi 10, 64-5

Brantenberg, Gerd 198, 205-6, 210-11

Brexit 15

British Film Institute (BFI) 19, 175, 178-81, 188

British National Film Archives 182

Brunow, Dagmar 13, 19, 20

Burke, Tarana 2

Butler, Judith 2, 5-6, 10-12, 14-15, 43, $85,122,162,191 \mathrm{n} .2,218$

Campion, Jane 14, 116-18, 122-3, 129n.2 Canada 32, 81

capitalism 13, 47, 96, 142-3, 153, 197-8

care $6,9,31,33,35,37,39-41,44,46-7$, $87,96,99,104-5,110-12,134$, $140-2,147,183,217,220$

Carter, Angela 31, 36, 44

censorship 37, 42, 51, 53, 64, 73, 81, 86

Chehrehgosha, Aida 154-5, 165-6, 168

cisgendered $5,95,98,106,133$

cis-sexism/cis-sexist 29, 34-5, 37-8, 40, 47

cis-women 1-2

citizenship 3, 11, 20, 119-20, 122, 195-6, 200, 203, 211, 230

Citron, Michelle 185

class $15,40,55,61,72,98,110,118,121$, $123,126-8,143,145,158,210,220$

classroom 16, 29-30, 36, 38, 42-3, 51-7, $62,64,205$

climate change 14

Coates, Ta-Nehisi 167

Cole, Alyson 6

colonialism 13, 63, 72, 74, 76-7, 82-4, $119-21,123,126-7,159$

Combahee River Collective 96 compassion $2-3,7-8,15-18,38,44,161$, 200, 205, 217, 220, 227-9, 231-2

confession $2-3$

consciousness-raising 40, 62-3, 197, 207, 209

content warning see trigger warning

contraceptives 20, 120-1, 200-1, 203

Cook, Matt 182

Cook, Terry 177

Cooper, Brittney 38, 43

corporeality $7,9-11,39,43,144,224$

see also embodiment

Council of Europe 13

Cox, Laverne 97

Crimp, Douglas 222, 230

critical race studies $6,8,10-11,13,30$, $39-4.0,43,46$

critical theory $10-12$

Cvetkovich, Ann 9, 18, 176, 183, 232

Dagens Nyheter (Sweden) 74, 76-7, 81, 154, 219

death $6-9,17,20,71,80-3,88,107-8$, $121,125,134,139,167-8,221-3$, 226-7, 229-30

Deller, Ruth 133, 137

democracy 72, 79, 81-2, 88, 156-7, 188

dependency $5-6,10-11,20,140$, 143, 208

desire $43,64-5,77,120,124-5,127-8$, $133-4,136-9,142-6,155,158,169$, 182, 196, 202, 206, 210-12

DiAngelo, Robin 85

disability 9, 33, 35-6, 39, 53, 66n.3, 120,178

disability studies (crip theory) 9, 35-6

discomfort 11, 30, 39-40, 42-3, 51, 140, 153

discrimination $4,7-8,13,17,33,76$, $83,108,120,171 \mathrm{n} .17,195-6,202$, 204-5, 211-12

discussion forums 16, 29-34, 135

disgust $8,43,152,166,186,205$

disposable bodies 2, 7-8, 43, 84, 97, 122,128

diversity 15, 19, 55, 76, 104, 152-3, 161, $178,191 \mathrm{n} .5$

diversity policy 151-4, 157-8, 161, 169-70, 171n.13, 175-9, 189, 191n.5

Doane, Mary Ann 4.1

documentary 95, 98-102, 107-8, 110, $112,162,181,195-7,219,221-3$

domination 11, 35, 76, 122, 136, 139, 199

Du Bois, W. E. B. 166-7 
Due, Clemence 121

DuPuis, Reshela 123

Dutch 77, 81-2 see also Netherlands

Dworkin, Andrea 57

Dyer, Richard 197-8

Early Frost, An (1985) 228

Edenheim, Sara 176, 191n.3, 200, 202-4, 206, 208, 232

education $19,30,32,38,43-4,55,62,80$, $82,111,120-1,156,170$. 9,187 , 195-6, 198-200, 202-5, 207-8, 211 see also classroom

Eisikovits, Mary 185, 195, 197

embodiment $5-8,10,81,140,152,165$, 216, 225-6

see also body

emotion $15-16,18-19,31-2,37,82,84$, $87,102-3,119-20,124-5,127-9$, $139-41,145-6,152,158,161,163-9$, $186-7,202,223$

racial emotion $19,152,165-9$

emotional labour 82, 84, 139-41, 145-7, $161,163-4$

see also affective labour

empathy $2,15,39,127,141,14.4-5$, 160-1, 200, 227-8

empowerment 1, 3-4, 19, 127, 154, 159, $170,176,178,189-90$

equality $5,7,12-13,19,35,41,46-7$, 66n.3, 72, 76, 79, 96, 98, 122, 146, 151-4, 157-8, 170n.10, 171n.13, 176, $178,188,196,201-2$

ethics $5-6,13,64,162$

ethnic minority 13, 178-9, 181, 190 ethnographic documentary 97, 99, 101-2, 106, 112

European Court of Human Rights 13

European Union 13, 15

Eva och Maria [Eva and Maria]

(1983) 186-8, 191n.12-14,

195-200, 203-12

exceptionalism $72,74,80-1$

exploitation 4, 8, 96-7, 99, 103, 110, $126-8,145,153,164$

Facebook 14, 30, 34, 74, 76, 84, 86, 87, 89 Falksten, Marie 185, 195, 197, 202-3

Fanon, Frantz 84, 165

fantasy $15,74,90,108,110,134-47,216$, 224, 228

sexual fantasy $15,134,137,140-5$ fear $7-8,14,20,47,52-3,73,80,88,95$, $108,167,176,187,204,224$.

feeling $3,7-8,11,14,18,29,32,43,46$, $54,6 \mathrm{o}-5,66 \mathrm{n} .5,84-5,87,103,111$, $118,124,128,141-2,144,152-3$, $158,163-8,198,204-6,217,224$, 228, 231

Feminale (Cologne) 184

feminism $30,35-7,56-7,59,60-5$, 65n.2, 66n.3, 117, 120-1, 155

feminist movement 1,196

Ferreira da Silva, Denise 80, 84, 90

Fifty Shades (novel series) 15, 133-47

film archives 175-90

film festivals 19, 82, 100, 108, 117, 158, $184-5,190$

film production 190, 195-6, 199, 203-12

Filmarkivet.se 175, 178-82, 185-6, 191n.9, 192n.17

Filmverkstan [Film Workshop] (Stockholm) 187, 199

Folkets Bio (Sweden) 74-5, 82

fragility $6-7,16,43,59,62-3,71,81$, $85,88-9$

see also whiteness, white fragility

Frye, Marilyn 46

Fusion Programme 151-70

Gambetti, Zeynep 5

Garbo, Greta 181-2

Garcia, Bianey 106, 13

Gardell, Jonas 216-32

gay liberation 195, 231

Gay, Roxane 30, 39

Gilmore, Ruth Wilson 8

Gilson, Erinn 5-6

Gomani, Saleen 154-5

Gondouin, Johanna 13-17, 20

Gossett, Reina 97-8, 109

Gothic romance 135, 142

Guantanamo Bay 7

Gutiérrez-Rodriquez, Encarnación 164

Habel, Ylva 9, 13, 16, 17-18, 20

Haidt, Jonathan 55

Halberstam, Jack 13, 15-17, 20, 30-1, $39-4.1,45,140-1$

Hallas, Roger 221-2, 224

Hallgren, Hanna 210-11

Handmaid's Tale (2017-) 117, 128

Hanisch, Carol 4.0

happiness 61, 63, 65, 66n.5, 161, 205, 223

Happy Birthday, Marsha! (2018) 109 
Haritaworn, Jin 8, 13, 98

Hartman, Saidiya 71, 80, 83

hate $11,17,103,135,153,162,168$, 232, 233n.7

hate crime 17

hate speech 11, 162

Hayek, Salma 2

Hays Code 53

healing 4, 9, 134, 139, 14.4-5, 216, 231

heteronormativity $13,37,183,212$

heterosexism 29, 37-8, 47

heterosexuality $15,43,117,122,133-4$, $136-7,139-40,142-5,182,186,188$, 201-2, 209, 212

Hirschfeld, Magnus 200

HIV 106, 216, 218-23, 225-8, 230-2 see also AIDS

Hochschild, Arlie Russell 15, 14.0, 163

homonationalism 8, 230

homosexuality $38,53,186-7,195-211$, $222-3,226$

Hon dansade en sommar [One Summer of Happiness] (1951) 206

hooks, bell 72, 77, 97, 99, 163, 165

hope $12,83,89,100,103,122$

Horak, Laura 181

humanitarian 18, 102, 201

human rights $6,12-14,19,120-1$, 125,157

hurt 1, 4, 8, 14, 17-19, 31, 33-4, 37-8, $41,43,45,59,61-5,71,85,95,124$, $128,133-4,141,162-4$

Hussain, Saadia $154-5$

identity $8,19,33,35-6,38,66,72,96$, $102,104-5,108,111-12,180-1$, $186-7,196,200$

identity politics $12,16-17,19,154-5,232$ illness 14, 29, 32, 187, 198, 201-2, 204-5, 208, 211-12, 221, 227, 231

Illouz, Eva 134, 14.2-4

immigrants $96-7,101,110-12,155$, 159-60

India 119, 121

indigenous feminism 13

individualism 6, 66

individualistic narrative 12

inequality $4,102,105,121,127,153,188$ see also equality

injury $1-7,9,11-12,64-5,87,220$

injustice $5-7,46,64$

intersectionality 20,89

intimate publics 18
James, E. L. 133-42, 144-6

Jansson, Tove 184

Jay Z 56

Jelača, Dijana 102

journalism 15

justice 1, 7, 13-15, 51, 57, 95, 97, 108, 119, $121,127,129,146$

Kafer, Alison 9-10

Kaijser, Simon 217

Karim, Baker 153-7, 170

Khemiri, Jonas Hassen 73

Kidman, Nicole 117

Kim, Janine Young 166

kinship 95-7, 99, 104, 117, 126, 128

Kipnis, Laura 52

Kirste, Lynne 179, 182-3

Koivunen, Anu 5, 224.

Krafft-Ebing, Richard von 200

Kristeva, Julia 7, 10

Kuntsman, Adi 8

Kushner, Tony 219-20

Kvinnan i ditt liv är du [The Woman In Your Life Is You] (1978) 195-7, 200, 203, 206, 208-12

Kyrölä, Katariina 30, 42-3

Lagerlöf, Selma 182

language $18,31,34,36,37-8,44,47,103$, 106, 113n.4, 122, 146, 154, 156-7, 162-4, 209, 220, 225-6

language of rights 13,120

language of vulnerability $4,13-20$, $145,152,168-9,203,212$

vulnerability as political language 1 , $10,12-13,19-20$

Längs vägen [Along the Road] (2011) 181

Latina 96, 100, 109-10

Latinx 95-6, 99, 106-7, 111

see also translatina

Lee Gerdén, Mara 154

Lennerhed, Lena 200-1, 207-8

Lesben in Sicht (1994-98) 184

Lesbian Home Movie Project (LHMP,

Maine) 175, 179, 184-5, 188

lesbianism 196, 200, 202-4, 206-12

lesbians 9, 20, 99-100, 105, 139, 180, 184-7, 195-200, 203, 205, 208-12

lesbian desire 202, 206, 210, 212

lesbian feminist 20, 209-11

Lesbisk front [Lesbian Front]

(Stockholm) 195-7, 206-9 
LGBT 13, 19, 98, 108-9, 113, 120, 175-83, 186, 188-9o, 191n.3, 192n.19, 196, 198, 212, 231

liberation 89, 112, 195, 197, 199-200, 208, 231

Linde, Makode 73, 76

Lindeqvist, Karin 198

Linder, Anna 190

Liten skär och alla små brokiga [Little Pink and the Motley Crew] (2012) $16,71,73-8,80-6,88-9$

Lonergan, Kenneth 15

Lorde, Audre 59, 61-2, 88, 105, 151, 164, 166, 185

Loverin, Bailey 52

Lukianoff, Greg 55

MacKinnon, Catherine 57

Mad Men (2007-15) 117, 128

Mahoyo 155

Manchester by the Sea (2016) 15

Mapplethorpe, Robert 53

marginalisation 2, 7, 20, 29, 37, 39, 47, 86, 177

Martina, Egbert Alejandro 74, 77, 82-4, 88-9

Mbembe, Achille 8, 10

McClintock, Anne 159

McKittrick, Katherine 83

melodrama 15, 52, 225, 227-9

memory 59-61, 80, 183, 220, 228

counter-memory 44

men's rights activism 14

\#MeToo 1-4, 7, 18-19, 42

Milano, Alyssa 2

minority $13,104,175-6,178,181$, 189-90, 191n.5, 202, 209

misogynoir 87,90 n.7

Mitt enda liv [My Only Life] (2013) 225-6, 230

Mohanty, Chandra 97, 120, 123

Mokhtari, Arash 75, 85

Moraga, Cherrie 9on.8, 97

Morgan, Robin 57

Morrison, Toni 167

mourning 11, 218, 220-1, 230-1

Muñoz, José Esteban 33, 100

Muslim 66n.5, 155, 159

narcissism $62-3,66$ n. 4

nation $3,15,45,72,79,81-2,216-17$, 219-20, 226, 228-32

nation state 9,13
National Board of Health and Welfare

(Socialstyrelsen, Sweden) 185, 187, 195-6, 199-201, 203-4, 206, 208, 211

National Library of Sweden (KB) 175,178

nationalism 14, 31, 41, 55, 226, 232

Nazism 41

necropolitics 8-9, 98

neoliberalism 12, 16, 43, 62, 66n.4, 72, $83,89,120,127$

Netherlands 74, 83

see also Dutch

new materialism 10-11

news $15,17,54,103$

newspapers 20, 61, 74, 112, 160, 219

Nicht der Homosexuelle ist pervers, sondern die Situation, in der er lebt (1971) 186

Ninotschka (1939) 181

norm 5, 9, 11-12, 35, 4. , 54, 66n.2, 66n.3, 86, 122, 157, 177, 182, 206

norm creativity $153-4,157$

norm criticism 154

Nuit et brouillard [Night and Fog] (1955) 4.0, 56

Nyong'o, Tavia 108, 112

offence $8,29,31,55,64,66 \mathrm{n} .5,74,77,84$, 180,231

Öhrström, Annalena 185, 195, 197

Olsson, Birgitta 196, 206, 212

Ömheten [Tenderness] (1989) 227

oppression 9, 14, 32-3, 35-8, 4.0, 4.6-7, $57,79,96,103-4,126,167-8$, 208-9, 212

Oram, Alison 182

Orange Is the New Black (2013) 17, 171n.16

Outfest LGBT Film Festival 108

Outfest UCLA Legacy Project for LGBT Moving Image Preservation 189-90

Paasonen, Susanna 36, 144

pain $9,12,16,17-18,31,39,41,47$, $61,65,124-5,136,152-3,155$, 158-61, 163, 165-6, 168-9, 207, 219, 222, 229

Paris is Burning (1990) 99-100, 102, 111 paternalism 5-6, 17, 43-4, 52, 55, 57, 84 patriarchy $2,10,13,41,44,47,118,127$, 209, 212

Patterson, Orlando 80, 82 pedagogy $43,51-2,57,154$ 
Pelze Multimedia (Berlin) 184

performativity $11,85,99,162-3,177,180$

phenomenology 10-12, 43

philosophy 4, 5, 40, 55, 167

Play (2011) 72-3

pleasure 9-12, 33, 41-2, 76-7, 77, 85, 99, $133,137,142-5,153,159$

sexual pleasure $135-7,142-4$

polarisation 14

policy 4, 12-13, 15, 19-20, 32, 34, 46, 51, $118,120-1,151-7,169,170-1,178$, 181, 183, 195-6, 200, 206, 208, 211-12, 223, 231

archival policy $175-90$

cultural policy 4, 12-13, 19

film policy 151, 154, 156-7, 170n.2, 171n.13, 178, 181

sexual harassment policy 52

sexual policy 195-6, 200, 206, 208, 211-12, 231

see also diversity, diversity policy

Polite, Oivvio 72, 76-7, 81, 86

politics $6,8,10,12-13,15-17,19,36,46$, 51-2, 63, 65n.2, 83, 95-6, 112, 117, 123, 146, 154-5, 177, 187, 196, 209, 211, 220, 226

affective politics 15,151

biopolitics 83

feel-good politics 153

politics of exclusion 187,190

politics of recognition $15,177,189$

welfare politics 72

see also identity politics

popular culture $15,54,171$ n.16

Posocco, Silvia 8

postcolonial $72,119,120,123,126-7$

power $1,2,4,6-9,11-13,14,16,18-20$, $30,41-2,44-7$

powerlessness 20, 127

Praunheim, Rosa von 186

precariousness $6-7,11,16,100,105,112$, 122-4, 166

Precious (2009) 17

prejudice 106, 171n.17, 182, 186-7, 189, 196, 202, 204-5, 209, 212, 220

pride 183, 189, 198, 219, 230

Gay Pride 181, 182, 216, 226

privilege $2,3,15-16,33,35-8,41,43-4$, $46-7,119,120-2,126-8,133-47$, $152,165,170$

psychoanalysis $7,10-12,41,139,141-3$, $145,146,201,224$ queer 2, 4-6, 8-11, 13, 16, 18-19, 29, $30-1,33-4,36-7,39-41,44,46-7$, 66n.4, 96, 98-100, 108-12, 139, 175-90, 195, 199, 224, 225, 226, 230

Queer Manifesto 226

racism $5,8,16,18,29,34,35,37,38,40$, $41,4.4,46-7,61-5,66$ n.2, 71-9o, $121,123,129$ n.1, 16o-4, 168-9

anti-black racism 9, 71, 74, 77, 79-83, $85,88,89$

Radway, Janice $134-5,142$

rage $3,12,74,81-3,166$

reception $55,71,74-8,133,165,185,187$, $217,219,231$

recognition $7,11,15,32,35,37,40,41$, $45,85,100,105,122,134,139,168$, 175-7, 188-90, 202-3, 209, 211, 217

representation $3,4,9,14-17,20,31$, $40-1,43,47,55-7,71,73,76-7,95$, 97-103, 105, 108, 111-12, 119, 123-4, $126,145,152-4,157-61,163,165$, $169,176,177,179,181-3,185,187-8$, 196-8, 221-3, 226

politics of representation 16, 179

reproduction 116-29, 191

reproductive justice $14,119-22,127,129$

reproductive rights $14,119-22,127$, 129, 208

reproductive technology 120

reproductive vulnerability 16 , 121-2, 127

reproductive work 118

resistance $6-9,12,77,83,89,103,105$, 108, 110, 126, 170, 185, 212

RFSL [the National Organisation for Sexual Equality in Sweden] 196, 201-2

Riggs, Damien 120-2

right-wing movements 31, 41, 192, 226

risk $5,7,9,14,17,36,46,60,87,95,112$, $119,121,124,127,128,135,145,153$, $155,158-61,175-7,180,182-4,189$

Rist, Pipilotti 184

Roberts, Dorothy 121

romance 134-47

Rosenqvist, Sonja 206, 212

Rosler, Martha 184

Roya, Rastiger 107

Rubin-Dranger, Joanna 77

Ryberg, Ingrid 13, 20, 185-7, 191

Rydström, Jens 200-1 
Sabsay, Leticia 5

Sabuni, Kitimbwa 73-4, 82

sadism 15, 142, 161

safe space $33-8,108,109,176,183$

Salt Mines, The (1990) 14, 95, 96, 99, 100-13

Sami minority 178

Savran, David 219-20

Schaffer, Johanna $175-7,182$

Schein, Harry 156-7, 162, 170, 182

Schwartz, Joan 177

Scott, Darieck 7

Scough, Katarina 74.

Serano, Julia 45

Serner, Anna 19, 152, 154

sex work 17, 96-7, 99, 101, 102, 104, 105, $116,118-19,122,126,128$

sexual abuse 1, 2, 3, 18, 42, 96, 127

sexual desire $133,137,138,139,142,144$, 196, 202, 206, 211

sexual harassment $1,19,39,43,52$

sexual identity $180,187,200$

sexual violence $5,6,29,42,55-7,128$

sexuality $6,9,20,29,55,137-8,144,154$, 176, 186, 200, 202, 204, 210

see also heterosexuality; homosexuality

shame $3,7,8,85,106,183-5,230$

shaming $176,177,183-5$

Sharpe, Christina 80, 82, 89, 90

Shome, Raka 86

Skarsgård, Stellan 75

Skeggs, Beverley 10, 11, 86

Skilda tiders danser [Dances Through the Ages] (1909) 181

Smith, Clarissa 137

Smittad - när hiv kom till Sverige [Infected - When HIV came to Sweden] (2012) 219

Snitow, Ann 134, 137-8, 142

Snorton, C. Riley 98

'snowflake' 31, 44, 46

social democracy 157

social media 1-3, 14, 21, 29, 45, 55, 73, $77,87-8,179,224$

see also blogs; discussion forums;

Facebook; Tumblr; Twitter

solidarity 18, 89, 124, 159, 183

Sommaren med Monika [Summer with Monika] (1953) 206

Sontag, Susan 56, 152

South Korea 160
Souza, Valeria 35, 37

Spade, Dean 96, 108

spectator $17,18,41,57,98,99,110$

Spillers, Hortense 84

state power 2, 3, 7, 8, 9

Steorn, Patrick 175, 177, 180, 190

stereotype $71-89,122,123,124,153,155$, $157,158,159,176,179,188,210,223$

of Asian women 123, 124, 128

black stereotype $71-89,153,159,161$

of lesbians 176, 179, 210

racial stereotype 16, 155, 161

stigma 3, 9, 31, 220, 222, 225

Storm, Ruth 184, 185

Sturken, Marita 218, 220, 228, 231

subjugation $7,8,9,35$

subordination $7,11,29,34,40-2,45$, 118,155

suffering $4,7,8,12,17,18,39,40,45-7$, $62,65,80,98,101,103,105,128$, 145, 147, 217, 229, 231

surrogacy 13, 14, 16, 117-29

surveillance 14, 17, 52, 176, 190

surviving $1,3,18,36,38,39,59,66,83$, 95-9, 104, 105, 106, 111-12, 169, 221-2, 225-6

the figure of the survivor 18,36

Sweden 6, 9, 16, 19, 20, 71-90, 118, 122, 151-70, 175-90, 195-212, 216-32

Swedish Film Institute (SFI) 19, 151-8, $175,178,187,199$

Swedish Media Database 180, 186

Swedish National Film Archives 175, 182

Swedish Radio (SR) 199

Swedish Television (SVT) 75, 76, 117, 178, 187, 199, 217, 227

Tea Party movement 15

terrorism 7,14

testimony 102, 221-4, 231

Thailand 117-19, 126, 127

Thente, Jonas 74,76

therapy $32,36,39-40,134,140,142$

Thurman, Uma 2

\#TimesUp 1

Tinghög, Petter 160

Top of the Lake: China Girl (2017) 14, $16,116-29$

Torka aldrig tårar utan handskar 1-3 [Don't Ever Wipe Tears Without

Gloves] (2012) 20, 216-33

trans activism 1, 13, 95-8, 100, 107, 109 
transgender 15, 95, 96, 97, 100, 104, 109, $110,113,181$

translatina 14, 95-112

transphobia 46, 176, 183

trauma 1, 3, 7-10, 14-16, 20, 29, 31, 32, $35-42,51,53,55-7,62,77,116,124$, $127,128,134-47,216,218,220,224$, 225, 227, 228, 231, 232

post-traumatic stress (PTSD) 29, 31, $35,39,40,62$

trauma narratives 16

trigger warning 4, 11, 16, 29-47, $51-8,62,66$

Trump, Donald 14, 15, 31, 38

Tsang, Wu 14, 95-6, 100, 107-12

Tumblr 51

Twine, France Winddance 119-21

Twitter 2, 84, 85, 217

Tyler, Imogen 7, 45, 62-3

United Kingdom 13, 15, 20, 16, 46, 175, 178-80, 188

United States 2, 16, 32, 37, 38, 53, 96, 97, 100, 105, 112, 121, 146, 191, 219, 220, 228

Urban, Keith 56

Väninnor [Girlfriends] (1996) 199

victimhood 1, 6, 31, 32, 41, 44, 81, 124,202

victimisation $5,6,57,200$

violence $3-7,9,11,13,14,17$

visibility $3,4,16,17,18,40,55,97-8$, 106, 112, 120, 146, 153, 175-90, 219,225

voice $2,3,19,31,35,36,38,39,44-8,60$, $73-6,84,85,88,89,96,102,103$, 110, 111, 138, 153, 157, 159, 162, 232

Vora, Kalindi 118, 121

Wasniowski, Andréaz 201

Watney, Simon 222-4 weakness 3, 5, 7, 9, 81, 85, 229

Wekker, Gloria 72, 74, 81

welfare state 217, 220, 231

whiteness

white femininity $84,86,124,128$

white fragility $16,71,82,85,89$

white man $15,16,35,45,123,127$, $133-4,140-7$

white saviour $105,123,126-8$, 145-6, 159

white supremacy $31,44,45,47,72,76$, $79,81,85,87$

whitewashing 2, 128

see also women, white women

Whitney, Shiloh 152, 164-5

Wiegman, Robyn 5

Wilderson, Frank B. 72, 80, 83

Wildness (2012) 14, 95, 96, 99, 100, 107-13

Williams, Raymond 62, 142

Wiman, Björn 73, 74, 76-7, 80, 219

Winfrey, Oprah 2, 18

Wirsén, Stina 16, 75, 76-8, 82, 87

women

Asian women 118, 122-3, 158-9

black women $63,72,84,85,87,88$, 96, 105, 159, 164

Thai women 119, 122-8

trans women 2, 3, 17, 42, 96-8, 106, 109

white women $86,87,118-20,122,128$

women of colour 1-3, 17, 19, 42, 95, $97-8,106,121,152-70$

Women's Studies 17, 62-3

Wool-Rim Sjöblom, Lisa 118-19

World Health Organization 13

world-making $14,33,35,36,37,46,47$, 95-10o, 106, 107, 108, 111-12

wound $4,15,17,41,54,141,159,161,168$, 169,228

Yancy, George 2, 26 